\section{To: (Receiving Organization) \\ DISTRIBUTION \\ 5. Proj./Prog./Dept./Div.: \\ dP INTERLOCK SYSTEM}

8. Originator Remarks:

This EDT releases the Software Verification and Validation Test Report for the HEPA Filter Differential Pressure Fan Interlock System.

11. Receiver Remarks: 11A. Design Baseline Document? $\triangle$ Yes $\square$ No

3. From: (Originating Organization)
COGEMA Engineering Corporation
6. Design Authority/Design Agent/Cog. Engr.: sos $8 / 23 / \mathrm{ces}$
CC SCAIEF / AM ERMI / W WOARASPIAN

Wi WINKEF
4. Related EDT No.:

$\mathrm{N} / \mathrm{A}$

7. Purchase Order No.

$\mathrm{N} / \mathrm{A}$

9. Equip./Component No.:

$\mathrm{N} / \mathrm{A}$

10. System/Bldg./Facility:

241-G

12. Major Assm. Dwg. No.:

H-14-104165

13. Permit/Permit Application No.:

$\mathrm{N} / \mathrm{A}$

14. Required Response Date: $\mathrm{N} / \mathrm{A}$

15.

DATA TRANSMITTED

\begin{tabular}{|l|l|l|l|l|}
\hline $\begin{array}{c}\text { (A) } \\
\text { Item } \\
\text { No. }\end{array}$ & (B) Document/Drawing No. & $\begin{array}{c}\text { (C) Sheet } \\
\text { No. }\end{array}$ & $\begin{array}{l}\text { (D) Rev. } \\
\text { No. }\end{array}$ \\
\hline 1 & RPP - 6582 & - & 0 & \\
\hline & & & & \\
\hline & & & & \\
\hline & & & & \\
\hline & & & & \\
\hline & & & & \\
\hline & & & & \\
\hline
\end{tabular}

16.

\begin{tabular}{|c|}
\hline Approval Designator $(F)$ \\
\hline E, S, Q, D OR N/A \\
(See WHC-CM-3-5, \\
Sec. 12.7) \\
\hline
\end{tabular}

17.

\begin{tabular}{|c|c|c|}
\hline $\begin{array}{c}\text { (G) } \\
\text { Rea- } \\
\text { son }\end{array}$ & $\begin{array}{c}(\mathrm{H}) \\
\text { Disp. }\end{array}$ & (J) Name \\
\hline 1 & 1 & Design Authority $\mathrm{CC} S$ \\
\hline 1 & i & Design Agent AM ER \\
\hline 1 & 1 & Cog. Eng. TD KAIS \\
\hline 1 & $A$ & Cog. Mgr. DG BAID \\
\hline 1 & 1 & WL ADAM \\
\hline 1 & $k$ & KA CUTF \\
\hline 1 & $y$ & TA DILI \\
\hline 18. & & $8-17.00$ \\
\hline $\begin{array}{l}\text { Sign } \\
\text { Orig }\end{array}$ & $\begin{array}{l}\text { Ire o } \\
\text { tor }\end{array}$ & Date \\
\hline
\end{tabular}

BD-7400-172-2 (10/97)

\begin{tabular}{l} 
1. Approval \\
2. Release \\
3. Information \\
\hline
\end{tabular}

Reason for Transmittal (G)

4. Review

5. Post-Review

6. Dist. (Receipt Acknow. Required)

SIGNATURE/DISTRIBUTION

(See Approval Designator for required signatures)

THEY
KEY

\begin{tabular}{|ll}
\hline \multicolumn{3}{|c}{ Disposition (H) \& (I) } \\
$\begin{array}{ll}\text { 1. Approved } & \text { 4. Reviewed no/comment } \\
\text { 2. Approved w/comment } & \text { 5. Reviewed w/comment } \\
\text { 3. Disapproved w/comment } & \text { 6. Receipt acknowledged }\end{array}$
\end{tabular}

(F)

F)

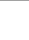

$(\mathrm{G})$

\begin{tabular}{|c|c|c|c|}
\hline (F) & $(\mathrm{G})$ & $(\mathrm{H})$ & $(\mathrm{l})$ \\
\hline $\begin{array}{c}\text { Approval } \\
\text { Desig- } \\
\text { nator }\end{array}$ & $\begin{array}{c}\text { Reason } \\
\text { frans- } \\
\text { mittal }\end{array}$ & $\begin{array}{c}\text { Origi- } \\
\text { nator } \\
\text { Dispo- } \\
\text { stion }\end{array}$ & $\begin{array}{c}\text { Receiv- } \\
\text { er } \\
\text { Dispo- } \\
\text { sition }\end{array}$ \\
\hline ESQ & 1 & 1 & \\
\hline & & & \\
\hline & & & \\
\hline
\end{tabular}

(E) Title or Description of Data Transmitted SOFTWARE VERIFICATION AND VALIDATION TEST REPORT FOR THE HEPA FILTER DIFFERENTIAL PRESSURE FAN INTERLOCK SYSTEM

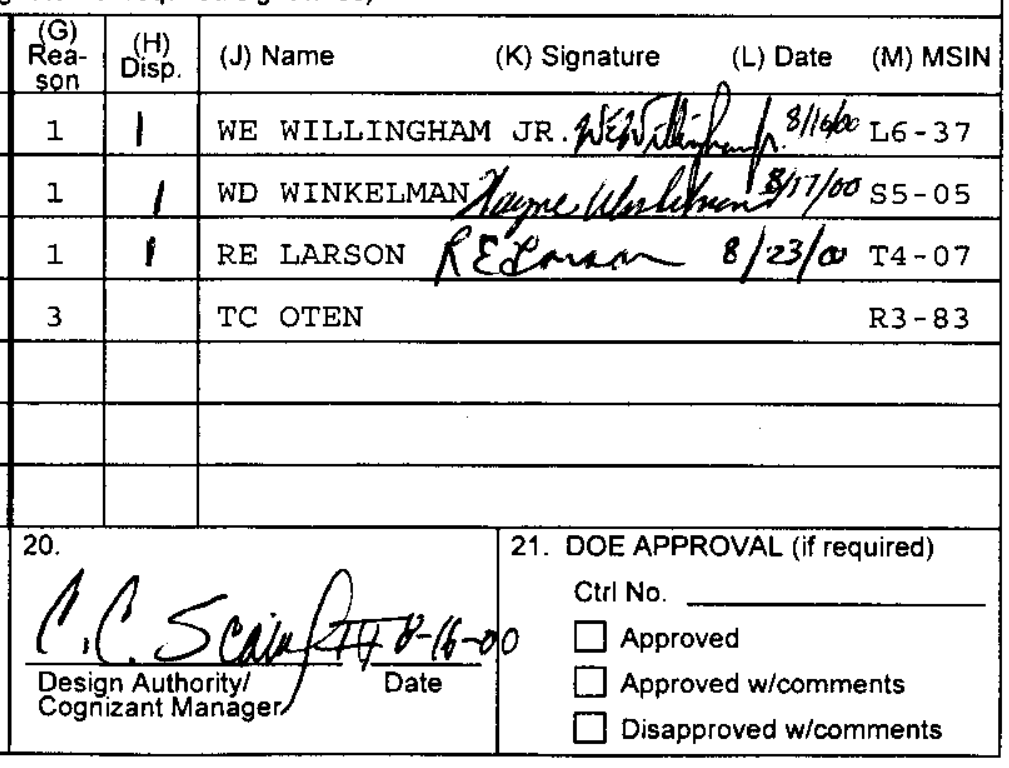

\begin{tabular}{c|c|c|c} 
(M) MSIN & $\begin{array}{c}\text { Rea- } \\
\text { Rea } \\
\text { Son }\end{array}$ & $\begin{array}{c}\text { (H) } \\
\text { Disp. }\end{array}$ & (J) Name
\end{tabular} $8-16-00$ $8+17.00 L 6-37$ ;signaty 404 son Disp. II OME

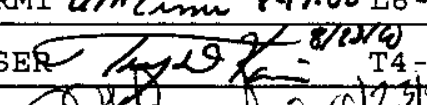
(2) rescatio ceid 0 ( 6125105 $56-15$ on
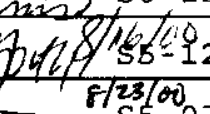

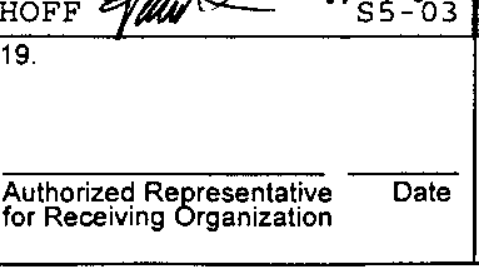

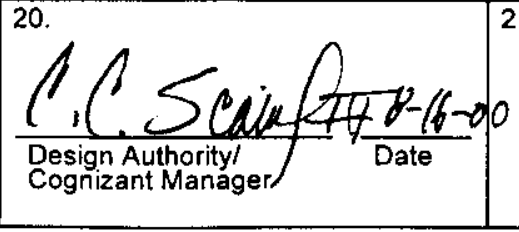




\title{
SOFTWARE VERIFICATION AND VALIDATION TEST REPORT FOR THE HEPA FILTER DIFFERENTIAL PRESSURE FAN INTERLOCK SYSTEM
}

A. M. Ermi and R. W. Truitt

For: CH2M Hill Hanford Group, Inc.

Richland, WA 99352

U.S. Department of Energy Contract DE-AC06-96RL13200

\author{
EDT/ECN: $613087 \quad$ UC: $\mathrm{N} / \mathrm{A}$ \\ Org Code: 7C200 Charge Code: 102613 \\ B\&R Code: N/A Total Pages: 117
}

Key Words: Software, Verification, Validation, Test Plan, HEPA, Differential Pressure, Interlock, Fan, Ventilation

Abstract: This document provides the test report for the Software Verification and Validation Test Plan for the HEPA Filter Differential Pressure Fan Interlock System, RPP-6581.

TRADEMARK DISCLAIMER. Reference herein to any specific commercial product, process, or service by trade name, trademark, manufacturer, or otherwise, does not necessarily constitute or imply its endorsement, recommendation, or favoring by the United States Government or any agency thereof or its contractors or subcontractors.

Printed in the United States of America. To obtain copies of this document, contact: Document Control Services, P.O. Box 950, Mailstop H6-08, Richland WA 99352, Phone (509) 372-2420; Fax(509) 376-4989.

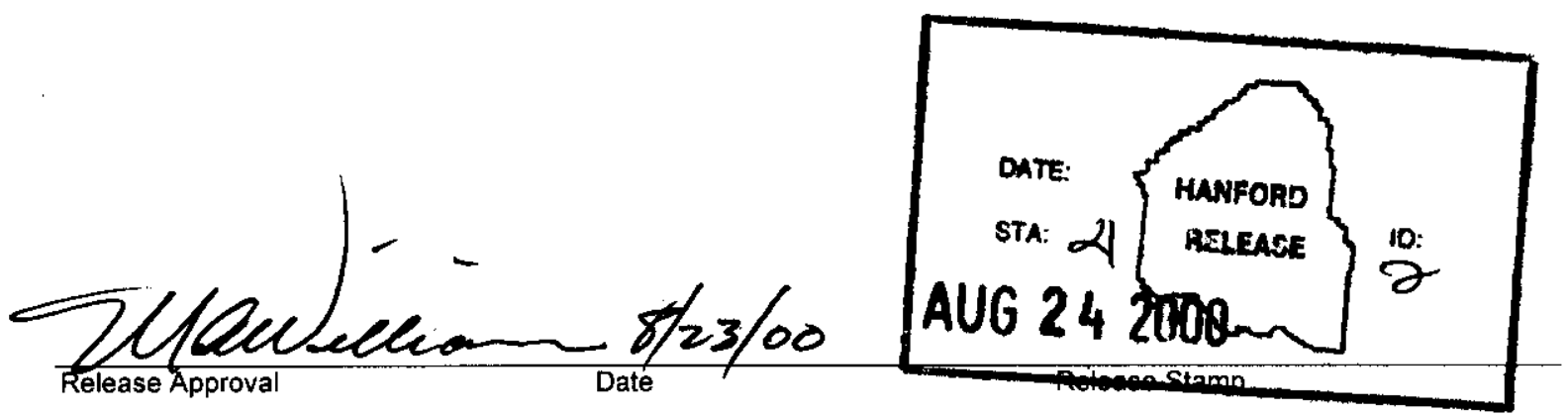

Approved for Public Release 
RPP-6582

Revision 0

\section{Software Verification and Validation Test Report for the HEPA Filter Differential Pressure Fan Interlock System}

August 2000

Prepared by:

A. M. Ermi, COGEMA Engineering Corporation

And

R. W. Truitt, PLCs Plus

Prepared for:

K. E. Carpenter, CH2M Hill Hanford Group 
V\&V Test Repont RPP-6582, Rev 0

Page ii

Software Verification and Validation Test Report for the HEPA Filter Differential Pressure Fan Interlock System

\section{TABLE OF CONTENTS}

$1.0 \quad$ PURPOSE

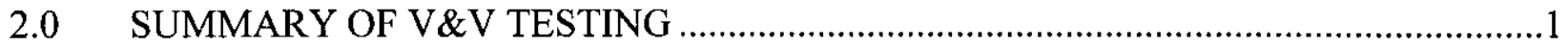

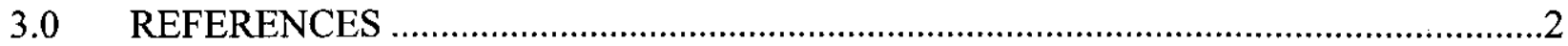

RPP-6581, "Software Verification and Validation Test Plan for the HEPA Filter

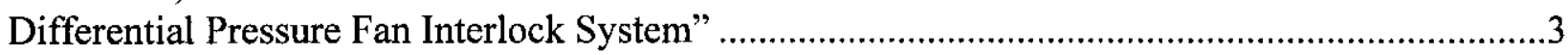

RPP-6581 Verification and Validation Completion Approvals............................................87

RPP-6581 Attachment 1, Test Exceptions.....................................................................113

RPP-6581 Attachment 2, Test Plan Changes.................................................................114 


\section{Software Verification and Validation Test Report for the HEPA Filter Differential Pressure Fan Interlock System}

\subsection{PURPOSE}

The HEPA Filter Differential Pressure Fan Interlock System PLC ladder logic software was tested using a Software Verification and Validation (V\&V) Test Plan [Ref. 1] as required by the "Computer Software Quality Assurance Requirements" [Ref. 2].

The purpose of his document is to report on the results of the software qualification.

\section{$2.0 \quad$ SUMMARY OF V\&V TESTING}

Testing was performed in the Hanford 300 Area 306E Building Remote Automation and Instrumentation Laboratory. The PLC subsystem hardware for the laboratory test is described in Reference 1. Various digital and analog sources were used to provide the inputs to the PLC modules to simulate the field signals and field instrument readings for up to a two fan, three filter train system.

Testing commenced August 8, 2000, and was completed on August 9, 2000. A summary of the V\&V Test Plan is as follows:

- Section 4.0 consisted of verification checks of the PLC ladder logic software and documentation.

- Section 5.0 consisted of validation checks of the PLC ladder logic software:

- Section 5.1 checked the system configuration

- Section 5.2 checked the PLC watchdog timer

- Section 5.3 checked the data FIFO stacks

- Section 5.4 checked the data averaging method

- Section 5.5 checked the transmitter failures, both with the fans off and on, and the event $\log$

- Section 5.6 checked the $\mathrm{dP} 1$ high and $\mathrm{dP} 2$ low alarms with the fan on, and the event log

- Section 5.7 checked the two minute log leading up to the last event

- Section 5.8 checked the 10 minute (24 hour) history log

Only one Test Exception was written during the testing. That occurred on August 8 during the test of the filter train A dP1 transmitter failure alarm with the fan running. When an alarm condition was simulated, the fan interlocks tripped "open" as expected. However, the interlocks returned to the "closed" state when the fan was stopped and the filter train was taken offline. The existing transmitter failure alarm would still prevent the fan from running, but since the interlocks were not latched in the "open" state, restarting the fan would result in a fan "bump". 
The Design Authority indicated that, according to the requirements, a system shutdown must prevent restart of any fan until the "Reset" is selected. Allowing a fan "bump" violates this requirement.

Testing was halted, and the PLC ladder logic software was modified to include the required interlock latching for transmitter failure alarms. The new version of the software, "DP INTERLOCK V1.01.RSS", was documented in the baseline Computer Software Description document [Ref. 3] via an ECN. The Test Exception was also documented in the V\&V Test Plan in Attachment 1, "Test Exceptions". The new software was downloaded onto the laboratory system, and testing resumed on August 9. The remainder of the V\&V was successfully completed.

Clarification to the information in one of the tables is to be noted: In Table 22, the expected "Time (mmss)" values were designated as " $t ", " t+6 ", \ldots$, , $t+108$ ", " $t+114$ ". However, the " $t$ ", " $t+6$ ", etc., values are in units of seconds (which was not explicitly stated). Therefore, when adding the " $\mathrm{t}+n$ " values to " $\mathrm{t}$ ", the actual values (in units of mmss) would rollover to the next minute when the last two digits were equal to or greater than "60" (e.g., " $t+24$ " $\rightarrow$ " $t+30$ " would result in " 4454 " $\rightarrow$ " 4500 ", where $t=4430$. Similarly, all subsequent " $t+n$ " actual values needed to take this same minute rollover "conversion" into account.

Only one minor pen-and-ink correction was made to the V\&V Test Plan, and the record of the change was documented in the V\&V Test Plan in Attachment 2, "Test Plan Changes".

The remainder of this V\&V Test Report consists of all of the pages of the V\&V Test Plan, which describes the testing that was conducted and attests to the results that were obtained. The page numbers for this report appear in the shaded boxes at the upper left of the pages, and the page numbers of the original V\&V Test Plan (at the upper right corners) were left for reference.

\subsection{REFERENCES}

1. CH2M-Hill Hanford Group, "Software Verification and Validation Test Plan for the HEPA Filter Differential Pressure Fan Interlock System", RPP-6581, Rev. 0 (2000).

2. "Computer Software Quality Assurance Requirements", HNF-PRO-309, Rev. 0 (1999).

3. CH2M-Hill Hanford Group, "Computer Software Description for the HEPA Filter Differential Pressure Fan Interlock System", RPP-6546, Rev. 0-A (2000). 


\section{RPP-6581}

Revision 0

Software Verification and Validation Test Plan for the HEPA Filter Differential Pressure

Fan Interlock System

August 2000

Prepared by:

A. M. Ermi, COGEMA Engineering Corporation

And

R. W. Truitt, PLCs Plus

Prepared for:

K. E. Carpenter, CH2M Hill Hanford Group 
Software Verification and Validation Test Plan for the HEPA Filter Differential Pressure Fan Interlock System

\section{TABLE OF CONTENTS}

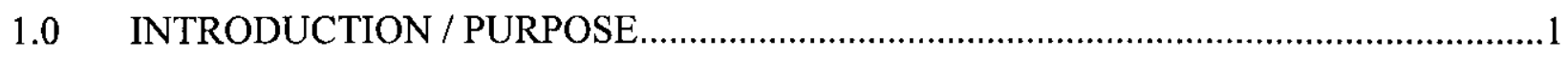

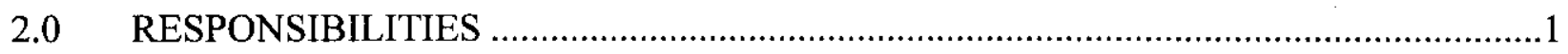

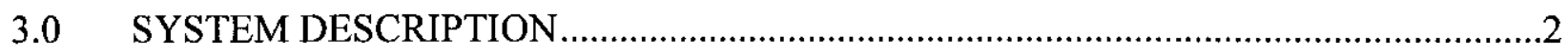

4.0 VERIFICATION OF dP INTERLOCK LADDER LOGIC …...........................................

4.1 LADDER LOGIC SOFTWARE REQUIREMENTS ..............................................

4.2 LADDER LOGIC SOFTWARE REQUIREMENTS VERIFICATION ….................

4.3 DOCUMENTATION REQUIREMENTS …………...............................................

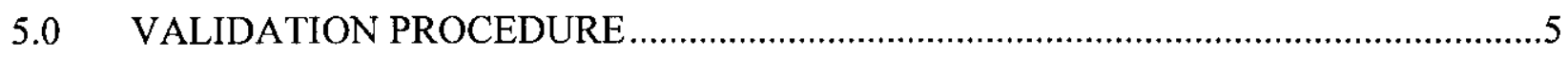

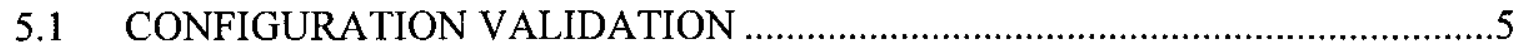

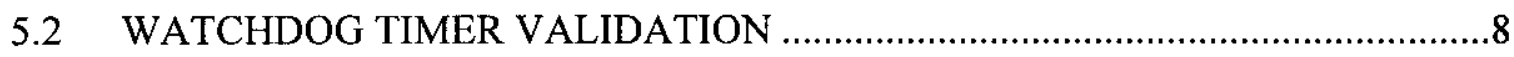

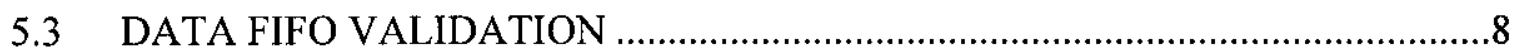

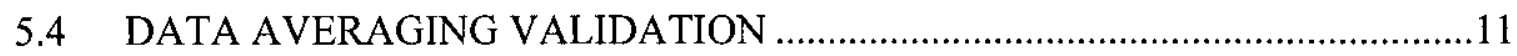

5.5 TRANSMITTER FAILURES VALIDATION ..................................................

5.6 dP1 HIGH AND dP2 LOW ALARMS VALIDATION .....................................65

5.7 TWO-MINUTE EVENT LOG VALIDATION …….............................................77

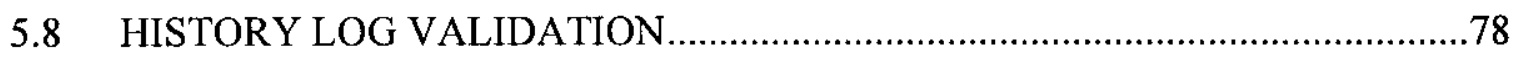

6.0 VERIFICATION AND VALIDATION COMPLETION APPROVALS ..........................81

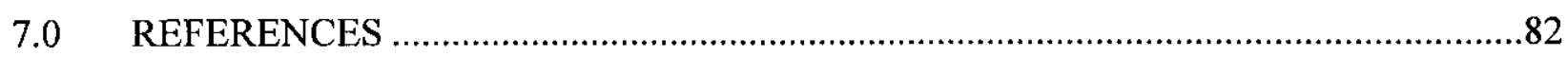

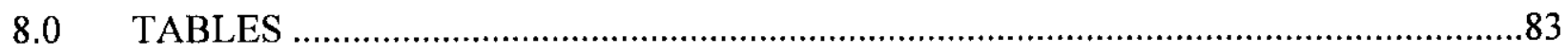

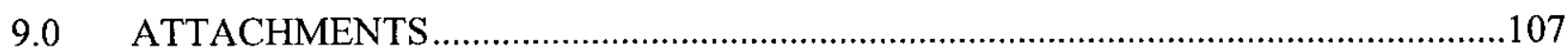




\section{Software Verification and Validation Test Plan for the HEPA Filter Differential Pressure Fan Interlock System}

\section{LIST OF TABLES}

Table 1. Verification of dP Interlock Ladder Logic Software ..................................................84

Table 2. Validation / Requirements Cross Reference for Ladder Logic Software ......................85

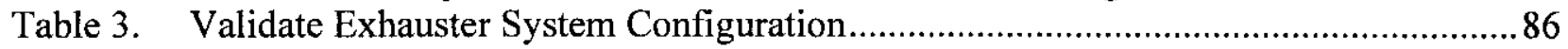

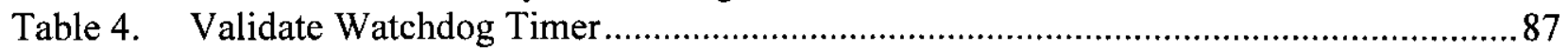

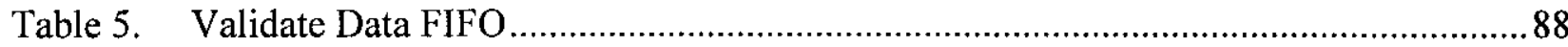

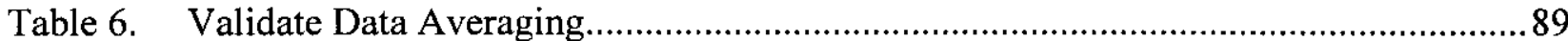

Table 7. Validate Train A Transmitter Failure Alarms With Fan Not Running.........................99

Table 8. Validate Train B Transmitter Failure Alarms With Fan Not Running ..........................91

Table 9. Validate Train C Transmitter Failure Alarms With Fan Not Running .........................99

Table 10. Validate Train A dP1 Transmitter Failure Alarms With Fan Running.........................93

Table 11. Validate Train A dP2 Transmitter Failure Alarms With Fan Running..........................94

Table 12. Validate Train A dP12 Transmitter Failure Alarms With Fan Running.......................95

Table 13. Validate Train B dP1 Transmitter Failure Alarms With Fan Running........................96

Table 14. Validate Train B dP2 Transmitter Failure Alarms With Fan Running .........................97

Table 15. Validate Train B dP12 Transmitter Failure Alarms With Fan Running ......................98

Table 16. Validate Train C dP1 Transmitter Failure Alarms With Fan Running ..........................99

Table 17. Validate Train C dP2 Transmitter Failure Alarms With Fan Running ........................ 100

Table 18. Validate Train C dP12 Transmitter Failure Alarms With Fan Running ......................101

Table 19. Validate Train A High dP1 and Low dP2 Alarms With Fan Running ........................102

Table 20. Validate Train B High dP1 and Low dP2 Alarms With Fan Running.......................103

Table 21. Validate Train C High dP1 and Low dP2 Alarms With Fan Running........................104

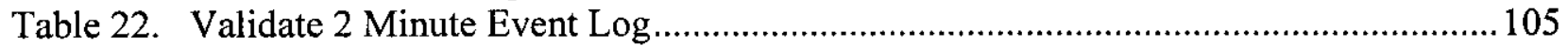

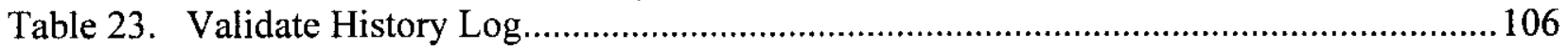

\section{LIST OF ATTACHMENTS}

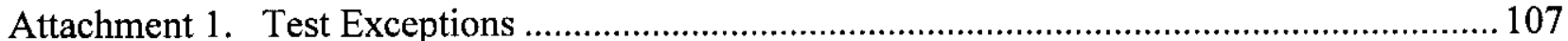

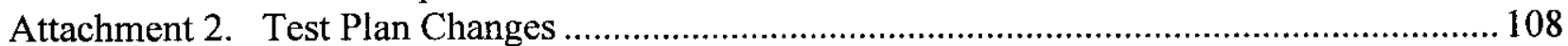




\section{TRADEMARK CREDITS}

Allen-Bradley is a trademark of the Allen-Bradley Corporation

RSLogix 500 is a trademark of Rockwell Software, Inc.

SLC 5/03 is a trademark of the Allen-Bradley Corporation

Yokogawa is a registered trademark of the Yokogawa Electric Corporation

Other product names may be trademarks or registered trademarks of their respective companies and are hereby acknowledged. 


\section{Software Verification and Validation Test Plan for the HEPA Filter Differential Pressure Fan Interlock System}

\subsection{INTRODUCTION / PURPOSE}

Double-Shell Tanks (DSTs) and Double Contained Receiver Tanks (DCRTs) are actively ventilated, along with certain Single-Shell Tanks (SSTs) and other River Protection Project (RPP) facilities. The exhaust air stream on a typical primary ventilation system is drawn through two stages of High-Efficiency Particulate Air (HEPA) filtration to ensure confinement of airborne radioactive materials. Active ventilation exhaust stacks traditionally have required a stack CAM interlock to detect releases from postulated accidents, and to shut down the exhaust fan when high radiation levels are detected in the stack airstream.

The HEPA Filter Differential Pressure Fan Interlock System (hereafter referred to as "dP Interlock System") has been determined to be technically equivalent to the stack CAM interlock and therefore able to perform its safety function. This system can provide the requisite level of control specified in the facility safety analysis, and is expected to perform this function more reliably and with fewer operational and maintenance problems.

The purpose of his document is to provide a means to qualify the PLC ladder logic software ("dP Interlock v1.00", July 2000) that controls the dP Interlock System. These Verification and Validation (V\&V) activities are performed to "Computer Software Quality Assurance Requirements", HNF-PRO-309 [ref. 1].

\section{0}

\section{RESPONSIBILITIES}

The following personnel will be required for the performance of this test plan:

- Cognizant Engineer / Project Representative: Has direct responsibility for the performance and adequacy of the test. Records information, initials and dates the sign-off blocks, and signs the V\&V completion approvals.

- Test Director: Has responsibility for assisting in the performance of the test. This individual must be familiar with Allen-Bradley SLC PLCs, and with Rockwell Software RSLogix 500 programming. Signs the overall V\&V completion approval.

- Quality Assurance Representative: Has responsibility for assuring that any test exceptions are adequately addressed and resolved. May also provide direct oversight during test performance (optional). Signs the overall V\&V completion approval.

- Design Authority: Has responsibility for reviewing results, and assuring that any test exceptions are adequately resolved. Signs the overall V\&V completion approval.

If, during testing, any indicated parameter or control function is not correct or appears to be malfunctioning, then the Cognizant Engineer / Project Representative conducting this test shall make a determination as to the feasibility of continuing testing. Since actual dP Interlock operations will not occur during this test, there is no safety impact to continuing the test and completing corrective actions later. A record of all noted test exceptions will be kept on copies of 
Attachment 1, "Test Exceptions". Quality Assurance shall review the test exceptions and concur with the resolution.

Any required changes or corrections to this test plan (e.g., typos, step modifications) shall be approved by the Cognizant Engineer / Project Representative and may be made as "pen-and-ink" changes in the official working copy of the test plan. Corrections are to be made by drawing a single line through incorrect information and writing in the correct information. The correction is then dated and initialed by the individual authorized to make the correction. A record of all test plan changes will be kept on Attachment 2, "Test Plan Changes". Upon completion of the Test Plan, Quality Assurance shall review the changes and concur with the correction.

Approval of successful completion of the verification phase shall be documented by the Cognizant Engineer / Project Representative at the end of Section 4.0, and approval of successful completion of the validation phase shall be documented by the Cognizant Engineer / Project Representative at the end of Section 5.0. Approval of successful completion of the entire test plan shall be documented by all responsible parties in Section 6.0. A V\&V Test Report, summarizing the results of the Test Plan and containing a copy of the completed Test Plan, will be issued following completion of the Test Plan.

\subsection{SYSTEM DESCRIPTION}

The PLC subsystem hardware for the field dP Interlock System is comprised of a 13-slot rack, a PLC CPU, and various I/O cards. Only 8 of the slots are used in a fully-configured system (three filter trains), leaving 5 slots free for future expansion. For a single filter train system, 5 slots are used, while 6 slots are used for a two-train configuration.

The PLC subsystem hardware for the laboratory test dP Interlock System consists of an Allen-Bradley SLC 5/03 PLC, power supply, and all I/O modules required for a three train system. The following table shows the $\mathrm{I} / \mathrm{O}$ configuration for the 10 -slot rack used for the laboratory system:

\begin{tabular}{|c||l||l|}
\hline Slot & \multicolumn{1}{|c|}{ Part Number } & \multicolumn{1}{|c|}{ Description } \\
\hline 0 & $1747-$ L532C/D & 5/03 CPU - 16K Mem. OS302 \\
\hline 1 & $1746-$ IB8 & 8-Input 24 VDC Module \\
\hline 2 & $1746-$ OX8 & 8-Output Isolated Relay \\
\hline 3 & $1746-$ NI4 & Analog 4 Channel Input Module \\
\hline 4 & $1746-$ OX8 & 8-Output Isolated Relay \\
\hline 5 & $1746-$ NI4 & Analog 4 Channel Input Module \\
\hline 6 & $1746-$ OX8 & 8-Output Isolated Relay \\
\hline 7 & $1746-$ N14 & Analog 4 Channel Input Module \\
\hline 8 & -- & <Unused> \\
\hline 9 & -- & <Unused> \\
\hline
\end{tabular}

Slot 0 contains the Allen-Bradley SLC 5/03 CPU (Allen Bradley part number 1747-L532). This is the main processor for the $\mathrm{dP}$ Interlock System. Additionally, an Allen-Bradley Flash Memory card (part number 1747-M11) is installed in the PLC CPU to allow the logic program to reside on flash memory. The CPU is configured to always load the program from the flash memory upon PLC power up. 
Slot 1 contains an Allen-Bradley 1746-IB8 8-Input 24 VDC Input Module. All digital inputs from the system are routed through this card. This includes the reset button, the fan running inputs, and the train online inputs.

Slots 2, 4 and 6 all use Allen-Bradley 1746-OX8 Relay Contact Output Modules. These cards are used for illuminating front panel indicators, fan interlocks, the watchdog timer, and annunciator contacts.

Slots 3, 5 and 7 use Allen-Bradley 1746-NI44-Channel Analog Input Modules. These cards can handle either voltage $( \pm 20 \mathrm{VDC})$ or current inputs $( \pm 20 \mathrm{~mA})$, but are configured without jumpers to handle voltage inputs for laboratory testing use only.

\subsection{VERIFICATION OF dP INTERLOCK LADDER LOGIC}

\subsection{LADDER LOGIC SOFTWARE REQUIREMENTS}

The following requirements, collected from the noted references, were used to establish the ladder logic acceptance criteria:

4.1.1 The HEPA Filter dP Interlock System shall activate an interlock to shut down the ventilation system automatically when the $\mathrm{dP}$ across the first (or dP1) HEPA filter stage reaches a preset high setpoint, indicating an impending filter failure [ref. 2,3].

4.1.2 The HEPA Filter dP Interlock System shall activate an interlock to shut down the ventilation system automatically when the $\mathrm{dP}$ across the last (or $\mathrm{dP} 2$ ) HEPA filter stage reaches a preset low setpoint, indicating an impending filter failure [ref. 2,3].

4.1.3 The actual dP limits and operating modes for the proposed system shall be based on an approved AB change (TSR controls). The ideal system design will provide the flexibility to support a reasonable range of operational settings, alarms, and interlocks to be dictated by such analysis [ref. 2].

4.1.4 The system shall be continuously operable and it must fail in a safe condition (exhauster shutdown) upon loss of power or a detectable failure [ref. 2,3].

4.1.5 The system shall provide a means of signal conditioning to prevent spurious alarms and shutdowns [ref. 2].

4.1.6 The system shall have the capability to track the rate of change in the various filter $\mathrm{dP}$ readings over time for diagnostics purposes. These parameters should be accessible (i.e., via a laptop computer) [ref. 2].

4.1.7 The system shall include provisions for periodic calibration and functional testing of interlock functions, and shall provide means to calibrate and test components in place, with or without shutting the ventilation system down [ref. 2]. 
The following features were also to be incorporated into the ladder logic software and are to be verified and validated:

4.1.8 Failure of the $\mathrm{dP}$ transmitter that provides the overall $\mathrm{dP}$ (both filter stages, $\mathrm{dP} 12$ ) will alarm locally, but will not shut down the $\mathrm{dP}$ Interlock System. The remote annunciator transmitter fail will not indicate the status of the dP12 transmitter failure.

4.1.9 Failure of a dP transmitter on an inactive filter train will not shut down the $\mathrm{dP}$ Interlock System.

4.1.10 System shutdown will prevent restart of any filter train until the "Reset" is selected.

4.1.11 Alarms (local and remote annunciator) for low or high $\mathrm{dP}$ will indicate the status at the time of shutdown and will remain latched until the "Reset" is selected. The alarms (local and remote annunciator) will not be reactivated until the fan is restarted, the filter train is online and the alarm condition is present.

4.1.12 Alarms (local and remote annunciator) for the first and second filter $\mathrm{dP}$ transmitter fail status will latch until the "Reset" is selected. After "Reset", the local alarm lights will indicate current status. The remote annunciators will not be reactivated until the fan is restarted, the filter train is online and the alarm condition is present.

4.1.13 Upon an interlock trip, the system shall store all input data and time stamp information to PLC memory. The 10 most recent events should be retained in PLC memory for remote access (i.e., via a laptop computer). The most recent trip shall also store the previous 2 minutes of exhauster data, logged every 6 seconds, leading up to the event.

4.1.14 All input data and time stamp information shall be stored to PLC memory every 10 minutes, with up to 24 hours of continuous data.

\subsection{LADDER LOGIC SOFTWARE REQUIREMENTS VERIFICATION 26 a $m \varepsilon$} The ladder logic used in the dP Interlock System consists of 24 user-programmed ladder logic files, programmed and informally tested utilizing Rockwell Software's RSLogix 500 programming package. The program consists of one "MAIN" logic network and 23, additional logic networks (called as subroutines) to perform specific tasks. 25 a $m \varepsilon$

The requirements listed in Section 4.1 must be fulfilled by the PLC ladder logic. Table 1 provides a matrix indicating where in the ladder logic each requirement was addressed.

4.2.1 Using Table 1, verify that each requirement was addressed in the ladder logic. Refer to the hardcopy of the ladder logic "Program File List" included as an appendix in the Computer Software Description [ref. 5]. Initial and date the appropriate "(a)" through "(n)" blocks. 


\subsection{DOCUMENTATION REQUIREMENTS}

The $\mathrm{dP}$ Interlock software documentation shall include a Software Configuration Management Plan (SCMP), a Computer Software Description (CSWD), and Software Verification/Validation Plan (V\&V) per ref. 1.

These requirements were fulfilled by the following:

- SCMP: CH2M-Hill Hanford Group, "Software System Configuration Management Plan for the HEPA Filter Differential Pressure Fan Interlock System", RPP-6547, Rev. 0 (2000). [ref. 6]

- CSWD: CH2M-Hill Hanford Group, "Computer Software Description for the HEPA Filter Differential Pressure Fan Interlock System", RPP-6546, Rev. 0 (2000). [ref. 5]

- V\&V: CH2M-Hill Hanford Group, "Software Verification and Validation Test Plan for the HEPA Filter Differential Pressure Fan Interlock System", RPP-6581, Rev. 0 (2000). [this document]

Approval of Section 4.0 Verification Phase:

Cog. Eng. / Proj. Rep.

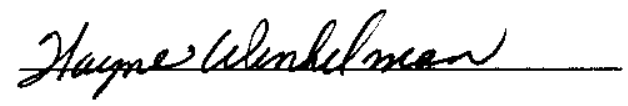

Date: $\beta-7-\infty 0$

\subsection{VALIDATION PROCEDURE}

\subsection{CONFIGURATION VALIDATION}

Parameters that define the configuration of each exhauster system and corresponding $\mathrm{I} / \mathrm{O}$ hardware are hardcoded into the PLC. These are (1) the filter train configuration - can be either Train A, Trains A \& B, or Trains A, B \& C; (2) exhauster I.D. code - each number corresponds to a unique system (not used in the PLC ladder logic, but used for laptop computer diagnostics software); (3) high dP1 and low dP2 alarm setpoints; and (4) PLC I/O module configuration - additional slots for two-filter train and three filter train systems must be enabled.

This test plan is to be performed on a laboratory simulation system which is configured for a 2 fan, 3 filter train exhauster system.

5.1.1 Start the "SLC 5/03 CPU" PLC.

5.1.2 Start the RSLogix 500 application.

5.1.3 Load the "DP INTERLOCK V1.00.RSS" ladder logic file. 
5.1.4 Customize the "DP INTERLOCK V1.00.RSS" file to correspond to a single filter train exhauster system by typing a " 0 " into the "LAD 3 - INITVALUES" rung 0000 FLL block "Source" field.

5.1.5 Download the ladder logic to the PLC and then go online with the PLC.

Refer to Table 3 when performing the following steps. When directed to verify values, record the values in the appropriate "Actual" blocks.

Test for the single filter train configuration and alarm setpoints:

5.1.6 Validate the single train exhauster configuration (ref. "LAD 3 INITVALUES").

5.1.6.1 Bring up Data File "B3 - BINARY".

5.1.6.2 Verify that bits B3:0/0 (B_TRAIN_EXISTS) and B3:0/1 (C_TRAIN_EXISTS) are "0".

5.1.6.3 Verify that word B3:1 (EXHAUSTER_ID) is "1".

5.1.7 Validate alarm setpoints (ref. "LAD 3 - INITVALUES").

5.1.7.1 Bring up Data File "N7 - INTEGER".

5.1.7.2 Verify that word N7:91 (HIGH_DP1_LIMIT) is 10748 (corresponds to 5.7000 inwg).

5.1.7.3 Verify that word N7:92 (LOW_DP2_LIMIT) is 3670 (corresponds to 0.2998 inwg).

5.1.8 Validate the single filter train I/O Slot Enables (ref. "LAD 4 - IO CONFIG").

5.1.8.1 Bring up Data File "S2 - STATUS", Tab "IO".

5.1.8.2 Verify that bits S:11/0 thru S:11/4 (I/O Slot Enables for slots 0 thru 4) are "1", and that bits $\mathrm{S}: 11 / 5$ thru S:11/12 (I/O Slot Enables for slots 5 thru 12) are "0".

5.1.8.3 Initial and date the Table 3 "(a)" block.

Test for the two filter train configuration:

5.1.9 Go offline with the PLC.

5.1.10 Customize the "DP INTERLOCK V1.00.RSS" file to correspond to a two filter train exhauster system by typing a " 1 " into the "LAD 3 - INITVALUES" rung 0000 FLL block "Source" field.

5.1.11 Download the ladder logic to the PLC and then go online with the PLC. 
5.1.12 Validate the two filter train exhauster configuration (ref. "LAD 3 INITVALUES").

\subsubsection{Bring up Data File "B3 - BINARY".}

5.1.12.2 Verify that bit B3:0/0 (B_TRAIN_EXISTS) is "1" and bit B3:0/1 (C_TRAIN_EXISTS) is "0".

5.1.13 Validate the two filter train I/O Slot Enables (ref. "LAD 4 - IO CONFIG").

5.1.13.1 Bring up Data File "S2 - STATUS", Tab "IO".

5.1.13.2 Verify that bits S:11/0 thru S:11/5 (I/O Slot Enables for slots 0 thru 5) are "1", and that bits S:11/6 thru S:11/12 (I/O Slot Enables for slots 6 thru 12) are "0".

5.1.13.3 Initial and date the Table 3 "(b)" block.

Test for the three filter train configuration:

5.1.14 Go offline with the PLC.

5.1.15 Customize the "DP INTERLOCK V1.00.RSS" file to correspond to a three filter train exhauster system by typing a " 3 " into the "LAD 3 - INITVALUES" rung 0000 FLL block "Source" field.

5.1.16 Download the ladder logic to the PLC and then go online with the PLC.

5.1.17 Validate the three filter train exhauster configuration (ref. "LAD 3 INITVALUES").

5.1.17.1 Bring up Data File "B3 - BINARY".

5.1.17.2 Verify that bits B3:0/0 (B_TRAIN_EXISTS) and B3:0/1 (C_TRAIN_EXISTS) are "1".

5.1.18 Validate the three filter train I/O Slot Enables (ref. "LAD 4 - IO CONFIG").

5.1.18.1 Bring up Data File "S2 - STATUS", Tab "IO".

5.1.18.2 Verify that bits S:11/0 thru S:11/7 (I/O Slot Enables for slots 0 thru 7) are "1", and that bits S:11/8 thru S:11/12 (I/O Slot Enables for slots 8 thru 12) are "0".

5.1.18.3 Initial and date the Table 3 "(c)" block. 


\subsection{WATCHDOG TIMER VALIDATION}

The watchdog timer logic is used to send a square wave pulse (1 minute on / 1 minute off) to a solid state relay timer. If the pulse is not sent due to loss of PLC power or PLC failure, the relay timer is designed to trip the fan interlock after 3 minutes.

Refer to Table 4 when performing the following steps. When directed to verify values, record the values in the appropriate "Actual" blocks.

5.2.1 Validate the 1 minute watchdog timer output (ref. "LAD 5 - WATCHDOG").

5.2.1.1 Bring up Data Files "O0 - OUTPUT" and "T4 - TIMER".

5.2.1.2 Verify that when T4:0.ACC (WATCHDOG TIMER.ACC) is between 0 and 60 , that bit $\mathrm{O}: 2.0 / 7$ (O_WATCHDOG_TMR) is "1".

5.2.1.3 Initial and date the Table 4 "(a)" block.

5.2.1.4 Verify that when T4:0.ACC (WATCHDOG_TIMER.ACC) is between 61 and 120, that bit O:2.0/7 (O_WATTCHDOG_TMR) is " 0 ".

5.2.1.5 Initial and date the Table 4 "(b)" block.

\subsection{DATA FIFO VALIDATION}

The data FIFO (first in - first out) stacks are the PLC memory regions used to store the last 10 values of $\mathrm{dP} 1, \mathrm{dP} 2$ and $\mathrm{dP} 12$ for each filter train. The data values are acquired every six seconds, providing the last 1 minute of data to be used for calculating 1 minute running averages.

Refer to Table 5 when performing the following steps. When directed to verify values, record the values in the appropriate "Actual" blocks.

5.3.1 Bring up Data Files "T4 - TIMER" and "N7 - INTEGER" (ref. "LAD 6 - DATA FIFO").

5.3.2 Validate the 1 minute data first-in, first-out (FIFO) words for Train A, dP1.

5.3.2.1 Verify that words N7:0 thru N7:9 (A_DP1_10) are nearly identical values.

5.3.2.2 Adjust the input for Train A dP1 to change the value.

5.3.2.3 Verify that when T4:1.ACC (DATA_FIFO_TIMER.ACC) reaches " 6 ", the new value appears at N7:9. 
5.3.2.4 Verify that when T4:1.ACC (DATA_FIFO_TIMER.ACC) reaches " 6 ", the new value moves from right to left towards N7:0.

5.3.2.5 Initial and date the Table 5 "(a)" block.

5.3.3 Validate the 1 minute data first-in, first-out (FIFO) words for Train A, dP2.

5.3.3.1 Verify that words N7:10 thru N7:19 (A_DP2_10) are nearly identical values.

5.3.3.2 Adjust the input for Train A dP2 to change the value.

5.3.3.3 Verify that when T4:1.ACC (DATA_FIFO_TIMER.ACC) reaches "6", the new value appears at N7:19.

5.3.3.4 Verify that when T4:1.ACC (DATA_FIFO_TIMER.ACC) reaches " 6 ", the new value moves from right to left towards $\mathrm{N} 7: 10$.

5.3.3.5 Initial and date the Table 5 "(b)" block.

5.3.4 Validate the 1 minute data first-in, first-out (FIFO) words for Train A, dP12.

5.3.4.1 Verify that words N7:20 thru N7:29 (A_DP12_10) are nearly identical values.

5.3.4.2 Adjust the input for Train A dP12 to change the value.

5.3.4.3 Verify that when T4:1.ACC (DATA_FIFO_TIMER.ACC) reaches " 6 ", the new value appears at N7:29.

5.3.4.4 Verify that when T4:1.ACC (DATA_FIFO_TIMER.ACC) reaches " 6 ", the new value moves from right to left towards N7:20.

5.3.4.5 Initial and date the Table 5 "(c)" block.

5.3.5 Validate the 1 minute data first-in, first-out (FIFO) words for Train B, dP1.

5.3.5.1 Verify that words N7:30 thru N7:39 (B_DP1_10) are nearly identical values.

5.3.5.2 Adjust the input for Train B dP1 to change the value.

5.3.5.3 Verify that when T4:1.ACC (DATA_FIFO_TIMER.ACC) reaches " 6 ", the new value appears at $\mathrm{N} 7: 3 \overline{9}$.

5.3.5.4 Verify that when T4:1.ACC (DATA_FIFO_TIMER.ACC) reaches "6", the new value moves from right to left towards $\mathrm{N} 7: 30$. 
5.3.5.5 Initial and date the Table 5 "(d)" block.

5.3.6 Validate the 1 minute data first-in, first-out (FIFO) words for Train B, dP2.

5.3.6.1 Verify that words N7:40 thru N7:49 (B_DP2_10) are nearly identical values.

5.3.6.2 Adjust the input for Train $\mathrm{B} \mathrm{dP} 2$ to change the value.

5.3.6.3 Verify that when T4:1.ACC (DATA_FIFO_TIMER.ACC) reaches " 6 ", the new value appears at $\mathrm{N} 7: 4 \overline{9}$.

5.3.6.4 Verify that when T4:1.ACC (DATA_FIFO_TIMER.ACC) reaches " 6 ", the new value moves from right to left towards N7:40.

5.3.6.5 Initial and date the Table 5 "(e)" block.

5.3.7 Validate the 1 minute data first-in, first-out (FIFO) words for Train B, dP12.

5.3.7.1 Verify that words N7:50 thru N7:59 (B_DP12_10) are nearly identical values.

5.3.7.2 Adjust the input for Train $\mathrm{B} \mathrm{dP} 12$ to change the value.

5.3.7.3 Verify that when T4:1.ACC (DATA_FIFO_TIMER.ACC) reaches " 6 ", the new value appears at N7:59.

5.3.7.4 Verify that when T4:1.ACC (DATA_FIFO_TIMER.ACC) reaches " 6 ", the new value moves from right to left towards N7:50.

5.3.7.5 Initial and date the Table 5 "(f)" block.

5.3.8 Validate the 1 minute data first-in, first-out (FIFO) words for Train $\mathrm{C}, \mathrm{dP} 1$.

5.3.8.1 Verify that words N7:60 thru N7:69 (C_DP1_10) are nearly identical values.

5.3.8.2 Adjust the input for Train $\mathrm{C} \mathrm{dP1}$ to change the value.

5.3.8.3 Verify that when T4:1.ACC (DATA_FIFO_TIMER.ACC) reaches "6", the new value appears at N7:69.

5.3.8.4 Verify that when T4:1.ACC (DATA_FIFO_TIMER.ACC) reaches " 6 ", the new value moves from right to left towards N7:60.

5.3.8.5 Initial and date the Table 5 " $(\mathrm{g})$ " block. 
5.3.9 Validate the 1 minute data first-in, first-out (FIFO) words for Train C, dP2.

5.3.9.1 Verify that words N7:70 thru N7:79 (C_DP2_10) are nearly identical values.

5.3.9.2 Adjust the input for Train C dP2 to change the value.

5.3.9.3 Verify that when T4:1.ACC (DATA_FIFO_TIMER.ACC) reaches " 6 ", the new value appears at $\mathrm{N} 7: 79$.

5.3.9.4 Verify that when T4:1.ACC (DATA_FIFO_TIMER.ACC) reaches " 6 ", the new value moves from right to left towards N7:70.

5.3.9.5 Initial and date the Table 5 "(h)" block.

5.3.10 Validate the 1 minute data first-in, first-out (FIFO) words for Train C, dP12.

5.3.10.1 Verify that words N7:80 thru N7:89 (C_DP12_10) are nearly identical values.

5.3.10.2 Adjust the input for Train $\mathrm{C} \mathrm{dP} 12$ to change the value.

5.3.10.3 Verify that when T4:1.ACC (DATA_FIFO_TIMER.ACC) reaches "6", the new value appears at N7:89.

5.3.10.4 Verify that when T4:1.ACC (DATA_FIFO_TIMER.ACC) reaches " 6 ", the new value moves from right to left towards N7:80.

5.3.10.5 Initial and date the Table 5 "(i)" block.

\subsection{DATA AVERAGING VALIDATION}

Data averaging uses the last 10 values of $\mathrm{dP} 1, \mathrm{dP} 2$ and $\mathrm{dP} 12$ for each filter train (from the data FIFO stacks) to calculate 1 minute running averages, updated every six seconds. These averaged values are used for all alarming and data logging purposes.

Refer to Table 6 when performing the following steps. When directed to verify values, record the values in the appropriate "Actual" blocks.

5.4.1 Bring up Data File "N7 - INTEGER" (ref. "LAD 8 - A AVERAGES").

5.4.2 Validate the Train A dP1 six second running averages.

5.4.2.1 Verify that words N7:0 thru N7:9 (A_DP1_10) are nearly identical values, and that the average value appears in word N7:93 (A_TRAIN_DP1_AVG).

5.4.2.2 Adjust the input for Train A dP1 to change the value. 
5.4.2.3 When five words are updated with the new value in N7:5 thru $N 7: 9$, verify that the average in N7:93 is the average of the values in $\mathrm{N} 7: 0$ thru $\mathrm{N} 7: 9$.

5.4.2.4 Initial and date the Table 6 "(a)" block.

5.4.3 Validate the Train $\mathrm{A} \mathrm{dP} 2$ six second running averages.

5.4.3.1 Verify that words N7:10 thru N7:19 (A_DP2_10) are nearly identical values, and that the average value appears in word N7:94 (A_TRAIN_DP2_AVG).

5.4.3.2 Adjust the input for Train A dP2 to change the value.

5.4.3.3 When five words are updated with the new value in N7:15 thru $\mathrm{N} 7: 19$, verify that the average in N7:94 is the average of the values in $\mathrm{N} 7: 10$ thru $\mathrm{N} 7: 19$.

5.4.3.4 Initial and date the Table 6 "(b)" block.

5.4.4 Validate the Train A dP12 six second running averages.

5.4.4.1 Verify that words N7:20 thru N7:29 (A_DP12_10) are nearly identical values, and that the average value appears in word N7:95 (A_TRAIN_DP12_AVG).

5.4.4.2 Adjust the input for Train A dP12 to change the value.

5.4.4.3 When five words are updated with the new value in N7:25 thru $\mathrm{N} 7: 29$, verify that the average in N7:95 is the average of the values in N7:20 thru N7:29.

5.4.4.4 Initial and date the Table 6 "(c)" block.

5.4.5 Bring up Data File "N7 - INTEGER" (ref. "LAD 9 - B AVERAGES").

5.4.6 Validate the Train $\mathrm{B} \mathrm{dP} 1$ six second running averages.

5.4.6.1 Verify that words N7:30 thru N7:39 (B_DP1_10) are nearly identical values, and that the average value appears in word N7:96 (B_TRAIN_DP1_AVG).

5.4.6.2 Adjust the input for Train B dP1 to change the value.

5.4.6.3 When five words are updated with the new value in N7:35 thru $\mathrm{N} 7: 39$, verify that the average in N7:96 is the average of the values in $\mathrm{N} 7: 30$ thru $\mathrm{N} 7: 39$.

5.4.6.4 Initial and date the Table 6 "(d)" block. 
5.4.7 Validate the Train $\mathrm{B} \mathrm{dP} 2$ six second running averages.

5.4.7.1 Verify that words N7:40 thru N7:49 (B_DP2_10) are nearly identical values, and that the average value appears in word N7:97 (B_TRAIN_DP2_AVG).

5.4.7.2 Adjust the input for Train $\mathrm{B} \mathrm{dP2}$ to change the value.

5.4.7.3 When five words are updated with the new value in N7:45 thru $\mathrm{N} 7: 49$, verify that the average in N7:97 is the average of the values in N7:40 thru N7:49.

5.4.7.4 Initial and date the Table 6 "(e)" block.

5.4.8 Validate the Train B dP12 six second running averages.

5.4.8.1 Verify that words N7:50 thru N7:59 (B_DP12_10) are nearly identical values, and that the average value appears in word N7:98 (B_TRAIN_DP12_AVG).

5.4.8.2 Adjust the input for Train B dP1 to change the value.

5.4.8.3 When five words are updated with the new value in N7:55 thru $\mathrm{N} 7: 59$, verify that the average in N7:98 is the average of the values in $\mathrm{N} 7: 50$ thru $\mathrm{N} 7: 59$.

5.4.8.4 Initial and date the Table 6 "(f)" block.

5.4.9 Bring up Data File "N7 - INTEGER" (ref. "LAD 10 - C AVERAGES").

5.4.10 Validate the Train $\mathrm{C} \mathrm{dP} 1$ six second running averages.

5.4.10.1 Verify that words N7:60 thru N7:69 (C_DP1_10) are nearly identical values, and that the average value appears in word N7:99 (C_TRAIN_DP1_AVG).

5.4.10.2 Adjust the input for Train $\mathrm{C} \mathrm{dP1}$ to change the value.

5.4.10.3 When five words are updated with the new value in N7:65 thru $\mathrm{N} 7: 69$, verify that the average in N7:99 is the average of the values in N7:60 thru N7:69.

5.4.10.4 Initial and date the Table 6 " $(\mathrm{g})$ " block.

5.4.11 Validate the Train $\mathrm{C} \mathrm{dP} 2$ six second running averages.

5.4.11.1 Verify that words N7:70 thru N7:79 (C_DP2_10) are nearly identical values, and that the average value appears in word N7:100 (C_TRAIN_DP2_AVG).

5.4.11.2 Adjust the input for Train $\mathrm{C}$ dP2 to change the value. 
5.4.11.3 When five words are updated with the new value in N7:75 thru $\mathrm{N} 7: 79$, verify that the average in N7:100 is the average of the values in N7:70 thru N7:79.

5.4.11.4 Initial and date the Table 6 "(h)" block.

5.4.12 Validate the Train $\mathrm{C} \mathrm{dP12}$ six second running averages.

5.4.12.1 Verify that words N7:80 thru N7:89 (C_DP12_10) are nearly identical values, and that the average value appears in word N7:101 (C_TRAIN_DP12_AVG).

5.4.12.2 Adjust the input for Train $\mathrm{C} \mathrm{dP} 12$ to change the value.

5.4.12.3 When five words are updated with the new value in N7:85 thru $\mathrm{N} 7: 89$, verify that the average in N7:101 is the average of the values in N7:80 thru N7:89.

5.4.12.4 Initial and date the Table 6 "(i)" block.

\subsection{TRANSMITTER FAILURES VALIDATION}

The dP1, dP2 and dP12 Yokogawa Model EJA110A transmitters for each filter train are considered failed when the transmitters yield outputs that are outside the normal $4-20 \mathrm{~mA}$ range by specified amounts. The down-scale failure setpoint is $-5 \%$ (corresponding to $3.2 \mathrm{~mA}$, or a PLC reading of 2621). The up-scale failure setpoint is $110 \%$ (corresponding to $21.6 \mathrm{~mA}$, or a PLC reading of 17695 ).

One minute after initial PLC power up, and when no fans are running, all transmitter failure conditions result in illuminating the local panel lamps (no fan interlock trips). The dP1 and $\mathrm{dP} 2$ outputs to the lamps are latched, while $\mathrm{dP} 12$ is not latched (self-clearing).

In addition, if a fan is running and a filter train is online, a corresponding filter train's $\mathrm{dP} 1$ or dP2 transmitter failure condition results in a transmitter failure annunciator alarm and an interlock trip, shutting off the fan. This "trip event" is stored in an "Event Log" memory region in the PLC. The $\mathrm{dP} 12$ failure conditions only results in a local panel lamp indication, and never result in a transmitter failure annunciator alarm or a trip event.

Refer to Table 7 when performing the Train A Section 5.5.1 to 5.5.3 steps. When directed to verify values, record the values in the appropriate "Actual" blocks.

5.5.1 Bring up Data Files "O0 - OUTPUT", "I1 - INPUT", "T4 - TIMER" and "N7 - INTEGER".

5.5.2 Validate that the Train A "down-scale" transmitter failure alarms function as expected when a fan is not running (ref. "LAD 15 - A XMITFAIL"). 
5.5.2.1 Verify that Fan 1 and Fan 2 are not running by verifying that bits I:1.0/2 (I_FAN_1_ON) and I:1.0/3 (I_FAN_2_ON) are "0" (Use the simulator "FAN $1 \mathrm{ON}^{-}$and "FAN $2 \mathrm{ON}^{\prime \prime}$ switches to turn the fans off, if necessary).

5.5.2.2 Verify that Train A is not online by verifying that bit I:1.0/4 (I_A_TRAIN_ONLINE) is "0" (Use the simulator "TRAIN A ONLINE" switch to place Train A offline, if necessary).

5.5.2.3 Adjust the inputs for $\mathrm{dP} 1, \mathrm{dP} 2$ and $\mathrm{dP} 12$, and verify that words N7:93 (A_TRAIN_DP1_AVG), N7:94 (A_TRAIN_DP2_AVG), and N7:95 (A_TRAIN_DP12_AVG) are less than or equal to the transmitter failure low setpoint of 2621 (corresponds to -0.5005 inwg).

5.5.2.4 Verify that the three transmitter failure alarms exist by verifying that bits $0: 2.0 / 3$ (O_A_XMIT_FAIL_DP1), O:2.0/4 (O_A_XMIT_FAIL_DP2), O:2.0/5 (O_A_XMIT_FAIL_DP12) are "1".

5.5.2.5 Verify that the Fan 1 and Fan 2 Interlocks have not tripped by verifying that bits O:2.0/0 (O_FAN_1_INTERLOCK) and O:4.0/0 (O_FAN_2_INTERLOCK) are "1" (the fail-safe tripped condition is " 0 ").

5.5.2.6 Initial and date the Table 7 "(a)" block.

Test for cleared ("Reset") alarms $<60$ seconds before power up:

Note: Steps 5.5.2.7 to 5.5.2.10 need to be performed in less than 60 seconds.

5.5.2.7 Turn the SLC 5/03 CPU key switch to "PROG", to "RUN", then to "REM" (Performs a power up restart of the PLC).

5.5.2.8 Toggle bit I:1.0/0 (I_RESET) by using the simulator "RESET" switch. This clears the two latched $\mathrm{dP} 1$ and $\mathrm{dP} 2$ transmitter failure alarms.

5.5.2.9 Verify that the three transmitter failure alarms are cleared by verifying that bits $\mathrm{O}: 2.0 / 3$ (O_A_XMIT_FAIL_DP1), O:2.0/4 (O_A_XMIT_FAIL_DP2), O:2.0/5 (O_A_XMIT_FAIL_DP12) are "0".

5.5.2.10 Verify that the Fan 1 and Fan 2 Interlocks remain not tripped by verifying that bits O:2.0/0 (O_FAN_1_INTERLOCK) and O:4.0/0 (O_FAN_2_INTERLOCK) are still "1".

5.5.2.11 Initial and date the Table 7 "(b)" block. 
Test for reappearance of alarms 60 seconds after power up:

5.5.2.12 Verify that when T4:8.ACC

(POWER_ON_DELAY_TIMER.ACC) reaches "60", the three transmitter failure alarms reappear by verifying that bits $\mathrm{O}: 2.0 / 3$ (O_A_XMIT_FAIL_DP1), O:2.0/4 (O_A_XMIT_FAIL_DP2), $\mathrm{O}: \overline{2} \cdot \overline{0} \overline{5}\left(\mathrm{O}_{-} \mathrm{A}_{-} \mathrm{XMIT}\right.$-FAIL_DP12) are " $\overline{1}$ ".

5.5.2.13 Verify that the Fan 1 and Fan 2 Interlocks remain not tripped by verifying that bits $0: 2.0 / 0\left(O_{-}\right.$FAN_1_INTERLOCK $)$and O:4.0/0 (O_FAN_2_INTERLOCK) are still "1".

5.5.2.14 Initial and date the Table 7 "(c)" block.

Re-establish normal non-alarming conditions:

5.5.2.15 Adjust the input for $\mathrm{dP} 1$ so that word N7:93

(A_TRAIN_DP1_AVG) is between the transmitter failure low setpoint (2621) and the high setpoint (17695); verify that bit $\mathrm{O}: 2.0 / 3$ (O_A_XMIT_FAIL_DP1) returns to " 0 " only when the simulator "RESET" switch (bit I:1.0/0, I_RESET) is toggled.

5.5.2.16 Adjust the input for $\mathrm{dP} 2$ so that word N7:94

(A_TRAIN_DP2_AVG) is between the transmitter failure low setpoint (2621) and the high setpoint (17695); verify that bit O:2.0/4 (O_A_XMIT_FAIL_DP2) returns to "0" only when the simulator "RESET" switch (bit I:1.0/0, I_RESET) is toggled.

5.5.2.17 Adjust the input for dP12 so that word N7:95

(A_TRAIN_DP12_AVG) is between the transmitter failure low setpoint (2621) and the high setpoint (17695); verify that the self-clearing bit O:2.0/5 (O_A_XMIT_FAIL_DP12) returns to "0".

5.5.2.18 Verify that the Fan 1 and Fan 2 Interlocks remain not tripped by verifying that bits $0: 2.0 / 0$ (O_FAN_1_INTERLOCK) and $0: 4.0 / 0$ (O_FAN_2_INTERLOCK) are still "1".

\subsubsection{Initial and date the Table 7 "(d)" block.}

5.5.3 Validate that the Train A "up-scale" transmitter failure alarms function as expected when a fan is not running (ref. "LAD 15 - A XMITFAIL").

Test for transmitter failure alarms before power up:

5.5.3.1 Adjust the inputs for $\mathrm{dP1}, \mathrm{dP} 2$ and $\mathrm{dP12}$, and verify that words N7:93 (A_TRAIN_DP1_AVG), N7:94 (A_TRAIN_DP2_AVG), and N7:95 (A_TRAIN_DP12_AVG) are greater than or equal to the 
transmitter failure high setpoint of 17695 (corresponds to 11.0002 inwg).

5.5.3.2 Verify that the three transmitter failure alarms exist by verifying that bits O:2.0/3 (O_A_XMIT_FAIL_DP1), O:2.0/4 (O_A XMIT_FAIL_DP2), O: $\overline{2} .0 / 5$ (O_A_XMIT_FAIL_DP12) are "1".

5.5.3.3 Verify that the Fan 1 and Fan 2 Interlocks have not tripped by verifying that bits $\mathrm{O}: 2.0 / 0$ (O_FAN_1_INTERLOCK) and O:4.0/0 (O_FAN_2_INTERLOCK) are "1" (the fail-safe tripped condition is " 0 ").

5.5.3.4 Initial and date the Table 7 "(e)" block.

Test for cleared ("Reset") alarms $<60$ seconds before power up:

Note: Steps 5.5.3.5 to 5.5.3.8 need to be performed in less than 60 seconds.

5.5.3.5 Turn the SLC 5/03 CPU key switch to "PROG", to "RUN", then to "REM" (Performs a power up restart of the PLC).

5.5.3.6 Toggle bit I:1.0/0 (I_RESET) by using the simulator "RESET" switch. This clears the two latched $\mathrm{dP} 1$ and $\mathrm{dP} 2$ transmitter failure alarms.

5.5.3.7 Verify that the three transmitter failure alarms are cleared by verifying that bits $\mathrm{O}: 2.0 / 3\left(\mathrm{O} \_\right.$A X XMIT_FAIL_DP1), O:2.0/4 (O_A_XMIT_FAIL_DP2), $0: 2.0 / 5$ (O_A_XMIT_FAIL_DP12) are "0".

5.5.3.8 Verify that the Fan 1 and Fan 2 Interlocks remain not tripped by verifying that bits $\mathrm{O}: 2.0 / 0$ (O_FAN_1_INTERLOCK) and $\mathrm{O}: 4.0 / 0$ (O_FAN_2_INTERLOCK) are still "1".

5.5.3.9 Initial and date the Table 7 "(f)" block.

Test for reappearance of alarms 60 seconds after power up:

5.5.3.10 Verify that when T4:8.ACC

(POWER_ON_DELAY_TIMER.ACC) reaches "60", the three transmitter failure alarms reappear by verifying that bits $\mathrm{O}: 2.0 / 3$ (O_A_XMIT_FAIL_DP1), O:2.0/4 (O_A_XMIT_FAIL_DP2), $\mathrm{O}: \overline{2} .0 / 5$ (O_A_XMIT_FAIL_DP12) are " $\overline{1}$ ".

5.5.3.11 Verify that the Fan 1 and Fan 2 Interlocks remain not tripped by verifying that bits $\mathrm{O}: 2.0 / 0\left(\mathrm{O} \_\right.$FAN_1_INTERLOCK) and O:4.0/0 (O_FAN_2_INTERLOCK) are still "1".

5.5.3.12 Initial and date the Table 7 " $(\mathrm{g})$ " block. 
Re-establish normal non-alarming conditions:

5.5.3.13 Adjust the input for $\mathrm{dP} 1$ so that word N7:93

(A_TRAIN_DP1_AVG) is between the transmitter failure low setpoint (2621) and the high setpoint (17695); verify that bit $O: 2.0 / 3$ (O A XMIT_FAIL_DP1) returns to "0" only when the simulator "RESET" switch (bit I:1.0/0, I_RESET) is toggled.

5.5.3.14 Adjust the input for $\mathrm{dP} 2$ so that word N7:94 (A_TRAIN_DP2_AVG) is between the transmitter failure low setpoint (2621) and the high setpoint (17695); verify that bit O:2.0/4 (O_A_XMIT_FAIL_DP2) returns to " 0 " only when the simulator "RESET" switch (bit I:1.0/0, I_RESET) is toggled.

5.5.3.15 Adjust the input for dP12 so that word N7:95

(A_TRAIN_DP12_AVG) is between the transmitter failure low setpoint (2621) and the high setpoint (17695); verify that the self-clearing bit O:2.0/5 (O_A_XMIT_FAIL_DP12) returns to "0".

5.5.3.16 Verify that the Fan 1 and Fan 2 Interlocks remain not tripped by verifying that bits $0: 2.0 / 0$ (O_FAN_1_INTERLOCK) and O:4.0/0 (O_FAN_2 INTERLOCK) are still "1".

\subsubsection{Initial and date the Table 7 "(h)" block.}

Refer to Table 8 when performing the Train B Section 5.5.4 to 5.5.6 steps. When directed to verify values, record the values in the appropriate "Actual" blocks.

5.5.4 Bring up Data Files "O0 - OUTPUT", "I1 - INPUT", "T4 - TIMER" and "N7 - INTEGER".

5.5.5 Validate that the Train B "down-scale" transmitter failure alarms function as expected when a fan is not running (ref. "LAD 16 - B XMITFAIL").

Test for transmitter failure alarms before power up:

5.5.5.1 Verify that Fan 1 and Fan 2 are not running by verifying that bits I:1.0/2 (I_FAN_1_ON) and I:1.0/3 (I_FAN_2_ON) are "0" (Use the simulator "FAN $10 N "$ and "FAN 2 ON" switches to turn the fans off, if necessary).

5.5.5.2 Verify that Train B is not online by verifying that bit I:1.0/5 (I_B_TRAIN_ONLINE) is "0" (Use the simulator "TRAIN B ONLINE" switch to place Train B offline, if necessary).

5.5.5.3 Adjust the inputs for $\mathrm{dP1}, \mathrm{dP} 2$ and $\mathrm{dP12}$, and verify that words N7:96 (B_TRAIN_DP1_AVG), N7:97 (B_TRAIN_DP2_AVG), and 
N7:98 (B_TRAIN_DP12_AVG) are less than or equal to the transmitter failure low setpoint of 2621 (corresponds to -0.5005 inwg).

5.5.5.4 Verify that the three transmitter failure alarms exist by verifying that bits O:4.0/3 (O_B_XMIT_FAIL_DP1), O:4.0/4 (O_B_XMIT_FAIL_DP2), O:4.0/5 (O_B_XMIT_FAIL_DP12) are $" 1 "$.

5.5.5.5 Verify that the Fan 1 and Fan 2 Interlocks have not tripped by verifying that bits O:2.0/0 (O_FAN_1_INTERLOCK) and O:4.0/0 (O_FAN_2_INTERLOCK) are "1" (the fail-safe tripped condition is " $0 ")$.

5.5.5.6 Initial and date the Table 8 "(a)" block.

Test for cleared ("Reset") alarms $<60$ seconds before power up:

Note: Steps 5.5.5.7 to 5.5.5.10 need to be performed in less than 60 seconds.

5.5.5.7 Turn the SLC 5/03 CPU key switch to "PROG", to "RUN", then to "REM" (Performs a power up restart of the PLC).

5.5.5.8 Toggle bit I:1.0/0 (I_RESET) by using the simulator "RESET" switch. This clears the two latched $\mathrm{dP} 1$ and $\mathrm{dP} 2$ transmitter failure alarms.

5.5.5.9 Verify that the three transmitter failure alarms are cleared by verifying that bits O:4.0/3 (O_B_XMIT_FAIL_DP1), O:4.0/4 (O_B_XMIT_FAIL_DP2), O:4.0/5 (O_B_XMIT_FAIL_DP12) are" $0 "$ ".

5.5.5.10 Verify that the Fan 1 and Fan 2 Interlocks remain not tripped by verifying that bits $\mathrm{O}: 2.0 / 0$ (O_FAN____INTERLOCK) and O:4.0/0 (O_FAN_2_INTERLOCK) are still "1".

5.5.5.11 Initial and date the Table 8 "(b)" block.

Test for reappearance of alarms 60 seconds after power up:

5.5.5.12 Verify that when T4:8.ACC

(POWER_ON_DELAY_TIMER.ACC) reaches "60", the three transmitter failure alarms reappear by verifying that bits $0: 4.0 / 3$ (O_B_XMIT_FAIL_DP1), O:4.0/4 (O_B_XMIT_FAIL_DP2), $\mathrm{O}: \overline{4} .0 / 5\left(\mathrm{O}{ }_{-}\right.$B_XMIT_FAIL_DP12) are "1".

5.5.5.13 Verify that the Fan 1 and Fan 2 Interlocks remain not tripped by verifying that bits $\mathrm{O}: 2.0 / 0$ (O_FAN_1_INTERLOCK) and O:4.0/0 (O_FAN_2_INTERLOCK) are still "1". 
5.5.5.14 Initial and date the Table 8 "(c)" block.

Re-establish normal non-alarming conditions:

5.5.5.15 Adjust the input for $\mathrm{dP} 1$ so that word N7:96

(B_TRAIN_DP1_AVG) is between the transmitter failure low setpoint (2621) and the high setpoint (17695); verify that bit O:4.0/3 (O_B_XMIT_FAIL_DP1) returns to " 0 " only when the simulator "RESET" switch (bit I:1.0/0, I_RESET) is toggled.

5.5.5.16 Adjust the input for $\mathrm{dP} 2$ so that word N7:97

(B TRAIN_DP2_AVG) is between the transmitter failure low setpoint (2621) and the high setpoint (17695); verify that bit O:4.0/4 (O_B_XMIT_FAIL_DP2) returns to "0" only when the simulator "RESET" switch (bit I:1.0/0, I_RESET) is toggled.

5.5.5.17 Adjust the input for dP12 so that word N7:98

(B_TRAIN_DP12_AVG) is between the transmitter failure low setpoint (2621) and the high setpoint (17695); verify that the self-clearing bit O:4.0/5 (O_B_XMIT_FAIL_DP12) returns to " 0 ".

5.5.5.18 Verify that the Fan 1 and Fan 2 Interlocks remain not tripped by verifying that bits $\mathrm{O}: 2.0 / 0\left(\mathrm{O} \_\mathrm{FAN}\right.$ 1_INTERLOCK $)$ and $0: 4.0 / 0$ (O_FAN_2_INTERLOCK) are still "1".

5.5.5.19 Initial and date the Table 8 "(d)" block.

5.5.6 Validate that the Train B "up-scale" transmitter failure alarms function as expected when a fan is not running (ref. "LAD 16 - B XMITFAIL").

Test for transmitter failure alarms before power up:

5.5.6.1 Adjust the inputs for $\mathrm{dP} 1, \mathrm{dP} 2$ and $\mathrm{dP} 12$, and verify that words N7:96 (B_TRAIN_DP1_AVG), N7:97 (B-TRAIN_DP2 AVG), and N7:98 (B_TRAIN_DP1 2 _AVG) are greater than or equal to the transmitter failure high setpoint of 17695 (corresponds to 11.0002 inwg).

5.5.6.2 Verify that the three transmitter failure alarms exist by verifying that bits $\mathrm{O}: 4.0 / 3$ (O_B XMIT_FAIL_DP1), O:4.0/4 (O_B_XMIT_FAIL_DP2), $\overline{0}: \overline{4} .0 / 5(\overline{\mathrm{O}}$ B_XXIT_FAIL_DP12) are"1".

5.5.6.3 Verify that the Fan 1 and Fan 2 Interlocks have not tripped by verifying that bits $\mathrm{O}: 2.0 / 0$ (O_FAN_1_INTERLOCK) and $\mathrm{O}: 4.0 / 0$ (O_FAN_2_INTERLOCK) are "1" (the fail-safe tripped condition is " 0 "). 
5.5.6.4 Initial and date the Table 8 "(e)" block.

Test for cleared ("Reset") alarms $<60$ seconds before power up:

Note: Steps 5.5.6.5 to 5.5.6.8 need to be performed in less than 60 seconds.

5.5.6.5 Turn the SLC 5/03 CPU key switch to "PROG", to "RUN", then to "REM" (Performs a power up restart of the PLC).

5.5.6.6 Toggle bit I:1.0/0 (I RESET) by using the simulator "RESET" switch. This clears the two latched $\mathrm{dP} 1$ and $\mathrm{dP} 2$ transmitter failure alarms.

5.5.6.7 Verify that the three transmitter failure alarms are cleared by verifying that bits $\mathrm{O}: 4.0 / 3$ (O_B_XMIT_FAIL_DP1), O:4.0/4 (O_B_XMIT_FAIL_DP2), $\overline{0}: \overline{4} \overline{0} / 5(\mathrm{O}$ B_X XMIT_FAIL_DP12) are "0".

5.5.6.8 Verify that the Fan 1 and Fan 2 Interlocks remain not tripped by verifying that bits O:2.0/0 (O_FAN_1_INTERLOCK) and O:4.0/0 (O_FAN_2_INTERLOCK) are still "1".

5.5.6.9 Initial and date the Table 8 "(f)" block.

Test for reappearance of alarms 60 seconds after power up:

5.5.6.10 Verify that when T4:8.ACC (POWER ON DELAY_TIMER.ACC) reaches "60", the three transmitter failure alarms reappear by verifying that bits $\mathrm{O}: 4.0 / 3$ (O_B_XMIT_FAIL_DP1), O:4.0/4 (O_B_XMIT_FAIL_DP2), $\mathrm{O}: \overline{4} .0 / 5\left(\mathrm{O}_{-} \mathrm{B}-\mathrm{XMIT}\right.$ FAIL_DP12) are " $1 "$ ".

5.5.6.11 Verify that the Fan 1 and Fan 2 Interlocks remain not tripped by verifying that bits $\mathrm{O}: 2.0 / 0$ (O_FAN_1_INTERLOCK) and O:4.0/0 (O_FAN_2_INTERLOCK) are still "1".

5.5.6.12 Initial and date the Table 8 " $(\mathrm{g})$ " block.

Re-establish normal non-alarming conditions:

5.5.6.13 Adjust the input for $\mathrm{dP1}$ so that word N7:96

(B_TRAIN_DP1_AVG) is between the transmitter failure low setpoint (2621) and the high setpoint (17695); verify that bit O:4.0/3 (O_B_XMIT_FAIL_DP1) returns to "0" only when the simulator "RESET" switch (bit I:1.0/0, I_RESET) is toggled.

5.5.6.14 Adjust the input for $\mathrm{dP} 2$ so that word N7:97

(B_TRAIN_DP2_AVG) is between the transmitter failure low setpoint (2621) and the high setpoint (17695); verify that bit 
O:4.0/4 (O_B_XMIT_FAIL_DP2) returns to "0" only when the simulator "RESET" switch (bit I:1.0/0, I_RESET) is toggled.

5.5.6.15 Adjust the input for dP12 so that word N7:98

(B_TRAIN_DP12_AVG) is between the transmitter failure low setpoint (2621) and the high setpoint (17695); verify that the self-clearing bit O:4.0/5 (O_B_XMIT_FAIL_DP12) returns to " 0 ".

5.5.6.16 Verify that the Fan 1 and Fan 2 Interlocks remain not tripped by

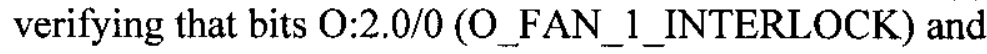
O:4.0/0 (O_FAN_2_INTERLOCK) are still "1".

5.5.6.17 Initial and date the Table 8 "(h)" block.

Refer to Table 9 when performing the Train C Section 5.5.7 to 5.5.9 steps. When directed to verify values, record the values in the appropriate "Actual" blocks.

5.5.7 Bring up Data Files "O0 - OUTPUT", "I1 - INPUT", "T4 - TIMER" and "N7 - INTEGER".

5.5.8 Validate that the Train $\mathrm{C}$ "down-scale" transmitter failure alarms function as expected when a fan is not running (ref. "LAD 17 - C XMITFAIL").

Test for transmitter failure alarms before power up:

5.5.8.1 Verify that Fan 1 and Fan 2 are not running by verifying that bits I:1.0/2 (I_FAN_1_ON) and I:1.0/3 (I_FAN_2_ON) are "0" (Use the simulator "FAN 1 ON" and "FAN 2 ON" switches to turn the fans off, if necessary).

5.5.8.2 Verify that Train $\mathrm{C}$ is not online by verifying that bit $\mathrm{I}: 1.0 / 6$ (I_C_TRAIN_ONLINE) is "0" (Use the simulator "TRAIN C ONLINE" switch to place Train C offline, if necessary).

5.5.8.3 Adjust the inputs for $\mathrm{dP} 1, \mathrm{dP} 2$ and $\mathrm{dP} 12$, and verify that words N7:99 (C_TRAIN_DP1_AVG), N7:100 (C TRAIN_DP $\overline{2}$ AVG), and N7:101 (C_TRAIN_DP12_AVG) are less than or equal to the transmitter failure low setpoint of 2621 (corresponds to -0.5005 inwg).

5.5.8.4 Verify that the three transmitter failure alarms exist by verifying that bits O:6.0/3 (O_C_XMIT_FAIL_DP1), O:6.0/4 (O_C XMIT_FAIL_DP2), O: $\overline{6} .0 / 5(\overline{\mathrm{O}}$ _C_XMIT_FAIL_DP12) are "1".

5.5.8.5 Verify that the Fan 1 and Fan 2 Interlocks have not tripped by verifying that bits $\mathrm{O}: 2.0 / 0$ (O_FAN_1_INTERLOCK) and 
O:4.0/0 (O_FAN_2_INTERLOCK) are "1" (the fail-safe tripped condition is " 0 ").

\subsubsection{Initial and date the Table 9 "(a)" block.}

Test for cleared ("Reset") alarms $<60$ seconds before power up:

Note: Steps 5.5.8.7 to 5.5.8.10 need to be performed in less than 60 seconds.

5.5.8.7 Turn the SLC 5/03 CPU key switch to "PROG", to "RUN", then to "REM" (Performs a power up restart of the PLC).

5.5.8.8 Toggle bit I:1.0/0 (I_RESET) by using the simulator "RESET" switch. This clears the two latched $\mathrm{dP} 1$ and $\mathrm{dP} 2$ transmitter failure alarms.

5.5.8.9 Verify that the three transmitter failure alarms are cleared by verifying that bits $\mathrm{O}: 6.0 / 3$ (O_C_XMIT_FAIL_DP1), O:6.0/4 (O_C_XMIT_FAIL_DP2), O:6.0/5 (O_C_XMIT_FAIL_DP12) are "0".

5.5.8.10 Verify that the Fan 1 and Fan 2 Interlocks remain not tripped by verifying that bits $0: 2.0 / 0\left(O_{-}\right.$FAN_1_INTERLOCK) and O:4.0/0 (O_FAN_2_INTERLOCK) are still "1".

5.5.8.11 Initial and date the Table 9 "(b)" block.

Test for reappearance of alarms 60 seconds after power up:

5.5.8.12 Verify that when T4:8.ACC (POWER_ON_DELAY_TIMER.ACC) reaches "60", the three transmitter failure alarms reappear by verifying that bits $\mathrm{O}: 6.0 / 3$ (O_C_XMIT_FAIL_DP1), O:6.0/4 (O_C_XMIT_FAIL_DP2), $\mathrm{O}: \overline{6} \cdot \overline{0 / 5}\left(\mathrm{O}_{-} \mathrm{C}_{-} \mathrm{XMIT}\right.$ _FAIL_DP12) are " $\overline{1} "$.

5.5.8.13 Verify that the Fan 1 and Fan 2 Interlocks remain not tripped by verifying that bits $0: 2.0 / 0$ (O_FAN_1_INTERLOCK) and $0: 4.0 / 0$ (O_FAN_2_INTERLOCK) are still "1".

5.5.8.14 Initial and date the Table 9 "(c)" block.

Re-establish normal non-alarming conditions:

5.5.8.15 Adjust the input for dP1 so that word N7:99

(C_TRAIN_DP1_AVG) is between the transmitter failure low setpoint (2621) and the high setpoint (17695); verify that bit O:6.0/3 (O_C_XMIT_FAIL_DP1) returns to " 0 " only when the simulator "RESET" switch (bit I:1.0/0, I_RESET) is toggled. 
5.5.8.16 Adjust the input for $\mathrm{dP} 2$ so that word N7:100

(C_TRAIN_DP2_AVG) is between the transmitter failure low setpoint (2621) and the high setpoint (17695); verify that bit O:6.0/4 (O_C_XMIT_FAIL_DP2) returns to "0" only when the simulator "RESET" switch (bit I:1.0/0, I_RESET) is toggled.

5.5.8.17 Adjust the input for dP12 so that word N7:101 (C_TRAIN_DP12_AVG) is between the transmitter failure low setpoint (2621) and the high setpoint (17695); verify that the self-clearing bit O:6.0/5 (O_C_XMIT_FAIL_DP12) returns to "0".

5.5.8.18 Verify that the Fan 1 and Fan 2 Interlocks remain not tripped by verifying that bits $\mathrm{O}: 2.0 / 0\left(\mathrm{O} \_\mathrm{FAN} \_1\right.$ INTERLOCK $)$ and O:4.0/0 (O_FAN_2_INTERLOCK) are still "1".

5.5.8.19 Initial and date the Table 9 "(d)" block.

5.5.9 Validate that the Train C "up-scale" transmitter failure alarms function as expected when a fan is not running (ref. "LAD 17 - C XMITFAIL").

Test for transmitter failure alarms before power up:

5.5.9.1 Adjust the inputs for $\mathrm{dP} 1, \mathrm{dP} 2$ and $\mathrm{dP} 12$, and verify that words N7:99 (C_TRAIN_DP1_AVG), N7:100 (C_ $\bar{C}$ TRAIN $\bar{N}$ DP $\overline{2}$ AVG $)$, and N7:101 (C_TRAIN_DP12_AVG) are greater than or equal to the transmitter failure high setpoint of 17695 (corresponds to 11.0002 inwg).

5.5.9.2 Verify that the three transmitter failure alarms exist by verifying that bits O:6.0/3 (O_C_XMIT_FAIL_DP1), O:6.0/4 (O_C_XMIT_FAIL_DP2), O: $\overline{6} .0 / 5\left(\bar{O} \_\right.$_C_XMIT_FAIL_DP12) are "1".

5.5.9.3 Verify that the Fan 1 and Fan 2 Interlocks have not tripped by verifying that bits $\mathrm{O}: 2.0 / 0$ (O_FAN_1_INTERLOCK) and $\mathrm{O}: 4.0 / 0$ (O_FAN_2_INTERLOCK) are "1" (the fail-safe tripped condition is " 0 ").

5.5.9.4 Initial and date the Table 9 "(e)" block.

Test for cleared ("Reset") alarms $<60$ seconds before power up:

Note: Steps 5.5.9.5 to 5.5.9.8 need to be performed in less than 60 seconds.

5.5.9.5 Turn the SLC 5/03 CPU key switch to "PROG", to "RUN", then to "REM" (Performs a power up restart of the PLC). 
5.5.9.6 Toggle bit I:1.0/0 (I_RESET) by using the simulator "RESET" switch. This clears the two latched $\mathrm{dP} 1$ and $\mathrm{dP} 2$ transmitter failure alarms.

5.5.9.7 Verify that the three transmitter failure alarms are cleared by verifying that bits O:6.0/3 (O_C_XMIT_FAIL_DP1), O:6.0/4 (O_C_XMIT_FAIL_DP2), O:6.0/5 (O_C_XMIT_FAIL_DP12) are "0".

5.5.9.8 Verify that the Fan 1 and Fan 2 Interlocks remain not tripped by verifying that bits $\mathrm{O}: 2.0 / 0$ (O_FAN_1_INTERLOCK) and O:4.0/0 (O_FAN_2_INTERLOCK) are still "1".

5.5.9.9 Initial and date the Table 9 "(f)" block.

Test for reappearance of alarms 60 seconds after power up:

5.5.9.10 Verify that when T4:8.ACC (POWER_ON_DELAY_TIMER.ACC) reaches "60", the three transmitter failure alarms reappear by verifying that bits $\mathrm{O}: 6.0 / 3$ (O_C_XMIT_FAIL_DP1), O:6.0/4 (O_C_XMIT_FAIL_DP2), $\mathrm{O}: \overline{6} .0 / 5\left(\mathrm{O}_{-} \mathrm{C}_{-} \mathrm{XMIT}\right.$. FAIL_DP12) are " $\overline{1}$.

5.5.9.11 Verify that the Fan 1 and Fan 2 Interlocks remain not tripped by verifying that bits $\mathrm{O}: 2.0 / 0$ (O_FAN_1_INTERLOCK) and O:4.0/0 (O_FAN_2_INTERLOCK) are still "1".

5.5.9.12 Initial and date the Table 9 "(g)" block.

Re-establish normal non-alarming conditions:

5.5.9.13 Adjust the input for $\mathrm{dP} 1$ so that word N7:99 (C_TRAIN_DP1_AVG) is between the transmitter failure low setpoint (2621) and the high setpoint (17695); verify that bit O:6.0/3 (O_C_XMIT_FAIL_DP1) returns to " 0 " only when the simulator "RESET" switch (bit I:1.0/0, I_RESET) is toggled.

5.5.9.14 Adjust the input for $\mathrm{dP} 2$ so that word $\mathrm{N} 7: 100$ (C_TRAIN_DP2_AVG) is between the transmitter failure low setpoint (2621) and the high setpoint (17695); verify that bit O:6.0/4 (O_C_XMIT_FAIL_DP2) returns to "0" only when the simulator "RESET" switch (bit I:1.0/0, I_RESET) is toggled.

5.5.9.15 Adjust the input for $\mathrm{dP} 12$ so that word N7:101 (C_TRAIN_DP12_AVG) is between the transmitter failure low setpoint (2621) and the high setpoint (17695); verify that the self-clearing bit O:6.0/5 (O_C_XMIT_FAIL_DP12) returns to " 0 ". 
5.5.9.16 Verify that the Fan 1 and Fan 2 Interlocks remain not tripped by verifying that bits $\mathrm{O}: 2.0 / 0(\mathrm{O}$ FAN_1_INTERLOCK) and O:4.0/0 (O_FAN_2_INTERLOCK) are still "1".

\subsubsection{Initial and date the Table 9 "(h)" block.}

Refer to Table 10 when performing the Train A Section 5.5.10 to 5.5.12.26 steps. When directed to verify values, record the values in the appropriate "Actual" blocks.

5.5.10 Bring up Data Files "O0 - OUTPUT", "I1 - INPUT", "N7 - INTEGER", and "N21 - EVENT LOG".

5.5.11 Validate that the Train A dP1 "down-scale" transmitter failure alarm functions as expected when a fan is running (ref. "LAD 15 - A XMITFAIL").

Establish non-alarming reference condition:

5.5.11.1 Verify that Fan 1 and Fan 2 are not running by verifying that bits I:1.0/2 (I_FAN_1_ON) and I:1.0/3 (I_FAN_2_ON) are "0" (Use the simulator "FAN 1 ON" and "FAN 2 ON" switches to turn the fans off, if necessary).

5.5.11.2 Verify that Train $\mathrm{A}$ is not online by verifying that bit $\mathrm{I}: 1.0 / 4$ (I_A_TRAIN_ONLINE) is "0" (Use the simulator "TRAIN A ONLINE" switch to place Train A offline, if necessary).

5.5.11.3 Verify that the inputs for $\mathrm{dP1}$, word N7:93 (A_TRAIN_DP1_AVG), and dP2, word N7:94 (A_TRAIN_DP2_AVG) are between the low dP setpoint (3670) and the high $\mathrm{dP}$ setpoint (10748). Adjust the inputs, if necessary.

5.5.11.4 Verify that bits $\mathrm{O}: 2.0 / 3$ (O_A_XMIT_FAIL_DP1) and O:2.0/4 (O_A_XMIT_FAIL_DP2) are "0". Toggle the simulator "RESET" switch, if necessary.

5.5.11.5 Verify that the Transmitter Failure Alarm Annunciator bit $0: 2.0 / 6$ (O_XMIT_FAIL_ALARM) is "0".

5.5.11.6 Verify that the Fan 1 and Fan 2 Interlocks are not tripped by verifying that bits $\mathrm{O}: 2.0 / 0$ (O_FAN_1_INTERLOCK) and $\mathrm{O}: 4.0 / 0$ (O_FAN_2_INTERLOCK) are "1".

5.5.11.7 Initial and date the Table 10 "(a)" block.

Test for dPI transmitter failure alarm after fan is started:

5.5.11.8 Use the simulator "FAN 1 ON" switch to turn Fan 1 on. Verify that Fan 1 is running by verifying that bit $\mathrm{I}: 1.0 / 2$ (I_FAN_1_ON) is "1". 
5.5.11.9 Use the simulator "TRAIN A ONLINE" switch to place Train A online. Verify that Train $A$ is online by verifying that bit $\mathrm{I}: 1.0 / 4$ (I_A_TRAIN_ONLINE) is "1".

5.5.11.10 Adjust the input for dP1 down towards "0", and verify that word N7:93 (A_TRAIN_DP1_AVG) is less than or equal to the transmitter failure low setpoint of 2621 (corresponds to -0.5005 inwg).

5.5.11.11 Verify that the Train A dP1 transmitter failure alarm exists by verifying that bit $0: 2.0 / 3$ (O_A_XMIT_FAIL_DP1) is "1".

5.5.11.12 Verify that the Transmitter Failure Alarm Annunciator bit $\mathrm{O}: 2.0 / 6$ (O_XMIT_FAIL_ALARM) is "1".

5.5.11.13 Verify that both Fan 1 and Fan 2 Interlocks have tripped by verifying that bits $0: 2.0 / 0(\mathrm{O}$ FAN_1_INTERLOCK) and O:4.0/0 (O_FAN_2_INTERLOCK) are " 0 ".

5.5.11.14 Initial and date the Table 10 "(b)" block.

Test for dPI transmitter failure alarm after fan is stopped and "Reset".

5.5.11.15 Use the simulator "FAN 1 ON" switch to turn Fan 1 off. Verify that Fan 1 is not running by verifying that bit $I: 1.0 / 2$ (I_FAN_1_ON) is "0".

5.5.11.16 Use the simulator "TRAIN A ONLINE" switch to place Train A offline. Verify that Train A is offline by verifying that bit $\mathrm{I}: 1.0 / 4$ (I_A_TRAIN_ONLINE) is "0".

5.5.11.17 Toggle bit I:1.0/0 (I_RESET) by using the simulator "RESET" switch. Verify that the latched dP1 transmitter failure alarm, bit O:2.0/3 (O_A_XMIT_FAIL_DP1), is still "1".

5.5.11.18 Verify that the Transmitter Failure Alarm Annunciator bit $0: 2.0 / 6\left(O_{-}\right.$XMIT_FAIL_ALARM) is "0".

5.5.11.19 Verify that the Fan 1 and Fan 2 Interlocks are no longer tripped by verifying that bits $\mathrm{O}: 2.0 / 0$ (O_FAN_1_INTERLOCK) and $\mathrm{O}: 4.0 / 0\left(\mathrm{O} \_\mathrm{FAN} 2\right.$ INTERLOCK$)$ are " $\overline{1} "$.

5.5.11.20 Initial and date the Table 10 "(c)" block.

Re-establish normal non-alarming conditions and test Event Log:

5.5.11.21 Adjust the input for dP1, word N7:93 (A_TRAIN_DP1_AVG), and verify that it is between the low $\mathrm{dP}$ setpoint (3670) and the high dP setpoint (10748). 
5.5.11.22 Toggle bit I:1.0/0 (I_RESET) by using the simulator "RESET" switch. Verify that the dP1 transmitter failure alarm, bit $\mathrm{O}: 2.0 / 3$ (O_A_XMIT_FAIL_DP1), is now "0".

5.5.11.23 Verify that the Transmitter Failure Alarm Annunciator bit O:2.0/6 (O_XMIT_FAIL_ALARM) remains "0".

5.5.11.24 Verify that the Fan 1 and Fan 2 Interlocks remain not tripped by verifying that bits $0: 2.0 / 0$ (O_FAN_1_INTERLOCK) and O:4.0/0 (O_FAN_2_INTERLOCK) are "1".

5.5.11.25 Verify that the above interlock trip resulted in the event being logged to "N21 - EVENT LOG" by verifying that N21:117 contains the year (e.g. "2000"), N21: 119 contains the time, and $\mathrm{N} 21: 121$ contains the low dP1 trip value $(\leq 2621)$.

5.5.11.26 Initial and date the Table 10 "(d)" block.

5.5.12 Validate that the Train A dP1 "up-scale" transmitter failure alarm functions as expected when a fan is running (ref. "LAD 15 - A XMITFAIL").

Establish non-alarming reference condition:

5.5.12.1 Verify that Fan 1 and Fan 2 are not running by verifying that bits I:1.0/2 (I_FAN_1_ON) and I:1.0/3 (I_FAN_2_ON) are "0" (Use the simulator "FAN 1 ON" and "FAN 2 ON" switches to turn the fans off, if necessary).

5.5.12.2 Verify that Train A is not online by verifying that bit I:1.0/4 (I_A_TRAIN_ONLINE) is "0" (Use the simulator "TRAIN A ONLINE" switch to place Train A offline, if necessary).

5.5.12.3 Verify that the inputs for $\mathrm{dP1}$, word N7:93

(A_TRAIN_DP1_AVG), and dP2, word N7:94

(A_TRAIN_DP2_AVG) are between the low dP setpoint (3670) and the high $\mathrm{dP}$ setpoint (10748). Adjust the inputs, if necessary.

5.5.12.4 Verify that bits O:2.0/3 (O_A_XMIT_FAIL_DP1) and O:2.0/4 (O_A_XMIT_FAIL_DP2) are "0". Toggle the simulator "RESET" switch, if necessary.

5.5.12.5 Verify that the Transmitter Failure Alarm Annunciator bit $\mathrm{O}: 2.0 / 6$ (O_XMIT_FAIL_ALARM) is "0".

5.5.12.6 Verify that the Fan 1 and Fan 2 Interlocks are not tripped by verifying that bits $\mathrm{O}: 2.0 / 0(\mathrm{O}$ FAN_1_INTERLOCK) and $\mathrm{O}: 4.0 / 0$ (O_FAN_2_INTERLOCK) are "1".

5.5.12.7 Initial and date the Table 10 "(e)" block. 
Note: Steps 5.5.12.8 to 5.5.12.10 need to be performed in less than 120 seconds.

Test for dPI transmitter failure alarm after fan is started:

5.5.12.8 Use the simulator "FAN 2 ON" switch to turn Fan 2 on. Verify that Fan 2 is running by verifying that bit $\mathrm{I}: 1.0 / 3$ (I_FAN_2_ON) is "1".

5.5.12.9 Use the simulator "TRAIN A ONLINE" switch to place Train A online. Verify that Train A is online by verifying that bit I:1.0/4 (I_A_TRAIN_ONLINE) is "1".

5.5.12.10 Adjust the input for dP1 upwards until word N7:93 (A_TRAIN_DP1_AVG) is greater than or equal to the transmitter failure high setpoint of 17695 (corresponds to 11.0002 inwg). Verify the value in Table 10.

5.5.12.11 Verify that the Train A dP1 transmitter failure alarm exists by

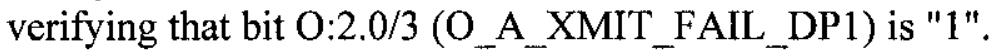

5.5.12.12 Verify that the Transmitter Failure Alarm Annunciator bit $0: 2.0 / 6$ (O_XMIT_FAIL_ALARM) is "1".

5.5.12.13 Verify that both Fan 1 and Fan 2 Interlocks have tripped by verifying that bits $\mathrm{O}: 2.0 / 0$ (O_FAN_1_INTERLOCK) and $\mathrm{O}: 4.0 / 0$ (O_FAN_2_INTERLOCK) are " 0 ".

5.5.12.14 Initial and date the Table 10 "(f)" block.

Test for dP1 transmitter failure alarm after fan is stopped and "Reset":

5.5.12.15 Use the simulator "FAN $2 \mathrm{ON}^{\prime}$ switch to turn Fan 2 off. Verify that Fan 2 is not running by verifying that bit $\mathrm{I}: 1.0 / 3$ (I_FAN_2_ON) is " 0 ".

5.5.12.16 Use the simulator "TRAIN A ONLINE" switch to place Train A offline. Verify that Train A is offline by verifying that bit $\mathrm{I}: 1.0 / 4$ (I_A_TRAIN_ONLINE) is " 0 ".

5.5.12.17 Toggle bit I:1.0/0 (I_RESET) by using the simulator "RESET" switch. Verify that the latched $\mathrm{dP} 1$ transmitter failure alarm, bit $0: 2.0 / 3$ (O_A_XMIT_FAIL_DP1), is still "1".

5.5.12.18 Verify that the Transmitter Failure Alarm Annunciator bit $\mathrm{O}: 2.0 / 6$ (O XMIT_FAIL_ALARM) is " 0 ". 
5.5.12.19 Verify that the Fan 1 and Fan 2 Interlocks are no longer tripped by verifying that bits $\mathrm{O}: 2.0 / 0$ (O_FAN_1_INTERLOCK) and O:4.0/0 (O_FAN_2_INTERLOCK) are "1".

5.5.12.20 Initial and date the Table 10 " $(\mathrm{g})$ " block.

Re-establish normal non-alarming conditions and test Event Log:

5.5.12.21 Adjust the input for dP1, word N7:93 (A_TRAIN_DP1_AVG), and verify that it is between the low dP setpoint (3670) and the high dP setpoint (10748).

5.5.12.22 Toggle bit I:1.0/0 (I_RESET) by using the simulator "RESET" switch. Verify that the dP1 transmitter failure alarm, bit $\mathrm{O}: 2.0 / 3$ (O_A_XMIT_FAIL_DP1), is now "0".

5.5.12.23 Verify that the Transmitter Failure Alarm Annunciator bit O:2.0/6 (O_XMIT_FAIL_ALARM) remains "0".

5.5.12.24 Verify that the Fan 1 and Fan 2 Interlocks remain not tripped by verifying that bits $0: 2.0 / 0$ (O_FAN_1_INTERLOCK) and $\mathrm{O}: 4.0 / 0$ (O_FAN 2 INTERLOCK) are " $1 "$.

5.5.12.25 Verify that the above interlock trip resulted in the event being logged to "N21 - EVENT LOG" by verifying that N21:117 contains the year (e.g. "2000"), N21: 119 contains the time, and $\mathrm{N} 21: 121$ contains the high $\mathrm{dP} 1$ trip value $(\geq 17695)$.

5.5.12.26 Initial and date the Table 10 "(h)" block.

Refer to Table 11 when performing the Train A Section 5.5.13 to 5.5.15.26 steps. When directed to verify values, record the values in the appropriate "Actual" blocks.

5.5.13 Bring up Data Files "O0 - OUTPUT", "I1 - INPUT", "N7 - INTEGER", and "N21 - EVENT LOG".

5.5.14 Validate that the Train A dP2 "down-scale" transmitter failure alarm functions as expected when a fan is running (ref. "LAD 15 - A XMITFAIL").

Establish non-alarming reference condition:

5.5.14.1 Verify that Fan 1 and Fan 2 are not running by verifying that bits I:1.0/2 (I_FAN_1_ON) and I:1.0/3 (I_FAN_2_ON) are "0" (Use the simulator "FAN 1 ON" and "FAN 2 ON" switches to turn the fans off, if necessary).

5.5.14.2 Verify that Train $A$ is not online by verifying that bit I:1.0/4 (I_A_TRAIN ONLINE) is "0" (Use the simulator "TRAIN A ONLINE" switch to place Train A offline, if necessary). 
5.5.14.3 Verify that the inputs for $\mathrm{dP} 1$, word N7:93

(A_TRAIN_DP1_AVG), and dP2, word N7:94

(A_TRAIN_DP2_AVG) are between the low dP setpoint (3670) and the high $\mathrm{dP}$ setpoint (10748). Adjust the inputs, if necessary.

5.5.14.4 Verify that bits $\mathrm{O}: 2.0 / 3$ (O_A_XMIT_FAIL_DP1) and O:2.0/4 (O_A_XMIT_FAIL_DP2) are "0". Toggle the simulator "RESET" switch, if necessary.

5.5.14.5 Verify that the Transmitter Failure Alarm Annunciator bit $\mathrm{O}: 2.0 / 6$ (O XMIT_FAIL_ALARM) is "0".

5.5.14.6 Verify that the Fan 1 and Fan 2 Interlocks are not tripped by verifying that bits $\mathrm{O}: 2.0 / 0$ (O_FAN_1_INTERLOCK) and O:4.0/0 (O_FAN_2_INTERLOCK) are "1".

5.5.14.7 Initial and date the Table 11 "(a)" block.

Note: Steps 5.5.14.8 to 5.5.14.10 need to be performed in less than 120 seconds.

Test for dP2 transmitter failure alarm after fan is started:

5.5.14.8 Use the simulator "FAN $1 \mathrm{ON}^{\prime}$ switch to turn Fan 1 on. Verify that Fan 1 is running by verifying that bit $\mathrm{I}: 1.0 / 2$ (I_FAN_1_ON) is "1".

5.5.14.9 Use the simulator "TRAIN A ONLINE" switch to place Train A online. Verify that Train $A$ is online by verifying that bit $\mathrm{I}: 1.0 / 4$ (I_A_TRAIN_ONLINE) is "1".

5.5.14.10 Adjust the input for $\mathrm{dP} 2$ down towards "0", and verify that word N7:94 (A_TRAIN_DP2_AVG) is less than or equal to the transmitter failure low setpoint of 2621 (corresponds to -0.5005 inwg).

5.5.14.11 Verify that the Train A dP2 transmitter failure alarm exists by verifying that bit O:2.0/4 (O_A_XMIT_FAIL_DP2) is "1".

5.5.14.12 Verify that the Transmitter Failure Alarm Annunciator bit $0: 2.0 / 6$ (O_XMIT_FAIL_ALARM) is "1".

5.5.14.13 Verify that both Fan 1 and Fan 2 Interlocks have tripped by verifying that bits $0: 2.0 / 0\left(O_{-}\right.$FAN_1_INTERLOCK) and O:4.0/0 (O_FAN_2_INTERLOCK) are "0".

5.5.14.14 Initial and date the Table 11 "(b)" block. 
Test for dP2 transmitter failure alarm after fan is stopped and "Reset":

5.5.14.15 Use the simulator "FAN 1 ON" switch to turn Fan 1 off. Verify that Fan 1 is not running by verifying that bit $\mathrm{I}: 1.0 / 2$ (I_FAN_1_ON) is " 0 ".

5.5.14.16 Use the simulator "TRAIN A ONLINE" switch to place Train A offline. Verify that Train A is offline by verifying that bit $\mathrm{I}: 1.0 / 4$ (I_A_TRAIN_ONLINE) is "0".

5.5.14.17 Toggle bit I:1.0/0 (I_RESET) by using the simulator "RESET" switch. Verify that the latched $\mathrm{dP} 2$ transmitter failure alarm, bit $\mathrm{O}: 2.0 / 4$ (O_A_XMIT_FAIL_DP2), is still " 1 ".

5.5.14.18 Verify that the Transmitter Failure Alarm Annunciator bit O:2.0/6 (O_XMIT_FAIL_ALARM) is "0".

5.5.14.19 Verify that the Fan 1 and Fan 2 Interlocks are no longer tripped by verifying that bits $0: 2.0 / 0\left(O_{2}\right.$ FAN_1_INTERLOCK) and O:4.0/0 (O_FAN_2_INTERLOCK) are "1".

5.5.14.20 Initial and date the Table 11 "(c)" block.

Re-establish normal non-alarming conditions and test Event Log:

5.5.14.21 Adjust the input for dP2, word N7:94 (A_TRAIN_DP2_AVG), and verify that it is between the low dP setpoint (3670) and the high dP setpoint (10748).

5.5.14.22 Toggle bit I:1.0/0 (I_RESET) by using the simulator "RESET" switch. Verify that the dP2 transmitter failure alarm, bit $\mathrm{O}: 2.0 / 4$ (O_A_XMIT_FAIL_DP2), is now "0".

5.5.14.23 Verify that the Transmitter Failure Alarm Annunciator bit O:2.0/6 (O_XMIT_FAIL_ALARM) remains " 0 ".

5.5.14.24 Verify that the Fan 1 and Fan 2 Interlocks remain not tripped by verifying that bits $\mathrm{O}: 2.0 / 0(\mathrm{O}$ FAN_1 INTERLOCK) and $\mathrm{O}: 4.0 / 0$ (O_FAN_2_INTERLOCK) are "1".

5.5.14.25 Verify that the above interlock trip resulted in the event being logged to "N21 - EVENT LOG" by verifying that N21:117 contains the year (e.g. "2000"), N21: 119 contains the time, and $\mathrm{N} 21: 122$ contains the low dP2 trip value $(\leq 2621)$.

5.5.14.26 Initial and date the Table 11 "(d)" block.

5.5.15 Validate that the Train A dP2 "up-scale" transmitter failure alarm functions as expected when a fan is running (ref. "LAD 15 - A XMITFAIL"). 
Establish non-alarming reference condition:

5.5.15.1 Verify that Fan 1 and Fan 2 are not running by verifying that bits I:1.0/2 (I_FAN_1_ON) and I:1.0/3 (I_FAN_2_ON) are "0" (Use the simulator "FAN 1 ON" and "FAN $2 \mathrm{ON}^{\prime \prime}$ switches to turn the fans off, if necessary).

5.5.15.2 Verify that Train $\mathrm{A}$ is not online by verifying that bit I:1.0/4 (I_A_TRAIN_ONLINE) is "0" (Use the simulator "TRAIN A ONLINE" switch to place Train A offline, if necessary).

5.5.15.3 Verify that the inputs for $\mathrm{dP} 1$, word N7:93

(A_TRAIN_DP1_AVG), and dP2, word N7:94

(A_TRAIN_DP2_AVG) are between the low dP setpoint (3670) and the high $\mathrm{dP}$ setpoint (10748). Adjust the inputs, if necessary.

5.5.15.4 Verify that bits $0: 2.0 / 3\left(\mathrm{O} \_\right.$A_XMIT_FAIL_DP1) and $0: 2.0 / 4$ (O_A_XMIT_FAIL_DP2) are "0". Toggle the simulator "RESET" switch, if necessary.

5.5.15.5 Verify that the Transmitter Failure Alarm Annunciator bit $\mathrm{O}: 2.0 / 6(\mathrm{O}$ XMIT_FAIL_ALARM) is "0".

5.5.15.6 Verify that the Fan 1 and Fan 2 Interlocks are not tripped by verifying that bits $\mathrm{O}: 2.0 / 0$ (O_FAN_1_INTERLOCK) and O:4.0/0 (O_FAN_2_INTERLOCK) are "1".

5.5.15.7 Initial and date the Table 11 "(e)" block.

Test for dP2 transmitter failure alarm after fan is started:

5.5.15.8 Use the simulator "FAN 2 ON" switch to turn Fan 2 on. Verify that Fan 2 is running by verifying that bit $\mathrm{I}: 1.0 / 3$ (I_FAN_2_ON) is "1".

5.5.15.9 Use the simulator "TRAIN A ONLINE" switch to place Train A online. Verify that Train $A$ is online by verifying that bit $\mathrm{I}: 1.0 / 4$ (I_A_TRAIN_ONLINE) is "1".

5.5.15.10 Adjust the input for $\mathrm{dP} 2$ upwards until word N7:94 (A_TRAIN_DP2_AVG) is greater than or equal to the transmitter failure high setpoint of 17695 (corresponds to 11.0002 inwg). Verify the value in Table 11.

5.5.15.11 Verify that the Train A dP2 transmitter failure alarm exists by verifying that bit O:2.0/4 (O_A_XMIT_FAIL_DP2) is "1".

5.5.15.12 Verify that the Transmitter Failure Alarm Annunciator bit $\mathrm{O}: 2.0 / 6(\mathrm{O}$ XMIT_FAIL_ALARM) is " $1 "$. 
5.5.15.13 Verify that both Fan 1 and Fan 2 Interlocks have tripped by verifying that bits $\mathrm{O}: 2.0 / 0\left(\mathrm{O} \_\right.$FAN_1_INTERLOCK $)$and $\mathrm{O}: 4.0 / 0$ (O_FAN_2_INTERLOCK) are "0".

5.5.15.14 Initial and date the Table 11 "(f)" block.

Test for dP2 transmitter failure alarm after fan is stopped and "Reset":

5.5.15.15 Use the simulator "FAN 2 ON" switch to turn Fan 2 off. Verify that Fan 2 is not running by verifying that bit $\mathrm{I}: 1.0 / 3$ (I_FAN_2_ON) is " 0 ".

5.5.15.16 Use the simulator "TRAIN A ONLINE" switch to place Train A offline. Verify that Train A is offline by verifying that bit I:1.0/4 (I_A_TRAIN_ONLINE) is "0".

5.5.15.17 Toggle bit I:1.0/0 (I_RESET) by using the simulator "RESET" switch. Verify that the latched $\mathrm{dP} 2$ transmitter failure alarm, bit $0: 2.0 / 4$ (O_A_XMIT_FAIL_DP2), is still "1".

5.5.15.18 Verify that the Transmitter Failure Alarm Annunciator bit $\mathrm{O}: 2.0 / 6\left(\mathrm{O}_{-} \mathrm{XMIT} F \mathrm{FAIL}\right.$ _ALARM $)$ is "0".

5.5.15.19 Verify that the Fan 1 and Fan 2 Interlocks are no longer tripped by verifying that bits $0: 2.0 / 0(\mathrm{O}$ FAN_1_INTERLOCK) and O:4.0/0 (O_FAN_2_INTERLOCK) are " $\overline{1} "$.

5.5.15.20 Initial and date the Table 11 "(g)" block.

Re-establish normal non-alarming conditions and test Event Log:

5.5.15.21 Adjust the input for dP2, word N7:94 (A_TRAIN_DP2_AVG), and verify that it is between the low dP setpoint (3670) and the high dP setpoint (10748).

5.5.15.22 Toggle bit I:1.0/0 (1_RESET) by using the simulator "RESET" switch. Verify that the dP2 transmitter failure alarm, bit $\mathrm{O}: 2.0 / 4$ (O_A_XMIT_FAIL_DP2), is now "0".

5.5.15.23 Verify that the Transmitter Failure Alarm Annunciator bit O:2.0/6 (O_XMIT_FAIL_ALARM) remains "0".

5.5.15.24 Verify that the Fan 1 and Fan 2 Interlocks remain not tripped by verifying that bits $\mathrm{O}: 2.0 / 0$ (O_FAN_1_INTERLOCK) and O:4.0/0 (O_FAN_2_INTERLOCK) are "1".

5.5.15.25 Verify that the above interlock trip resulted in the event being logged to "N21 - EVENT LOG" by verifying that N21:117 contains the year (e.g. "2000"), N21: 119 contains the time, and $\mathrm{N} 21: 122$ contains the high $\mathrm{dP} 2$ trip value $(\geq 17695)$. 
5.5.15.26 Initial and date the Table 11 "(h)" block.

Refer to Table 12 when performing the Train A Section 5.5.16 to 5.5.18.25 steps. When directed to verify values, record the values in the appropriate "Actual" blocks.

5.5.16 Bring up Data Files "O0 - OUTPUT", "I1 - INPUT", and "N7 - INTEGER".

5.5.17 Validate that the Train A dP12 "down-scale" transmitter failure alarm functions as expected when a fan is running (ref. "LAD 15 - A XMITFAIL").

Establish non-alarming reference condition:

5.5.17.1 Verify that Fan 1 and Fan 2 are not running by verifying that bits I:1.0/2 (I_FAN_1_ON) and I:1.0/3 (I_FAN_2_ON) are "0" (Use the simulator "FAN 1 ON" and "FAN 2 ON" switches to turn the fans off, if necessary).

5.5.17.2 Verify that Train A is not online by verifying that bit $\mathrm{I}: 1.0 / 4$ (I_A_TRAIN_ONLINE) is "0" (Use the simulator "TRAIN A ONLINE" switch to place Train A offline, if necessary).

5.5.17.3 Verify that the inputs for $\mathrm{dP1}$, word N7:93

(A TRAIN DP1_AVG), dP2, word N7:94

(A_TRAIN_DP2_AVG), and dP12, word N7:95

(A_TRAIN_DP12_AVG) are between the low dP setpoint (3670) and the high $\mathrm{dP}$ setpoint (10748). Adjust the inputs, if necessary.

5.5.17.4 Verify that bit $0: 2.0 / 5\left(O_{-}\right.$A_XMIT_FAIL_DP12) is " $0 "$ ".

5.5.17.5 Verify that the Transmitter Failure Alarm Annunciator bit

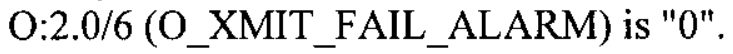

5.5.17.6 Verify that the Fan 1 and Fan 2 Interlocks are not tripped by verifying that bits $\mathrm{O}: 2.0 / 0$ (O_FAN_1_INTERLOCK) and $0: 4.0 / 0$ (O_FAN_2_INTERLOCK) are "1".

5.5.17.7 Initial and date the Table 12 "(a)" block.

Test for dP12 transmitter failure alarm after fan is started:

5.5.17.8 Use the simulator "FAN $1 \mathrm{ON}^{\prime \prime}$ switch to turn Fan 1 on. Verify that Fan 1 is running by verifying that bit $\mathrm{I}: 1.0 / 2$ (I_FAN_1_ON) is "1".

5.5.17.9 Use the simulator "TRAIN A ONLINE" switch to place Train A online. Verify that Train A is online by verifying that bit $\mathrm{I}: 1.0 / 4$ (I_A_TRAIN_ONLINE) is " 1 " . 
5.5.17.10 Adjust the input for dP12 down towards "0", and verify that word N7:95 (A_TRAIN_DP12_AVG) is less than or equal to the transmitter failure low setpoint of 2621 (corresponds to -0.5005 inwg).

5.5.17.11 Verify that the Train A dP12 transmitter failure alarm exists by verifying that bit O:2.0/5 (O_A_XMIT_FAIL_DP12) is "1".

5.5.17.12 Verify that the Transmitter Failure Alarm Annunciator bit O:2.0/6 (O_XMIT_FAIL_ALARM) remains "0".

5.5.17.13 Verify that neither Fan 1 and Fan 2 Interlocks have tripped by verifying that bits $\mathrm{O}: 2.0 / 0(\mathrm{O}$ FAN_1_INTERLOCK) and $\mathrm{O}: 4.0 / 0$ (O_FAN_2 INTERLOCK) remain "1".

5.5.17.14 Initial and date the Table 12 "(b)" block.

Test for dP12 transmitter failure alarm after fan is stopped:

5.5.17.15 Use the simulator "FAN $1 \mathrm{ON}^{\prime}$ switch to turn Fan 1 off. Verify that Fan 1 is not running by verifying that bit $\mathrm{I}: 1.0 / 2$ (I_FAN_1_ON) is " 0 ".

5.5.17.16 Use the simulator "TRAIN A ONLINE" switch to place Train A offline. Verify that Train A is offline by verifying that bit $\mathrm{I}: 1.0 / 4$ (I_A_TRAIN_ONLINE) is "0".

5.5.17.17 Verify that the dP12 transmitter failure alarm, bit O:2.0/5 (O_A_XMIT_FAIL_DP12), is still "1".

5.5.17.18 Verify that the Transmitter Failure Alarm Annunciator bit O:2.0/6 (O_XMIT_FAIL_ALARM) is still "0".

5.5.17.19 Verify that the Fan 1 and Fan 2 Interlocks are still not tripped by verifying that bits $\mathrm{O}: 2.0 / 0$ (O_FAN_1_INTERLOCK) and $0: 4.0 / 0$ (O_FAN_2_INTERLOCK) are "1".

5.5.17.20 Initial and date the Table 12 "(c)" block.

Re-establish normal non-alarming conditions:

5.5.17.21 Adjust the input for dP12, word N7:95

(A TRAIN DP12_AVG), and verify that it is between the low $\mathrm{dP}$ setpoint (3670) and the high $\mathrm{dP}$ setpoint (10748).

5.5.17.22 Verify that the self-clearing dP12 transmitter failure alarm, bit $\mathrm{O}: 2.0 / 5$ (O_A_XMIT_FAIL_DP12), is now "0".

5.5.17.23 Verify that the Transmitter Failure Alarm Annunciator bit O:2.0/6 (O_XMIT_FAIL_ALARM) remains "0". 
5.5.17.24 Verify that the Fan 1 and Fan 2 Interlock bits O:2.0/0

(O_FAN_1_INTERLOCK) and O:4.0/0

(O_FAN_2_INTERLOCK) are still "1".

5.5.17.25 Initial and date the Table 12 "(d)" block.

5.5.18 Validate that the Train A dP12 "up-scale" transmitter failure alarm functions as expected when a fan is running (ref. "LAD 15 - A XMITFAIL").

Establish non-alarming reference condition:

5.5.18.1 Verify that Fan 1 and Fan 2 are not running by verifying that bits I:1.0/2 (I_FAN_1_ON) and I:1.0/3 (I_FAN_2_ON) are "0" (Use the simulator "FAN 1 ON" and "FAN $2 \mathrm{ON}^{\prime \prime}$ switches to turn the fans off, if necessary).

5.5.18.2 Verify that Train A is not online by verifying that bit $\mathrm{I}: 1.0 / 4$ (I_A_TRAIN_ONLINE) is "0" (Use the simulator "TRAIN A ONLINE" switch to place Train A offline, if necessary).

5.5.18.3 Verify that the inputs for $\mathrm{dP} 1$, word N7:93 (A_TRAIN_DP1_AVG), dP2, word N7:94 (A TRAIN_DP2_AVG), and dP12, word N7:95 (A_TRAIN_DP12_AVG) are between the low dP setpoint (3670) and the high $\mathrm{dP}$ setpoint (10748). Adjust the inputs, if necessary.

5.5.18.4 Verify that bit O:2.0/5 (O_A_XMIT_FAIL_DP12) is "0".

5.5.18.5 Verify that the Transmitter Failure Alarm Annunciator bit O:2.0/6 (O_XMIT_FAIL_ALARM) is "0".

5.5.18.6 Verify that the Fan 1 and Fan 2 Interlocks are not tripped by verifying that bits O:2.0/0 (O_FAN_1_INTERLOCK) and O:4.0/0 (O_FAN_2_INTERLOCK) are "1".

5.5.18.7 Initial and date the Table 12 "(e)" block.

Test for $1 P 12$ transmitter failure alarm after fan is started:

5.5.18.8 Use the simulator "FAN $2 \mathrm{ON"}$ switch to turn Fan 2 on. Verify that Fan 2 is running by verifying that bit $\mathrm{I}: 1.0 / 3$ (I_FAN_2_ON) is "1".

5.5.18.9 Use the simulator "TRAIN A ONLINE" switch to place Train A online. Verify that Train A is online by verifying that bit I:1.0/4 (I_A_TRAIN_ONLINE) is "1".

5.5.18.10 Adjust the input for dP12 upwards until word N7:95

(A_TRAIN_DP12_AVG) is greater than or equal to the 
transmitter failure high setpoint of 17695 (corresponds to 11.0002 inwg). Verify the value in Table 12.

5.5.18.11 Verify that the Train A dP12 transmitter failure alarm exists by verifying that bit O:2.0/5 (O_A_XMIT_FAIL_DP12) is "1".

5.5.18.12 Verify that the Transmitter Failure Alarm Annunciator bit $\mathrm{O}: 2.0 / 6(\mathrm{O}$ XMIT_FAIL_ALARM) remains " 0 ".

5.5.18.13 Verify that neither Fan 1 and Fan 2 Interlocks have tripped by verifying that bits $0: 2.0 / 0\left(O_{-}\right.$FAN_1_INTERLOCK) and O:4.0/0 (O_FAN_2_INTERLOCK) remain "1".

5.5.18.14 Initial and date the Table 12 "(f)" block.

Test for dP12 transmitter failure alarm after fan is stopped:

5.5.18.15 Use the simulator "FAN $2 \mathrm{ON}^{\prime}$ switch to turn Fan 2 off. Verify that Fan 2 is not running by verifying that bit $\mathrm{I}: 1.0 / 3$ (I_FAN_2 ON) is " 0 ".

5.5.18.16 Use the simulator "TRAIN A ONLINE" switch to place Train A offline. Verify that Train A is offline by verifying that bit I:1.0/4 (I_A_TRAIN_ONLINE) is "0".

5.5.18.17 Verify that the $\mathrm{dP} 12$ transmitter failure alarm, bit $\mathrm{O}: 2.0 / 5$ (O_A_XMIT_FAIL_DP12), is still "1".

5.5.18.18 Verify that the Transmitter Failure Alarm Annunciator bit $\mathrm{O}: 2.0 / 6$ (O_XMIT_FAIL_ALARM) is still " 0 ".

5.5.18.19 Verify that the Fan 1 and Fan 2 Interlocks are still not tripped by verifying that bits $\mathrm{O}: 2.0 / 0$ (O_FAN_1_INTERLOCK) and O:4.0/0 (O_FAN_2_INTERLOCK) are "1".

5.5.18.20 Initial and date the Table 12 "(g)" block.

Re-establish normal non-alarming conditions:

5.5.18.21 Adjust the input for dP12, word N7:95

(A_TRAIN_DP12_AVG), and verify that it is between the low $\mathrm{dP}$ setpoint (3670) and the high dP setpoint (10748).

5.5.18.22 Verify that the self-clearing $\mathrm{dP} 12$ transmitter failure alarm, bit O:2.0/5 (O_A_XMIT_FAIL_DP12), is now "0".

5.5.18.23 Verify that the Transmitter Failure Alarm Annunciator bit $\mathrm{O}: 2.0 / 6\left(\mathrm{O} \_\mathrm{XMIT}\right.$ _FAIL_ALARM) remains " 0 ". 
5.5.18.24 Verify that the Fan 1 and Fan 2 Interlock bits $\mathrm{O}: 2.0 / 0$ (O_FAN_1_INTERLOCK) and O:4.0/0 (O_FAN_2_INTERLOCK) are still "1".

\subsubsection{Initial and date the Table 12 "(h)" block.}

Refer to Table 13 when performing the Train B Section 5.5.19 to 5.5.21.26 steps. When directed to verify values, record the values in the appropriate "Actual" blocks.

5.5.19 Bring up Data Files "O0 - OUTPUT", "I1 - INPUT", "N7 - INTEGER", and "N21 - EVENT LOG".

5.5.20 Validate that the Train B dP1 "down-scale" transmitter failure alarm functions as expected when a fan is running (ref. "LAD 16 - B XMITFAIL").

Establish non-alarming reference condition:

5.5.20.1 Verify that Fan 1 and Fan 2 are not running by verifying that bits I:1.0/2 (I_FAN_1_ON) and I:1.0/3 (I_FAN_2_ON) are "0" (Use the simulator "FAN $1 \mathrm{ON}^{\prime}$ and "FAN 2 ON" switches to turn the fans off, if necessary).

5.5.20.2 Verify that Train B is not online by verifying that bit I:1.0/5 (I B TRAIN ONLINE) is "0" (Use the simulator "TRAIN B ONLINE" switch to place Train B offline, if necessary).

5.5.20.3 Verify that the inputs for $\mathrm{dP1}$, word N7:96 (B_TRAIN_DP1_AVG), and dP2, word N7:97 (B_TRAIN_DP2_AVG) are between the low dP setpoint (3670) and the high dP setpoint (10748). Adjust the inputs, if necessary.

5.5.20.4 Verify that bits O:4.0/3 (O_B_XMIT_FAIL_DP1) and O:4.0/4 (O_B_XMIT_FAIL_DP2) are "0". Toggle the simulator "RESET" switch, if necessary.

5.5.20.5 Verify that the Transmitter Failure Alarm Annunciator bit $\mathrm{O}: 2.0 / 6(\mathrm{O}$ XMIT_FAIL_ALARM) is "0".

5.5.20.6 Verify that the Fan 1 and Fan 2 Interlocks are not tripped by verifying that bits $\mathrm{O}: 2.0 / 0$ (O_FAN_1_INTERLOCK) and $\mathrm{O}: 4.0 / 0$ (O_FAN_2_INTERLOCK) are "1".

5.5.20.7 Initial and date the Table 13 "(a)" block.

Test for dPI transmitter failure alarm after fan is started:

5.5.20.8 Use the simulator "FAN 1 ON" switch to turn Fan 1 on. Verify that Fan 1 is running by verifying that bit $\mathrm{I}: 1.0 / 2$

(I_FAN_1_ON) is "1". 
5.5.20.9 Use the simulator "TRAIN B ONLINE" switch to place Train B online. Verify that Train $\mathrm{B}$ is online by verifying that bit $\mathrm{I}: 1.0 / 5$ (I_B_TRAIN_ONLINE) is " 1 ".

5.5.20.10 Adjust the input for $\mathrm{dP1}$ down towards "0", and verify that word N7:96 (B_TRAIN_DP1_AVG) is less than or equal to the transmitter failure low setpoint of 2621 (corresponds to -0.5005 inwg).

5.5.20.11 Verify that the Train $\mathrm{B} \mathrm{dP} 1$ transmitter failure alarm exists by verifying that bit O:4.0/3 (O_B_XMIT_FAIL_DP1) is "1".

5.5.20.12 Verify that the Transmitter Failure Alarm Annunciator bit $\mathrm{O}: 2.0 / 6(\mathrm{O}$ XMIT_FAIL_ALARM) is " 1 ".

5.5.20.13 Verify that both Fan 1 and Fan 2 Interlocks have tripped by verifying that bits $\mathrm{O}: 2.0 / 0$ (O_FAN_1_INTERLOCK) and O:4.0/0 (O_FAN_2_INTERLOCK) are " 0 ".

5.5.20.14 Initial and date the Table 13 "(b)" block.

Test for AP1 transmitter failure alarm after fan is stopped and "Reset":

5.5.20.15 Use the simulator "FAN $1 \mathrm{ON}^{\prime \prime}$ switch to turn Fan 1 off. Verify that Fan 1 is not running by verifying that bit $\mathrm{I}: 1.0 / 2$ (I_FAN_1_ON) is "0".

5.5.20.16 Use the simulator "TRAIN B ONLINE" switch to place Train B offline. Verify that Train B is offline by verifying that bit $\mathrm{I}: 1.0 / 5$ (I_B_TRAIN_ONLINE) is "0".

5.5.20.17 Toggle bit I:1.0/0 (I_RESET) by using the simulator "RESET" switch. Verify that the latched $\mathrm{dP} 1$ transmitter failure alarm, bit $0: 4.0 / 3$ (O_B_XMIT_FAIL_DP1), is still "1".

5.5.20.18 Verify that the Transmitter Failure Alarm Annunciator bit $\mathrm{O}: 2.0 / 6$ (O_XMIT_FAIL_ALARM) is " 0 ".

5.5.20.19 Verify that the Fan 1 and Fan 2 Interlocks are no longer tripped by verifying that bits $\mathrm{O}: 2.0 / 0(\mathrm{O}$ FAN_1_INTERLOCK) and $\mathrm{O}: 4.0 / 0$ (O_FAN_2_INTERLOCK) are " $\overline{1} "$.

5.5.20.20 Initial and date the Table 13 "(c)" block.

Re-establish normal non-alarming conditions and test Event Log:

5.5.20.21 Adjust the input for dP1, word N7:96 (B_TRAIN_DP1_AVG), and verify that it is between the low dP setpoint ( 3670$)$ and the high $\mathrm{dP}$ setpoint (10748). 
5.5.20.22 Toggle bit I:1.0/0 (I_RESET) by using the simulator "RESET" switch. Verify that the $\mathrm{dP} 1$ transmitter failure alarm, bit $\mathrm{O}: 4.0 / 3$ (O_B_XMIT_FAIL_DP1), is now "0".

5.5.20.23 Verify that the Transmitter Failure Alarm Annunciator bit O:2.0/6 (O_XMIT_FAIL_ALARM) remains "0".

5.5.20.24 Verify that the Fan 1 and Fan 2 Interlocks remain not tripped by verifying that bits O:2.0/0 (O_FAN_1_INTERLOCK) and O:4.0/0 (O_FAN_2_INTERLOCK) are "1".

5.5.20.25 Verify that the above interlock trip resulted in the event being logged to "N21 - EVENT LOG" by verifying that N21:117 contains the year (e.g. "2000"), N21: 119 contains the time, and $\mathrm{N} 21: 124$ contains the low dP1 trip value $(\leq 2621)$.

5.5.20.26 Initial and date the Table 13 "(d)" block.

5.5.21 Validate that the Train B dP1 "up-scale" transmitter failure alarm functions as expected when a fan is running (ref. "LAD 16 - B XMITFAIL").

Establish non-alarming reference condition:

5.5.21.1 Verify that Fan 1 and Fan 2 are not running by verifying that bits I:1.0/2 (I_FAN_1_ON) and I:1.0/3 (I_FAN_2_ON) are "0" (Use the simulator "FAN $10 N$ " and "FAN 2 ON" switches to turn the fans off, if necessary).

5.5.21.2 Verify that Train B is not online by verifying that bit I:1.0/5 (I_B_TRAIN_ONLINE) is "0" (Use the simulator "TRAIN B ONLINE" switch to place Train B offline, if necessary).

5.5.21.3 Verify that the inputs for $\mathrm{dP1}$, word N7:96

(B_TRAIN_DP1_AVG), and dP2, word N7:97

(B_TRAIN_DP2_AVG) are between the low dP setpoint (3670) and the high $\mathrm{dP}$ setpoint (10748). Adjust the inputs, if necessary.

5.5.21.4 Verify that bits $0: 4.0 / 3$ (O_B_XMIT_FAIL_DP1) and O:4.0/4 (O_B_XMIT_FAIL_DP2) are "0". Toggle the simulator "RESET" switch, if necessary.

5.5.21.5 Verify that the Transmitter Failure Alarm Annunciator bit $\mathrm{O}: 2.0 / 6$ (O_XMIT_FAIL_ALARM) is " 0 ".

5.5.21.6 Verify that the Fan 1 and Fan 2 Interlocks are not tripped by verifying that bits $0: 2.0 / 0$ (O_FAN 1 INTERLOCK) and $0: 4.0 / 0$ (O_FAN_2_INTERLOCK) are "1".

5.5.21.7 Initial and date the Table 13 "(e)" block. 
Note: Steps 5.5.21.8 to 5.5.21.10 need to be performed in less than 120 seconds.

Test for dP1 transmitter failure alarm after fan is started:

5.5.21.8 Use the simulator "FAN 2 ON" switch to turn Fan 2 on. Verify that Fan 2 is running by verifying that bit $\mathrm{I}: 1.0 / 3$ (I_FAN_2_ON) is " 1 ".

5.5.21.9 Use the simulator "TRAIN B ONLINE" switch to place Train B online. Verify that Train $B$ is online by verifying that bit I:1.0/5 (I_B_TRAIN_ONLINE) is "1".

5.5.21.10 Adjust the input for dP1 upwards until word N7:96 (B_TRAIN_DP1_AVG) is greater than or equal to the transmitter failure high setpoint of 17695 (corresponds to 11.0002 inwg). Verify the value in Table 13.

5.5.21.11 Verify that the Train B dP1 transmitter failure alarm exists by verifying that bit $\mathrm{O}: 4.0 / 3$ (O_B_XMIT_FAIL_DP1) is "1".

5.5.21.12 Verify that the Transmitter Failure Alarm Annunciator bit $0: 2.0 / 6$ (O_XMIT_FAIL_ALARM) is "1".

5.5.21.13 Verify that both Fan 1 and Fan 2 Interlocks have tripped by verifying that bits $0: 2.0 / 0(\mathrm{O}$ FAN_1_INTERLOCK) and $\mathrm{O}: 4.0 / 0$ (O_FAN_2_INTERLOCK) are "0".

5.5.21.14 Initial and date the Table 13 "(f)" block.

Test for dPI transmitter failure alarm after fan is stopped and "Reset":

5.5.21.15 Use the simulator "FAN $2 \mathrm{ON}^{\prime}$ "switch to turn Fan 2 off. Verify that Fan 2 is not running by verifying that bit $\mathrm{I}: 1.0 / 3$ (I_FAN_2_ON) is " 0 ".

5.5.21.16 Use the simulator "TRAIN B ONLINE" switch to place Train B offline. Verify that Train B is offline by verifying that bit $\mathrm{I}: 1.0 / 5$ (I_B_TRAIN_ONLINE) is " 0 ".

5.5.21.17 Toggle bit I:1.0/0 (I_RESET) by using the simulator "RESET" switch. Verify that the latched $\mathrm{dP} 1$ transmitter failure alarm, bit O:4.0/3 (O_B_XMIT_FAIL_DP1), is still "1".

5.5.21.18 Verify that the Transmitter Failure Alarm Annunciator bit O:2.0/6 (O_XMIT_FAIL_ALARM) is "0". 
5.5.21.19 Verify that the Fan 1 and Fan 2 Interlocks are no longer tripped by verifying that bits $0: 2.0 / 0\left(O_{-}\right.$FAN_1_INTERLOCK) and O:4.0/0 (O_FAN_2_INTERLOCK) are "1".

5.5.21.20 Initial and date the Table 13 "(g)" block.

Re-establish normal non-alarming conditions and test Event Log:

5.5.21.21 Adjust the input for dP1, word N7:96 (B_TRAIN_DP1_AVG), and verify that it is between the low $\mathrm{dP}$ setpoint (3670) and the high dP setpoint (10748).

5.5.21.22 Toggle bit I:1.0/0 (I_RESET) by using the simulator "RESET" switch. Verify that the dP1 transmitter failure alarm, bit $\mathrm{O}: 4.0 / 3$ (O_B_XMIT_FAIL_DP1), is now "0".

5.5.21.23 Verify that the Transmitter Failure Alarm Annunciator bit O:2.0/6 (O_XMIT_FAIL_ALARM) remains "0".

5.5.21.24 Verify that the Fan 1 and Fan 2 Interlocks remain not tripped by verifying that bits $\mathrm{O}: 2.0 / 0$ (O_FAN_1_INTERLOCK) and O:4.0/0 (O_FAN_2_INTERLOCK) are "1".

5.5.21.25 Verify that the above interlock trip resulted in the event being logged to "N21 - EVENT LOG" by verifying that N21:117 contains the year (e.g. "2000"), N21: 119 contains the time, and $\mathrm{N} 21: 124$ contains the high $\mathrm{dP} 1$ trip value $(\geq 17695)$.

\subsubsection{Initial and date the Table 13 "(h)" block.}

Refer to Table 14 when performing the Train B Section 5.5.22 to 5.5.24.26 steps. When directed to verify values, record the values in the appropriate "Actual" blocks.

5.5.22 Bring up Data Files "O0 - OUTPUT", "I1 - INPUT", "N7 - INTEGER", and "N21 - EVENT LOG".

5.5.23 Validate that the Train B dP2 "down-scale" transmitter failure alarm functions as expected when a fan is running (ref. "LAD 16 - B XMITFAIL").

Establish non-alarming reference condition:

5.5.23.1 Verify that Fan 1 and Fan 2 are not running by verifying that bits I:1.0/2 (I_FAN_1_ON) and I:1.0/3 (I_FAN_2_ON) are "0" (Use the simulator "FAN $10 N$ " and "FAN $2 \mathrm{ON}^{\prime \prime}$ switches to turn the fans off, if necessary).

5.5.23.2 Verify that Train B is not online by verifying that bit I:1.0/5 (I_B_TRAIN_ONLINE) is "0" (Use the simulator "TRAIN B ONLINE" switch to place Train B offline, if necessary). 
5.5.23.3 Verify that the inputs for $\mathrm{dP1}$, word N7:96

(B_TRAIN_DP1_AVG), and dP2, word N7:97

(B_TRAIN_DP2_AVG) are between the low dP setpoint (3670) and the high $\mathrm{dP}$ setpoint (10748). Adjust the inputs, if necessary.

5.5.23.4 Verify that bits O:4.0/3 (O_B_XMIT_FAIL_DP1) and O:4.0/4 (O_B_XMIT_FAIL_DP2) are "0". Toggle the simulator "RE $\bar{E} \bar{E} T "$ switch, if necessary.

5.5.23.5 Verify that the Transmitter Failure Alarm Annunciator bit $0: 2.0 / 6$ (O_XMIT_FAIL_ALARM) is " 0 ".

5.5.23.6 Verify that the Fan 1 and Fan 2 Interlocks are not tripped by verifying that bits $0: 2.0 / 0\left(\mathrm{O} \_\right.$FAN_1_INTERLOCK) and $0: 4.0 / 0$ (O_FAN_2_INTERLOCK) are "1".

5.5.23.7 Initial and date the Table 14 "(a)" block.

Note: Steps 5.5.23.8 to 5.5.23.10 need to be performed in less than 120 seconds.

Test for dP2 transmitter failure alarm after fan is started:

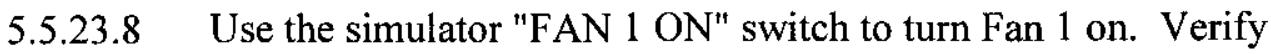
that Fan 1 is running by verifying that bit $\mathrm{I}: 1.0 / 2$ (I_FAN_1_ON) is "1".

5.5.23.9 Use the simulator "TRAIN B ONLINE" switch to place Train B online. Verify that Train B is online by verifying that bit $\mathrm{I}: 1.0 / 5$ (I_B_TRAIN_ONLINE) is "1".

5.5.23.10 Adjust the input for $\mathrm{dP} 2$ down towards "0", and verify that word N7:97 (B_TRAIN_DP2_AVG) is less than or equal to the transmitter failure low setpoint of 2621 (corresponds to -0.5005 inwg).

5.5.23.11 Verify that the Train $\mathrm{B} \mathrm{dP} 2$ transmitter failure alarm exists by verifying that bit O:4.0/4 (O_B_XMIT_FAIL_DP2) is "1".

5.5.23.12 Verify that the Transmitter Failure Alarm Annunciator bit $0: 2.0 / 6\left(O \_X M I T\right.$ FAIL_ALARM) is "1".

5.5.23.13 Verify that both Fan 1 and Fan 2 Interlocks have tripped by verifying that bits $\mathrm{O}: 2.0 / 0$ (O_FAN_1_INTERLOCK) and $\mathrm{O}: 4.0 / 0$ (O_FAN_2_INTERLOCK) are " 0 ".

5.5.23.14 Initial and date the Table 14 "(b)" block.

Test for dP2 transmitter failure alarm after fan is stopped and "Reset": 
5.5.23.15 Use the simulator "FAN $1 \mathrm{ON}$ " switch to turn Fan 1 off. Verify that Fan 1 is not running by verifying that bit $\mathrm{I}: 1.0 / 2$ (I_FAN_1_ON) is " 0 ".

5.5.23.16 Use the simulator "TRAIN B ONLINE" switch to place Train B offline. Verify that Train B is offline by verifying that bit $\mathrm{I}: 1.0 / 5$ (I_B_TRAIN_ONLINE) is "0".

5.5.23.17 Toggle bit I:1.0/0 (I_RESET) by using the simulator "RESET" switch. Verify that the latched dP2 transmitter failure alarm, bit 0:4.0/4 (O_B_XMIT_FAIL_DP2), is still "1".

5.5.23.18 Verify that the Transmitter Failure Alarm Annunciator bit $\mathrm{O}: 2.0 / 6(\mathrm{O}$ _XMIT_FAIL_ALARM) is "0".

5.5.23.19 Verify that the Fan 1 and Fan 2 Interlocks are no longer tripped by verifying that bits $\mathrm{O}: 2.0 / 0$ (O_FAN_1_INTERLOCK) and $0: 4.0 / 0($ O_FAN_2_INTERLOCK) are " $\overline{1} "$.

5.5.23.20 Initial and date the Table 14 "(c)" block.

Re-establish normal non-alarming conditions and test Event Log:

5.5.23.21 Adjust the input for dP2, word N7:97 (B_TRAIN_DP2_AVG), and verify that it is between the low dP setpoint (3670) and the high dP setpoint (10748).

5.5.23.22 Toggle bit I:1.0/0 (I_RESET) by using the simulator "RESET" switch. Verify that the $\mathrm{dP} 2$ transmitter failure alarm, bit $\mathrm{O}: 4.0 / 4$ (O_B_XMIT_FAIL_DP2), is now "0".

5.5.23.23 Verify that the Transmitter Failure Alarm Annunciator bit $\mathrm{O}: 2.0 / 6\left(\mathrm{O} \_\mathrm{XMIT}\right.$ FAIL_ALARM) remains " 0 ".

5.5.23.24 Verify that the Fan 1 and Fan 2 Interlocks remain not tripped by verifying that bits $\mathrm{O}: 2.0 / 0(\mathrm{O}$ FAN_1_INTERLOCK $)$ and $\mathrm{O}: 4.0 / 0$ (O_FAN_2_INTERLOCK) are "1".

5.5.23.25 Verify that the above interlock trip resulted in the event being logged to "N21 - EVENT LOG" by verifying that N21:117 contains the year (e.g. "2000"), N21: 119 contains the time, and $\mathrm{N} 21: 125$ contains the low dP2 trip value $(\leq 2621)$.

5.5.23.26 Initial and date the Table 14 "(d)" block.

5.5.24 Validate that the Train B dP2 "up-scale" transmitter failure alarm functions as expected when a fan is running (ref. "LAD 16 - B XMITFAIL"). 
Establish non-alarming reference condition:

5.5.24.1 Verify that Fan 1 and Fan 2 are not running by verifying that bits I:1.0/2 (I_FAN_1_ON) and I:1.0/3 (I_FAN_2_ON) are "0" (Use the simulator "FAN $1 \mathrm{ON}^{\prime}$ and "FAN $2 \mathrm{ON}^{\prime}$ switches to turn the fans off, if necessary).

5.5.24.2 Verify that Train $\mathrm{B}$ is not online by verifying that bit $\mathrm{I}: 1.0 / 5$ (I_B_TRAIN_ONLINE) is "0" (Use the simulator "TRAIN B ONLINE" switch to place Train B offline, if necessary).

5.5.24.3 Verify that the inputs for $\mathrm{dP} 1$, word N7:96

(B_TRAIN_DP1_AVG), and dP2, word N7:97

(B TRAIN DP2 AVG) are between the low dP setpoint (3670) and the high $\mathrm{dP}$ setpoint (10748). Adjust the inputs, if necessary.

5.5.24.4 Verify that bits O:4.0/3 (O_B_XMIT_FAIL_DP1) and O:4.0/4 (O_B_XMIT_FAIL_DP2) are "0". Toggle the simulator "RESET" switch, if necessary.

5.5.24.5 Verify that the Transmitter Failure Alarm Annunciator bit $\mathrm{O}: 2.0 / 6(\mathrm{O}$ XMIT_FAIL_ALARM) is " 0 ".

5.5.24.6 Verify that the Fan 1 and Fan 2 Interlocks are not tripped by verifying that bits O:2.0/0 (O_FAN_1_INTERLOCK) and $0: 4.0 / 0$ (O_FAN_2_INTERLOCK) are "1".

5.5.24.7 Initial and date the Table 14 "(e)" block.

Test for dP2 transmitter failure alarm after fan is started:

5.5.24.8 Use the simulator "FAN 2 ON" switch to turn Fan 2 on. Verify that Fan 2 is running by verifying that bit $\mathrm{I}: 1.0 / 3$ (I_FAN_2_ON) is "1"

5.5.24.9 Use the simulator "TRAIN B ONLINE" switch to place Train B online. Verify that Train $B$ is online by verifying that bit I:1.0/5 (I_B_TRAIN_ONLINE) is "1"

5.5.24.10 Adjust the input for dP2 upwards until word N7:97 (B_TRAIN_DP2_AVG) is greater than or equal to the transmitter failure high setpoint of 17695 (corresponds to 11.0002 inwg). Verify the value in Table 14.

5.5.24.11 Verify that the Train $\mathrm{B} \mathrm{dP} 2$ transmitter failure alarm exists by verifying that bit O:4.0/4 (O_B_XMIT_FAIL_DP2) is "1".

5.5.24.12 Verify that the Transmitter Failure Alarm Annunciator bit $\mathrm{O}: 2.0 / 6$ (O_XMIT_FAIL_ALARM) is "1". 
5.5.24.13 Verify that both Fan 1 and Fan 2 Interlocks have tripped by verifying that bits $0: 2.0 / 0\left(\mathrm{O} \_\right.$FAN_1_INTERLOCK) and O:4.0/0 (O_FAN_2_INTERLOCK) are "0".

5.5.24.14 Initial and date the Table 14 "(f)" block.

Test for dP2 transmitter failure alarm after fan is stopped and "Reset":

5.5.24.15 Use the simulator "FAN 2 ON" switch to turn Fan 2 off. Verify that Fan 2 is not running by verifying that bit $\mathrm{I}: 1.0 / 3$ (I_FAN_2_ON) is " 0 ".

5.5.24.16 Use the simulator "TRAIN B ONLINE" switch to place Train B offline. Verify that Train B is offline by verifying that bit $\mathrm{I}: 1.0 / 5$ (I_B_TRAIN_ONLINE) is "0".

5.5.24.17 Toggle bit I:1.0/0 (I_RESET) by using the simulator "RESET" switch. Verify that the latched $\mathrm{dP} 2$ transmitter failure alarm, bit O:4.0/4 (O_B_XMIT_FAIL_DP2), is still "1".

5.5.24.18 Verify that the Transmitter Failure Alarm Annunciator bit $\mathrm{O}: 2.0 / 6(\mathrm{O}$ XMIT_FAIL_ALARM) is "0".

5.5.24.19 Verify that the Fan 1 and Fan 2 Interlocks are no longer tripped by verifying that bits $\mathrm{O}: 2.0 / 0$ (O_FAN_1_INTERLOCK) and $\mathrm{O}: 4.0 / 0$ (O_FAN_2_INTERLOCK) are " $1 "$.

5.5.24.20 Initial and date the Table 14 "(g)" block.

Re-establish normal non-alarming conditions and test Event Log:

5.5.24.21 Adjust the input for dP2, word N7:97 (B_TRAIN_DP2_AVG), and verify that it is between the low $\mathrm{dP}$ setpoint $(3670)$ and the high dP setpoint (10748).

5.5.24.22 Toggle bit I:1.0/0 (I_RESET) by using the simulator "RESET" switch. Verify that the dP2 transmitter failure alarm, bit $\mathrm{O}: 4.0 / 4$ (O_B_XMIT_FAIL_DP2), is now "0".

5.5.24.23 Verify that the Transmitter Failure Alarm Annunciator bit O:2.0/6 (O_XMIT_FAIL_ALARM) remains "0".

5.5.24.24 Verify that the Fan 1 and Fan 2 Interlocks remain not tripped by verifying that bits $\mathrm{O}: 2.0 / 0$ (O_FAN_1_INTERLOCK) and $\mathrm{O}: 4.0 / 0$ (O_FAN_2_INTERLOCK) are "1".

5.5.24.25 Verify that the above interlock trip resulted in the event being logged to "N21 - EVENT LOG" by verifying that N21:117 contains the year (e.g. "2000"), N21: 119 contains the time, and $\mathrm{N} 21: 125$ contains the high dP2 trip value ( $\geq 17695)$. 
5.5.24.26 Initial and date the Table 14 "(h)" block.

Refer to Table 15 when performing the Train B Section 5.5.25 to 5.5.27.25 steps. When directed to verify values, record the values in the appropriate "Actual" blocks.

5.5.25 Bring up Data Files "O0 - OUTPUT", "I1 - INPUT", and "N7 - INTEGER".

5.5.26 Validate that the Train B dP12 "down-scale" transmitter failure alarm functions as expected when a fan is running (ref. "LAD 16 - B XMITFAIL").

Establish non-alarming reference condition:

5.5.26.1 Verify that Fan 1 and Fan 2 are not running by verifying that bits I:1.0/2 (I_FAN_1_ON) and I:1.0/3 (I_FAN_2_ON) are "0" (Use the simulator "FAN $1 \mathrm{ON}^{\prime}$ and "FAN $2 \mathrm{ON}^{\prime \prime}$ switches to turn the fans off, if necessary).

5.5.26.2 Verify that Train $B$ is not online by verifying that bit $\mathrm{I}: 1.0 / 5$ (I_B_TRAIN_ONLINE) is "0" (Use the simulator "TRAIN B ONLINE" switch to place Train B offline, if necessary).

5.5.26.3 Verify that the inputs for $\mathrm{dP} 1$, word N7:96 (B TRAIN DP1 AVG), dP2, word N7:97 (B_TRAIN_DP2_AVG), and dP12, word N7:98 (B_TRAIN_DP12_AVG) are between the low dP setpoint (3670) and the high $\mathrm{dP}$ setpoint (10748). Adjust the inputs, if necessary.

5.5.26.4 Verify that bit $0: 4.0 / 5\left(O_{-}\right.$B_XMIT_FAIL_DP12) is " $0 "$ ".

5.5.26.5 Verify that the Transmitter Failure Alarm Annunciator bit $\mathrm{O}: 2.0 / 6$ (O_XMIT_FAIL_ALARM) is "0".

5.5.26.6 Verify that the Fan 1 and Fan 2 Interlocks are not tripped by verifying that bits $\mathrm{O}: 2.0 / 0\left(\mathrm{O} \_\mathrm{FAN}\right.$ 1_INTERLOCK $)$ and $\mathrm{O}: 4.0 / 0(\mathrm{O}$ FAN_2 INTERLOCK) are "1".

5.5.26.7 Initial and date the Table 15 "(a)" block.

Test for dP12 transmitter failure alarm after fan is started:

5.5.26.8 Use the simulator "FAN 1 ON" switch to turn Fan 1 on. Verify that Fan 1 is running by verifying that bit $\mathrm{I}: 1.0 / 2$ (I_FAN_1_ON) is "1".

5.5.26.9 Use the simulator "TRAIN B ONLINE" switch to place Train B online. Verify that Train $\mathrm{B}$ is online by verifying that bit $\mathrm{I}: 1.0 / 5$ (I B_TRAIN_ONLINE) is "1" . 
5.5.26.10 Adjust the input for $\mathrm{dP} 12$ down towards " 0 ", and verify that word N7:98 (B_TRAIN_DP12_AVG) is less than or equal to the transmitter failure low setpoint of 2621 (corresponds to -0.5005 inwg).

5.5.26.11 Verify that the Train B dP12 transmitter failure alarm exists by verifying that bit O:4.0/5 (O_B_XMIT_FAIL_DP12) is "1".

5.5.26.12 Verify that the Transmitter Failure Alarm Annunciator bit O:2.0/6 (O_XMIT_FAIL_ALARM) remains " 0 ".

5.5.26.13 Verify that neither Fan 1 and Fan 2 Interlocks have tripped by verifying that bits $\mathrm{O}: 2.0 / 0\left(\mathrm{O} \_\right.$FAN_1_INTERLOCK) and

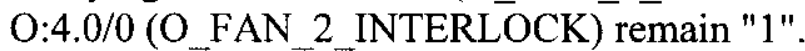

5.5.26.14 Initial and date the Table 15 "(b)" block.

Test for dP12 transmitter failure alarm after fan is stopped:

5.5.26.15 Use the simulator "FAN 1 ON" switch to turn Fan 1 off. Verify that Fan 1 is not running by verifying that bit $\mathrm{l}: 1.0 / 2$ (I_FAN___ ON) is " 0 ".

5.5.26.16 Use the simulator "TRAIN B ONLINE" switch to place Train B offline. Verify that Train $B$ is offline by verifying that bit $\mathrm{I}: 1.0 / 5$ (I_B_TRAIN_ONLINE) is "0".

5.5.26.17 Verify that the $\mathrm{dP} 12$ transmitter failure alarm, bit $\mathrm{O}: 4.0 / 5$ (O_B_XMIT_FAIL_DP12), is still "1".

5.5.26.18 Verify that the Transmitter Failure Alarm Annunciator bit $\mathrm{O}: 2.0 / 6(\mathrm{O}$ XMIT_FAIL_ALARM) is still " 0 ".

5.5.26.19 Verify that the Fan 1 and Fan 2 Interlocks are still not tripped by verifying that bits $\mathrm{O}: 2.0 / 0$ (O_FAN_1_INTERLOCK) and $\mathrm{O}: 4.0 / 0$ (O_FAN_2_INTERLOCK) are "1".

5.5.26.20 Initial and date the Table 15 "(c)" block.

Re-establish normal non-alarming conditions:

5.5.26.21 Adjust the input for dP12, word N7:98 (B_TRAIN_DP12_AVG), and verify that it is between the low dP setpoint (3670) and the high dP setpoint (10748).

5.5.26.22 Verify that the self-clearing $\mathrm{dP} 12$ transmitter failure alarm, bit $0: 4.0 / 5$ (O_B_XMIT_FAIL_DP12), is now " 0 ".

5.5.26.23 Verify that the Transmitter Failure Alarm Annunciator bit O:2.0/6 (O_XMIT_FAIL_ALARM) remains "0". 
5.5.26.24 Verify that the Fan 1 and Fan 2 Interlock bits O:2.0/0

(O_FAN_1_INTERLOCK) and O:4.0/0

(O_FAN_2_INTERLOCK) are still "1".

5.5.26.25 Initial and date the Table 15 "(d)" block.

5.5.27 Validate that the Train B dP12 "up-scale" transmitter failure alarm functions as expected when a fan is running (ref. "LAD 16 - B XMITFAIL").

Establish non-alarming reference condition:

5.5.27.1 Verify that Fan 1 and Fan 2 are not running by verifying that bits I:1.0/2 (I_FAN_1_ON) and I:1.0/3 (I_FAN_2_ON) are "0" (Use the simulator "FAN 1 ON" and "FAN 2 ON" switches to turn the fans off, if necessary).

5.5.27.2 Verify that Train $B$ is not online by verifying that bit $\mathrm{I}: 1.0 / 5$ (I_B_TRAIN_ONLINE) is "0" (Use the simulator "TRAIN B ONLINE" switch to place Train B offline, if necessary).

5.5.27.3 Verify that the inputs for $\mathrm{dP1}$, word N7:96 (B_TRAIN DP1 AVG), dP2, word N7:97

(B TRAIN DP2 AVG), and dP12, word N7:98

(B_TRAIN_DP12_AVG) are between the low dP setpoint $(3 \overline{6} 70)$ and the high $\mathrm{dP}$ setpoint (10748). Adjust the inputs, if necessary.

5.5.27.4 Verify that bit $0: 4.0 / 5\left(O_{-}\right.$B_XMIT_FAIL_DP12) is "0".

5.5.27.5 Verify that the Transmitter Failure Alarm Annunciator bit $\mathrm{O}: 2.0 / 6(\mathrm{O}$ _XMIT_FAIL_ALARM) is "0".

5.5.27.6 Verify that the Fan 1 and Fan 2 Interlocks are not tripped by verifying that bits $\mathrm{O}: 2.0 / 0$ (O_FAN_1_INTERLOCK) and $\mathrm{O}: 4.0 / 0$ (O_FAN_2_INTERLOCK) are "1".

5.5.27.7 Initial and date the Table 15 "(e)" block.

Test for dP12 transmitter failure alarm after fan is started:

5.5.27.8 Use the simulator "FAN 2 ON" switch to turn Fan 2 on. Verify that Fan 2 is running by verifying that bit I:1.0/3 (I_FAN_2_ON) is "1".

5.5.27.9 Use the simulator "TRAIN B ONLINE" switch to place Train B online. Verify that Train $B$ is online by verifying that bit $I: 1.0 / 5$ (I_B_TRAIN_ONLINE) is "1".

5.5.27.10 Adjust the input for dP12 upwards until word N7:98

(B_TRAIN_DP12_AVG) is greater than or equal to the 
transmitter failure high setpoint of 17695 (corresponds to 11.0002 inwg). Verify the value in Table 15.

5.5.27.11 Verify that the Train B dP12 transmitter failure alarm exists by verifying that bit $\mathrm{O}: 4.0 / 5$ (O_B_XMIT_FAIL_DP12) is "1".

5.5.27.12 Verify that the Transmitter Failure Alarm Annunciator bit O:2.0/6 (O_XMIT_FAIL_ALARM) remains "0".

5.5.27.13 Verify that neither Fan 1 and Fan 2 Interlocks have tripped by verifying that bits $\mathrm{O}: 2.0 / 0$ (O_FAN_1_INTERLOCK) and O:4.0/0 (O_FAN_2_INTERLOCK) remain "1".

5.5.27.14 Initial and date the Table 15 "(f)" block.

Test for dP12 transmitter failure alarm after fan is stopped:

5.5.27.15 Use the simulator "FAN $2 \mathrm{ON}^{\prime}$ switch to turn Fan 2 off. Verify that Fan 2 is not running by verifying that bit $\mathrm{I}: 1.0 / 3$ (1_FAN_2_ON) is " 0 ".

5.5.27.16 Use the simulator "TRAIN B ONLINE" switch to place Train B offline. Verify that Train B is offline by verifying that bit $\mathrm{I}: 1.0 / 5$ (I_B_TRAIN_ONLINE) is "0".

5.5.27.17 Verify that the dP12 transmitter failure alarm, bit O:4.0/5 (O_B_XMIT_FAIL_DP12), is still "1".

5.5.27.18 Verify that the Transmitter Failure Alarm Annunciator bit

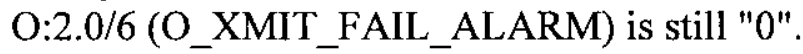

5.5.27.19 Verify that the Fan 1 and Fan 2 Interlocks are still not tripped by verifying that bits $0: 2.0 / 0\left(\mathrm{O} \_F A N \_1\right.$ INTERLOCK $)$ and $\mathrm{O}: 4.0 / 0(\mathrm{O}$ FAN 2 INTERLOCK) are "1".

5.5.27.20 Initial and date the Table 15 "(g)" block.

Re-establish normal non-alarming conditions:

5.5.27.21 Adjust the input for dP12, word N7:98

(B_TRAIN DP12_AVG), and verify that it is between the low $\mathrm{dP}$ setpoint (3670) and the high $\mathrm{dP}$ setpoint (10748).

5.5.27.22 Verify that the self-clearing $\mathrm{dP} 12$ transmitter failure alarm, bit O:4.0/5 (O_B_XMIT_FAIL_DP12), is now "0".

5.5.27.23 Verify that the Transmitter Failure Alarm Annunciator bit O:2.0/6 (O_XMIT_FAIL_ALARM) remains "0". 
5.5.27.24 Verify that the Fan 1 and Fan 2 Interlock bits $\mathrm{O}: 2.0 / 0$ (O_FAN_1_INTERLOCK) and $\mathrm{O}: 4.0 / 0(\mathrm{O}$-FAN_2_INTERLOCK) are still "1".

5.5.27.25 Initial and date the Table 15 "(h)" block.

Refer to Table 16 when performing the Train C Section 5.5.28 to 5.5.30.26 steps. When directed to verify values, record the values in the appropriate "Actual" blocks.

5.5.28 Bring up Data Files "O0 - OUTPUT", "I1 - INPUT", "N7 - INTEGER", and "N21 - EVENT LOG".

5.5.29 Validate that the Train C dP1 "down-scale" transmitter failure alarm functions as expected when a fan is running (ref. "LAD 17 - C XMITFAIL").

Establish non-alarming reference condition:

5.5.29.1 Verify that Fan 1 and Fan 2 are not running by verifying that bits I:1.0/2 (I_FAN_1_ON) and I:1.0/3 (I_FAN_2_ON) are "0" (Use the simulator "FAN $1 \mathrm{ON}^{\prime}$ and "FAN $2 \mathrm{ON}^{\prime}$ " switches to turn the fans off, if necessary).

5.5.29.2 Verify that Train $\mathrm{C}$ is not online by verifying that bit $\mathrm{I}: 1.0 / 6$ (I_C_TRAIN_ONLINE) is "0" (Use the simulator "TRAIN C ONLINE" switch to place Train C offline, if necessary).

5.5.29.3 Verify that the inputs for dP1, word N7:99

(C_TRAIN_DP1_AVG), and dP2, word N7:100

(C_TRAIN_DP2_AVG) are between the low dP setpoint (3670) and the high dP setpoint (10748). Adjust the inputs, if necessary.

5.5.29.4 Verify that bits O:6.0/3 (O_C_XMIT_FAIL_DP1) and O:6.0/4 (O_C XMIT_FAIL_DP2) are "0". Toggle the simulator "RESET" switch, if necessary.

5.5.29.5 Verify that the Transmitter Failure Alarm Annunciator bit O:2.0/6 (O_XMIT_FAIL_ALARM) is "0".

5.5.29.6 Verify that the Fan 1 and Fan 2 Interlocks are not tripped by verifying that bits $\mathrm{O}: 2.0 / 0\left(\mathrm{O} \_\mathrm{FAN}\right.$ 1_INTERLOCK) and O:4.0/0 (O_FAN_2_INTERLOCK) are "1".

5.5.29.7 Initial and date the Table 16 "(a)" block.

Test for dPI transmitter failure alarm after fan is started:

5.5.29.8 Use the simulator "FAN 1 ON" switch to turn Fan 1 on. Verify that Fan 1 is running by verifying that bit $\mathrm{I}: 1.0 / 2$

(I_FAN_1_ON) is "1". 
5.5.29.9 Use the simulator "TRAIN C ONLINE" switch to place Train C online. Verify that Train $\mathrm{C}$ is online by verifying that bit $\mathrm{I}: 1.0 / 6$ (I_C_TRAIN_ONLINE) is "1".

5.5.29.10 Adjust the input for $\mathrm{dP} 1$ down towards "0", and verify that word N7:99 (C_TRAIN_DP1_AVG) is less than or equal to the transmitter failure low setpoint of 2621 (corresponds to -0.5005 inwg).

5.5.29.11 Verify that the Train $\mathrm{C} \mathrm{dP} 1$ transmitter failure alarm exists by verifying that bit $\mathrm{O}: 6.0 / 3\left(\mathrm{O}_{2} \mathrm{C}_{\ldots} \mathrm{XMIT}\right.$ _FAIL_DP1) is " 1 ".

5.5.29.12 Verify that the Transmitter Failure Alarm Annunciator bit $0: 2.0 / 6\left(O_{-}\right.$XMIT_FAIL_ALARM) is "1".

5.5.29.13 Verify that both Fan 1 and Fan 2 Interlocks have tripped by verifying that bits $\mathrm{O}: 2.0 / 0$ (O_FAN_1_INTERLOCK) and $\mathrm{O}: 4.0 / 0$ (O_FAN_2_INTERLOCK) are "0".

5.5.29.14 Initial and date the Table 16 "(b)" block.

Test for dPI transmitter failure alarm after fan is stopped and "Reset":

5.5.29.15 Use the simulator "FAN 1 ON" switch to turn Fan 1 off. Verify that Fan 1 is not running by verifying that bit $\mathrm{I}: 1.0 / 2$ (I_FAN_1_ON) is " 0 ".

5.5.29.16 Use the simulator "TRAIN C ONLINE" switch to place Train C offline. Verify that Train $\mathrm{C}$ is offline by verifying that bit $\mathrm{I}: 1.0 / 6$ (I_C_TRAIN_ONLINE) is " 0 ".

5.5.29.17 Toggle bit I:1.0/0 (I_RESET) by using the simulator "RESET" switch. Verify that the latched $\mathrm{dP1}$ transmitter failure alarm, bit $0: 6.0 / 3$ (O_C_XMIT_FAIL_DP1), is still "1".

5.5.29.18 Verify that the Transmitter Failure Alarm Annunciator bit $\mathrm{O}: 2.0 / 6(\mathrm{O}$ XMIT_FAIL_ALARM) is "0".

5.5.29.19 Verify that the Fan 1 and Fan 2 Interlocks are no longer tripped by verifying that bits $\mathrm{O}: 2.0 / 0$ (O_FAN_1_INTERLOCK) and $\mathrm{O}: 4.0 / 0(\mathrm{O}$ FAN_2_INTERLOCK$)$ are " $1 "$.

5.5.29.20 Initial and date the Table 16 "(c)" block.

Re-establish normal non-alarming conditions and test Event Log:

5.5.29.21 Adjust the input for dP1, word N7:99 (C_TRAIN_DP1_AVG), and verify that it is between the low $\mathrm{dP}$ setpoint (3670) and the high dP setpoint (10748). 
5.5.29.22 Toggle bit I:1.0/0 (I_RESET) by using the simulator "RESET" switch. Verify that the dP1 transmitter failure alarm, bit O:6.0/3 (O_C_XMIT_FAIL_DP1), is now "0".

5.5.29.23 Verify that the Transmitter Failure Alarm Annunciator bit O:2.0/6 (O_XMIT_FAIL_ALARM) remains "0".

5.5.29.24 Verify that the Fan 1 and Fan 2 Interlocks remain not tripped by verifying that bits $\mathrm{O}: 2.0 / 0\left(\mathrm{O} \_\mathrm{FAN}\right.$ 1_INTERLOCK $)$ and $\mathrm{O}: 4.0 / 0(\mathrm{O}$ FAN_2_INTERLOCK) are "1".

5.5.29.25 Verify that the above interlock trip resulted in the event being logged to "N21 - EVENT LOG" by verifying that N21:117 contains the year (e.g. "2000"), N21: 119 contains the time, and N21:127 contains the low dP1 trip value $(\leq 2621)$.

5.5.29.26 Initial and date the Table 16 "(d)" block.

5.5.30 Validate that the Train $\mathrm{C} \mathrm{dP} 1$ "up-scale" transmitter failure alarm functions as expected when a fan is running (ref. "LAD 17 - C XMITFAIL").

Establish non-alarming reference condition:

5.5.30.1 Verify that Fan 1 and Fan 2 are not running by verifying that bits I:1.0/2 (I_FAN_1_ON) and I:1.0/3 (I_FAN_2_ON) are "0" (Use the simulator "FAN $10 N "$ and "FAN 2 ON" switches to turn the fans off, if necessary).

5.5.30.2 Verify that Train $\mathrm{C}$ is not online by verifying that bit I:1.0/6 (I_C_TRAIN_ONLINE) is "0" (Use the simulator "TRAIN C ONLINE" switch to place Train C offline, if necessary).

5.5.30.3 Verify that the inputs for $\mathrm{dP1}$, word N7:99

(C_TRAIN DP1_AVG), and dP2, word N7:100

(C_TRAIN_DP2_AVG) are between the low dP setpoint (3670) and the high dP setpoint (10748). Adjust the inputs, if necessary.

5.5.30.4 Verify that bits $0: 6.0 / 3$ (O_C_XMIT_FAIL_DP1) and O:6.0/4 (O_C_XMIT_FAIL_DP2) are "0". Toggle the simulator "RESET" switch, if necessary.

5.5.30.5 Verify that the Transmitter Failure Alarm Annunciator bit $\mathrm{O}: 2.0 / 6$ (O_XMIT_FAIL_ALARM) is " 0 ".

5.5.30.6 Verify that the Fan 1 and Fan 2 Interlocks are not tripped by verifying that bits $0: 2.0 / 0$ (O_FAN_1_INTERLOCK) and $\mathrm{O}: 4.0 / 0$ (O_FAN_2_INTERLOCK) are "1".

5.5.30.7 Initial and date the Table 16 "(e)" block. 
Note: Steps 5.5.30.8 to 5.5.30.10 need to be performed in less than 120 seconds.

Test for dP1 transmitter failure alarm after fan is started:

5.5.30.8 Use the simulator "FAN 2 ON" switch to turn Fan 2 on. Verify that Fan 2 is running by verifying that bit $\mathrm{I}: 1.0 / 3$

(I_FAN_2_ON) is " 1 ".

5.5.30.9 Use the simulator "TRAIN C ONLINE" switch to place Train C online. Verify that Train $\mathrm{C}$ is online by verifying that bit $\mathrm{I}: 1.0 / 6$ (I_C_TRAIN_ONLINE) is "1".

5.5.30.10 Adjust the input for dP1 upwards until word N7:99 (C_TRAIN_DP1_AVG) is greater than or equal to the transmitter failure high setpoint of 17695 (corresponds to 11.0002 inwg). Verify the value in Table 16.

5.5.30.11 Verify that the Train $\mathrm{C} \mathrm{dP} 1$ transmitter failure alarm exists by verifying that bit $\mathrm{O}: 6.0 / 3\left(\mathrm{O}_{-} \mathrm{C}_{-} \mathrm{XMIT}\right.$ FAIL_DP1) is "1".

5.5.30.12 Verify that the Transmitter Failure Alarm Annunciator bit $\mathrm{O}: 2.0 / 6$ (O_XMIT_FAIL_ALARM) is "1".

5.5.30.13 Verify that both Fan 1 and Fan 2 Interlocks have tripped by verifying that bits $\mathrm{O}: 2.0 / 0$ (O_FAN_1_INTERLOCK) and $\mathrm{O}: 4.0 / 0$ (O_FAN_2_INTERLOCK) are "0".

5.5.30.14 Initial and date the Table 16 "(f)" block.

Test for dPI transmitter failure alarm after fan is stopped and "Reset":

5.5.30.15 Use the simulator "FAN 2 ON" switch to turn Fan 2 off. Verify that Fan 2 is not running by verifying that bit $\mathrm{I}: 1.0 / 3$ (I_FAN_2_ON) is " 0 ".

5.5.30.16 Use the simulator "TRAIN C ONLINE" switch to place Train C offline. Verify that Train $\mathrm{C}$ is offline by verifying that bit $\mathrm{I}: 1.0 / 6$ (I_C_TRAIN_ONLINE) is " $0 "$ ".

5.5.30.17 Toggle bit I:1.0/0 (I_RESET) by using the simulator "RESET" switch. Verify that the latched $\mathrm{dP} 1$ transmitter failure alarm, bit O:6.0/3 (O_C_XMIT_FAIL_DP1), is still "1".

5.5.30.18 Verify that the Transmitter Failure Alarm Annunciator bit $0: 2.0 / 6\left(O_{-}\right.$XMIT_FAIL_ALARM) is "0". 
5.5.30.19 Verify that the Fan 1 and Fan 2 Interlocks are no longer tripped by verifying that bits $\mathrm{O}: 2.0 / 0\left(\mathrm{O} \_\mathrm{FAN}\right.$ 1_INTERLOCK) and O:4.0/0 (O_FAN_2_INTERLOCK) are "1".

5.5.30.20 Initial and date the Table 16 " $(\mathrm{g})$ " block.

Re-establish normal non-alarming conditions and test Event Log:

5.5.30.21 Adjust the input for dP1, word N7:99 (C_TRAIN_DP1_AVG), and verify that it is between the low $\mathrm{dP}$ setpoint $(\overline{3670)}$ and the high dP setpoint (10748).

5.5.30.22 Toggle bit I:1.0/0 (I_RESET) by using the simulator "RESET" switch. Verify that the dP1 transmitter failure alarm, bit $\mathrm{O}: 6.0 / 3$ (O_C_XMIT_FAIL_DP1), is now "0".

5.5.30.23 Verify that the Transmitter Failure Alarm Annunciator bit O:2.0/6 (O_XMIT_FAIL_ALARM) remains "0".

5.5.30.24 Verify that the Fan 1 and Fan 2 Interlocks remain not tripped by verifying that bits $\mathrm{O}: 2.0 / 0$ (O_FAN_1_INTERLOCK) and $0: 4.0 / 0$ (O_FAN_2_INTERLOCK) are "1".

5.5.30.25 Verify that the above interlock trip resulted in the event being logged to "N21 - EVENT LOG" by verifying that N21:117 contains the year (e.g. "2000"), N21: 119 contains the time, and $\mathrm{N} 21: 127$ contains the high dP1 trip value $(\geq 17695)$.

5.5.30.26 Initial and date the Table 16 "(h)" block.

Refer to Table 17 when performing the Train C Section 5.5.31 to 5.5.33.26 steps. When directed to verify values, record the values in the appropriate "Actual" blocks.

5.5.31 Bring up Data Files "O0 - OUTPUT", "I1 - INPUT", "N7 - INTEGER", and "N21 - EVENT LOG".

5.5.32 Validate that the Train $\mathrm{C} \mathrm{dP2}$ "down-scale" transmitter failure alarm functions as expected when a fan is running (ref. "LAD 17 - C XMITFAIL").

Establish non-alarming reference condition:

5.5.32.1 Verify that Fan 1 and Fan 2 are not running by verifying that bits I:1.0/2 (I_FAN_1_ON) and I:1.0/3 (I_FAN_2_ON) are "0" (Use the simulator "FAN 1 ON" and "FAN 2 ON" switches to turn the fans off, if necessary).

5.5.32.2 Verify that Train $\mathrm{C}$ is not online by verifying that bit $\mathrm{I}: 1.0 / 6$ (I_C_TRAIN_ONLINE) is "0" (Use the simulator "TRAIN C ONLINE" switch to place Train C offline, if necessary). 
5.5.32.3 Verify that the inputs for dP1, word N7:99

(C_TRAIN_DP1_AVG), and dP2, word N7:100

(C_TRAIN_DP2_AVG) are between the low dP setpoint (3670) and the high $\mathrm{dP}$ setpoint (10748). Adjust the inputs, if necessary.

5.5.32.4 Verify that bits O:6.0/3 (O_C_XMIT_FAIL_DP1) and O:6.0/4 (O_C_XMIT_FAIL_DP2) are "0". Toggle the simulator

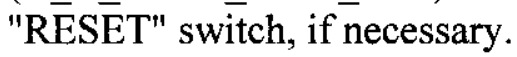

5.5.32.5 Verify that the Transmitter Failure Alarm Annunciator bit $\mathrm{O}: 2.0 / 6$ (O_XMIT_FAIL_ALARM) is " 0 ".

5.5.32.6 Verify that the Fan 1 and Fan 2 Interlocks are not tripped by verifying that bits O:2.0/0 (O_FAN_1_INTERLOCK) and $\mathrm{O}: 4.0 / 0\left(\mathrm{O}_{\mathrm{N}} \mathrm{FAN} 2\right.$ _INTERLOCK$)$ are "1".

5.5.32.7 Initial and date the Table 17 "(a)" block.

Note: Steps 5.5.32.8 to 5.5.32.10 need to be performed in less than 120 seconds.

Test for dP2 transmitter failure alarm after fan is started:

5.5.32.8 Use the simulator "FAN $1 \mathrm{ON}^{\prime}$ switch to turn Fan 1 on. Verify that Fan 1 is running by verifying that bit $\mathrm{I}: 1.0 / 2$ (I_FAN_1_ON) is "1".

5.5.32.9 Use the simulator "TRAIN C ONLINE" switch to place Train C online. Verify that Train $\mathrm{C}$ is online by verifying that bit $\mathrm{I}: 1.0 / 6$ (I_C_TRAIN_ONLINE) is " 1 ".

5.5.32.10 Adjust the input for $\mathrm{dP} 2$ down towards "0", and verify that word N7:100 (C_TRAIN_DP2_AVG) is less than or equal to the transmitter failure low setpoint of 2621 (corresponds to -0.5005 inwg).

5.5.32.11 Verify that the Train $\mathrm{C} \mathrm{dP} 2$ transmitter failure alarm exists by verifying that bit $\mathrm{O}: 6.0 / 4\left(\mathrm{O}_{-} \mathrm{C}_{-} \mathrm{XMIT}\right.$ _FAIL_DP2) is " 1 ".

5.5.32.12 Verify that the Transmitter Failure Alarm Annunciator bit $0: 2.0 / 6$ (O_XMIT_FAIL_ALARM) is "1".

5.5.32.13 Verify that both Fan 1 and Fan 2 Interlocks have tripped by verifying that bits $0: 2.0 / 0$ (O_FAN_1_INTERLOCK) and O:4.0/0 (O_FAN_2 INTERLOCK) are "0".

5.5.32.14 Initial and date the Table 17 "(b)" block. 
Test for dP2 transmitter failure alarm after fan is stopped and "Reset":

5.5.32.15 Use the simulator "FAN 1 ON" switch to turn Fan 1 off. Verify that Fan 1 is not running by verifying that bit $\mathrm{I}: 1.0 / 2$ (I_FAN_1_ON) is " 0 ".

5.5.32.16 Use the simulator "TRAIN C ONLINE" switch to place Train C offline. Verify that Train $\mathrm{C}$ is offline by verifying that bit I:1.0/6 (I_C_TRAIN_ONLINE) is "0".

5.5.32.17 Toggle bit I:1.0/0 (I_RESET) by using the simulator "RESET" switch. Verify that the latched $\mathrm{dP} 2$ transmitter failure alarm, bit O:6.0/4 (O_C_XMIT_FAIL_DP2), is still "1".

5.5.32.18 Verify that the Transmitter Failure Alarm Annunciator bit $\mathrm{O}: 2.0 / 6(\mathrm{O}$ _XMIT_FAIL_ALARM) is "0".

5.5.32.19 Verify that the Fan 1 and Fan 2 Interlocks are no longer tripped by verifying that bits $\mathrm{O}: 2.0 / 0$ (O_FAN_1_INTERLOCK) and $\mathrm{O}: 4.0 / 0$ (O_FAN_2 INTERLOCK) are " $\overline{1} "$.

5.5.32.20 Initial and date the Table 17 "(c)" block.

Re-establish normal non-alarming conditions and test Event Log:

5.5.32.21 Adjust the input for dP2, word N7:100 (C_TRAIN_DP2_AVG), and verify that it is between the low dP setpoint $(3 \overline{670})$ and the high dP setpoint (10748).

5.5.32.22 Toggle bit I:1.0/0 (I_RESET) by using the simulator "RESET" switch. Verify that the $\mathrm{dP} 2$ transmitter failure alarm, bit $\mathrm{O}: 6.0 / 4$ (O_C_XMIT_FAIL_DP2), is now "0".

5.5.32.23 Verify that the Transmitter Failure Alarm Annunciator bit O:2.0/6 (O_XMIT_FAIL_ALARM) remains " 0 ".

5.5.32.24 Verify that the Fan 1 and Fan 2 Interlocks remain not tripped by verifying that bits $\mathrm{O}: 2.0 / 0$ (O_FAN_1_INTERLOCK) and O:4.0/0 (O_FAN_2_INTERLOCK) are "1".

5.5.32.25 Verify that the above interlock trip resulted in the event being logged to "N21 - EVENT LOG" by verifying that N21:117 contains the year (e.g. "2000"), N21: 119 contains the time, and $\mathrm{N} 21: 128$ contains the low $\mathrm{dP} 2$ trip value $(\leq 2621)$.

5.5.32.26 Initial and date the Table 17 "(d)" block.

5.5.33 Validate that the Train $\mathrm{C} \mathrm{dP} 2$ "up-scale" transmitter failure alarm functions as expected when a fan is running (ref. "LAD 17 - C XMITFAIL"). 
Establish non-alarming reference condition:

5.5.33.1 Verify that Fan 1 and Fan 2 are not running by verifying that bits I:1.0/2 (I_FAN_1_ON) and I:1.0/3 (I_FAN_2_ON) are "0" (Use the simulator "FAN $10 \mathrm{ON}$ " and "FAN 2 ON" switches to turn the fans off, if necessary).

5.5.33.2 Verify that Train $\mathrm{C}$ is not online by verifying that bit $\mathrm{I}: 1.0 / 6$ (I_C_TRAIN_ONLINE) is "0" (Use the simulator "TRAIN C ONLINE" switch to place Train C offline, if necessary).

5.5.33.3 Verify that the inputs for $\mathrm{dP1}$, word N7:99

(C_TRAIN_DP1_AVG), and dP2, word N7:100

(C_TRAIN_DP2_AVG) are between the low dP setpoint (3670) and the high $\mathrm{dP}$ setpoint (10748). Adjust the inputs, if necessary.

5.5.33.4 Verify that bits $0: 6.0 / 3$ (O_C_XMIT_FAIL_DP1) and O:6.0/4 (O_C_XMIT_FAIL_DP2) are "0". Toggle the simulator "RESET" switch, if necessary.

5.5.33.5 Verify that the Transmitter Failure Alarm Annunciator bit $\mathrm{O}: 2.0 / 6(\mathrm{O}$ XMIT_FAIL_ALARM) is "0".

5.5.33.6 Verify that the Fan 1 and Fan 2 Interlocks are not tripped by verifying that bits $\mathrm{O}: 2.0 / 0(\mathrm{O}$ FAN_1_INTERLOCK $)$ and $0: 4.0 / 0$ (O_FAN_2_INTERLOCK) are "1".

5.5.33.7 Initial and date the Table 17 "(e)" block.

Test for dP2 transmitter failure alarm after fan is started:

5.5.33.8 Use the simulator "FAN 2 ON" switch to turn Fan 2 on. Verify that Fan 2 is running by verifying that bit I:1.0/3 (I_FAN_2_ON) is "1".

5.5.33.9 Use the simulator "TRAIN C ONLINE" switch to place Train C online. Verify that Train $\mathrm{C}$ is online by verifying that bit $\mathrm{I}: 1.0 / 6$ (I_C_TRAIN_ONLINE) is "1".

5.5.33.10 Adjust the input for $\mathrm{dP} 2$ upwards until word N7:100 (C_TRAIN_DP2_AVG) is greater than or equal to the transmitter failure high setpoint of 17695 (corresponds to 11.0002 inwg). Verify the value in Table 17.

5.5.33.11 Verify that the Train $\mathrm{C} \mathrm{dP} 2$ transmitter failure alarm exists by verifying that bit O:6.0/4 (O_C_XMIT_FAIL_DP2) is "1".

5.5.33.12 Verify that the Transmitter Failure Alarm Annunciator bit $\mathrm{O}: 2.0 / 6$ (O_XMIT_FAIL_ALARM) is "1". 
5.5.33.13 Verify that both Fan 1 and Fan 2 Interlocks have tripped by verifying that bits $\mathrm{O}: 2.0 / 0\left(\mathrm{O} \_\mathrm{FAN}\right.$ 1_INTERLOCK $)$ and O:4.0/0 (O_FAN_2_INTERLOCK) are "0".

5.5.33.14 Initial and date the Table 17 "(f)" block.

Test for dP2 transmitter failure alarm after fan is stopped and "Reset":

5.5.33.15 Use the simulator "FAN 2 ON" switch to turn Fan 2 off. Verify that Fan 2 is not running by verifying that bit $\mathrm{I}: 1.0 / 3$ (I_FAN_2_ON) is "0".

5.5.33.16 Use the simulator "TRAIN C ONLINE" switch to place Train C offline. Verify that Train $\mathrm{C}$ is offline by verifying that bit I:1.0/6 (I_C_TRAIN_ONLINE) is "0".

5.5.33.17 Toggle bit I:1.0/0 (I_RESET) by using the simulator "RESET" switch. Verify that the latched $\mathrm{dP} 2$ transmitter failure alarm, bit O:6.0/4 (O_C_XMIT_FAIL_DP2), is still "1".

5.5.33.18 Verify that the Transmitter Failure Alarm Annunciator bit $\mathrm{O}: 2.0 / 6\left(\mathrm{O} \_\mathrm{XMIT}\right.$ FAIL_ALARM) is "0".

5.5.33.19 Verify that the Fan 1 and Fan 2 Interlocks are no longer tripped by verifying that bits $\mathrm{O}: 2.0 / 0$ (O_FAN_1_INTERLOCK) and $\mathrm{O}: 4.0 / 0$ (O_FAN_2_INTERLOCK) are "1".

5.5.33.20 Initial and date the Table 17 "(g)" block.

Re-establish normal non-alarming conditions and test Event Log:

5.5.33.21 Adjust the input for dP2, word N7:100 (C_TRAIN_DP2_AVG), and verify that it is between the low dP setpoint (3670) and the high dP setpoint (10748).

5.5.33.22 Toggle bit I:1.0/0 (I_RESET) by using the simulator "RESET" switch. Verify that the dP2 transmitter failure alarm, bit O:6.0/4 (O_C_XMIT_FAIL_DP2), is now "0".

5.5.33.23 Verify that the Transmitter Failure Alarm Annunciator bit O:2.0/6 (O_XMIT_FAIL_ALARM) remains "0".

5.5.33.24 Verify that the Fan 1 and Fan 2 Interlocks remain not tripped by verifying that bits $\mathrm{O}: 2.0 / 0$ (O_FAN_1_INTERLOCK) and $0: 4.0 / 0$ (O_FAN_2_INTERLOCK) are "1".

5.5.33.25 Verify that the above interlock trip resulted in the event being logged to "N21 - EVENT LOG" by verifying that N21:117 contains the year (e.g. "2000"), N21: 119 contains the time, and N21:128 contains the high dP2 trip value ( $\geq 17695)$. 
5.5.33.26 Initial and date the Table 17 "(h)" block.

Refer to Table 18 when performing the Train C Section 5.5.34 to 5.5.36.25 steps. When directed to verify values, record the values in the appropriate "Actual" blocks.

5.5.34 Bring up Data Files "O0 - OUTPUT", "I1 - INPUT", and "N7 - INTEGER".

5.5.35 Validate that the Train C dP12 "down-scale" transmitter failure alarm functions as expected when a fan is running (ref. "LAD 17 - C XMITFAIL").

Establish non-alarming reference condition:

5.5.35.1 Verify that Fan 1 and Fan 2 are not running by verifying that bits I:1.0/2 (I_FAN_1_ON) and I:1.0/3 (I_FAN_2_ON) are "0" (Use the simulator "FAN $1 \mathrm{ON}^{\prime}$ and "FAN 2 ON" switches to turn the fans off, if necessary).

5.5.35.2 Verify that Train $\mathrm{C}$ is not online by verifying that bit I:1.0/6 (I_C_TRAIN_ONLINE) is "0" (Use the simulator "TRAIN C ONLINE" switch to place Train C offline, if necessary).

5.5.35.3 Verify that the inputs for $\mathrm{dP1}$, word N7:99 (C TRAIN DP1 AVG), dP2, word N7:100

(C TRAIN DP2_AVG), and dP12, word N7:101

(C_TRAIN_DP2_AVG) are between the low dP setpoint (3670) and the high $\mathrm{dP}$ setpoint (10748). Adjust the inputs, if necessary.

5.5.35.4 Verify that bit $0: 6.0 / 5\left(\mathrm{O}_{-} \mathrm{C}_{-} \mathrm{XMIT}\right.$ FAIL_DP12) is " 0 ".

5.5.35.5 Verify that the Transmitter Failure Alarm Annunciator bit $\mathrm{O}: 2.0 / 6(\mathrm{O}$ XMIT_FAIL_ALARM) is "0".

5.5.35.6 Verify that the Fan 1 and Fan 2 Interlocks are not tripped by verifying that bits $\mathrm{O}: 2.0 / 0$ (O_FAN_1_INTERLOCK) and O:4.0/0 (O_FAN_2_INTERLOCK) are "1".

5.5.35.7 Initial and date the Table 18 "(a)" block.

Test for dP12 transmitter failure alarm after fan is started:

5.5.35.8 Use the simulator "FAN 1 ON" switch to turn Fan 1 on. Verify that Fan 1 is running by verifying that bit $\mathrm{I}: 1.0 / 2$ (I_FAN_1_ON) is "1".

5.5.35.9 Use the simulator "TRAIN C ONLINE" switch to place Train C online. Verify that Train $\mathrm{C}$ is online by verifying that bit $\mathrm{I}: 1.0 / 6$ (I_C_TRAIN_ONLINE) is " 1 ". 
5.5.35.10 Adjust the input for dP12 down towards "0", and verify that word N7:101 (C_TRAIN_DP12_AVG) is less than or equal to the transmitter failure low setpoint of 2621 (corresponds to -0.5005 inwg).

5.5.35.11 Verify that the Train $\mathrm{C} \mathrm{dP} 12$ transmitter failure alarm exists by verifying that bit $\mathrm{O}: 6.0 / 5$ (O_C_XMIT_FAIL_DP12) is "1".

5.5.35.12 Verify that the Transmitter Failure Alarm Annunciator bit O:2.0/6 (O_XMIT_FAIL_ALARM) remains "0".

5.5.35.13 Verify that neither Fan 1 and Fan 2 Interlocks have tripped by verifying that bits $0: 2.0 / 0(\mathrm{O}$ FAN_1_INTERLOCK) and $\mathrm{O}: 4.0 / 0$ (O_FAN_2_INTERLOCK) remain "1".

5.5.35.14 Initial and date the Table 18 "(b)" block.

Test for dP12 transmitter failure alarm after fan is stopped:

5.5.35.15 Use the simulator "FAN $1 \mathrm{ON}$ " switch to turn Fan 1 off. Verify that Fan 1 is not running by verifying that bit $\mathrm{I}: 1.0 / 2$ (I_FAN_1_ON) is "0".

5.5.35.16 Use the simulator "TRAIN C ONLINE" switch to place Train C offline. Verify that Train $\mathrm{C}$ is offline by verifying that bit I:1.0/6 (I_C_TRAIN_ONLINE) is " 0 ".

5.5.35.17 Verify that the $\mathrm{dP} 12$ transmitter failure alarm, bit $\mathrm{O}: 6.0 / 5$ (O_C_XMIT_FAIL_DP12), is still "1".

5.5.35.18 Verify that the Transmitter Failure Alarm Annunciator bit $\mathrm{O}: 2.0 / 6$ (O_XMIT_FAIL_ALARM) is still " 0 ".

5.5.35.19 Verify that the Fan 1 and Fan 2 Interlocks are still not tripped by verifying that bits $\mathrm{O}: 2.0 / 0\left(\mathrm{O} \_\mathrm{FAN} \_1\right.$ INTERLOCK $)$ and O:4.0/0 (O_FAN_2_INTERLOCK) are "1".

5.5.35.20 Initial and date the Table 18 "(c)" block.

Re-establish normal non-alarming conditions:

5.5.35.21 Adjust the input for dP12, word N7:101

(C_TRAIN_DP12_AVG), and verify that it is between the low dP setpoint (3670) and the high dP setpoint (10748).

5.5.35.22 Verify that the self-clearing $\mathrm{dP} 12$ transmitter failure alarm, bit O:6.0/5 (O_C_XMIT_FAIL_DP12), is now "0".

5.5.35.23 Verify that the Transmitter Failure Alarm Annunciator bit O:2.0/6 (O_XMIT_FAIL_ALARM) remains "0". 
5.5.35.24 Verify that the Fan 1 and Fan 2 Interlock bits $O: 2.0 / 0$

(O_FAN_1_INTERLOCK) and O:4.0/0

(O_FAN_2_INTERLOCK) are still "1".

5.5.35.25 Initial and date the Table 18 "(d)" block.

5.5.36 Validate that the Train $\mathrm{C} \mathrm{dP} 12$ "up-scale" transmitter failure alarm functions as expected when a fan is running (ref. "LAD 17 - C XMITFAIL").

Establish non-alarming reference condition:

5.5.36.1 Verify that Fan 1 and Fan 2 are not running by verifying that bits I:1.0/2 (I_FAN_1_ON) and I:1.0/3 (I_FAN_2_ON) are "0" (Use the simulator "FAN 1 ON" and "FAN 2 ON" switches to turn the fans off, if necessary).

5.5.36.2 Verify that Train $\mathrm{C}$ is not online by verifying that bit I:1.0/6 (I_C_TRAIN ONLINE) is "0" (Use the simulator "TRAIN C ONLINE" switch to place Train C offline, if necessary).

5.5.36.3 Verify that the inputs for $\mathrm{dP} 1$, word N7:99

(C_TRAIN_DP1_AVG), dP2, word N7:100

(C_TRAIN_DP2 ${ }^{-}$AVG), and dP12, word N7:101

(C TRAIN_DP12_AVG) are between the low dP setpoint (3670) and the high $\mathrm{dP}$ setpoint (10748). Adjust the inputs, if necessary.

5.5.36.4 Verify that bit $\mathrm{O}: 6.0 / 5$ (O_C_XMIT_FAIL_DP12) is "0".

5.5.36.5 Verify that the Transmitter Failure Alarm Annunciator bit $\mathrm{O}: 2.0 / 6$ (O_XMIT_FAIL_ALARM) is "0".

5.5.36.6 Verify that the Fan 1 and Fan 2 Interlocks are not tripped by verifying that bits $\mathrm{O}: 2.0 / 0(\mathrm{O}$ FAN_1_INTERLOCK $)$ and $\mathrm{O}: 4.0 / 0$ (O_FAN_2_INTERLOCK) are "1".

5.5.36.7 Initial and date the Table 18 "(e)" block.

Test for dP12 transmitter failure alarm after fan is started:

5.5.36.8 Use the simulator "FAN 2 ON" switch to turn Fan 2 on. Verify that Fan 2 is running by verifying that bit $\mathrm{I}: 1.0 / 3$

(I_FAN_2_ON) is "1".

5.5.36.9 Use the simulator "TRAIN C ONLINE" switch to place Train C online. Verify that Train $\mathrm{C}$ is online by verifying that bit $\mathrm{I}: 1.0 / 6$ (I_C_TRAIN_ONLINE) is "1".

5.5.36.10 Adjust the input for dP12 upwards until word N7:101 (C_TRAIN_DP12_AVG) is greater than or equal to the 
transmitter failure high setpoint of 17695 (corresponds to 11.0002 inwg). Verify the value in Table 18.

5.5.36.11 Verify that the Train $\mathrm{C} \mathrm{dP} 12$ transmitter failure alarm exists by verifying that bit O:6.0/5 (O_C_XMIT_FAlL_DP12) is "1".

5.5.36.12 Verify that the Transmitter Failure Alarm Annunciator bit O:2.0/6 (O_XMIT_FAIL_ALARM) remains "0".

5.5.36.13 Verify that neither Fan 1 and Fan 2 Interlocks have tripped by verifying that bits $\mathrm{O}: 2.0 / 0$ (O_FAN_1_INTERLOCK) and $\mathrm{O}: 4.0 / 0$ (O_FAN_2_INTERLOCK) remain "1".

5.5.36.14 Initial and date the Table 18 "(f)" block.

Test for dP12 transmitter failure alarm after fan is stopped:

5.5.36.15 Use the simulator "FAN 2 ON" switch to turn Fan 2 off. Verify that Fan 2 is not running by verifying that bit $\mathrm{I}: 1.0 / 3$

(I_FAN_2_ON) is " 0 ".

5.5.36.16 Use the simulator "TRAIN C ONLINE" switch to place Train C offline. Verify that Train $\mathrm{C}$ is offline by verifying that bit $\mathrm{I}: 1.0 / 6$ (I_C_TRAIN_ONLINE) is "0".

5.5.36.17 Verify that the $\mathrm{dP} 12$ transmitter failure alarm, bit $\mathrm{O}: 6.0 / 5$ (O_C_XMIT_FAIL_DP12), is still "1".

5.5.36.18 Verify that the Transmitter Failure Alarm Annunciator bit $\mathrm{O}: 2.0 / 6\left(\mathrm{O} \_\mathrm{XMIT}\right.$ FAIL_ALARM) is still " 0 ".

5.5.36.19 Verify that the Fan 1 and Fan 2 Interlocks are still not tripped by verifying that bits $0: 2.0 / 0$ (O_FAN_1_INTERLOCK) and $0: 4.0 / 0$ (O_FAN_2_INTERLOCK) are "1".

5.5.36.20 Initial and date the Table 18 "(g)" block.

Re-establish normal non-alarming conditions:

5.5.36.21 Adjust the input for dP12, word N7:101

(C_TRAIN_DP12_AVG), and verify that it is between the low dP setpoint (3670) and the high dP setpoint (10748).

5.5.36.22 Verify that the self-clearing dP12 transmitter failure alarm, bit O:6.0/5 (O_C_XMIT_FAIL_DP12), is now "0".

5.5.36.23 Verify that the Transmitter Failure Alarm Annunciator bit O:2.0/6 (O_XMIT_FAIL_ALARM) remains "0". 
5.5.36.24 Verify that the Fan 1 and Fan 2 Interlock bits $\mathrm{O}: 2.0 / 0$ (O FAN 1 INTERLOCK $)$ and O:4.0/0 (O_FAN_2_INTERLOCK) are still "1".

\subsubsection{Initial and date the Table 18 "(h)" block.}

\section{6 dP1 HIGH AND dP2 LOW ALARMS VALIDATION}

The $\mathrm{dP} 1$ high alarm setpoint is at a PLC reading of 10748 (corresponding to $13.12 \mathrm{~mA}$ or 5.7000 inwg). The $\mathrm{dP} 2$ low alarm setpoint is at a PLC reading of 3670 (corresponding to $4.48 \mathrm{~mA}$ or 0.2998 inwg).

Two minutes after any fan startup, any $\mathrm{dP} 1$ high or $\mathrm{dP} 2$ low alarm condition for the online filter train results in illuminating the local panel lamp, setting off the corresponding $\mathrm{dP} 1$ high or dP2 low control room annunciator, and tripping the interlock which shuts down the fan. This "trip event" is stored in an "Event Log" memory region in the PLC. The dP1 high and $\mathrm{dP} 2$ low outputs to the lamps and annunciators are latched, requiring the local panel RESET to be depressed before any fan can be restarted. The RESET will clear the alarm indications, but, if the alarm condition has not been cleared, the fan interlock would again trip two minutes after the fan is restarted.

Refer to Table 19 when performing the Train A Section 5.6.1 to 5.6.3.23 steps. When directed to verify values, record the values in the appropriate "Actual" blocks.

5.6.1 Bring up Data Files "O0 - OUTPUT", "I1 - INPUT", "T4 - TIMER", "N7 - INTEGER", and "N21 - EVENT LOG".

5.6.2 Validate that the Train A High $\mathrm{dP} 1$ alarm functions as expected when a fan is running (ref. "LAD 12 - A ALARMS").

Establish non-alarming reference condition:

5.6.2.1 Verify that Fan 1 and Fan 2 are not running by verifying that bits I:1.0/2 (I_FAN_1_ON) and I:1.0/3 (I_FAN_2_ON) are "0" (Use the simulator "FAN 1 ON" and "FAN 2 ON" switches to turn the fans off, if necessary).

5.6.2.2 Verify that Train A is not online by verifying that bit I:1.0/4 (I_A_TRAIN_ONLINE) is "0" (Use the simulator "TRAIN A ONLINE" switch to place Train A offline, if necessary).

5.6.2.3 Verify that the inputs for $\mathrm{dP} 1$, word N7:93

(A_TRAIN_DP1_AVG), and dP2, word N7:94

(A_TRAIN.DP2_AVG) are between the low dP setpoint (3670) and the high $\mathrm{dP}$ setpoint (10748). Adjust the inputs, if necessary.

5.6.2.4 Verify that bits $\mathrm{O}: 2.0 / 1$ (O_A_HIGH_DP1) and O:2.0/2 (O_A_LOW_DP2) are "0". Toggle the simulator "RESET" switch, if necessary. 
5.6.2.5 Verify that the High dP Alarm Annunciator bit O:4.0/7 (O_HIGH_DP_ALARM) and the Low dP Alarm Annunciator bit O:4.0/6 (O_LOW_DP_ALARM) are "0".

5.6.2.6 Verify that the Fan 1 and Fan 2 Interlocks are not tripped by verifying that bits $\mathrm{O}: 2.0 / 0$ (O_FAN_1_INTERLOCK) and $\mathrm{O}: 4.0 / 0$ (O_FAN_2_INTERLOCK) are "1".

5.6.2.7 Initial and date the Table 19 "(a)" block.

Test for dP1 high alarm 120 seconds after fan is started:

5.6.2.8 Use the simulator "FAN 1 ON" switch to turn Fan 1 on. Verify that Fan 1 is running by verifying that bit $\mathrm{I}: 1.0 / 2$ (I_FAN_1_ON) is " 1 ".

5.6.2.9 Use the simulator "TRAIN A ONLINE" switch to place Train A online. Verify that Train A is online by verifying that bit I:1.0/4 (I_A_TRAIN_ONLINE) is " 1 ".

5.6.2.10 Adjust the input for $\mathrm{dP1}$ upwards until word N7:93 (A_TRAIN_DP1_AVG) is greater than or equal to the dP1 high setpoint of 10748 (corresponds to $5.7000 \mathrm{inwg}$ ). Verify the value in Table 19.

5.6.2.11 After T4:2 (FAN_ON_DELAY_TIMER) reaches 60, and after T4:3 (A_TRAIN_DELAY_TIMER) reaches 60, then verify that the Train A High dP1 alarm exists by verifying that bit $\mathrm{O}: 2.0 / 1$ (O_A_HIGH_DP1) is "1".

5.6.2.12 Verify that the High dP Alarm Annunciator bit O:4.0/7 (O_HIGH_DP_ALARM) is "1".

5.6.2.13 Verify that both Fan 1 and Fan 2 Interlocks have tripped by verifying that bits $\mathrm{O}: 2.0 / 0\left(\mathrm{O} \_\right.$FAN_1_INTERLOCK $)$and $\mathrm{O}: 4.0 / 0$ (O_FAN_2_INTERLOCK) are " 0 ".

5.6.2.14 Initial and date the Table 19 "(b)" block.

Test for dP1 high alarm after fan is stopped and "Reset":

5.6.2.15 Use the simulator "FAN $1 \mathrm{ON}^{\prime \prime}$ switch to turn Fan 1 off. Verify that Fan 1 is not running by verifying that bit $\mathrm{I}: 1.0 / 2$ (I_FAN_1_ON) is " 0 ".

5.6.2.16 Use the simulator "TRAIN A ONLINE" switch to place Train A offline. Verify that Train A is offline by verifying that bit $\mathrm{I}: 1.0 / 4$ (I_A_TRAIN_ONLINE) is "0". 
5.6.2.17 Toggle bit I:1.0/0 (I RESET) by using the simulator "RESET" switch. Verify that the high $\mathrm{dP} 1$ alarm, bit $\mathrm{O}: 2.0 / 1$ (O_A_HIGH_DP1), is "0".

5.6.2.18 Verify that the High dP Alarm Annunciator bit O:4.0/7 (O_HIGH_DP_ALARM) is "0".

5.6.2.19 Verify that the Fan 1 and Fan 2 Interlocks are no longer tripped by verifying that bits $\mathrm{O}: 2.0 / 0(\mathrm{O}$ FAN_1_INTERLOCK) and $\mathrm{O}: 4.0 / 0\left(\mathrm{O} \_\mathrm{FAN} 2\right.$ _INTERLOCK$)$ are " $\overline{1} "$.

5.6.2.20 Initial and date the Table 19 "(c)" block.

Re-establish normal non-alarming conditions and test Event Log:

5.6.2.21 Adjust the input for dP1, word N7:93 (A_TRAIN_DP1_AVG), and verify that it is between the low $\mathrm{dP}$ setpoint (3670) and the high dP setpoint (10748).

5.6.2.22 Verify that the above interlock trip resulted in the event being logged to "N21 - EVENT LOG" by verifying that N21:117 contains the year (e.g. "2000"), N21: 119 contains the time, and N21:121 contains the high $\mathrm{dP} 1$ trip value $(\geq 10748)$.

5.6.2.23 Initial and date the Table 19 "(d)" block.

5.6.3 Validate that the Train A Low dP2 alarm functions as expected when a fan is running (ref. "LAD 12 - A ALARMS").

Establish non-alarming reference condition:

5.6.3.1 Verify that Fan 1 and Fan 2 are not running by verifying that bits I:1.0/2 (I_FAN_1_ON) and I:1.0/3 (I_FAN_2_ON) are "0" (Use the simulator "FAN $1 \mathrm{ON}^{\prime}$ and "FĀ $2 \mathrm{ON}^{\prime}$ switches to turn the fans off, if necessary).

5.6.3.2 Verify that Train A is not online by verifying that bit I:1.0/4 (I_A_TRAIN ONLINE) is "0" (Use the simulator "TRAIN A ONLINE" switch to place Train A offline, if necessary).

5.6.3.3 Verify that the inputs for $\mathrm{dP1}$, word N7:93

(A_TRAIN_DP1_AVG), and dP2, word N7:94

(A_TRAIN_DP2_AVG) are between the low dP setpoint (3670) and the high $\mathrm{dP}$ setpoint (10748). Adjust the inputs, if necessary.

5.6.3.4 Verify that bits $0: 2.0 / 1\left(\mathrm{O} \_\right.$A_HIGH_DP1) and O:2.0/2 (O_A_LOW_DP2) are "0". Toggle the simulator "RESET" switch, if necessary. 
5.6.3.5 Verify that the High dP Alarm Annunciator bit O:4.0/7 (O_HIGH_DP_ALARM) and the Low dP Alarm Annunciator bit $\mathrm{O}: 4.0 / \overrightarrow{6}\left(\mathrm{O}_{-}\right.$LOW_DP_ALARM) are "0".

5.6.3.6 Verify that the Fan 1 and Fan 2 Interlocks are not tripped by verifying that bits $\mathrm{O}: 2.0 / 0$ (O_FAN_1_INTERLOCK) and $\mathrm{O}: 4.0 / 0$ (O_FAN_2_INTERLOCK) are "1".

5.6.3.7 Initial and date the Table 19 "(e)" block.

Test for dP2 low alarm 120 seconds after fan is started:

5.6.3.8 Use the simulator "FAN 2 ON" switch to turn Fan 2 on. Verify that Fan 2 is running by verifying that bit $\mathrm{I}: 1.0 / 3$ (I_FAN_2_ON) is "1".

5.6.3.9 Use the simulator "TRAIN A ONLINE" switch to place Train A online. Verify that Train $A$ is online by verifying that bit $\mathrm{I}: 1.0 / 4$ (I_A_TRAIN_ONLINE) is "1".

5.6.3.10 Adjust the input for $\mathrm{dP} 2$ down towards "0", and verify that word N7:94 (A_TRAIN_DP2_AVG) is less than or equal to the dP2 low setpoint of $36 \overline{70}$ (corresponds to 0.2998 inwg). Verify the value in Table 19.

5.6.3.11 After T4:2 (FAN_ON_DELAY_TIMER) reaches 60, and after T4:3 (A TRAIN_DELAY_TIMER) reaches 60 , then verify that the Train A Low dP2 alarm exists by verifying that bit $\mathrm{O}: 2.0 / 2$ (O_A_LOW_DP1) is " 1 ".

5.6.3.12 Verify that the Low dP Alarm Annunciator bit $0: 4.0 / 6$ (O_LOW_DP_ALARM) is "1".

5.6.3.13 Verify that both Fan 1 and Fan 2 Interlocks have tripped by verifying that bits $\mathrm{O}: 2.0 / 0\left(\mathrm{O} \_\mathrm{FAN}\right.$ 1_INTERLOCK) and $\mathrm{O}: 4.0 / 0$ (O_FAN 2 INTERLOCK) are "0".

5.6.3.14 Initial and date the Table 19 "(f)" block.

Test for dP2 low alarm after fan is stopped and "Reset":

5.6.3.15 Use the simulator "FAN 2 ON" switch to turn Fan 2 off. Verify that Fan 2 is not running by verifying that bit I:1.0/3 (I_FAN_2_ON) is " 0 ".

5.6.3.16 Use the simulator "TRAIN A ONLINE" switch to place Train A offline. Verify that Train A is offline by verifying that bit $\mathrm{I}: 1.0 / 4$ (I_A_TRAIN_ONLINE) is "0". 
5.6.3.17 Toggle bit I:1.0/0 (I_RESET) by using the simulator "RESET" switch. Verify that the low dP2 alarm, bit O:2.0/2 (O_A_LOW_DP1), is " 0 ".

5.6.3.18 Verify that the Low dP Alarm Annunciator bit O:4.0/6 (O_LOW_DP_ALARM) is " 0 ".

5.6.3.19 Verify that the Fan 1 and Fan 2 Interlocks are no longer tripped by verifying that bits $0: 2.0 / 0$ (O_FAN_ 1 INTERLOCK) and $\mathrm{O}: 4.0 / 0$ (O_FAN_2_INTERLOCK) are "1".

5.6.3.20 Initial and date the Table 19 "(g)" block.

Re-establish normal non-alarming conditions and test Event Log:

5.6.3.21 Adjust the input for dP2, word N7:94 (A_TRAIN_DP2_AVG), and verify that it is between the low dP setpoint $(\overline{3670})$ and the high dP setpoint (10748).

5.6.3.22 Verify that the above interlock trip resulted in the event being logged to "N21 - EVENT LOG" by verifying that N21:117 contains the year (e.g. "2000"), N21: 119 contains the time, and $\mathrm{N} 21: 122$ contains the low dP2 trip value $(\leq 3670)$.

5.6.3.23 Initial and date the Table 19 "(h)" block.

Refer to Table 20 when performing the Train B Section 5.6.4 to 5.6.6.23 steps. When directed to verify values, record the values in the appropriate "Actual" blocks.

5.6.4 Bring up Data Files "O0 - OUTPUT", "I1 - INPUT", "T4 - TIMER", "N7 - INTEGER", and "N21 - EVENT LOG".

5.6.5 Validate that the Train B High dP1 alarm functions as expected when a fan is running (ref. "LAD 13 - B ALARMS").

Establish non-alarming reference condition:

5.6.5.1 Verify that Fan 1 and Fan 2 are not running by verifying that bits I:1.0/2 (I_FAN_1_ON) and I:1.0/3 (I_FAN_2_ON) are "0" (Use the simulator "FAN 1 ON" and "FAN 2 ON" switches to turn the fans off, if necessary).

5.6.5.2 Verify that Train B is not online by verifying that bit I:1.0/5 (I_B_TRAIN_ONLINE) is "0" (Use the simulator "TRAIN B ONLINE" switch to place Train B offline, if necessary).

5.6.5.3 Verify that the inputs for $\mathrm{dP} 1$, word N7:96

(B_TRAIN_DP1_AVG), and dP2, word N7:97

(B_TRAIN_DP2_AVG) are between the low dP setpoint (3670) 
and the high $\mathrm{dP}$ setpoint (10748). Adjust the inputs, if necessary.

5.6.5.4 Verify that bits O:4.0/1 (O_B_HIGH_DP1) and O:4.0/2 (O_B_LOW_DP2) are "0". Toggle the simulator "RESET" switch, if necessary.

5.6.5.5 Verify that the High dP Alarm Annunciator bit O:4.0/7 (O_HIGH_DP_ALARM) and the Low dP Alarm Annunciator bit $\mathrm{O}: 4.0 / \overline{6}\left(\mathrm{O}_{-}\right.$LOW_DP_ALARM) are "0".

5.6.5.6 Verify that the Fan 1 and Fan 2 Interlocks are not tripped by verifying that bits $\mathrm{O}: 2.0 / 0(\mathrm{O}$ FAN_1_INTERLOCK) and O:4.0/0 (O_FAN_2_INTERLOCK) are "1".

5.6.5.7 Initial and date the Table 20 "(a)" block.

Test for dP1 high alarm 120 seconds after fan is started:

5.6.5.8 Use the simulator "FAN 1 ON" switch to turn Fan 1 on. Verify that Fan 1 is running by verifying that bit $\mathrm{I}: 1.0 / 2$ (I_FAN_1 ON) is "1".

5.6.5.9 Use the simulator "TRAIN B ONLINE" switch to place Train B online. Verify that Train $B$ is online by verifying that bit $\mathrm{I}: 1.0 / 5$ (I_B_TRAIN_ONLINE) is "1".

5.6.5.10 Adjust the input for dP1 upwards until word N7:96 (B TRAIN_DP1_AVG) is greater than or equal to the dP1 high

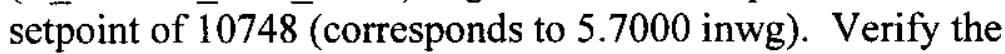
value in Table 20 .

5.6.5.11 After T4:2 (FAN_ON_DELAY_TIMER) reaches 60, and after T4:4 (B_TRAIN_DELAY_TIMER) reaches 60 , then verify that the Train $B$ High dP1 alarm exists by verifying that bit $0: 4.0 / 1$ (O_B_HIGH_DP1) is "1".

5.6.5.12 Verify that the High dP Alarm Annunciator bit O:4.0/7 (O_HIGH_DP_ALARM) is "1".

5.6.5.13 Verify that both Fan 1 and Fan 2 Interlocks have tripped by verifying that bits $\mathrm{O}: 2.0 / 0\left(\mathrm{O} \_\mathrm{FAN}\right.$ 1_INTERLOCK) and $0: 4.0 / 0$ (O_FAN_2_INTERLOCK) are "0".

5.6.5.14 Initial and date the Table 20 "(b)" block. 
Test for dPI high alarm after fan is stopped and "Reset":

5.6.5.15 Use the simulator "FAN 1 ON" switch to turn Fan 1 off. Verify that Fan 1 is not running by verifying that bit $\mathrm{I}: 1.0 / 2$ (I_FAN_1_ON) is " 0 ".

5.6.5.16 Use the simulator "TRAIN B ONLINE" switch to place Train B offline. Verify that Train B is offline by verifying that bit I:1.0/5 (I_B_TRAIN_ONLINE) is "0".

5.6.5.17 Toggle bit I:1.0/0 (I_RESET) by using the simulator "RESET" switch. Verify that the high $\mathrm{dP} 1$ alarm, bit $\mathrm{O}: 4.0 / 1$ (O_B_HIGH_DP1), is " 0 ".

5.6.5.18 Verify that the High dP Alarm Annunciator bit O:4.0/7 (O_HIGH_DP_ALARM) is " 0 ".

5.6.5.19 Verify that the Fan 1 and Fan 2 Interlocks are no longer tripped by verifying that bits $\mathrm{O}: 2.0 / 0$ (O_FAN_1_INTERLOCK) and O:4.0/0 (O_FAN_2_INTERLOCK) are " $\overline{1}$.

5.6.5.20 Initial and date the Table 20 "(c)" block.

Re-establish normal non-alarming conditions and test Event Log:

5.6.5.21 Adjust the input for dP1, word N7:96 (B_TRAIN_DP1_AVG), and verify that it is between the low dP setpoint (3670) and the high dP setpoint (10748).

5.6.5.22 Verify that the above interlock trip resulted in the event being logged to "N21 - EVENT LOG" by verifying that N21:117 contains the year (e.g. "2000"), N21: 119 contains the time, and N21:124 contains the high $\mathrm{dP} 1$ trip value $(\geq 10748)$.

5.6.5.23 Initial and date the Table 20 "(d)" block.

5.6.6 Validate that the Train B Low dP2 alarm functions as expected when a fan is running (ref. "LAD 13 - B ALARMS").

\section{Establish non-alarming reference condition:}

5.6.6.1 Verify that Fan 1 and Fan 2 are not running by verifying that bits I:1.0/2 (I_FAN_1_ON) and I:1.0/3 (I_FAN_2_ON) are "0" (Use the simulator "FAN $1 \mathrm{ON}^{\prime \prime}$ and "FAN $2 \mathrm{ON}^{\prime \prime}$ switches to turn the fans off, if necessary).

5.6.6.2 Verify that Train $\mathrm{B}$ is not online by verifying that bit I:1.0/5 (I_B_TRAIN_ONLINE) is "0" (Use the simulator "TRAIN B ONLINE" switch to place Train B offline, if necessary). 
5.6.6.3 Verify that the inputs for $\mathrm{dP1}$, word N7:96

(B_TRAIN_DP1_AVG), and dP2, word N7:97

(B_TRAIN_DP2_AVG) are between the low dP setpoint (3670) and the high $\mathrm{dP}$ setpoint (10748). Adjust the inputs, if necessary.

5.6.6.4 Verify that bits O:4.0/1 (O_B_HIGH_DP1) and O:4.0/2 (O_B_LOW_DP2) are "0". Toggle the simulator "RESET" switch, if necessary.

5.6.6.5 Verify that the High dP Alarm Annunciator bit $0: 4.0 / 7$ (O_HIGH_DP_ALARM) and the Low dP Alarm Annunciator bit $0: 4.0 / 6$ (O_LOW_DP_ALARM) are "0".

5.6.6.6 Verify that the Fan 1 and Fan 2 Interlocks are not tripped by verifying that bits $\mathrm{O}: 2.0 / 0$ (O_FAN_1_INTERLOCK) and $\mathrm{O}: 4.0 / 0$ (O_FAN_2_INTERLOCK) are "1".

5.6.6.7 Initial and date the Table 20 "(e)" block.

Test for dP2 low alarm 120 seconds after fan is started:

5.6.6.8 Use the simulator "FAN 2 ON" switch to turn Fan 2 on. Verify that Fan 2 is running by verifying that bit $\mathrm{I}: 1.0 / 3$

(I_FAN_2_ON) is "1".

5.6.6.9 Use the simulator "TRAIN B ONLINE" switch to place Train B online. Verify that Train B is online by verifying that bit $\mathrm{I}: 1.0 / 5$ (I_B_TRAIN_ONLINE) is " 1 ".

5.6.6.10 Adjust the input for $\mathrm{dP} 2$ down towards "0", and verify that word N7:97 (B_TRAIN_DP2_AVG) is less than or equal to the dP2 low setpoint of $36 \overline{70}$ (corresponds to 0.2998 inwg). Verify the value in Table 20 .

5.6.6.11 After T4:2 (FAN_ON_DELAY_TIMER) reaches 60, and after T4:4 (B_TRAIN_DELAY_TIMER) reaches 60 , then verify that the Train $B$ Low $\mathrm{dP} 2$ alarm exists by verifying that bit $0: 4.0 / 2$ (O_B_LOW_DP1) is " 1 ".

5.6.6.12 Verify that the Low dP Alarm Annunciator bit O:4.0/6 (O_LOW_DP_ALARM) is "1".

5.6.6.13 Verify that both Fan 1 and Fan 2 Interlocks have tripped by verifying that bits $0: 2,0 / 0$ (O_FAN_1_INTERLOCK) and O:4.0/0 (O_FAN_2_INTERLOCK) are "0".

5.6.6.14 Initial and date the Table 20 "(f)" block. 
Test for dP2 low alarm after fan is stopped and "Reset":

5.6.6.15 Use the simulator "FAN 2 ON" switch to turn Fan 2 off. Verify that Fan 2 is not running by verifying that bit $\mathrm{I}: 1.0 / 3$ (I_FAN_2_ON) is " 0 ".

5.6.6.16 Use the simulator "TRAIN B ONLINE" switch to place Train B offline. Verify that Train $B$ is offline by verifying that bit $\mathrm{I}: 1.0 / 5$ (I_B_TRAIN_ONLINE) is "0".

5.6.6.17 Toggle bit I:1.0/0 (I_RESET) by using the simulator "RESET" switch. Verify that the low dP2 alarm, bit $\mathrm{O}: 4: 0 / 2$ (O_B_LOW_DP1), is "0".

5.6.6.18 Verify that the Low dP Alarm Annunciator bit O:4.0/6 (O_LOW_DP_ALARM) is " 0 ".

5.6.6.19 Verify that the Fan 1 and Fan 2 Interlocks are no longer tripped by verifying that bits $\mathrm{O}: 2.0 / 0$ (O_FAN_1_INTERLOCK) and $\mathrm{O}: 4.0 / 0$ (O_FAN_2_INTERLOCK) are "1".

5.6.6.20 Initial and date the Table 20 "(g)" block.

Re-establish normal non-alarming conditions and test Event Log:

5.6.6.21 Adjust the input for dP2, word N7:97 (B_TRAIN_DP2_AVG), and verify that it is between the low dP setpoint (3670) and the high dP setpoint (10748).

5.6.6.22 Verify that the above interlock trip resulted in the event being logged to "N21 - EVENT LOG" by verifying that N21:117 contains the year (e.g. "2000"), N21: 119 contains the time, and $\mathrm{N} 21: 125$ contains the low dP2 trip value $(\leq 3670)$.

5.6.6.23 Initial and date the Table 20 "(h)" block.

Refer to Table 21 when performing the Train C Section 5.6.7 to 5.6.9.22 steps. When directed to verify values, record the values in the appropriate "Actual" blocks.

5.6.7 Bring up Data Files "O0 - OUTPUT", "I1 - INPUT", "T4 - TIMER", "N7 - INTEGER", and "N21 - EVENT LOG".

5.6.8 Validate that the Train $\mathrm{C}$ High $\mathrm{dP1}$ alarm functions as expected when a fan is running (ref. "LAD 14 - C ALARMS").

Establish non-alarming reference condition:

5.6.8.1 Verify that Fan 1 and Fan 2 are not running by verifying that bits I:1.0/2 (I_FAN_1_ON) and I:1.0/3 (I_FAN_2_ON) are "0" 
(Use the simulator "FAN $10 N "$ and "FAN 2 ON" switches to turn the fans off, if necessary).

5.6.8.2 Verify that Train $\mathrm{C}$ is not online by verifying that bit $\mathrm{I}: 1.0 / 6$ (I_C_TRAIN_ONLINE) is "0" (Use the simulator "TRAIN C ONLINE" switch to place Train C offline, if necessary).

5.6.8.3 Verify that the inputs for dP1, word N7:99

(C_TRAIN_DP1_AVG), and dP2, word N7:100

(C_TRAIN_DP2_AVG) are between the low dP setpoint (3670) and the high dP setpoint (10748). Adjust the inputs, if necessary.

5.6.8.4 Verify that bits O:6.0/1 (O_C_HIGH_DP1) and O:6.0/2 (O_C_LOW_DP2) are " 0 ". Toggle the simulator "RESET" switch, if necessary.

5.6.8.5 Verify that the High dP Alarm Annunciator bit O:4.0/7 (O_HIGH_DP_ALARM) and the Low dP Alarm Annunciator bit $\mathrm{O}: 4.0 / \overline{6}\left(\mathrm{O}_{-}\right.$LOW_DP_ALARM) are "0".

5.6.8.6 Verify that the Fan 1 and Fan 2 Interlocks are not tripped by verifying that bits $\mathrm{O}: 2.0 / 0\left(\mathrm{O} \_\mathrm{FAN} \_1\right.$ INTERLOCK) and O:4.0/0 (O_FAN_2_INTERLOCK) are "1".

5.6.8.7 Initial and date the Table 21 "(a)" block.

Test for dPI high alarm 120 seconds after fan is started:

5.6.8.8 Use the simulator "FAN 1 ON" switch to turn Fan 1 on. Verify that Fan 1 is running by verifying that bit I:1.0/2

(I_FAN_1_ON) is "1".

5.6.8.9 Use the simulator "TRAIN C ONLINE" switch to place Train C online. Verify that Train $\mathrm{C}$ is online by verifying that bit $\mathrm{I}: 1.0 / 6$ (I_C_TRAIN_ONLINE) is " 1 ".

5.6.8.10 Adjust the input for dP1 upwards until word N7:99

(C_TRAIN_DP1_AVG) is greater than or equal to the dP1 high setpoint of 10748 (corresponds to 5.7000 inwg). Verify the value in Table 20.

5.6.8.11 After T4:2 (FAN_ON_DELAY_TIMER) reaches 60, and after T4:5 (C_TRAIN_DELAY_TIMER) reaches 60 , then verify that the Train $C$ High $\mathrm{dP} 1$ alarm exists by verifying that bit $\mathrm{O}: 6.0 / 1$ (O_C_HIGH_DP1) is " 1 ".

5.6.8.12 Verify that the High dP Alarm Annunciator bit O:4.0/7 (O_HIGH_DP_ALARM) is "1". 
5.6.8.13 Verify that both Fan 1 and Fan 2 Interlocks have tripped by verifying that bits $\mathrm{O}: 2.0 / 0$ (O_FAN_1_INTERLOCK) and O:4.0/0 (O_FAN_2_INTERLOCK) are "0".

5.6.8.14 Initial and date the Table 21 "(b)" block.

Test for dPI high alarm after fan is stopped and "Reset":

5.6.8.15 Use the simulator "FAN $1 \mathrm{ON}$ " switch to turn Fan 1 off. Verify that Fan 1 is not running by verifying that bit $\mathrm{I}: 1.0 / 2$ (I_FAN_1_ON) is " 0 ".

5.6.8.16 Use the simulator "TRAIN C ONLINE" switch to place Train C offline. Verify that Train $\mathrm{C}$ is offline by verifying that bit $\mathrm{I}: 1.0 / 6$ (I_C_TRAIN_ONLINE) is " 0 ".

5.6.8.17 Toggle bit I:1.0/0 (I_RESET) by using the simulator "RESET" switch. Verify that the high $\mathrm{dP} 1$ alarm, bit $\mathrm{O}: 6.0 / 1$ (O_C_HIGH_DP1), is " 0 ".

5.6.8.18 Verify that the High dP Alarm Annunciator bit O:4.0/7 (O_HIGH_DP_ALARM) is "0".

5.6.8.19 Verify that the Fan 1 and Fan 2 Interlocks are no longer tripped by verifying that bits $0: 2.0 / 0$ (O_FAN_1_INTERLOCK) and $\mathrm{O}: 4.0 / 0$ (O_FAN_2_INTERLOCK) are " $1 "$ ".

5.6.8.20 Initial and date the Table 21 "(c)" block.

Re-establish normal non-alarming conditions and test Event Log:

5.6.8.21 Adjust the input for dP1, word N7:99 (C_TRAIN_DP1_AVG), and verify that it is between the low $\mathrm{dP}$ setpoint (3670) and the high dP setpoint (10748).

5.6.8.22 Verify that the above interlock trip resulted in the event being logged to "N21 - EVENT LOG" by verifying that N21:117 contains the year (e.g. "2000"), N21: 119 contains the time, and $\mathrm{N} 21: 127$ contains the high $\mathrm{dP} 1$ trip value $(\geq 10748)$.

5.6.8.23 Initial and date the Table 21 "(d)" block.

5.6.9 Validate that the Train C Low dP2 alarm functions as expected when a fan is running (ref. "LAD 14 - C ALARMS").

Establish non-alarming reference condition:

5.6.9.1 Verify that Fan 1 and Fan 2 are not running by verifying that bits I:1.0/2 (I_FAN_1_ON) and I:1.0/3 (I_FAN_2_ON) are "0" 
(Use the simulator "FAN 1 ON" and "FAN 2 ON" switches to turn the fans off, if necessary).

5.6.9.2 Verify that Train $\mathrm{C}$ is not online by verifying that bit $\mathrm{I}: 1.0 / 6$ (I_C_TRAIN_ONLINE) is "0" (Use the simulator "TRAIN C ONLINE" switch to place Train C offline, if necessary).

5.6.9.3 Verify that the inputs for $\mathrm{dP1}$, word N7:99

(C_TRAIN_DP1_AVG), and dP2, word N7:100

(C_TRAIN_DP2_AVG) are between the low dP setpoint (3670) and the high $\mathrm{dP}$ setpoint (10748). Adjust the inputs, if necessary.

5.6.9.4 Verify that bits O:6.0/1 (O_C_HIGH_DP1) and O:6.0/2 (O_C_LOW_DP2) are "0". Toggle the simulator "RESET" switch, if necessary.

5.6.9.5 Verify that the High dP Alarm Annunciator bit O:4.0/7 (O_HIGH_DP_ALARM) and the Low dP Alarm Annunciator bit $\mathrm{O}: 4.0 / \overline{6}\left(\mathrm{O}_{-}\right.$LOW_DP_ALARM) are "0".

5.6.9.6 Verify that the Fan 1 and Fan 2 Interlocks are not tripped by verifying that bits $\mathrm{O}: 2.0 / 0$ (O_FAN_1_INTERLOCK) and O:4.0/0 (O_FAN_2_INTERLOCK) are "1".

5.6.9.7 Initial and date the Table 21 "(e)" block.

Test for dP2 low alarm 120 seconds after fan is started:

5.6.9.8 Use the simulator "FAN 2 ON" switch to turn Fan 2 on. Verify that Fan 2 is running by verifying that bit $\mathrm{I}: 1.0 / 3$

(I_FAN_2_ON) is "1".

5.6.9.9 Use the simulator "TRAIN C ONLINE" switch to place Train C online. Verify that Train $\mathrm{C}$ is online by verifying that bit $\mathrm{I}: 1.0 / 6$ (I_C_TRAIN_ONLINE) is " 1 ".

5.6.9.10 Adjust the input for $\mathrm{dP} 2$ down towards "0", and verify that word N7:100 (C_TRAIN_DP2_AVG) is less than or equal to the dP2 low setpoint of $367 \overline{0}$ (corresponds to 0.2998 inwg). Verify the value in Table 21 .

5.6.9.11 After T4:2 (FAN_ON_DELAY_TIMER) reaches 60, and after T4:5 (C_TRAIN_DELAY_TIMER) reaches 60 , then verify that the Train C Low dP2 alarm exists by verifying that bit $\mathrm{O}: 6.0 / 2$ (O_C_LOW_DP1) is " 1 ".

5.6.9.12 Verify that the Low dP Alarm Annunciator bit O:4.0/6 (O_LOW_DP_ALARM) is "1". 
5.6.9.13 Verify that both Fan 1 and Fan 2 Interlocks have tripped by verifying that bits $0: 2.0 / 0\left(O_{\text {_FAN_}} 1\right.$ INTERLOCK) and $\mathrm{O}: 4.0 / 0$ (O_FAN_2_INTERLOCK) are "0".

5.6.9.14 Initial and date the Table 21 "(f)" block.

Test for dP2 low alarm after fan is stopped and "Reset".

5.6.9.15 Use the simulator "FAN 2 ON" switch to turn Fan 2 off. Verify that Fan 2 is not running by verifying that bit $\mathrm{I}: 1.0 / 3$ (I_FAN_2_ON) is "0".

5.6.9.16 Use the simulator "TRAIN C ONLINE" switch to place Train C offline. Verify that Train $\mathrm{C}$ is offline by verifying that bit $\mathrm{I}: 1.0 / 6$ (I_C_TRAIN_ONLINE) is " 0 ".

5.6.9.17 Toggle bit I:1.0/0 (I_RESET) by using the simulator "RESET" switch. Verify that the low dP2 alarm, bit $\mathrm{O}: 6.0 / 2$ (O_C_LOW_DP1), is "0".

5.6.9.18 Verify that the Low dP Alarm Annunciator bit $0: 4.0 / 6$ (O_LOW_DP_ALARM) is " 0 ".

5.6.9.19 Verify that the Fan 1 and Fan 2 Interlocks are no longer tripped by verifying that bits $0: 2.0 / 0$ (O_FAN_1_INTERLOCK) and $0: 4.0 / 0$ (O_FAN_2_INTERLOCK) are "1".

5.6.9.20 Initial and date the Table 21 "(g)" block.

Re-establish normal non-alarming conditions and test Event Log:

5.6.9.21 Adjust the input for dP2, word N7:100 (C_TRAIN_DP2_AVG), and verify that it is between the low dP setpoint $(3 \overline{670})$ and the high dP setpoint (10748).

5.6.9.22 Verify that the above interlock trip resulted in the event being logged to "N21 - EVENT LOG" by verifying that N21:117 contains the year (e.g. "2000"), N21: 119 contains the time, and $\mathrm{N} 21: 128$ contains the low dP2 trip value $(\leq 3670)$.

5.6.9.23 Initial and date the Table 21 "(h)" block.

\subsection{TWO-MINUTE EVEN'T LOG VALIDATION}

Data file "N22 - 2MIN FIFO" is the PLC memory region used to store the last 20 values of the various exhauster system parameters, acquired every six seconds. This provides the last 2 minutes ( 120 seconds) of data. Upon an interlock trip event, the data in file N22 is copied to file "N23 - 2MIN LOG" to save the 2 minutes of exhauster data leading up to this most recent event, which is then available for diagnostics. 
Refer to Table 22 when performing the following steps. When directed to verify values, record the values in the appropriate "Actual" blocks.

5.7.1 Validate the 2 Minute Event Log

5.7.1.1 Bring up Data FileS "N21 - EVENT LOG" and "N23 - 2MIN LOG".

5.7.1.2 Record the information that resulted from the interlock trip caused in Step 5.6.9.10 (Train C, low dP2): N21:117 (the year, e.g. "2000"), N21: 119 (the time, hhmm) and N21:128 (the low $\mathrm{dP} 2$ trip value, $\leq 3670$ ).

5.7.1.3 Verify that the last 2 minutes of time data (units of mmss, in 6 second increments) were transferred to N23 by verifying that the 20 time values are in NN23:1, N23:13, . . N23:117, N23:229.

5.7.1.4 Initial and date the Table 22 "(a)" block.

5.7.1.5 Verify that the last 2 minutes of low dP2 data were transferred to $\mathrm{N} 23$ by verifying that the 20 values in N23:10, N23:22 ... $\mathrm{N} 23: 226, \mathrm{~N} 23: 238$ approach or exceed the N21:128 low dP2 trip value $(\leq 3670)$.

5.7.1.6 Initial and date the Table 22 "(b)" block.

\subsection{HISTORY LOG VALIDATION}

Data files N9 through N20 are the PLC memory regions used to store the last 144 values of various exhauster system parameters. File "N9 - HIST DATE" contains the encoded date (mmdd, along with Fan 1, Fan 2, Train A, Train B and Train C status bits); File "N10 - HIST TIMES" contains the time (hhmm); Files "N11 - A DP1HIST", "N12 - A DP2HIST", "N13 - A DP12HIST", "N14 - B DP1HIST", "N15 - B DP2HIST", "N16 - B DP12HIST", "N17 - C DP1HIST", "N18 - C DP2HIST" and "N19 - C DP12HIST" contain the dP1, dP2 and dP12 raw values for each filter train. File "N20 - TEMP HIST" contains the panel temperature raw values. The values are placed into these files every ten minutes, providing the last 24 hours of data available for diagnostics.

Refer to Table 23 when performing the following steps. When directed to verify values, record the values in the appropriate "Actual" blocks.

5.8.1 Validate the History Log With Fan 1 Off.

5.8.1.1 Bring up Data File "I1 - INPUT".

5.8.1.2 Verify that Fan 1 and Fan 2 are not running by verifying that bits I:1.0/2 (I_FAN_1_ON) and I:1.0/3 (I_FAN_2_ON) are "0" 
(Use the simulator "FAN $1 \mathrm{ON}^{\text {" and "FAN } 2} \mathrm{ON}$ " switches to turn the fans off, if necessary).

5.8.1.3 Verify that Trains $\mathrm{A}, \mathrm{B}$ and $\mathrm{C}$ are not online by verifying that bits I:1.0/4 (I_A_TRAIN_ONLINE) I:1.0/5 (I_B_TRAIN_ONLINE), and I:1.0/6 (I_C_TRAIN_ONLINE) are " 0 " (Use the simulator "TRAIN A ONLINE", "TRAIN B ONLINE" and "TRAIN C ONLINE" switches to place the trains offline, if necessary).

5.8.1.4 Adjust the inputs for Train A dP1, word I:3.0 (I_A_DP1), Train A dP2, word I:3.1 (I_A_DP2), and Train A dP12, word I:3.2 (I_A_DP12), and verify that they are unique and between the low $\mathrm{dP}$ setpoint (3670) and the high $\mathrm{dP}$ setpoint (10748). Record them in the "Expected" row.

5.8.1.5 Adjust the inputs for Train B dP1, word I:5.0 (I_B_DP1), Train B dP2, word I:5.1 (I_B_DP2), and Train B $\overline{\mathrm{dP}} 12$, word I:5.2 (I_B_DP12), and verify that they are unique and between the low $\mathrm{dP}$ setpoint (3670) and the high $\mathrm{dP}$ setpoint (10748). Record them in the "Expected" row.

5.8.1.6 Adjust the inputs for Train C dP1, word I:7.0 (I_C_DP1), Train C dP2, word I:7.1 (I C _ DP2), and Train $\bar{C} \mathrm{dP} 12$, word I:7.2 (I_C_DP12), and verify that they are unique and between the low $\mathrm{dP}$ setpoint (3670) and the high $\mathrm{dP}$ setpoint (10748). Record them in the "Expected" row.

5.8.1.7 Adjust the input for panel temperature, word I:3.3

(I_PANEL_TEMP) and record it in the "Expected" row.

5.8.1.8 One-by-one, bring up the Data Files N9 through N20, and verify that, after 10 minutes, the expected values appear in the respective word Nxx:143.

5.8.1.9 Initial and date the Table 23 "(a)" block.

5.8.2 Validate the History Log With Fan 1 On.

5.8.2.1 Use the simulator "FAN 1 ON" switch to turn Fan 1 on. Verify that Fan 1 is running by verifying that bit $\mathrm{I}: 1.0 / 2$ (I_FAN_1_ON) is "1".

5.8.2.2 Adjust the inputs slightly for Train A dP1, word I:3.0 (I_A_DP1), Train A dP2, word I:3.1 (I_A_DP2), and Train A dP12, word I:3.2 (I_A_DP12), and verify that they are unique and between the low $\mathrm{dP}$ setpoint (3670) and the high $\mathrm{dP}$ setpoint (10748). Record them in the "Expected" row. 
5.8.2.3 Adjust the inputs slightly for Train B dP1, word I:5.0 (I_B_DP1), Train B dP2, word I:5.1 (I_B_DP2), and Train B dP12, word I:5.2 (I_B_DP12), and verify that they are unique and between the low $\mathrm{dP}$ setpoint (3670) and the high $\mathrm{dP}$ setpoint (10748). Record them in the "Expected" row.

5.8.2.4 Adjust the inputs slightly for Train C dP1, word I:7.0 (I_C_DP1), Train C dP2, word I:7.1 (I_C DP2), and Train C dP12, word I:7.2 (I_C_DP12), and verify that they are unique and between the low $\mathrm{dP}$ setpoint (3670) and the high $\mathrm{dP}$ setpoint (10748). Record them in the "Expected" row.

5.8.2.5 Adjust the input slightly for panel temperature, word I:3.3 (I_PANEL_TEMP) and record it in the "Expected" row.

5.8.2.6 One-by-one, bring up the Data Files N9 through N20, and verify that, after 10 minutes, the expected values appear in the respective word Nxx:143. The previous Nxx:143 values should move to Nxx: 142.

5.8.2.7 Initial and date the Table 23 "(b)" block.

Approval of Section 5.0 Validation Phase:

Cog. Eng. / Proj. Rep.

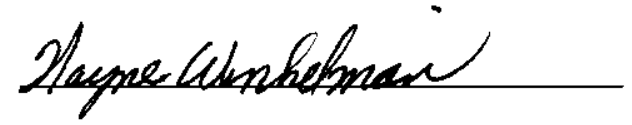

Date:

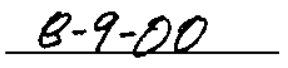


V\&V Test Report

RPP-6582, Rev. 0

RPP-6581

Page 87

Rev. 0

Page 81

6.0 VERIFICATION AND VALIDATION COMPLETION APPROVALS

Completion of this Verification And Validation Test Plan demonstrates that:

- The "DP INTERLOCK V1.00.RSS" PLC ladder logic software verification has been sucessfully completed, ensuring that the software baseline element meets the established requirements.

- The "DP INTERLOCK V1.00.RSS" PLC ladder logic software validation has been sucessfully completed, ensuring that the software baseline element has been tested and meets specified expectations.

A record of all test exceptions was kept on Attachment 1, Test Exceptions, and a record of all test plan changes was kept on Attachment 2, Test Plan Changes. All recorded test exceptions have been resolved and the resolutions approved.

Approved by:
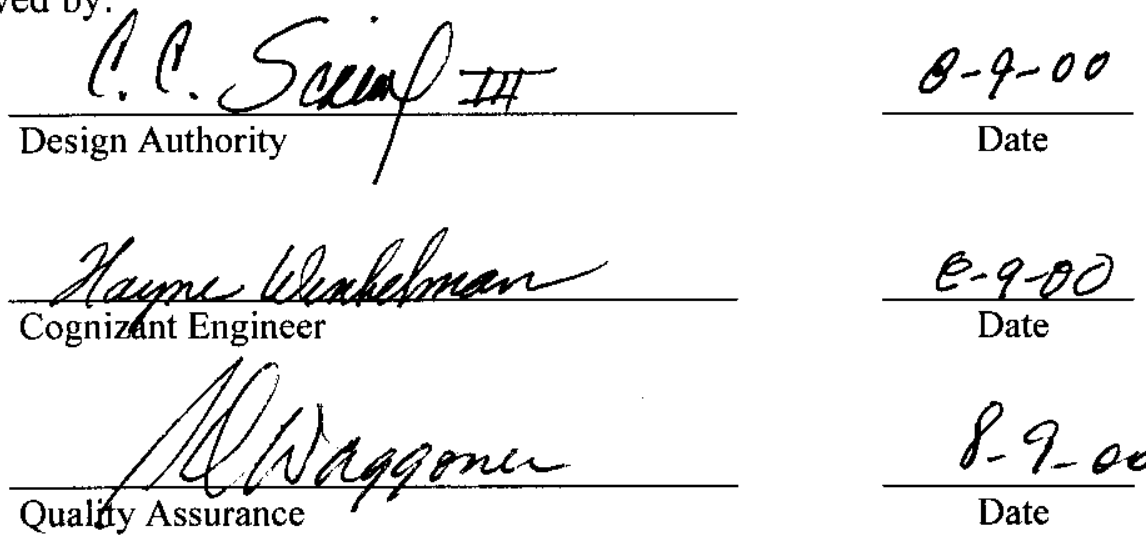

Angie M. Emu Test Director$$
\frac{8-9-00}{\text { Date }}
$$

$\frac{8-9-00}{\text { Date }}$ 


\subsection{REFERENCES}

1. "Computer Software Quality Assurance Requirements", HNF-PRO-309, Rev. 0 (1999).

2. CH2M-Hill Hanford Group, "HEPA Filter Differential Pressure Fan Interlock System Functional Requirements and Technical Design Criteria", RPP-5977, Rev. 0 (2000).

3. CH2M-Hill Hanford Group 2000c, Letter from M. P. DeLozier to R. T. French, ORP, "Completion of Fiscal Year 2000 Performance Incentive ORP3.2.3, 'Implementation of Field Optimizations', Section 3, standard 2, and Section 4 Item 2(b)", CHG-0000622 $\mathrm{R} 1$, dated April 13, 2000 with attached AB amendment package for Implementation of an Alternative Control Strategy for LCO 3.1.4.

4. ORP 2000, Letter from R. T. French to M. P. DeLozier, "Completion of Fiscal Year 2000 Performance Incentive ORP3.2.3, 'Implementation of Field Optimizations', Section 3, standard 2, and Section 4 Item 2(b)", CHG-0000622 R1, dated April 13, 2000 with attached SER for AB amendment package for Implementation of an Alternative Control Strategy for LCO 3.1.4.

5. CH2M-Hill Hanford Group, "Computer Software Description for the HEPA Filter Differential Pressure Fan Interlock System", RPP-6546, Rev. 0 (2000).

6. CH2M-Hill Hanford Group, "Software System Configuration Management Plan for the HEPA Filter Differential Pressure Fan Interlock System", RPP-6547, Rev. 0 (2000). 


\subsection{TABLES}

Table 1. Verification of dP Interlock Ladder Logic Software .....................................................8 84

Table 2. Validation / Requirements Cross Reference for Ladder Logic Software .......................85

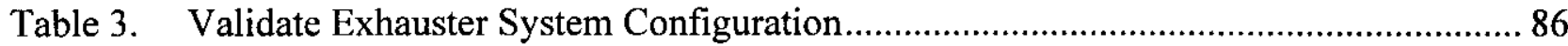

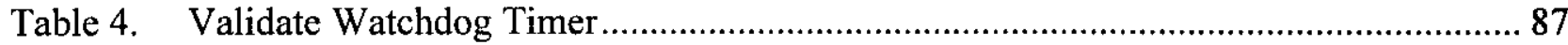

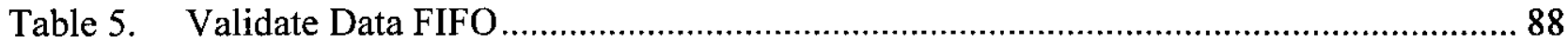

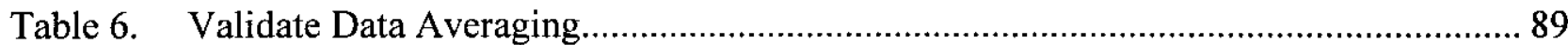

Table 7. Validate Train A Transmitter Failure Alarms With Fan Not Running ...........................99

Table 8. Validate Train B Transmitter Failure Alarms With Fan Not Running .......................... 91

Table 9. Validate Train C Transmitter Failure Alarms With Fan Not Running ..........................92

Table 10. Validate Train A dP1 Transmitter Failure Alarms With Fan Running...........................93

Table 11. Validate Train A dP2 Transmitter Failure Alarms With Fan Running........................... 94

Table 12. Validate Train A dP12 Transmitter Failure Alarms With Fan Running.........................95

Table 13. Validate Train B dP1 Transmitter Failure Alarms With Fan Running ...........................96

Table 14. Validate Train B dP2 Transmitter Failure Alarms With Fan Running .........................97

Table 15. Validate Train B dP12 Transmitter Failure Alarms With Fan Running ........................98

Table 16. Validate Train C dP1 Transmitter Failure Alarms With Fan Running .........................99

Table 17. Validate Train C dP2 Transmitter Failure Alarms With Fan Running ......................... 100

Table 18. Validate Train C dP12 Transmitter Failure Alarms With Fan Running ...................... 101

Table 19. Validate Train A High dP1 and Low dP2 Alarms With Fan Running ........................ 102

Table 20. Validate Train B High dP1 and Low dP2 Alarms With Fan Running......................... 103

Table 21. Validate Train C High dP1 and Low dP2 Alarms With Fan Running......................... 104

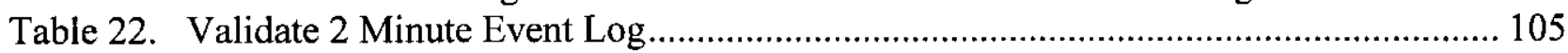

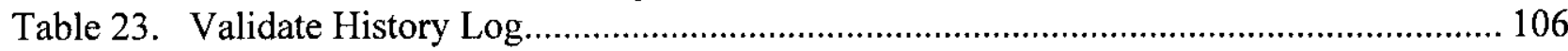



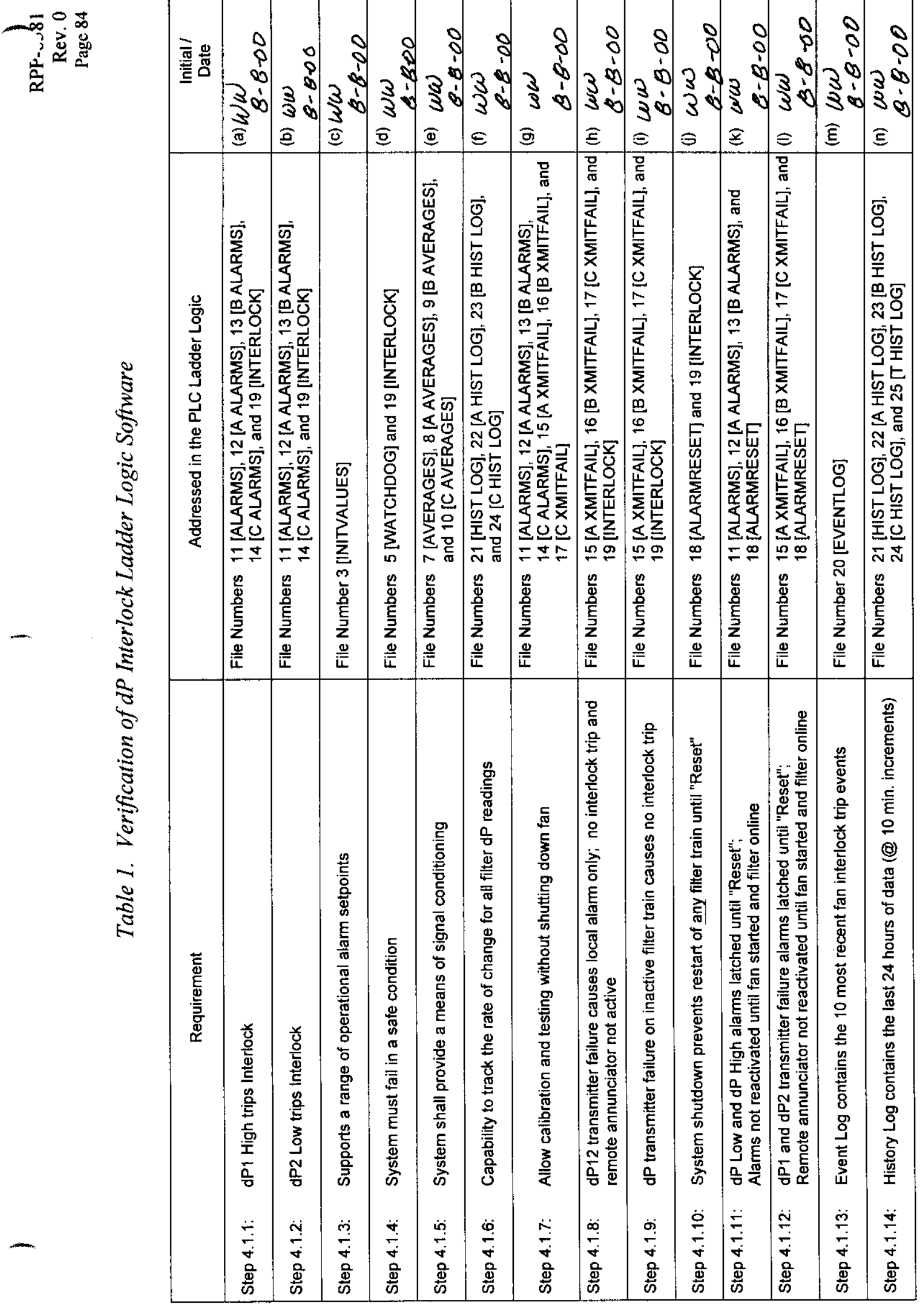

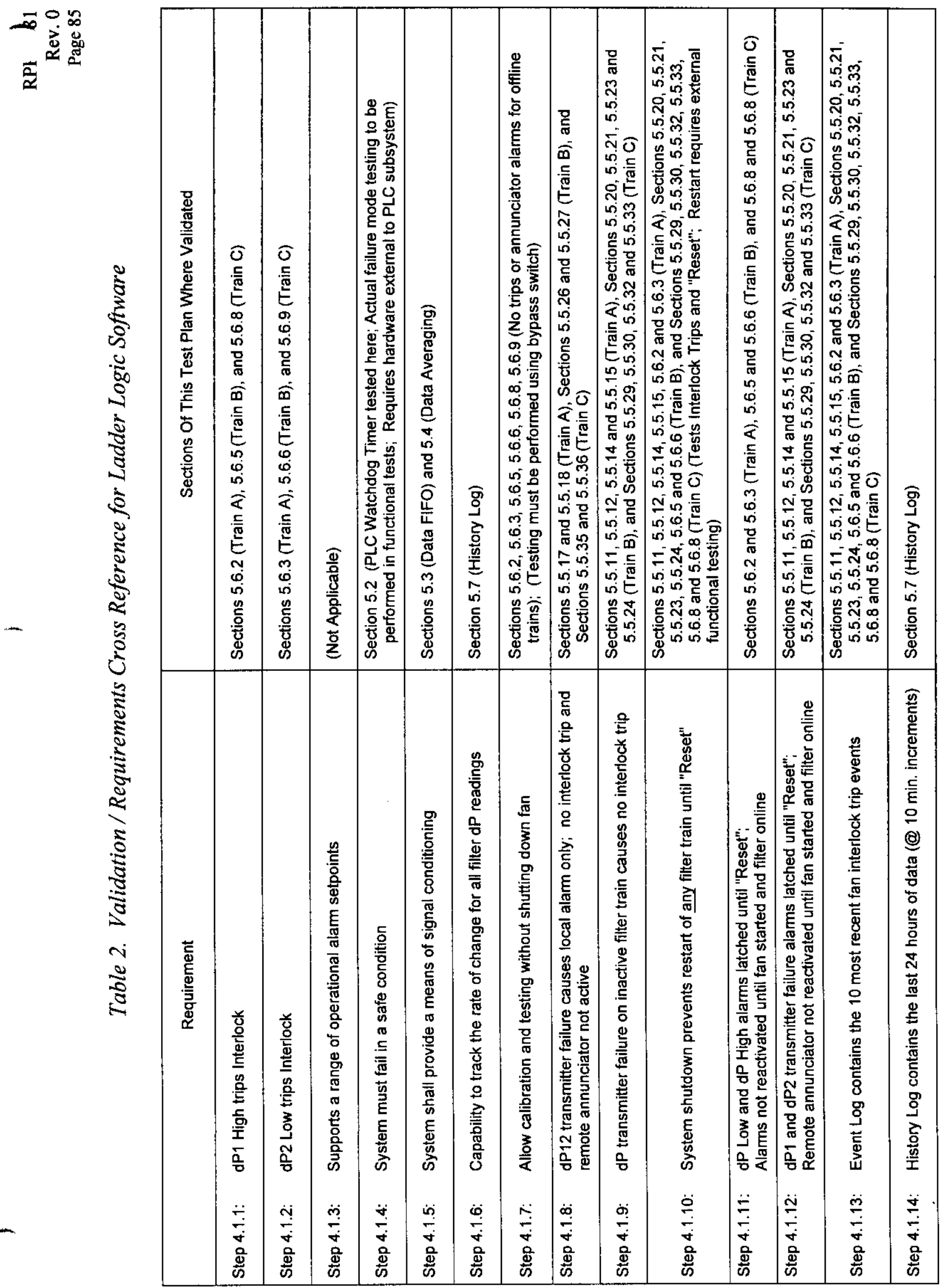


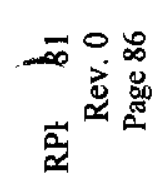

\begin{tabular}{|c|c|c|c|c|c|c|c|}
\hline \multicolumn{2}{|c|}{ 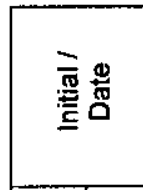 } & @ & $\begin{array}{l}8 \\
0 \\
0 \\
0\end{array}$ & $\begin{array}{r}3 \\
a^{3} \\
\end{array}$ & $\begin{array}{l}8 \\
0 \\
0 \\
0\end{array}$ & $0^{3}$ & $\begin{array}{l}0 \\
1 \\
0 \\
0 \\
0\end{array}$ \\
\hline \multirow{13}{*}{ 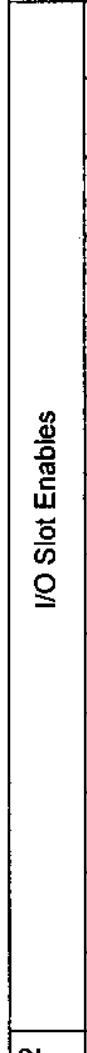 } & $\underset{\dot{o j}}{N}$ & 0 & 0 & 0 & 0 & 0 & 0 \\
\hline & $\sum_{i j}=$ & 0 & 0 & 0 & 0 & 0 & 0 \\
\hline & $\sum_{i s}$ & 0 & 0 & 0 & 0 & 0 & 0 \\
\hline & $F_{i s} \sigma$ & 0 & 3 & 0 & 0 & 0 & 0 \\
\hline & $\sum_{\infty}^{\infty}$ & 0 & 0 & 0 & 0 & 0 & 0 \\
\hline & $\sum_{i s}$ & 0 & 0 & 0 & 0 & - & - \\
\hline & $\sum_{i j} 0$ & 0 & 0 & 0 & 0 & $r$ & - \\
\hline & $\sum_{i \infty}^{\infty}$ & 0 & 0 & - & - & - & $\sim$ \\
\hline & $\sum_{i j}{ }^{+}$ & - & - & - & - & - & - \\
\hline & $\sum_{i j} m$ & - & - & - & - & - & - \\
\hline & $\sum_{i j} N$ & - & - & - & - & - & - \\
\hline & $\sum_{i j}-$ & $r$ & - & - & - & - & - \\
\hline & $\sum_{i j} 0$ & - & - & - & - & - & - \\
\hline 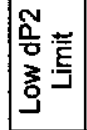 & 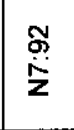 & 怘 & $\frac{0}{n}$ & 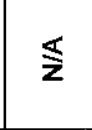 & 1 & $\frac{\widehat{s}}{\mathbf{z}}$ & 1 \\
\hline 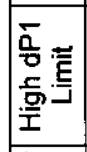 & $\begin{array}{l}\bar{\sigma} \\
\stackrel{5}{z}\end{array}$ & 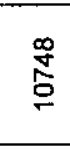 & \begin{tabular}{l}
$\infty$ \\
\multirow{2}{*}{} \\
0
\end{tabular} & $\underline{\mathbf{s}}$ & 1 & $\underline{\mathbf{z}}$ & 1 \\
\hline 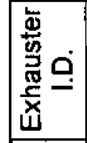 & 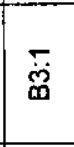 & $r$ & - & $\widehat{\Sigma}$ & 1 & $\frac{\tilde{x}}{\mathbf{z}}$ & 1 \\
\hline 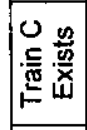 & 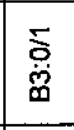 & 0 & 0 & 0 & 0 & - & - \\
\hline 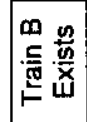 & $\begin{array}{l}\text { Oo } \\
\text { 弚 } \\
\end{array}$ & 0 & 0 & - & - & $r$ & - \\
\hline & & 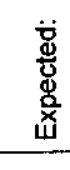 & $\begin{array}{l}\text { 产 } \\
\text { 焉 }\end{array}$ & 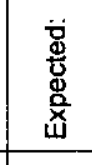 & 产 & 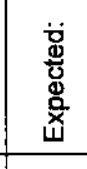 & 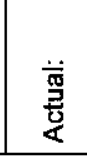 \\
\hline 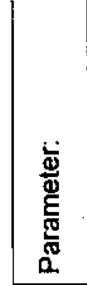 & 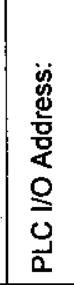 & & 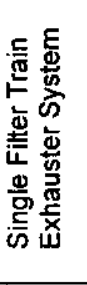 & 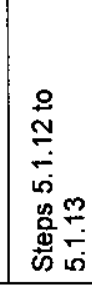 & 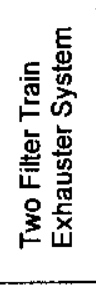 & 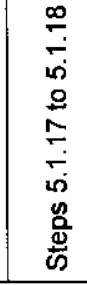 & 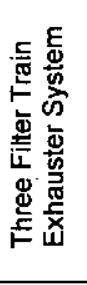 \\
\hline
\end{tabular}




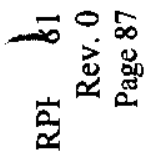

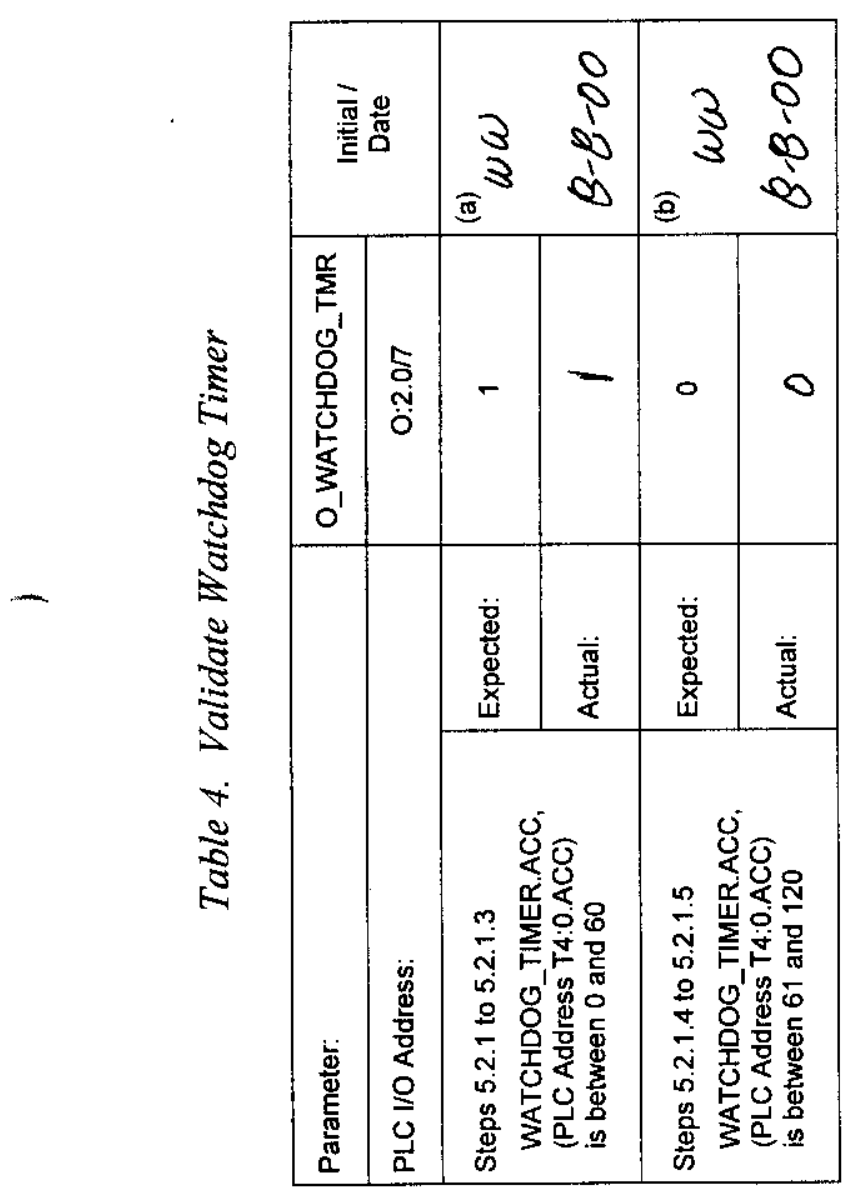




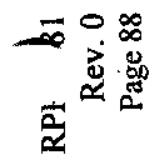

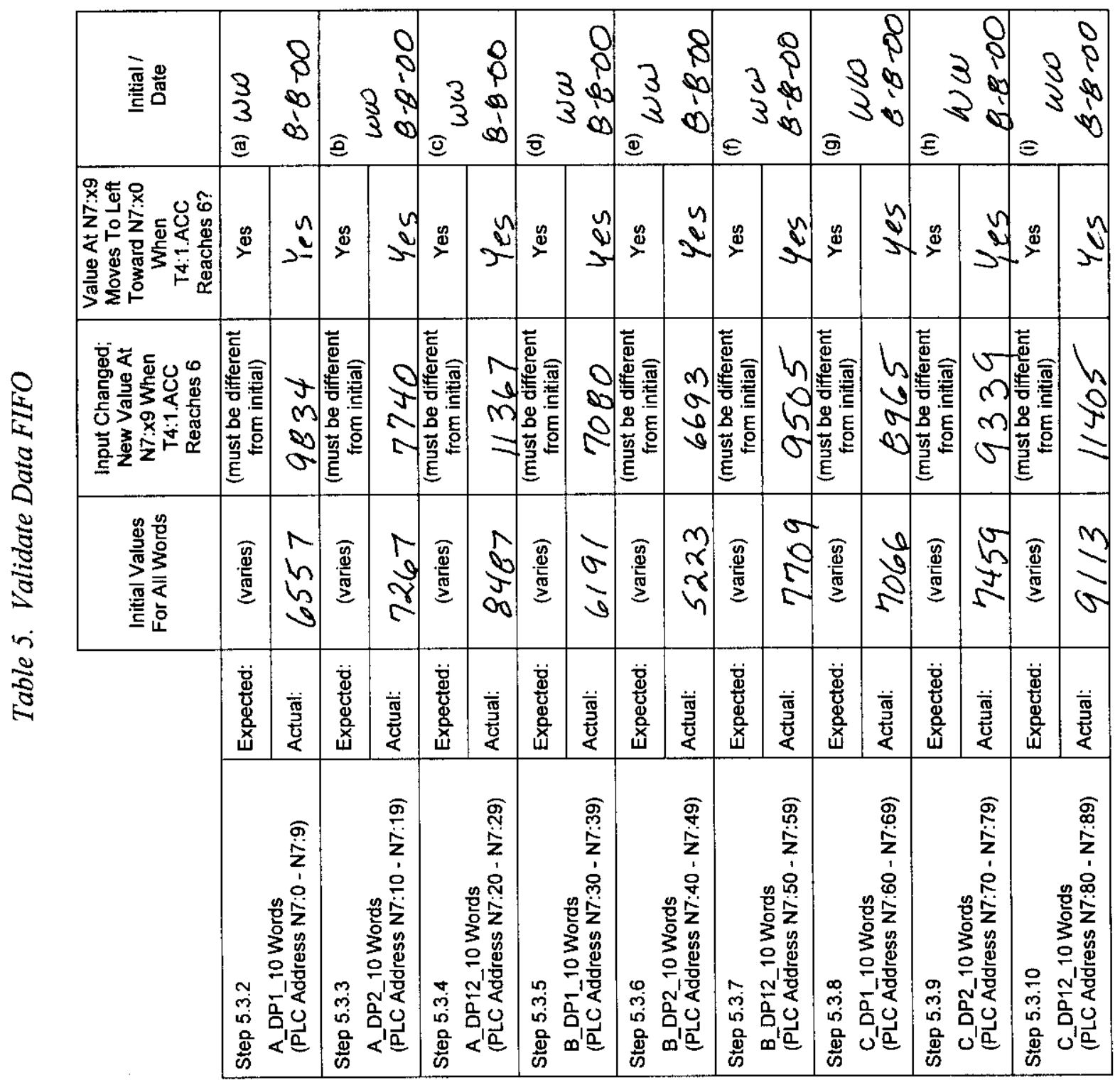




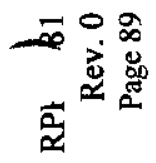

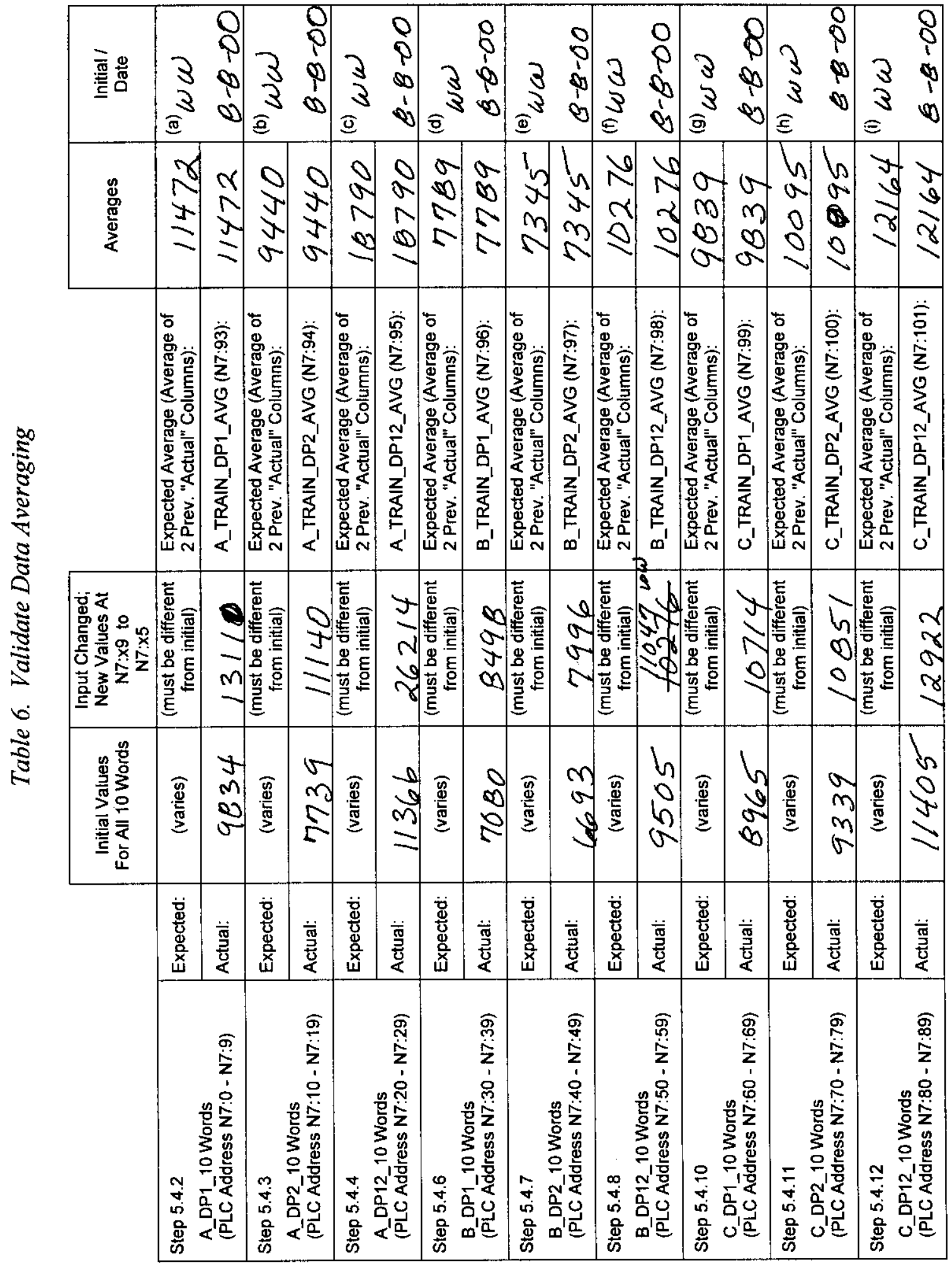




\begin{tabular}{|c|c|c|c|c|c|c|c|c|c|c|c|c|c|c|c|c|c|}
\hline \multicolumn{2}{|c|}{ 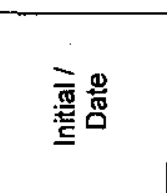 } & \multicolumn{2}{|c|}{$\left|\begin{array}{cc} & 8 \\
3 & 0 \\
3 & 0 \\
\sqrt[3]{3} & 0\end{array}\right|$} & \multicolumn{2}{|c|}{$\begin{array}{r}-39 \\
8 \\
30 \\
3 \\
3\end{array}$} & \multicolumn{2}{|c|}{$\mid \begin{array}{rr}0 \\
3 & 0 \\
3 & 0 \\
0 & 0\end{array}$} & \multicolumn{2}{|c|}{$\begin{array}{rr}8 \\
3 & 0 \\
3 & 1 \\
0 & 0 \\
0\end{array}$} & \multicolumn{2}{|c|}{$\left|\begin{array}{rr}0 \\
8 \\
3 & 0 \\
3 & 0 \\
3 & 0\end{array}\right|$} & \multicolumn{2}{|c|}{$\begin{array}{rr} & 6 \\
3 & 0 \\
3 & 0 \\
9 & 0\end{array}$} & \multicolumn{2}{|c|}{ 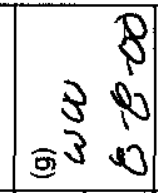 } & \\
\hline 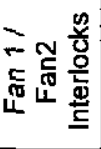 & 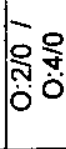 & - & $\doteq$ & $=$ & $\Sigma$ & $=$ & \pm & $=$ & $\searrow$ & $=$ & $\searrow$ & $=$ & $\approx$ & $=$ & 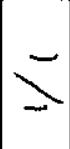 & $\Xi$ & \\
\hline 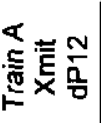 & ชิ & - & - & 0 & 0 & - & $\sim$ & 0 & 0 & - & $\sim$ & 0 & 0 & $1-$ & $\rightarrow$ & 0 & \\
\hline 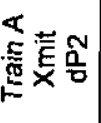 & ญิ & $r$ & - & 0 & 0 & - & $\sim$ & 0 & 0 & - & & 0 & 0 & $1-$ & - & 0 & \\
\hline$\frac{5}{6}$ & ๙ే & - & $\sim$ & 0 & 0 & $1-$ & - & 0 & 0 & - & 7 & 0 & $\theta$ & $1-$ & $\rightarrow$ & 0 & \\
\hline 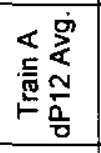 & 哭 & $\overline{\mathrm{Q}}$ & $\begin{array}{l}0 \\
0 \\
6 \\
\text { ry } \\
\end{array}$ & $\frac{\mathbf{s}}{\mathbf{z}}$ & 1 & $\mathbf{\Sigma}$ & 1 & 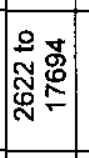 & $\begin{array}{l}0 \\
0 \\
0 \\
0\end{array}$ & 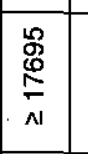 & $\begin{array}{l}m \\
\text { Dे } \\
\text { m }\end{array}$ & $\frac{\overleftarrow{z}}{\mathbf{z}}$ & 1 & $\underline{\underline{z}}$ & 1 & 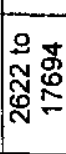 & \\
\hline 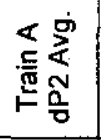 & 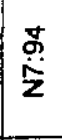 & ণ্ণ్ & $\begin{array}{l}\infty \\
m>s \\
m\end{array}$ & & 1 & $\mathbf{z}$ & 1 & 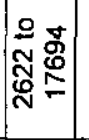 & $\begin{array}{l}\hat{m} \\
\dot{y} \\
\nabla\end{array}$ & 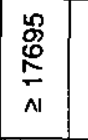 & 8 & $\frac{5}{z}$ & 1 & $\underline{\underline{z}}$ & 1 & 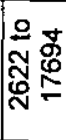 & \\
\hline 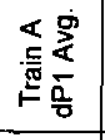 & ڤ̊. & 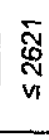 & $\mathrm{T}$ & $\underline{\mathbf{z}}$ & 1 & $\mathbf{z}$ & 1 & 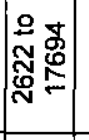 & $\begin{array}{l}\hat{n} \\
\hat{s}\end{array}$ & 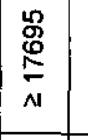 & जै & $\hat{\mathbf{s}}$ & 1 & $\frac{1}{z}$ & 1 & 总总 & \\
\hline 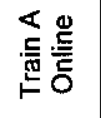 & $\stackrel{ \pm}{\Xi}$ & 0 & 0 & $\frac{\mathbf{s}}{\mathbf{z}}$ & 1 & $\mathbf{z}$ & 1 & $\overleftarrow{\mathbf{z}}$ & 1 & $\frac{\mathbf{s}}{\mathbf{z}}$ & 1 & $\underline{\mathbf{z}}$ & 1 & $z$ & 1 & $\frac{\Sigma}{z}$ & \\
\hline 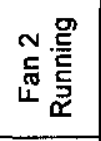 & 5 & 0 & 0 & $\underline{\mathbf{z}}$ & 1 & $\mathbf{s}$ & 1 & $\underline{\underline{z}}$ & 1 & $\underline{\mathbf{s}}$ & 1 & $\frac{\kappa}{z}$ & 1 & $\underline{\mathbf{s}}$ & 1 & $\frac{\mathbf{s}}{\mathbf{z}}$ & \\
\hline 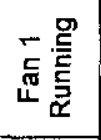 & 1 & 0 & $\theta$ & $\frac{5}{z}$ & 1 & $\frac{s}{z}$ & 1 & $\underline{\underline{z}}$ & 1 & $\frac{5}{z}$ & 1 & $\underline{\mathbf{s}}$ & 1 & $\underline{\mathbf{s}}$ & 1 & $\frac{s}{z}$ & \\
\hline & & $\begin{array}{l}\dot{8} \\
\mathbf{q} \\
\mathbf{q} \\
\square\end{array}$ & 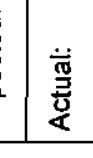 & 总 & 離 & 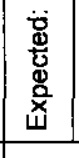 & 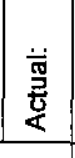 & 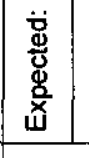 & 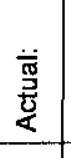 & 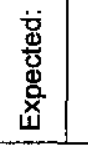 & 离 & 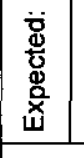 & 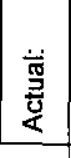 & 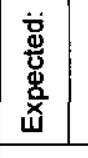 & 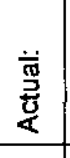 & 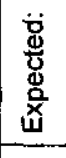 & 要 \\
\hline 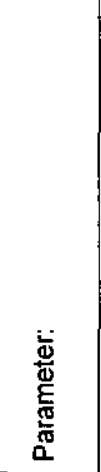 & 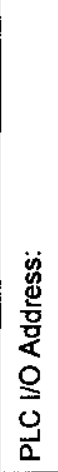 & & 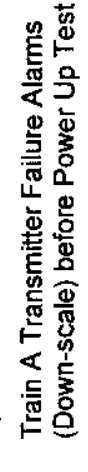 & & 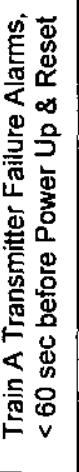 & 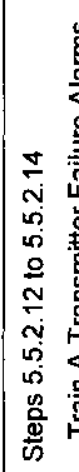 & 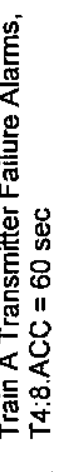 & 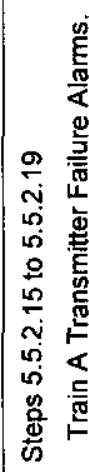 & 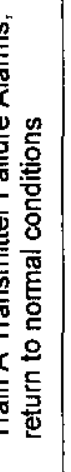 & 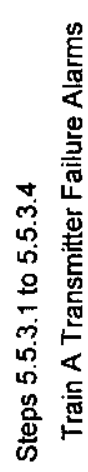 & 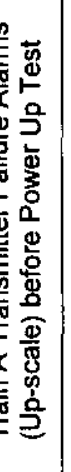 & 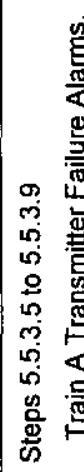 & 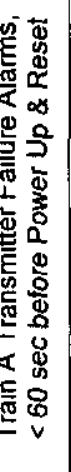 & 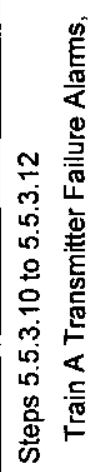 & 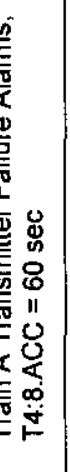 & 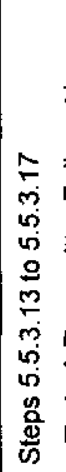 & 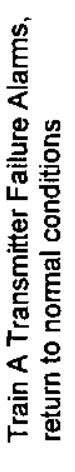 \\
\hline
\end{tabular}




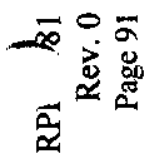

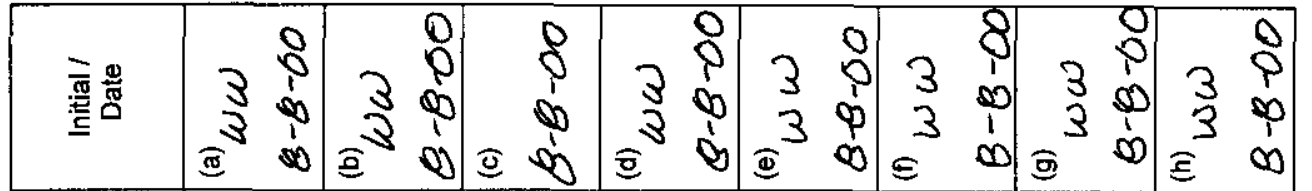

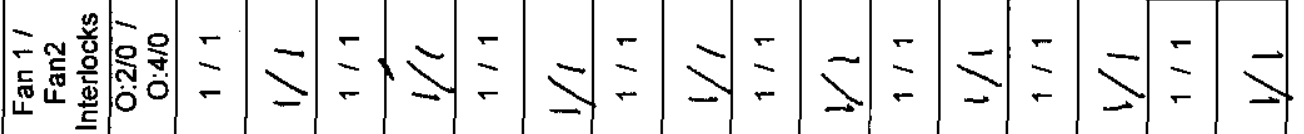

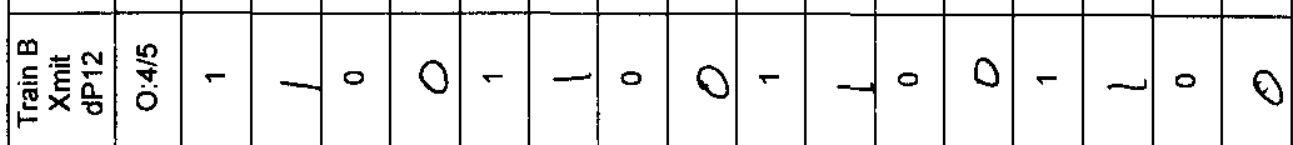



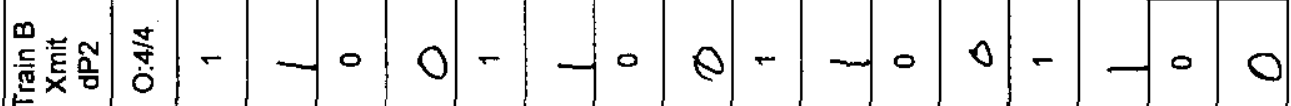

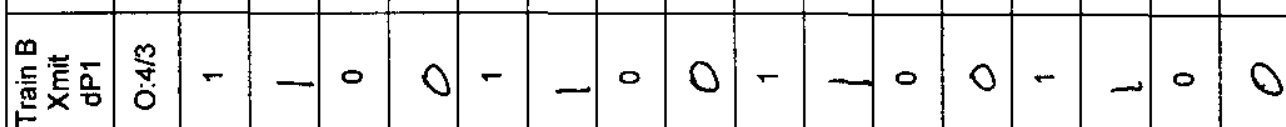

m商

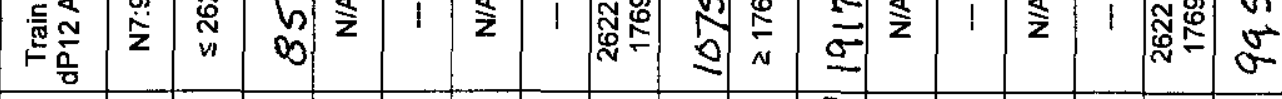

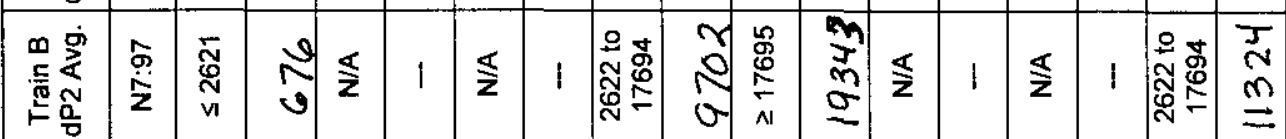

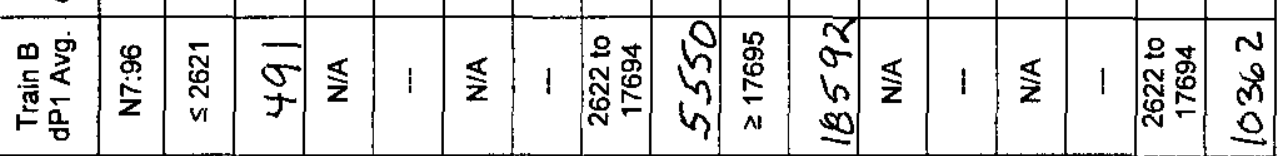

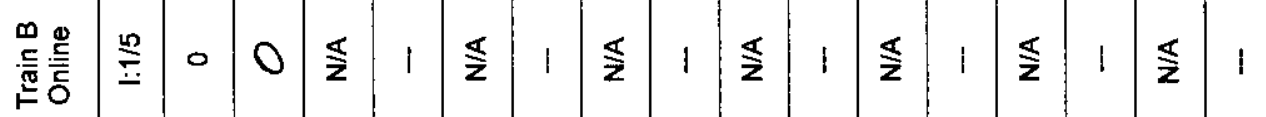

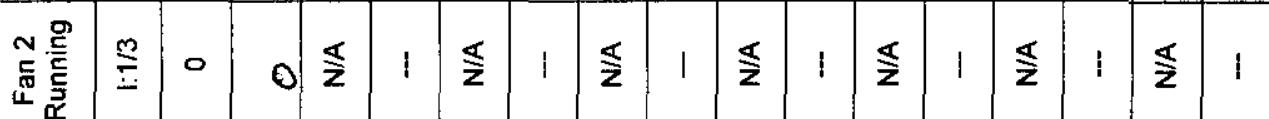

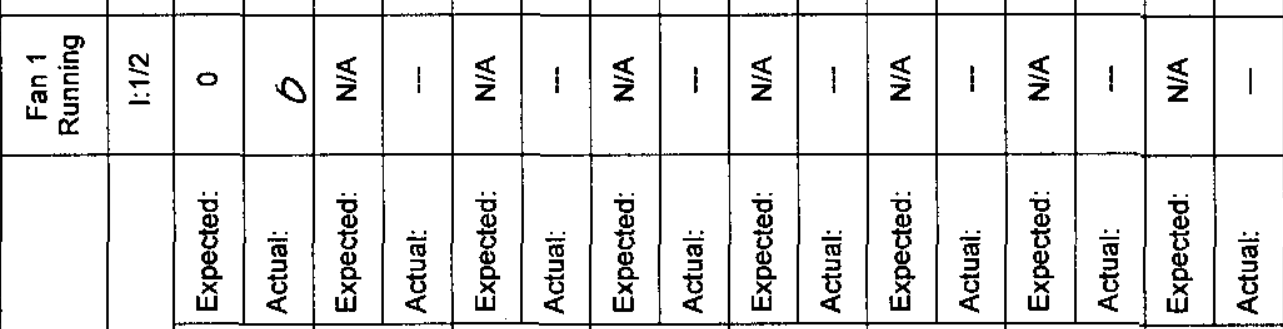

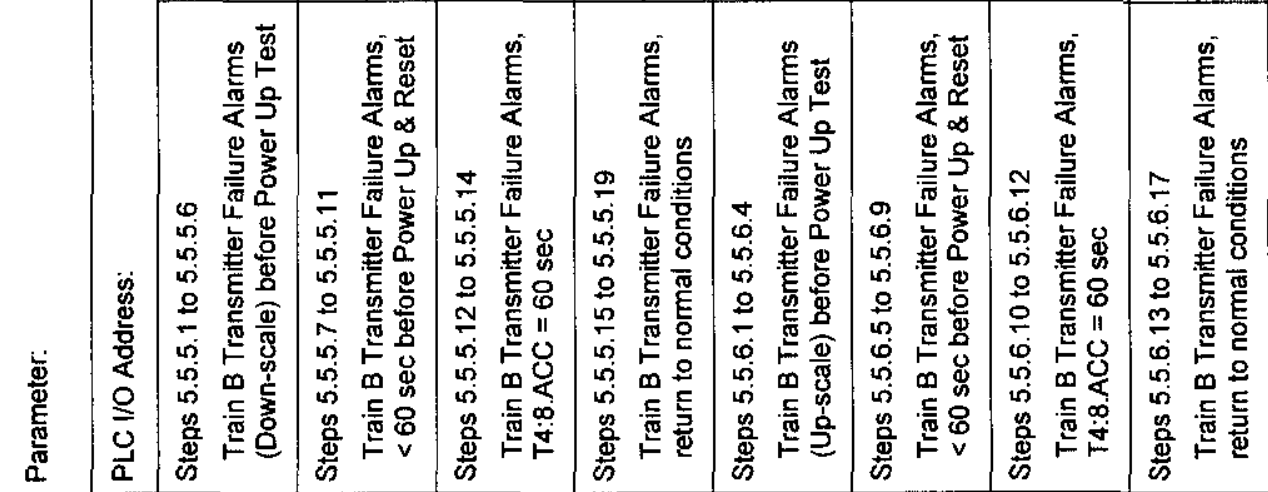




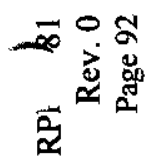

\begin{tabular}{|c|c|c|c|c|c|c|c|c|c|c|c|c|c|c|c|c|c|c|c|}
\hline \multicolumn{2}{|c|}{ 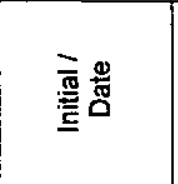 } & \multicolumn{2}{|c|}{$\begin{array}{|cc|} & 0 \\
3 & 9 \\
3 & 0 \\
3 & 1 \\
\text { त } & 0 \\
\end{array}$} & \multicolumn{2}{|c|}{$\begin{array}{ll} & 8 \\
3 & 0 \\
3 & 0 \\
3 & 0\end{array}$} & \multicolumn{2}{|c|}{$\begin{array}{cc} & 0 \\
3 & 9 \\
3 & 0 \\
0 & 0\end{array}$} & \multicolumn{3}{|c|}{$\begin{array}{r}38 \\
30 \\
30 \\
0 \quad 0\end{array}$} & \multicolumn{2}{|c|}{$\begin{array}{rr} & 0 \\
3 & 0 \\
3 & 0 \\
0 & 0 \\
0 & 0\end{array}$} & \multicolumn{2}{|c|}{$\mid \begin{array}{rr} & 0 \\
3 & 0 \\
3 & 0 \\
\varepsilon & 0\end{array}$} & \multicolumn{3}{|c|}{$\begin{array}{rr} & 8 \\
3 & 0 \\
3 & 0 \\
3 & 0\end{array}$} & \multicolumn{2}{|c|}{$\begin{array}{ll}3 & 8 \\
3 & 0 \\
3 & 0\end{array}$} \\
\hline 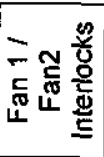 & ن & $=$ & $\searrow$ & $=$ & $\Sigma$ & $=$ & $\Sigma$ & & $=$ & 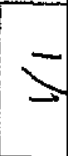 & $=$ & 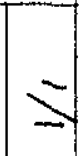 & $=$ & $\Sigma$ & 7 & $=$ & & $=$ & $\beth$ \\
\hline 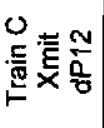 & \begin{tabular}{|l} 
\\
0 \\
60 \\
0
\end{tabular} & - & $\rightarrow$ & 0 & 0 & - & - & & 0 & 0 & - & - & 0 & 0 & 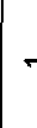 & - & & 0 & $\alpha$ \\
\hline 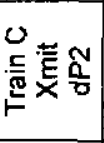 & 蒙 & - & - & 0 & 0 & - & - & & 0 & 0 & - & $\rightarrow$ & 0 & 0 & 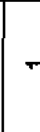 & - & & 0 & 0 \\
\hline 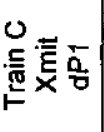 & ర0 & - & - & 0 & 0 & $r$ & - & & 0 & 0 & - & - & 0 & 0 & 7 & - & & 0 & 0 \\
\hline 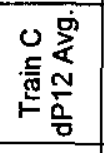 & $\frac{\bar{\sigma}}{\overline{\grave{z}}}$ & 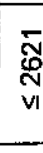 & $\stackrel{0}{m}$ & 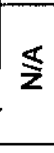 & 1 & $\widehat{\mathbf{z}}$ & 1 & & 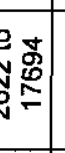 & 5 & $\frac{\stackrel{2}{8}}{8}$ & $\begin{array}{l}m \\
r \\
0 \\
0\end{array}$ & 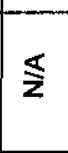 & 1 & $\bar{z}$ & 1 & & 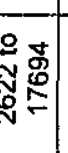 & \\
\hline 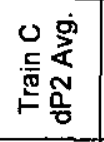 & $\frac{8}{\dot{\bar{z}}}$ & $\begin{array}{l}\overline{\overbrace ్ d ్} \\
\text { v }\end{array}$ & $\frac{\pi}{n}$ & $\frac{\pi}{z}$ & 1 & 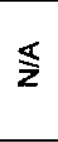 & 1 & & 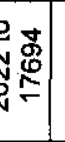 & $\frac{1}{n}$ & $\frac{2}{2}$ & 可 & 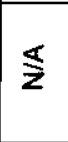 & 1 & $z$ & 1 & & 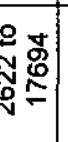 & \\
\hline 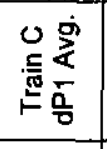 & \begin{tabular}{|l|} 
\\
$\stackrel{g}{\hat{~}}$ \\
\end{tabular} & 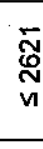 & $\frac{I}{\theta}$ & $\overleftarrow{\mathbf{z}}$ & 1 & $\mathbb{\mathbf { z }}$ & 1 & & 送: & $\begin{array}{l}0 \\
0 \\
0 \\
0\end{array}$ & 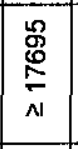 & $\begin{array}{l}n \\
\sigma \\
\sigma\end{array}$ & $\lesssim$ & 1 & $\bar{z}$ & 1 & & 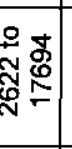 & $\begin{array}{l}\sigma \\
\sigma \\
\vdots \\
0\end{array}$ \\
\hline 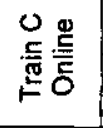 & $\stackrel{\mathscr{O}}{ \pm}$ & 0 & 0 & $\stackrel{\S}{\mathbf{z}}$ & I & $\overleftarrow{\mathbf{z}}$ & 1 & & $\overleftarrow{z}$ & 1 & $\S$ & I & 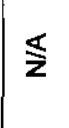 & 1 & z & 1 & & 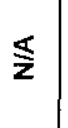 & 1 \\
\hline 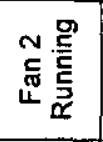 & $\stackrel{m}{I}$ & 0 & 0 & $\widehat{\mathbf{z}}$ & 1 & $\stackrel{\mathbf{z}}{\mathbf{z}}$ & 1 & & $\S$ & 1 & $\overleftarrow{\mathbf{z}}$ & 1 & $\S$ & 1 & $\bar{z}$ & 1 & & 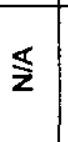 & 1 \\
\hline 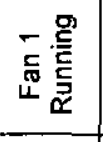 & $\stackrel{N}{I}$ & 0 & 0 & 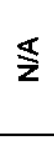 & 1 & $\frac{\kappa}{\mathbf{z}}$ & 1 & & 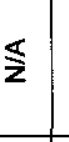 & i & $\frac{\kappa}{\mathbf{z}}$ & 1 & $\widehat{s}$ & 1 & z & 1 & & $\widehat{\underline{\mathbf{z}}}$ & 1 \\
\hline & & 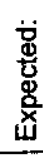 & $\begin{array}{l}\frac{1}{\mathrm{M}} \\
\text { 娄 } \\
\end{array}$ & 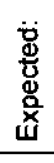 & 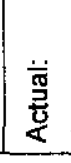 & 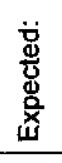 & 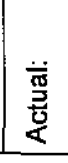 & & 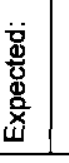 & 离 & 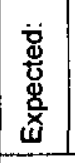 & 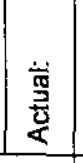 & 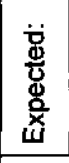 & 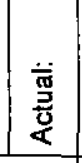 & & $\begin{array}{l}\text { 产 } \\
\frac{\vec{z}}{\mathrm{e}} \\
\end{array}$ & & 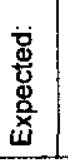 & 离 \\
\hline 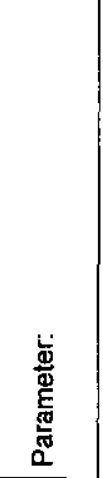 & 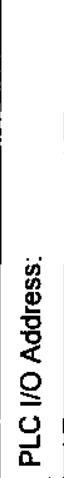 & 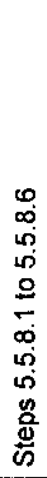 & 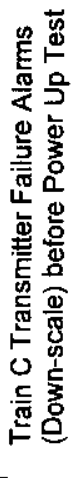 & 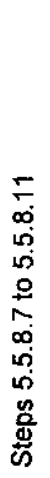 & 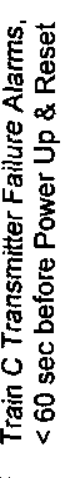 & 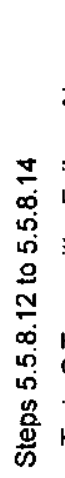 & 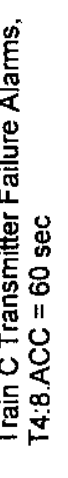 & & 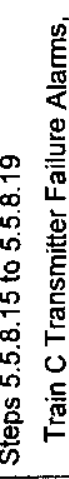 & 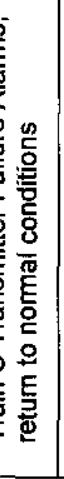 & 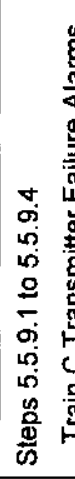 & 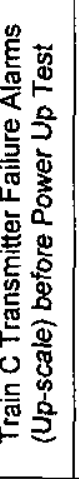 & 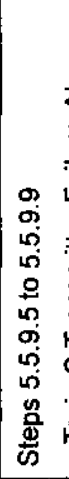 & 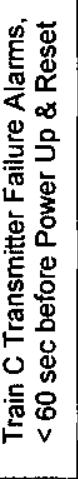 & & 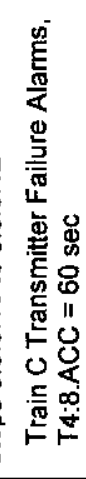 & & 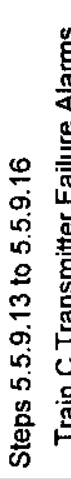 & 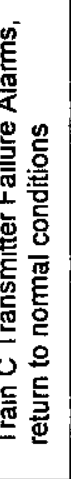 \\
\hline
\end{tabular}




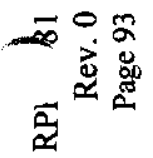

\begin{tabular}{|c|c|c|c|c|c|c|c|c|c|c|c|c|c|c|c|c|c|}
\hline \multicolumn{2}{|c|}{ 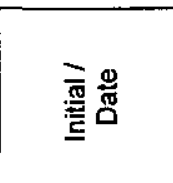 } & \multicolumn{2}{|c|}{$\begin{array}{ll}3 & 8 \\
3 & 1 \\
0 & \infty\end{array}$} & \multicolumn{2}{|c|}{$\begin{array}{cc}3 & 8 \\
3 & 0 \\
3 & 0 \\
3 & 0\end{array}$} & $\int_{0}^{0} 3$ & $\begin{array}{l}0 \\
0 \\
0 \\
0 \\
0\end{array}$ & \multicolumn{2}{|c|}{ 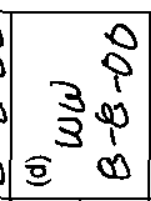 } & \multicolumn{2}{|c|}{ 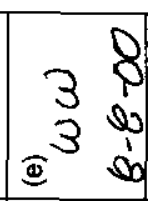 } & $\begin{array}{ll}3 & \\
3 & 3 \\
3 & 5\end{array}$ & $\begin{array}{l}0 \\
9 \\
0 \\
0\end{array}$ & \multicolumn{2}{|c|}{$\begin{array}{ll} & 0 \\
3 & 0 \\
3 & 0 \\
0 & 0\end{array}$} & \begin{tabular}{l|l}
0 & 5 \\
1 & 3 \\
1 & 3 \\
1 & 3 \\
0 & 3 \\
0
\end{tabular} & $\begin{array}{l}0 \\
0 \\
0\end{array}$ \\
\hline \multirow{2}{*}{ 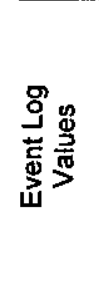 } & $\frac{\bar{N}}{\stackrel{\bar{N}}{\mathbf{N}}}$ & $\frac{\mathbf{x}}{\mathbf{z}}$ & 1 & $\S$ & 1 & 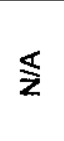 & 1 & $\begin{array}{l}\overline{\widetilde{d}} \\
\text { vin }\end{array}$ & 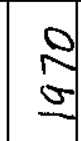 & $\S$ & 1 & 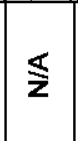 & 1 & 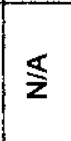 & 1 & $\begin{array}{l}\stackrel{0}{g} \\
\stackrel{9}{\circ} \\
\stackrel{N}{N}\end{array}$ & ڤે \\
\hline & 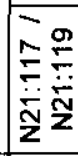 & $\frac{\pi}{z}$ & 1 & $\lesssim$ & 1 & $\widehat{\mathbf{z}}$ & 1 & 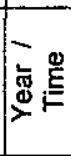 & $\begin{array}{l}1 \\
80 \\
0 \\
8 \% \\
\gamma\end{array}$ & $\frac{\Sigma}{\mathbf{z}}$ & 1 & $\widehat{\Sigma}$ & 1 & 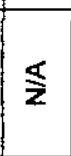 & 1 & 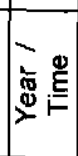 & $\begin{array}{l}8 \mathrm{x} \\
8 \% \\
\gamma^{\circ}\end{array}$ \\
\hline 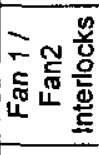 & 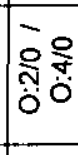 & $=$ & $\overline{-}$ & $\frac{0}{0}$ & $\frac{0}{0}$ & $=$ & 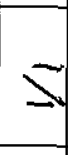 & $=$ & $\mp$ & $\bar{I}$ & $\approx$ & $\frac{0}{0}$ & 0 & $=$ & 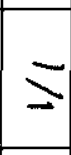 & $\equiv$ & $\rightarrow$ \\
\hline 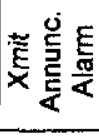 & 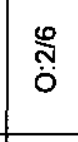 & 0 & 0 & - & - & 0 & 0 & 0 & 0 & 0 & 0 & - & - & 0 & 0 & 0 & 0 \\
\hline 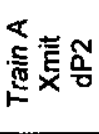 & 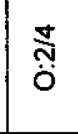 & 0 & 0 & 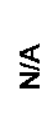 & 1 & $\widehat{\nwarrow}$ & 1 & 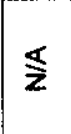 & 1 & 0 & 0 & $\S$ & 1 & $\frac{\varsigma}{z}$ & 1 & 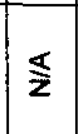 & 1 \\
\hline 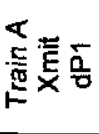 & 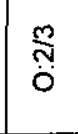 & 0 & 0 & $r$ & $\rightarrow$ & - & 7 & 0 & 0 & 0 & 0 & - & $\rightarrow$ & - & $\rightarrow$ & 0 & 0 \\
\hline 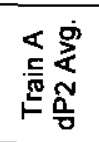 & 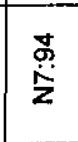 & 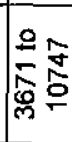 & $\begin{array}{l}0 \\
0 \\
7 \\
7\end{array}$ & 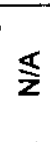 & 1 & 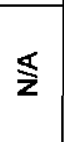 & 1 & $\$$ & 1 & 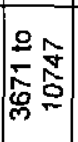 & 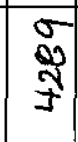 & 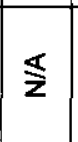 & 1 & 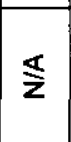 & 1 & $\frac{\pi}{z}$ & 1 \\
\hline 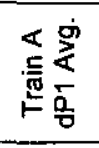 & $\begin{array}{l}\stackrel{\mathscr{S}}{\tilde{z}} \\
\text { zon }\end{array}$ & 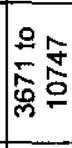 & $\hat{n}$ & $\begin{array}{l}\bar{N} \\
\underset{N}{N} \\
\text { vi }\end{array}$ & $J$ & 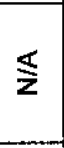 & 1 & 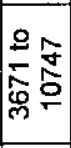 & $\begin{array}{l}n \\
6 \\
6\end{array}$ & 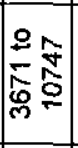 & $\begin{array}{l}n \\
n \\
b\end{array}$ & 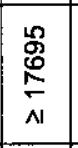 & $\begin{array}{l}0 \\
x \\
x \\
x\end{array}$ & $\lesssim$ & 1 & 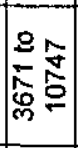 & $\begin{array}{l}n \\
\text { n } \\
\text { v }\end{array}$ \\
\hline 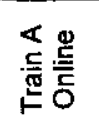 & $\stackrel{\Xi}{\Xi}$ & 0 & 0 & - & - & 0 & 0 & $\widehat{\Sigma}$ & 1 & 0 & 0 & - & - & 0 & 0 & $\S$ & 1 \\
\hline 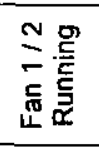 & $\stackrel{m}{=}$ & 0 & $\frac{0}{0}$ & $\underset{\mathbf{z}}{\mathbf{z}}$ & $\frac{1}{2}$ & $\frac{\$}{z}$ & $\frac{1}{0}$ & \begin{tabular}{|l|}
$\underline{z}$ \\
$\frac{\mathbf{s}}{\mathbf{z}}$ \\
\end{tabular} & $\frac{1}{1}$ & $\frac{0}{0}$ & $\begin{array}{l}0 \\
0\end{array}$ & $\frac{\Sigma}{\Sigma}$ & $\vec{i}$ & $\frac{0}{2}$ & $\frac{0}{1}$ & \begin{tabular}{|l|}
$\frac{5}{z}$ \\
$\frac{\mathbf{s}}{\mathbf{z}}$ \\
\end{tabular} & $\frac{1}{1}$ \\
\hline & & 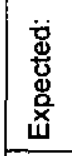 & 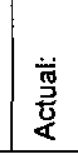 & 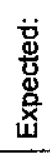 & 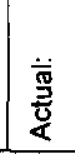 & 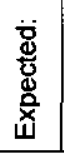 & 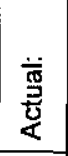 & 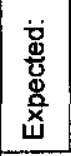 & $\begin{array}{l}\frac{1}{\bar{g}} \\
\frac{\vec{z}}{8}\end{array}$ & 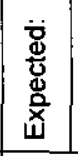 & 离 & 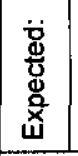 & 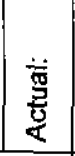 & 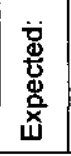 & 耪 & 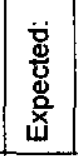 & 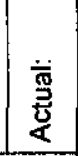 \\
\hline 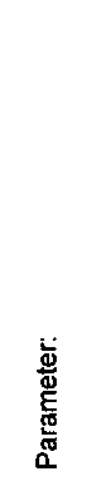 & 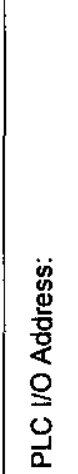 & 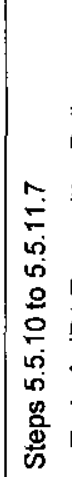 & 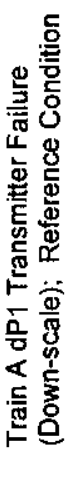 & 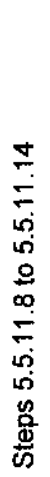 & 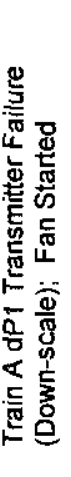 & 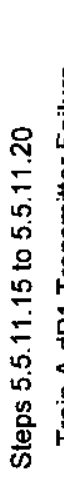 & 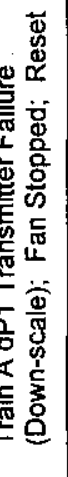 & 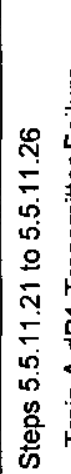 & 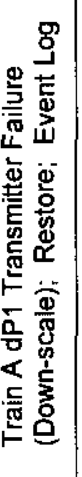 & 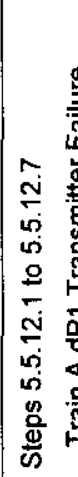 & 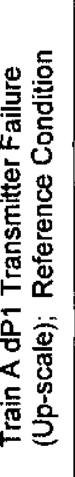 & 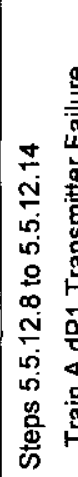 & 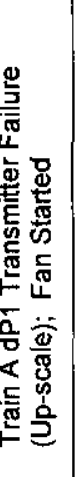 & 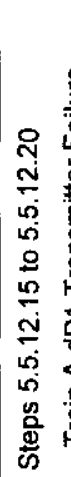 & 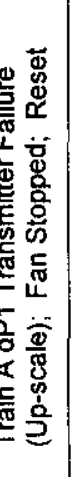 & 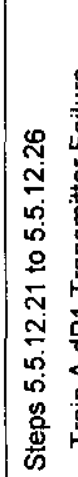 & 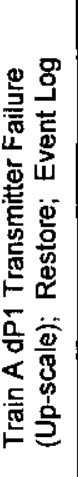 \\
\hline
\end{tabular}




\begin{tabular}{|c|c|c|c|c|c|c|c|c|c|c|c|c|c|c|c|c|c|}
\hline \multicolumn{2}{|c|}{ 产离 } & \multirow{2}{*}{$\frac{\frac{3}{3}}{\frac{3}{0}}$} & \multirow{2}{*}{$\begin{array}{l}8 \\
0 \\
0 \\
1\end{array}$} & \multicolumn{2}{|c|}{$\begin{array}{ll} & 8 \\
3 & 1 \\
3 & 1 \\
0 & 0\end{array}$} & \multicolumn{2}{|c|}{$\begin{array}{cc} & 0 \\
3 & 1 \\
3 & 1 \\
3 & 0\end{array}$} & \multicolumn{2}{|c|}{$\begin{array}{l}\frac{0}{3} \\
3 \\
3 \\
3\end{array}$} & \multicolumn{2}{|c|}{$\begin{array}{l}0 \\
0 \\
a \\
1 \\
0\end{array}$} & \multicolumn{2}{|c|}{\begin{tabular}{rr|} 
& 8 \\
3 & 1 \\
3 & 0 \\
0 & 1
\end{tabular}} & \multicolumn{2}{|c|}{$\mid \begin{array}{ll}3 & 0 \\
3 & 1 \\
3 & 1 \\
0 & 0\end{array}$} & \multicolumn{2}{|c|}{ 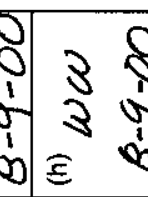 } \\
\hline \multirow{2}{*}{ 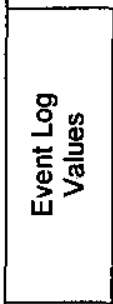 } & $\frac{\widetilde{N}}{\stackrel{\check{N}}{\mathbf{z}}}$ & & & 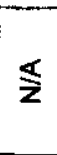 & 1 & $\widehat{\mathbf{z}}$ & I & $\begin{array}{l}\overline{\text { D్ }} \\
\text { vi }\end{array}$ & $\begin{array}{l}N \\
q \\
\gamma\end{array}$ & $\widehat{\mathbf{z}}$ & 1 & 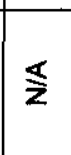 & I & $\frac{\pi}{\Sigma}$ & 1 & \begin{tabular}{|l|}
$\stackrel{2}{g}$ \\
$\stackrel{g}{\circ}$ \\
\end{tabular} & $\begin{array}{l}\forall \\
\ddot{n} \\
\text { है }\end{array}$ \\
\hline & $\frac{\overline{2}}{\frac{N}{2}}$ & $\S$ & 1 & $\widehat{\underline{z}}$ & 1 & $\widehat{\mathbf{z}}$ & 1 & 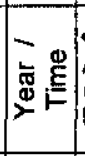 & $\begin{array}{l}0 \\
8 \\
8 \\
0\end{array}$ & 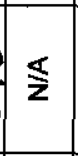 & 1 & 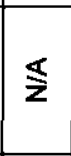 & 1 & $\widehat{\mathbf{s}}$ & 1 & 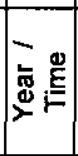 & $\begin{array}{l}0 \\
0 \\
0 \\
8 \\
\gamma \\
\gamma\end{array}$ \\
\hline 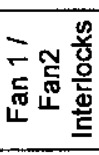 & ํํㅇ & $=$ & $\simeq$ & $\frac{0}{0}$ & $\frac{0}{0}$ & $=$ & 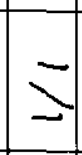 & $=$ & $\searrow$ & $=$ & 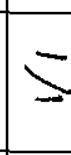 & $\frac{0}{0}$ & $\frac{0}{\Delta}$ & $=$ & 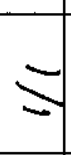 & $=$ & 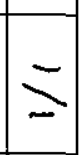 \\
\hline 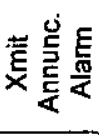 & 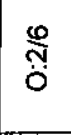 & 0 & 0 & - & - & 0 & 0 & 0 & 0 & 0 & 0 & - & ــ & 0 & $\mathrm{c}$ & 0 & 0 \\
\hline 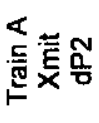 & 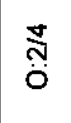 & 0 & 0 & $r$ & $\rightarrow$ & - & - & 0 & 0 & 0 & 0 & $r$ & - & - & - & 0 & 0 \\
\hline 乓䓂 & 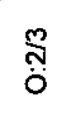 & 0 & 0 & 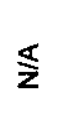 & 1 & $\S$ & 1 & $\overleftarrow{\mathbf{z}}$ & 1 & 0 & 0 & 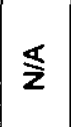 & 1 & 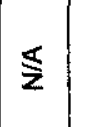 & 1 & $\widehat{\Sigma}$ & 1 \\
\hline 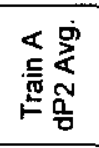 & 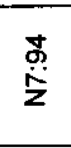 & 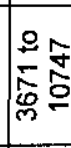 & $\begin{array}{l}m \\
8 \\
8\end{array}$ & $\begin{array}{l}\overline{\widetilde{N}} \\
\text { vi } \\
\text { vi }\end{array}$ & $\begin{array}{l}n \\
\infty \\
\infty\end{array}$ & $\overleftarrow{\mathbf{z}}$ & 1 & 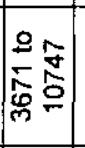 & $\begin{array}{l}\sigma \\
n \\
n \\
h\end{array}$ & 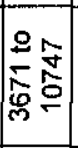 & $\begin{array}{l}0 \\
n \\
h \\
n\end{array}$ & 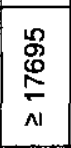 & 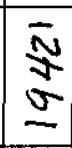 & $\widehat{\mathbf{z}}$ & 1 & 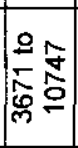 & $\begin{array}{c}\infty \\
0 \\
0\end{array}$ \\
\hline 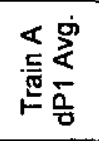 & 涡 & 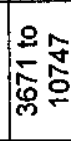 & $\begin{array}{l}n \\
h \\
v\end{array}$ & $\underset{\mathbf{z}}{\boldsymbol{z}}$ & 1 & $\widehat{\mathbf{z}}$ & 1 & $\widehat{s}$ & 1 & 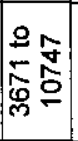 & $\begin{array}{l}n \\
n \\
b\end{array}$ & $\leqslant$ & 1 & $\S$ & 1 & 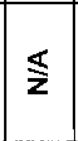 & 1 \\
\hline 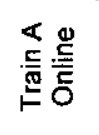 & $\stackrel{\Xi}{\Xi}$ & 0 & $D$ & - & - & 0 & 0 & $\widehat{\underline{z}}$ & I & 0 & 0 & - & - & 0 & 0 & $\S$ & 1 \\
\hline 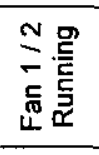 & $\stackrel{m}{=}$ & $\frac{0}{0}$ & $\frac{0}{0}$ & $\frac{5}{z}$ & $1=$ & $\begin{array}{l}\mathbf{s} \\
\mathbf{z} \\
\end{array}$ & $\frac{1}{0}$ & $\begin{array}{l}\frac{1}{z} \\
\frac{5}{z} \\
\end{array}$ & $\frac{1}{1}$ & $\frac{0}{0}$ & $\frac{0}{0}$ & $\frac{5}{z}$ & $\overline{1}$ & $\frac{0}{2}$ & $\frac{0}{1}$ & $\frac{5}{z}$ & $\frac{1}{1}$ \\
\hline & & 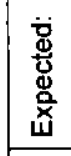 & 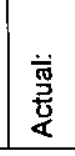 & 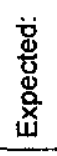 & 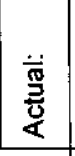 & 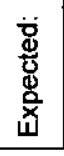 & 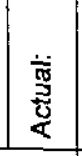 & $\begin{array}{l}\ddot{g} \\
\dot{y} \\
\mathrm{~d} \\
\underline{0} \\
\dot{x} \\
\end{array}$ & 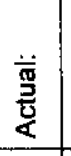 & 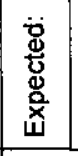 & 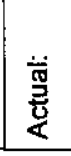 & 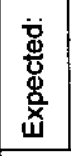 & 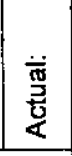 & 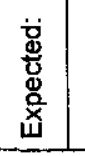 & $\begin{array}{l}\text { 产 } \\
\text { 丵 }\end{array}$ & 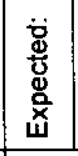 & 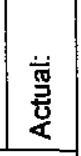 \\
\hline 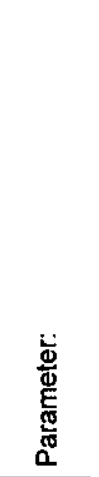 & 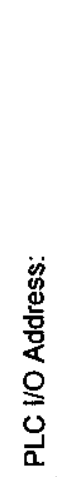 & 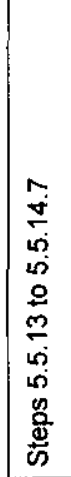 & 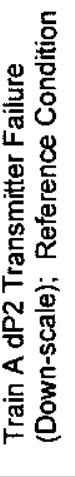 & 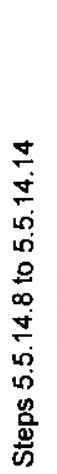 & 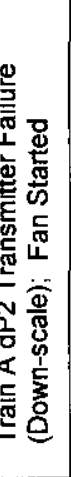 & 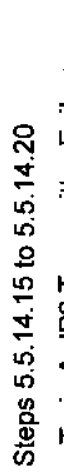 & 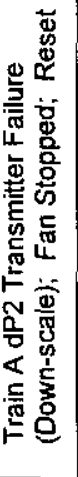 & 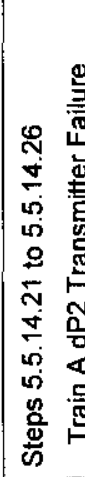 & 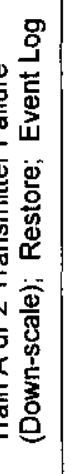 & 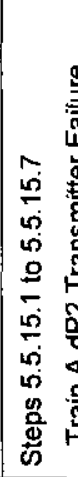 & 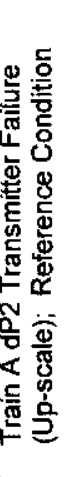 & 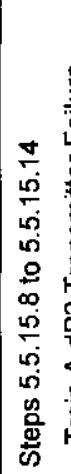 & 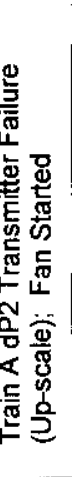 & 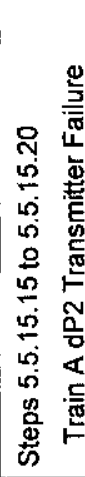 & 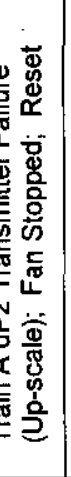 & 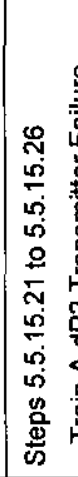 & 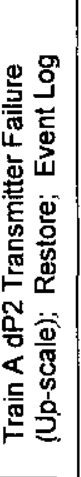 \\
\hline
\end{tabular}




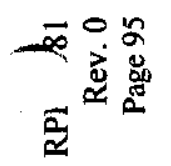

\begin{tabular}{|c|c|c|c|c|c|c|c|c|c|c|c|c|c|c|c|c|c|}
\hline \multicolumn{2}{|c|}{ 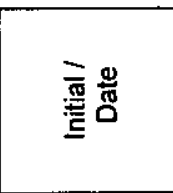 } & \multicolumn{2}{|c|}{$\mid \begin{array}{ll} & 0 \\
3 & 9 \\
3 & 0 \\
0 & 0\end{array}$} & \multicolumn{2}{|c|}{$\begin{array}{r}3 x \\
39 \\
3 \quad 0\end{array}$} & \begin{tabular}{l|l}
0 & 0 \\
0 & 5 \\
1 & 1 \\
1 & 0 \\
0 & 0
\end{tabular} & $\begin{array}{ll}3 & 8 \\
3 & 9 \\
3 & 0 \\
0 & 0\end{array}$ & $\begin{array}{ll}8 \\
1 \\
0 \\
0 \\
0\end{array}$ & $\begin{array}{ll}3 & 8 \\
3 & 5 \\
0 & 0\end{array}$ & \multicolumn{2}{|c|}{ 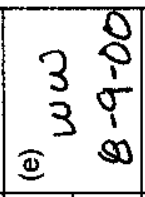 } & \multicolumn{2}{|c|}{$\begin{array}{ll}3 & 8 \\
3 & 0 \\
\varepsilon & \infty\end{array}$} & \multicolumn{2}{|c|}{$\left|\begin{array}{rr}3 & 9 \\
3 & 9 \\
0 & 0\end{array}\right|$} & \multicolumn{2}{|c|}{$\begin{array}{rr}0 \\
3 & 0 \\
3 & 5 \\
3 & 0\end{array}$} \\
\hline 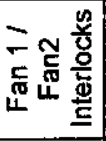 & कृ & $\Xi$ & $\mp$ & $=$ & $\overline{ }$ & $=$ & $\checkmark$ & $=$ & $\bar{z}$ & $=$ & - & $=$ & $\bar{\nu}$ & $=$ & 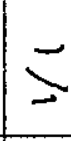 & $=$ & 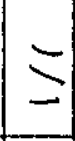 \\
\hline 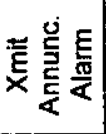 & กั & 0 & 0 & 0 & 0 & 0 & 0 & 0 & 0 & 0 & 0 & 0 & 0 & 0 & 0 & 0 & 0 \\
\hline 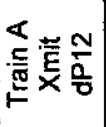 & ָั & 0 & 0 & - & $\rightarrow$ & - & - & 0 & 0 & 0 & 0 & - & - & - & $\sim$ & 0 & 0 \\
\hline 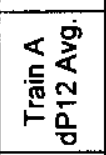 & $\begin{array}{l}\stackrel{\leftrightarrow}{\rho} \\
\tilde{\mathbf{z}}\end{array}$ & 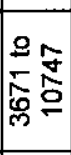 & 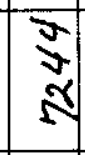 & 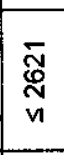 & $\stackrel{0}{5}$ & 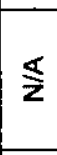 & 1 & $\begin{array}{l}\frac{9}{2} \\
\overline{\hat{N}} \\
\underline{0}\end{array}$ & $\begin{array}{l}8 \\
5 \\
4\end{array}$ & 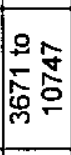 & $\begin{array}{l}\tilde{n} \\
\dot{\gamma} \\
\end{array}$ & $\frac{\mathscr{O}}{8}$ & $\begin{array}{l}n \\
1 \\
0 \\
0\end{array}$ & 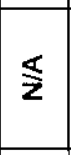 & I & 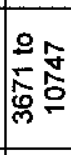 & $\begin{array}{l}\infty \\
2\end{array}$ \\
\hline 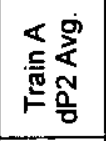 & 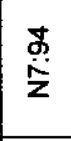 & 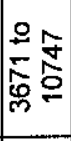 & $\begin{array}{l}\infty \\
0 \\
0\end{array}$ & $\S$ & 1 & 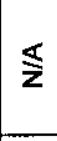 & 1 & $\S$ & 1 & 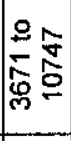 & $\begin{array}{l}\infty \\
0 \\
02\end{array}$ & 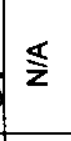 & 1 & $\overleftarrow{\mathbf{z}}$ & 1 & $\widehat{\varsigma}$ & 1 \\
\hline 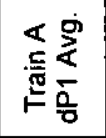 & 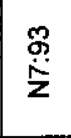 & $\begin{array}{l}2 \\
\frac{2}{5} \\
\frac{5}{0} \\
0 \\
0\end{array}$ & $\begin{array}{l}5 \\
5 \\
\sigma\end{array}$ & $\$$ & 1 & 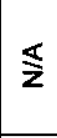 & 1 & $\widehat{\S}$ & 1 & 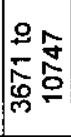 & $\begin{array}{l}n \\
\tilde{n} \\
\xi\end{array}$ & $\leqslant$ & 1 & $\stackrel{\varsigma}{\mathbf{z}}$ & 1 & 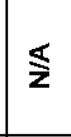 & 1 \\
\hline 造 & $\stackrel{ \pm}{\Xi}$ & 0 & 0 & - & - & 0 & $D$ & $\S$ & 1 & 0 & 0 & - & - & 0 & 0 & $\overleftarrow{\mathbf{z}}$ & 1 \\
\hline 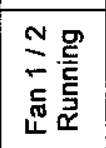 & $\stackrel{2}{=}$ & $\frac{0}{0}$ & $\begin{array}{l}0 \\
0\end{array}$ & $\frac{5}{\mathbf{z}}$ & $\frac{1}{-}$ & $\frac{\$}{\mathbf{z}}$ & $\frac{1}{0}$ & $\frac{\nwarrow}{z}$ & $\frac{1}{1}$ & $\frac{0}{0}$ & $\frac{0}{0}$ & $\frac{\bar{z}}{\mathbf{z}}$ & $\overline{1}$ & $\begin{array}{l}0 \\
\frac{1}{z}\end{array}$ & $\frac{0}{1}$ & $\begin{array}{l}\frac{5}{z} \\
\frac{5}{z}\end{array}$ & $\frac{1}{1}$ \\
\hline & & 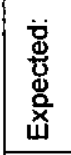 & 离 & 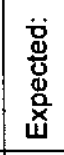 & 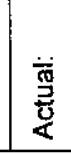 & 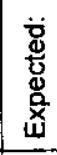 & 薆 & 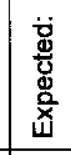 & 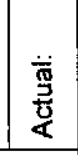 & 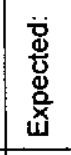 & 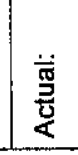 & 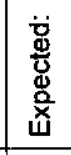 & 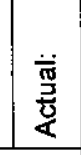 & 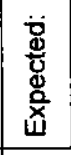 & 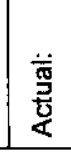 & 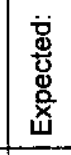 & 离 \\
\hline 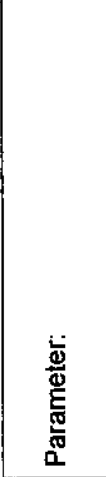 & 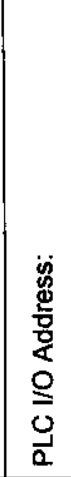 & 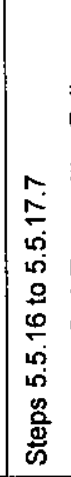 & 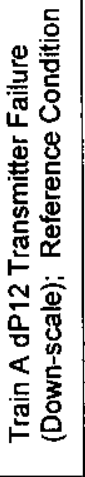 & 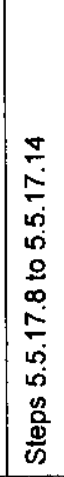 & 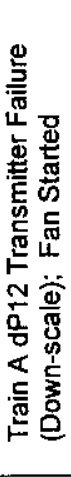 & 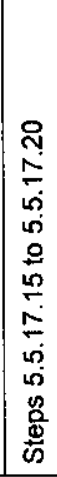 & 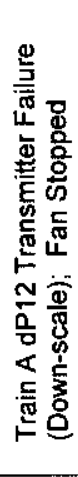 & 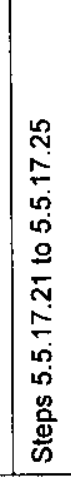 & 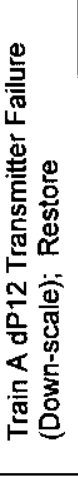 & 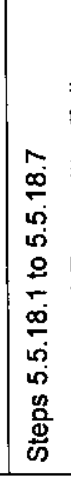 & 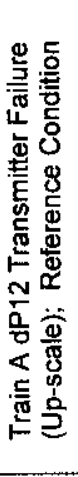 & 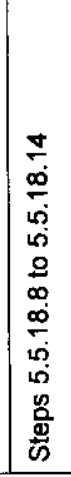 & 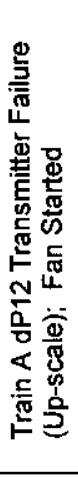 & 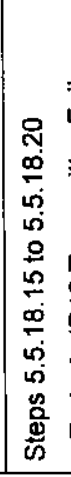 & 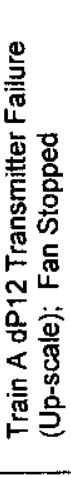 & 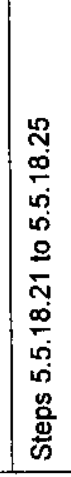 & 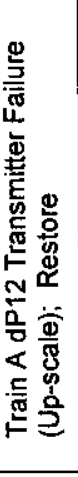 \\
\hline
\end{tabular}




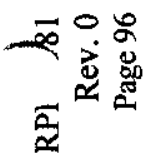

\begin{tabular}{|c|c|c|c|c|c|c|c|c|c|c|c|c|c|c|c|c|c|}
\hline \multicolumn{2}{|c|}{ 总 } & $\begin{array}{r}3 \\
3 \\
\text { న }\end{array}$ & $\begin{array}{l}8 \\
\sigma \\
1 \\
50\end{array}$ & $\frac{3}{3}$ & $\begin{array}{l}0 \\
0 \\
0 \\
1 \\
0\end{array}$ & $\begin{array}{l}3 \\
3 \\
0\end{array}$ & $\begin{array}{l}0 \\
0 \\
0 \\
1 \\
8\end{array}$ & $\begin{array}{c}3 \\
3 \\
5\end{array}$ & $\begin{array}{l}8 \\
8 \\
\sigma \\
50\end{array}$ & $\begin{array}{c}3 \\
3 \\
0\end{array}$ & $\begin{array}{l}0 \\
0 \\
\sigma \\
1 \\
0\end{array}$ & $\begin{array}{c}3 \\
6\end{array}$ & $\begin{array}{l}0 \\
9 \\
1 \\
1 \\
0\end{array}$ & $\begin{array}{l}3 \\
3 \\
0\end{array}$ & $\begin{array}{l}8 \\
1 \\
1 \\
1 \\
00\end{array}$ & 阜 & $\begin{array}{l}0 \\
0 \\
0\end{array}$ \\
\hline \multirow{2}{*}{ 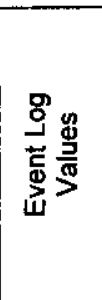 } & $\frac{\stackrel{\mathbb{N}}{\check{N}}}{\mathrm{~N}}$ & $\overleftarrow{\mathbf{z}}$ & 1 & $\S$ & 1 & $\overleftarrow{z}$ & 1 & $\begin{array}{l}\bar{N} \\
\text { vo } \\
\text { vi }\end{array}$ & $\begin{array}{l}m \\
\mathfrak{r} \\
\tilde{\sigma}\end{array}$ & 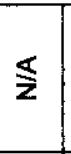 & 1 & 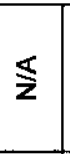 & 1 & 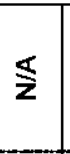 & 1 & 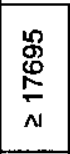 & 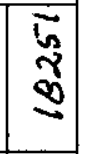 \\
\hline & 눈 & 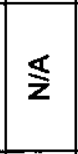 & 1 & $\widehat{\Sigma}$ & 1 & 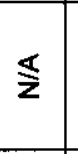 & 1 & $\sum_{2}^{\infty}$ & 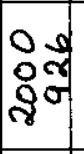 & $\lesssim$ & 1 & $\mathbf{s}$ & 1 & 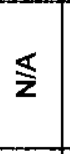 & 1 & 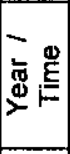 & $\begin{array}{l}0 \\
0 \\
0 \\
7\end{array}$ \\
\hline 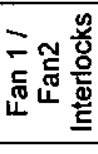 & ชุำ & $=$ & - & $\frac{0}{0}$ & $\frac{0}{0}$ & $=$ & $\overline{-}$ & $=$ & 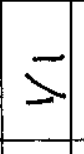 & $=$ & $\beth$ & $\frac{0}{0}$ & $\frac{0}{0}$ & $=$ & $\searrow$ & $=$ & $=$ \\
\hline 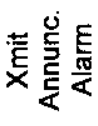 & ְ̊ & 0 & 0 & - & - & 0 & 0 & 0 & 0 & 0 & อ & - & - & 0 & 0 & 0 & 0 \\
\hline 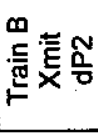 & 荬 & 0 & 0 & $\widehat{\widehat{z}}$ & 1 & $\stackrel{\mathbb{z}}{\mathbf{z}}$ & I & $\S$ & 1 & 0 & $\theta$ & $\overleftarrow{\mathbf{z}}$ & 1 & 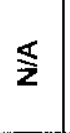 & 1 & $\widehat{\Sigma}$ & 1 \\
\hline 点 & \%ֶ & 0 & 0 & - & -1 & - & - & 0 & 0 & 0 & 0 & - & -1 & $\sigma$ & - & 0 & 0 \\
\hline 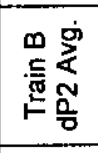 & $\begin{array}{c}\hat{\oplus} \\
\dot{z}\end{array}$ & 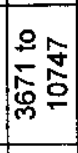 & $\frac{5}{30}$ & $\lesssim$ & 1 & $\overleftarrow{\mathbf{z}}$ & 1 & 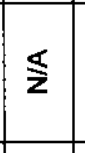 & 1 & 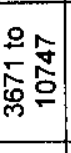 & $\begin{array}{l}\infty \\
\infty \\
\infty \\
\infty\end{array}$ & $\S$ & 1 & $\$$ & 1 & 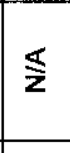 & 1 \\
\hline 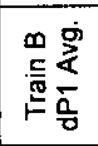 & 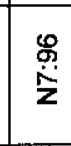 & 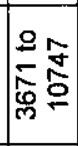 & $\begin{array}{l}\overline{0} \\
0\end{array}$ & $\begin{array}{l}\overline{\tilde{N}} \\
\mathrm{v}\end{array}$ & $\begin{array}{l}\sigma \\
n\end{array}$ & $\widehat{\underline{\mathbf{z}}}$ & 1 & 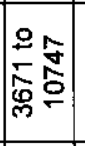 & $\begin{array}{l}7 \\
6 \\
6\end{array}$ & 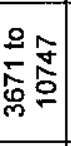 & $\begin{array}{l}5 \\
5 \\
0 \\
6\end{array}$ & 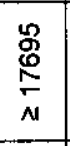 & $\begin{array}{l}0 \\
\mathbf{0} \\
\mathfrak{\sigma} \\
\mathfrak{v}\end{array}$ & $\overleftarrow{\mathbf{z}}$ & 1 & 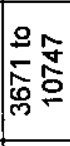 & $\begin{array}{l}n \\
n \\
5 \\
\infty\end{array}$ \\
\hline 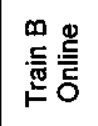 & $\stackrel{\rho}{\stackrel{2}{I}}$ & 0 & 0 & - & $\rightarrow$ & 0 & 0 & $\widehat{\mathbf{s}}$ & $!$ & 0 & 0 & - & - & 0 & 0 & 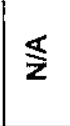 & I \\
\hline 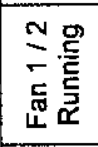 & $\stackrel{m}{=}$ & $\frac{0}{0}$ & $\begin{array}{l}0 \\
0\end{array}$ & $\begin{array}{l}\mathbf{s} \\
\mathbf{z} \\
-\end{array}$ & $\frac{1}{2}$ & $\frac{\mathbf{s}}{\mathbf{z}}$ & $\frac{1}{0}$ & $\frac{\mathbf{s}}{\mathbf{z}}$ & $\frac{1}{1}$ & $\frac{0}{0}$ & $\frac{0}{0}$ & $\frac{5}{\Sigma}$ & $=$ & $\frac{0}{z}$ & $\frac{0}{1}$ & $\frac{\$}{z}$ & $\frac{1}{1}$ \\
\hline & & 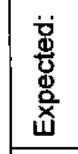 & 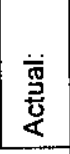 & 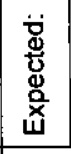 & 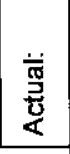 & \begin{tabular}{|l}
$\ddot{d}$ \\
du \\
du \\
斊 \\
\end{tabular} & 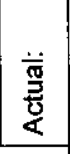 & 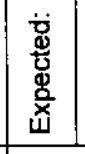 & 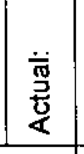 & 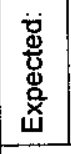 & 毘 & 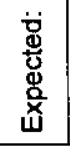 & 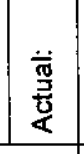 & 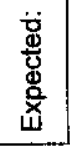 & $\begin{array}{l}\text { 离 } \\
\text { 壱 } \\
\end{array}$ & 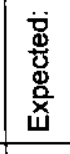 & 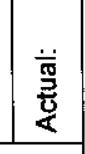 \\
\hline 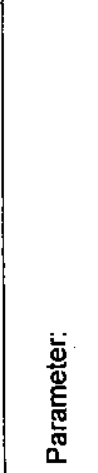 & 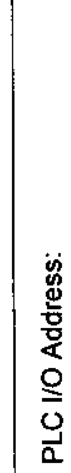 & 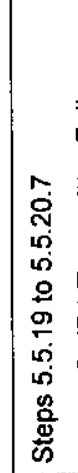 & 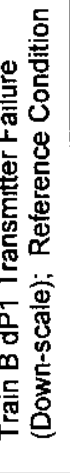 & 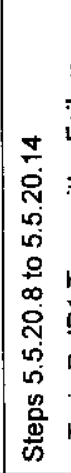 & 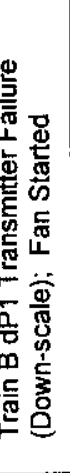 & 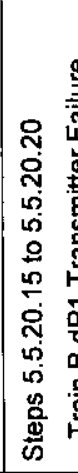 & 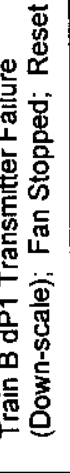 & 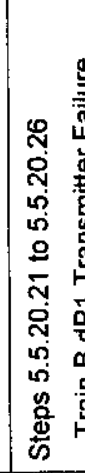 & 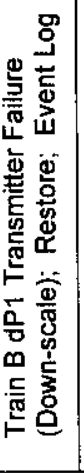 & 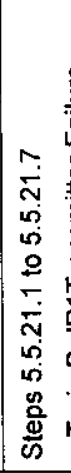 & 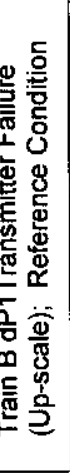 & 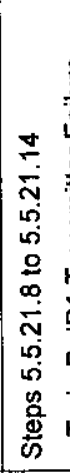 & 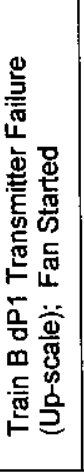 & 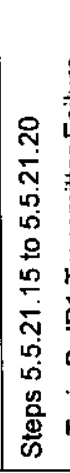 & 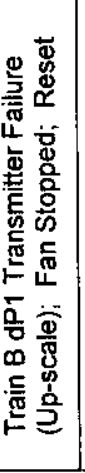 & 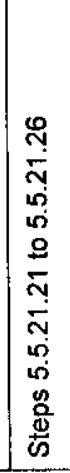 & 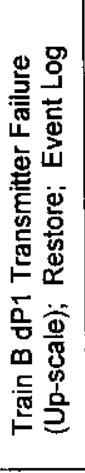 \\
\hline
\end{tabular}




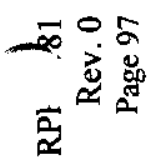

\begin{tabular}{|c|c|c|c|c|c|c|c|c|c|c|c|c|c|c|c|c|c|}
\hline \multicolumn{2}{|c|}{ 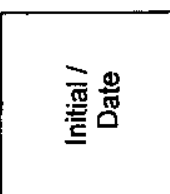 } & \multicolumn{2}{|c|}{$\begin{array}{ll}3 & 0 \\
3 & 0 \\
3 & 0 \\
\end{array}$} & \multicolumn{2}{|c|}{$\mid \begin{array}{cc}3 & 0 \\
3 & 1 \\
3 & 9 \\
0 & 0\end{array}$} & \multicolumn{2}{|c|}{$\begin{array}{ll}3 & 8 \\
3 & 1 \\
3 & 1 \\
0 & 0\end{array}$} & \multicolumn{2}{|c|}{$\begin{array}{ll}3 & 8 \\
3 & 0 \\
3 & 0\end{array}$} & \multicolumn{2}{|c|}{$\left|\begin{array}{ll} & 0 \\
3 & 0 \\
3 & 4 \\
0 & \infty\end{array}\right|$} & \multicolumn{2}{|c|}{$\begin{array}{cc}3 & 0 \\
3 & 1 \\
3 & 0 \\
E & 0\end{array}$} & \multicolumn{2}{|c|}{$\begin{array}{cc}3 & 8 \\
3 & 5 \\
3 & 5 \\
0 & 0\end{array}$} & \multicolumn{2}{|c|}{$\begin{array}{ll}3 & 8 \\
3 & 5 \\
3 & 1 \\
1 & 0\end{array}$} \\
\hline \multirow{2}{*}{ 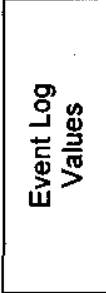 } & $\frac{\stackrel{\mathscr{N}}{\leftrightarrows}}{\stackrel{\check{N}}{z}}$ & $\widehat{\underline{z}}$ & 1 & $\widehat{\mathbf{z}}$ & 1 & $\S$ & 1 & $\begin{array}{l}\bar{N} \\
\stackrel{N}{N} \\
\text { vi }\end{array}$ & $\begin{array}{l}n \\
m \\
m\end{array}$ & 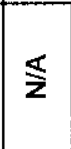 & 1 & 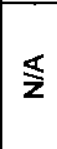 & 1 & $\frac{\mathbf{s}}{\mathbf{z}}$ & 1 & 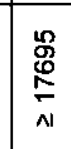 & $\begin{array}{l}h \\
3 \\
0 \\
2\end{array}$ \\
\hline & 온 & 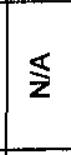 & 1 & $\widehat{\mathbf{z}}$ & 1 & $\mathbb{\mathbf { z }}$ & 1 & 象 & 8 & 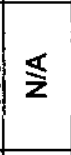 & 1 & 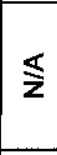 & 1 & 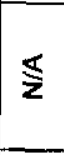 & 1 & 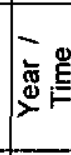 & $\begin{array}{l}0 \\
8 \\
0 \\
0\end{array}$ \\
\hline 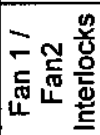 & ชั่ & $=$ & $>$ & $\frac{0}{0}$ & $\frac{0}{0}$ & 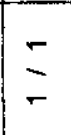 & $\searrow$ & 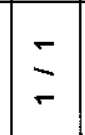 & 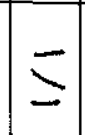 & 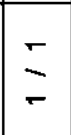 & $\searrow$ & $\frac{0}{0}$ & $\frac{0}{0}$ & $=$ & 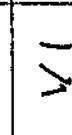 & 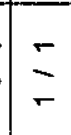 & $\Sigma$ \\
\hline 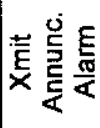 & 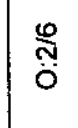 & 0 & 0 & - & - & 0 & 0 & 0 & 0 & 0 & 0 & - & - & 0 & 0 & 0 & 0 \\
\hline 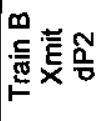 & $\frac{\pi}{*}$ & 0 & ○ & - & - & $r$ & - & 0 & 0 & 0 & 0 & - & - & - & - & 0 & 0 \\
\hline 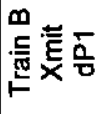 & $\frac{m}{3}$ & 0 & 0 & $\widehat{\underline{\mathbf{z}}}$ & 1 & 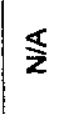 & 1 & $\S$ & I & 0 & $\theta$ & $\frac{\widehat{s}}{\mathbf{z}}$ & 1 & $\widehat{s}$ & 1 & 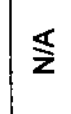 & 1 \\
\hline 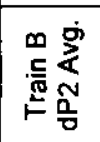 & 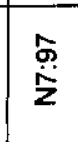 & 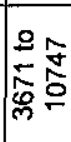 & $\begin{array}{l}8 \\
\infty \\
0\end{array}$ & $\begin{array}{l}\overline{ָ ্ \mathcal{N}} \\
\text { vi }\end{array}$ & ڤ્) & $\S$ & 1 & 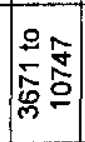 & $\begin{array}{l}\sigma \\
\tilde{\gamma}\end{array}$ & 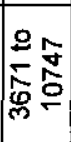 & $\begin{array}{l}\infty \\
\mathfrak{n}\end{array}$ & 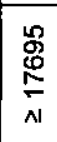 & $\begin{array}{l}m \\
\tilde{m}^{2} \\
\text { g }\end{array}$ & $\S$ & 1 & 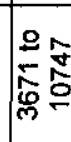 & $\frac{\infty}{2}$ \\
\hline 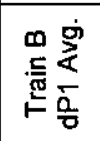 & $\begin{array}{l}\mathscr{\mathscr { S }} \\
\stackrel{\mathbf{z}}{\mathbf{z}}\end{array}$ & 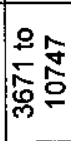 & $\begin{array}{l}5 \\
\text { on }\end{array}$ & $\overleftarrow{\mathbf{z}}$ & 1 & $\stackrel{\nwarrow}{z}$ & 1 & $\S$ & 1 & 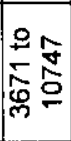 & $\begin{array}{l}5 \\
6 \\
0 \\
0\end{array}$ & $\S$ & 1 & $\widehat{\varsigma}$ & 1 & 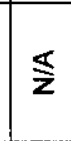 & 1 \\
\hline 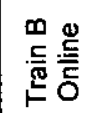 & 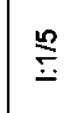 & 0 & 0 & - & 一 & 0 & 0 & $\S$ & 1 & 0 & 0 & - & - & 0 & 0 & $\widehat{\mathbf{z}}$ & 1 \\
\hline 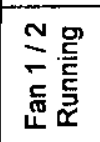 & $\stackrel{2}{=}$ & $\frac{0}{0}$ & $\frac{0}{0}$ & $\begin{array}{l}\mathbf{z} \\
\mathbf{z}\end{array}$ & 1 & $\frac{\mathbf{z}}{\mathbf{z}}$ & $\frac{1}{0}$ & $\frac{\$}{z}$ & $\frac{1}{1}$ & $\frac{0}{0}$ & $\begin{array}{l}0 \\
0\end{array}$ & $\frac{5}{2}$ & $i$ & $\frac{0}{2}$ & $\frac{0}{1}$ & $\frac{\$}{z}$ & $\frac{1}{1}$ \\
\hline & & 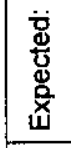 & 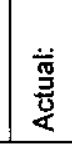 & 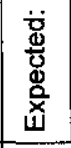 & 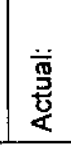 & 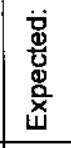 & 离 & 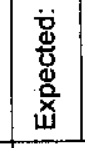 & 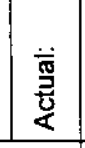 & 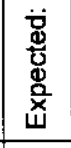 & 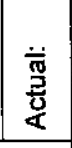 & 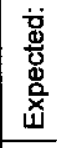 & $\begin{array}{l}\dot{\bar{g}} \\
\stackrel{\overrightarrow{\mathrm{U}}}{\mathrm{U}} \\
\end{array}$ & 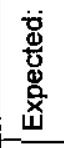 & 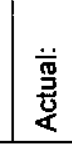 & 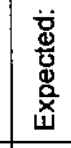 & $\begin{array}{l}\ddot{\bar{\Xi}} \\
\text { 苞 } \\
\end{array}$ \\
\hline 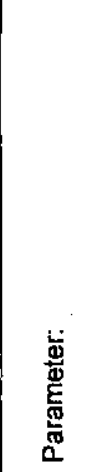 & 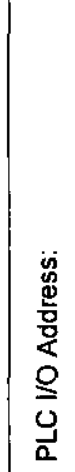 & 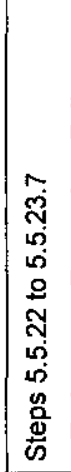 & 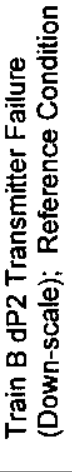 & 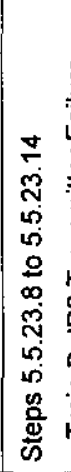 & 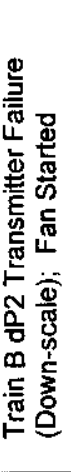 & 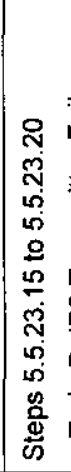 & 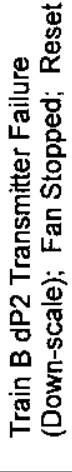 & \begin{tabular}{|l} 
\\
\end{tabular} & 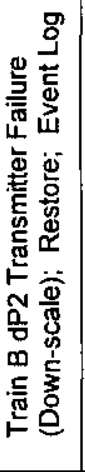 & 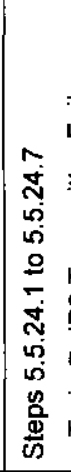 & 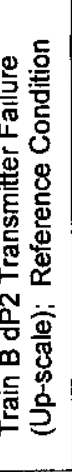 & 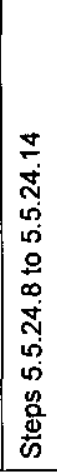 & 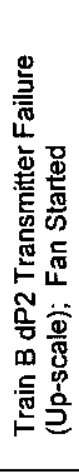 & 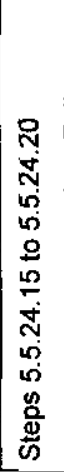 & 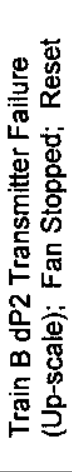 & 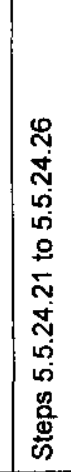 & 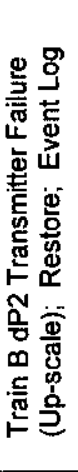 \\
\hline
\end{tabular}




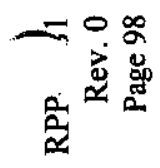

\begin{tabular}{|c|c|c|c|c|c|c|c|c|c|c|c|c|c|c|c|c|c|}
\hline \multicolumn{2}{|c|}{ 茜 } & \multicolumn{2}{|c|}{$\begin{array}{cc}3 & 0 \\
3 & 0 \\
0 & 1 \\
0 & 0\end{array}$} & 으 & $\begin{array}{l}8 \\
8 \\
1 \\
1 \\
3\end{array}$ & \multicolumn{2}{|c|}{$\begin{array}{r}38 \\
35 \\
35 \\
0 \quad 0\end{array}$} & \multicolumn{2}{|c|}{$\begin{array}{l}3 \\
3 \\
0\end{array}$} & $\begin{array}{l}0 \\
8 \\
0 \\
\infty \\
0 \\
0\end{array}$ & $\begin{array}{r}3 \\
3 \\
3 \\
0\end{array}$ & \multicolumn{2}{|c|}{$\begin{array}{cc}3 & 8 \\
3 & 0 \\
3 & 1 \\
E & 0\end{array}$} & \multicolumn{2}{|c|}{$\begin{array}{cc} & 0 \\
3 & 0 \\
3 & 0 \\
1 \\
0 & 0\end{array}$} & \multicolumn{2}{|c|}{\begin{tabular}{|cc} 
& 0 \\
3 & 0 \\
3 & 9 \\
$\varepsilon$ & 0
\end{tabular}} \\
\hline 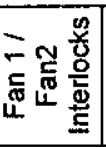 & 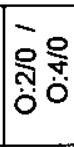 & $=$ & $\beth$ & $=$ & 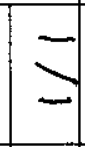 & $=$ & $\overline{ }$ & $=$ & 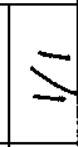 & $=$ & 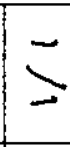 & $=$ & 工 & $=$ & $\searrow$ & $=$ & $\bar{z}$ \\
\hline 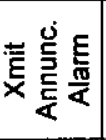 & 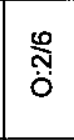 & 0 & 0 & 0 & 0 & 0 & 0 & 0 & 0 & 0 & 0 & 0 & 0 & 0 & 0 & 0 & 0 \\
\hline 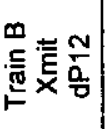 & $\frac{\text { on }}{8}$ & 0 & 0 & - & - & - & - & 0 & 0 & 0 & 0 & - & $\longrightarrow$ & $r$ & - & 0 & 0 \\
\hline 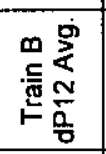 & $\begin{array}{l}\stackrel{a}{\stackrel{\leftrightarrow}{\tilde{z}}} \\
\mathbf{z}\end{array}$ & 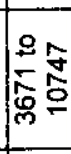 & $\begin{array}{l}5 \\
\sigma \\
\sigma\end{array}$ & $\underset{\substack{N \\
v i}}{\bar{v}}$ & $\begin{array}{l}N \\
\Xi \\
\end{array}$ & $\overleftarrow{\mathbf{z}}$ & 1 & 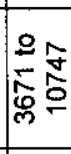 & $\begin{array}{l}m \\
3 \\
r \\
n\end{array}$ & $\frac{2}{5}$ & $\begin{array}{l}n \\
\tilde{n} \\
\text { ñ }\end{array}$ & $\frac{\stackrel{2}{8}}{\stackrel{8}{\circ}}$ & 0 & 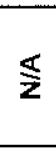 & I & 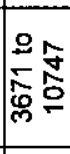 & $\begin{array}{l}7 \\
8 \\
8\end{array}$ \\
\hline 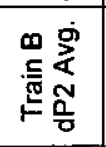 & 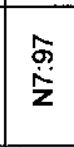 & 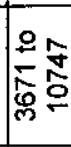 & $\frac{2}{2}$ & $\S$ & 1 & $\mathbf{s}$ & 1 & $\S$ & 1 & 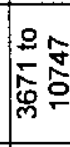 & $\tilde{n}$ & $\frac{\mathbb{Z}}{\mathbf{z}}$ & I & 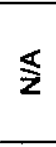 & 1 & 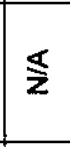 & 1 \\
\hline 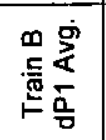 & $\begin{array}{l}\mathscr{\mathscr { m }} \\
\hat{\mathbf{z}}\end{array}$ & 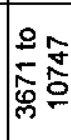 & $\begin{array}{l}v \\
w \\
w\end{array}$ & 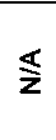 & 1 & 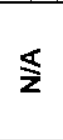 & 1 & $\overleftarrow{\mathbf{z}}$ & 1 & 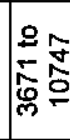 & $\begin{array}{l}n \\
5 \\
\infty\end{array}$ & $\frac{\varsigma}{\mathbf{z}}$ & 1 & $\widehat{\mathbf{z}}$ & 1 & 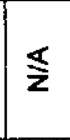 & 1 \\
\hline 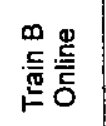 & $\stackrel{?}{\check{I}}$ & 0 & 0 & - & - & 0 & 0 & $\underset{\mathbf{z}}{\mathbf{z}}$ & 1 & 0 & 0 & - & - & 0 & 0 & 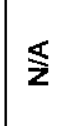 & 1 \\
\hline 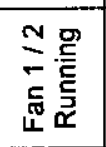 & $\stackrel{2}{=}$ & $\frac{0}{0}$ & $\frac{0}{0}$ & $\frac{s}{z}$ & 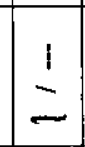 & $\frac{5}{2}$ & $\frac{1}{0}$ & $\frac{\frac{\pi}{z}}{\frac{\pi}{z}}$ & $\frac{1}{1}$ & $\frac{0}{0}$ & $\frac{0}{0}$ & $\frac{5}{z}$ & $=$ & $\frac{0}{2}$ & $\frac{0}{1}$ & $\frac{\$}{z}$ & $\frac{1}{1}$ \\
\hline & & 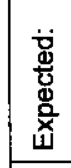 & 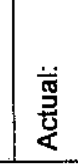 & 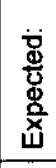 & 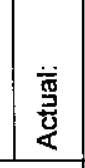 & 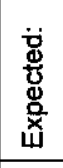 & 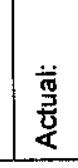 & 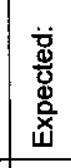 & $\begin{array}{l}\dot{\bar{g}} \\
\dot{\vec{Z}} \\
\text { \& }\end{array}$ & 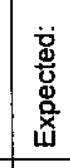 & $\begin{array}{l}\dot{\bar{g}} \\
\dot{\vec{z}} \\
\end{array}$ & 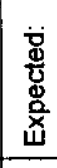 & 毘 & 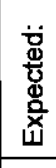 & $\begin{array}{l}\dot{\bar{g}} \\
\dot{\vec{z}} \\
\dot{8}\end{array}$ & 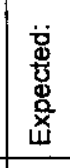 & 芴 \\
\hline 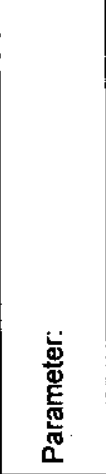 & 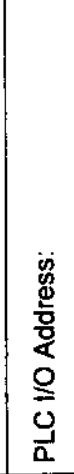 & 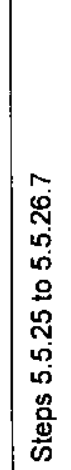 & 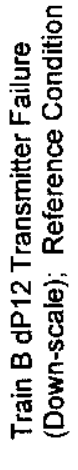 & 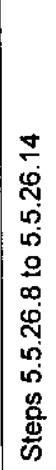 & 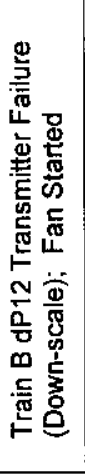 & 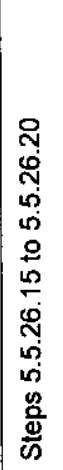 & 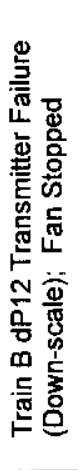 & 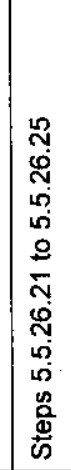 & 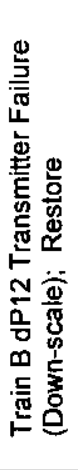 & 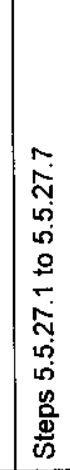 & 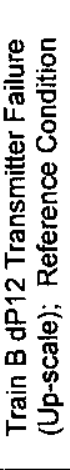 & 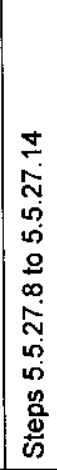 & 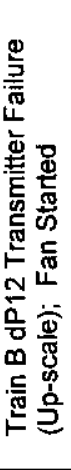 & 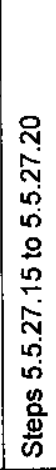 & 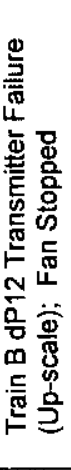 & 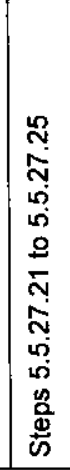 & 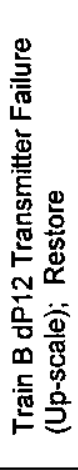 \\
\hline
\end{tabular}




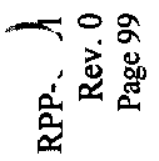

\begin{tabular}{|c|c|c|c|c|c|c|c|c|c|c|c|c|c|c|c|c|c|}
\hline \multicolumn{2}{|c|}{ 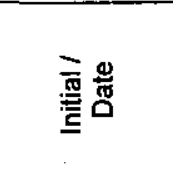 } & \multicolumn{2}{|c|}{$\begin{array}{ll}3 & 0 \\
3 & 1 \\
3 & 1 \\
0 & 0\end{array}$} & \multicolumn{2}{|c|}{$\begin{array}{cc}3 & 6 \\
3 & 1 \\
3 & 1 \\
0 & 0\end{array}$} & $\begin{array}{c}3 \\
3 \\
0\end{array}$ & $\begin{array}{l}0 \\
0 \\
1 \\
1 \\
0\end{array}$ & \multicolumn{2}{|c|}{$\begin{array}{ll}3 & 8 \\
3 & 1 \\
0 & 0\end{array}$} & \multicolumn{2}{|c|}{$\begin{array}{cc} & 0 \\
3 & 1 \\
3 & 5 \\
3 & 1 \\
0 & 0\end{array}$} & \multicolumn{2}{|c|}{$\begin{array}{ll}3 & 8 \\
3 & 0 \\
= & \infty\end{array}$} & \multicolumn{2}{|c|}{$\begin{array}{ll}3 & 0 \\
3 & 0 \\
3 & 0 \\
0 & 0\end{array}$} & \multicolumn{2}{|l|}{$-\frac{3}{3}$} \\
\hline \multirow{2}{*}{ 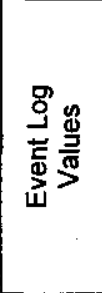 } & 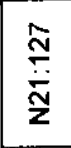 & $\frac{5}{2}$ & 1 & $\S$ & 1 & 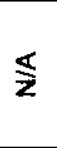 & 1 & $\begin{array}{l}\overline{\mathbb{d}} \\
\mathrm{v}\end{array}$ & $\begin{array}{l}n \\
\tilde{n} \\
\tilde{\gamma}\end{array}$ & $\overleftarrow{\mathbf{z}}$ & 1 & 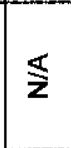 & 1 & 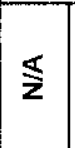 & 1 & 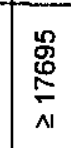 & $\begin{array}{l}\text { b } \\
\text { z } \\
0\end{array}$ \\
\hline & 紊告 & $\frac{\pi}{\Sigma}$ & 1 & $\$$ & 1 & $\widehat{\nwarrow}$ & 1 & 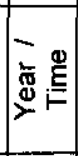 & $\begin{array}{l}0 y \\
8 z \\
0 \\
\gamma\end{array}$ & 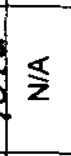 & 1 & 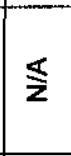 & 1 & $\S$ & 1 & 离 & $\mid \begin{array}{ll}0 & 0 \\
8 & 0 \\
8 & 0\end{array}$ \\
\hline 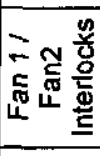 & 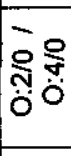 & $=$ & \pm & $\frac{0}{0}$ & $\frac{0}{5}$ & $=$ & 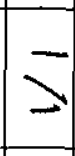 & $E$ & $\Sigma$ & $=$ & $=$ & $\frac{0}{0}$ & 0 & $=$ & - & $=$ & 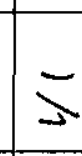 \\
\hline 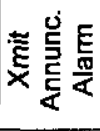 & $\begin{array}{l}\text { งั } \\
\text { Oे }\end{array}$ & 0 & 0 & - & - & 0 & 0 & 0 & 0 & 0 & $\theta$ & - & - & 0 & 0 & 0 & 0 \\
\hline 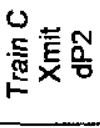 & ठै. & $\circ$ & 0 & 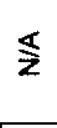 & 1 & $\frac{\widehat{s}}{\mathbf{z}}$ & 1 & 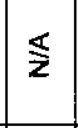 & 1 & 0 & 0 & 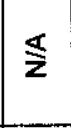 & 1 & 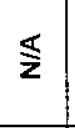 & 1 & $\frac{\zeta}{z}$ & 1 \\
\hline 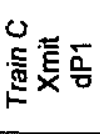 & 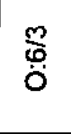 & 0 & of & - & - & - & - & 0 & 0 & 0 & 0 & - & - & - & - & 0 & 0 \\
\hline 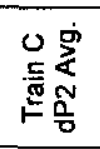 & $\frac{8}{\grave{\pi}}$ & 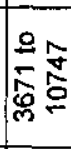 & $\begin{array}{l}n \\
n \\
\infty\end{array}$ & 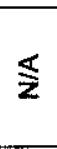 & i & 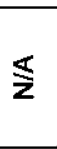 & 1 & $\S$ & 1 & 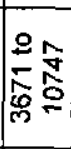 & $\begin{array}{l}l \\
r \\
m \\
0\end{array}$ & $\overleftarrow{\mathbf{z}}$ & 1 & $\widehat{s}$ & 1 & 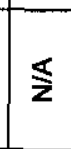 & 1 \\
\hline 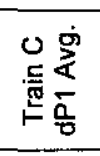 & $\begin{array}{l}\stackrel{g}{\stackrel{g}{2}} \\
\text { z }\end{array}$ & 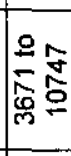 & $\underset{x}{x}$ & 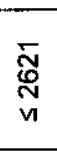 & $\frac{\sigma}{8}$ & $\overleftarrow{\Sigma}$ & 1 & 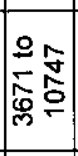 & $\begin{array}{c}m \\
n \\
3\end{array}$ & 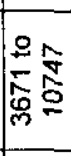 & $\begin{array}{l}n \\
0 \\
n \\
y\end{array}$ & 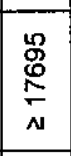 & $\begin{array}{l}n \\
0 \\
5 \\
5\end{array}$ & 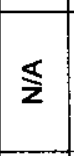 & 1 & 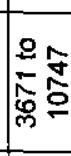 & $\frac{0}{\frac{\pi}{\infty}}$ \\
\hline 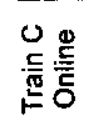 & $\stackrel{\varphi}{\leftrightarrows}$ & 0 & 0 & - & $\longrightarrow$ & 0 & 0 & $\widehat{z}$ & 1 & 0 & 0 & - & - & 0 & 0 & $\widehat{\nwarrow}$ & I \\
\hline 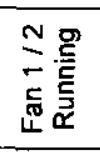 & $\stackrel{-1}{2}$ & 0 & $\frac{0}{0}$ & $\underline{\mathbf{z}}$ & 1 & $\frac{5}{2}$ & $\frac{1}{0}$ & $\frac{\$}{z}$ & $\frac{1}{1}$ & $\frac{0}{0}$ & $\begin{array}{l}0 \\
0\end{array}$ & $\frac{5}{2}$ & - & $\frac{0}{3}$ & $\frac{0}{1}$ & $\begin{array}{l}\mathbf{s} \\
\mathbf{z} \\
\mathbf{z}\end{array}$ & $\frac{1}{1}$ \\
\hline & & 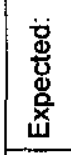 & 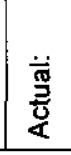 & 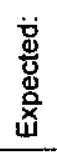 & 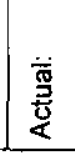 & 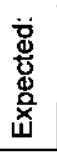 & 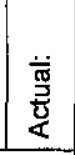 & 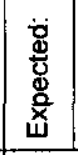 & 蒙 & 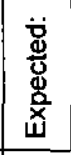 & 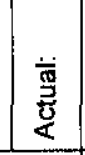 & 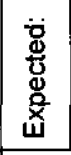 & $\begin{array}{l}\dot{\bar{m}} \\
\dot{\vec{z}} \\
\dot{z}\end{array}$ & $\begin{array}{l}\dot{\ddot{g}} \\
\dot{y} \\
\dot{z} \\
\dot{x} \\
\end{array}$ & 蒿 & 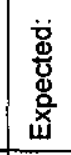 & 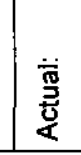 \\
\hline 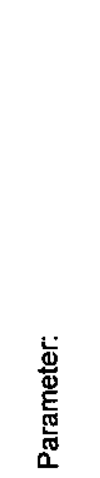 & 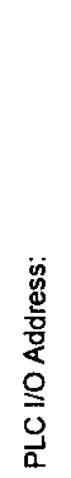 & 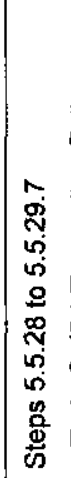 & 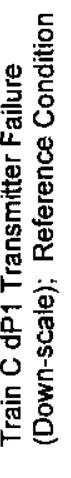 & 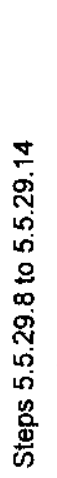 & 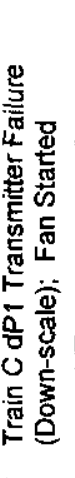 & 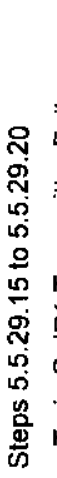 & 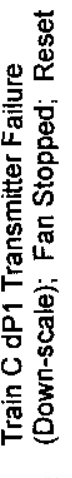 & 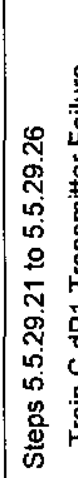 & 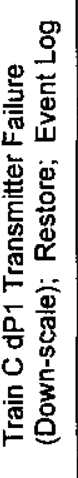 & 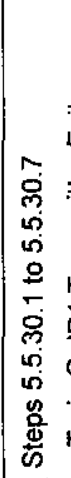 & 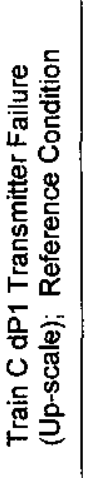 & 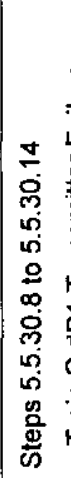 & 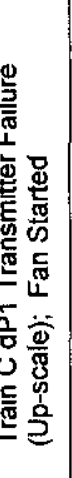 & 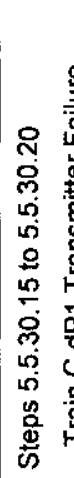 & 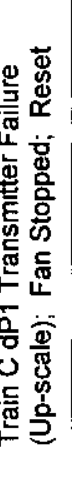 & 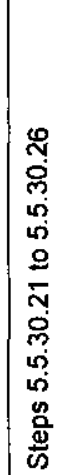 & 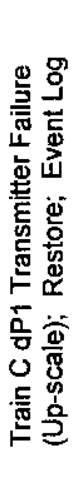 \\
\hline
\end{tabular}




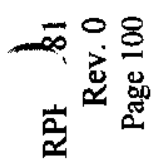

\begin{tabular}{|c|c|c|c|c|c|c|c|c|c|c|c|c|c|c|c|}
\hline 产岕 & $\frac{3}{3}$ & $\begin{array}{l}r \\
\infty \\
\infty\end{array}$ & $\widehat{a}$ & $\begin{array}{l}0 \\
0 \\
1 \\
0 \\
0\end{array}$ & ब & $\begin{array}{l}0 \\
1 \\
1 \\
0\end{array}$ & ब्र & $\begin{array}{l}5 \\
5 \\
1 \\
0\end{array}$ & $\begin{array}{l}3 \\
3 \\
0\end{array}$ & $\begin{array}{l}8 \\
1 \\
5 \\
1 \\
\infty\end{array}$ & $\begin{array}{l}3 \\
3 \\
E\end{array}$ & $\begin{array}{l}8 \\
0 \\
5 \\
0\end{array}$ & $\begin{array}{r}3 \\
3 \\
0\end{array}$ & $\begin{array}{l}0 \\
1 \\
5 \\
0\end{array}$ & $\begin{array}{l}3 \\
3 \\
\equiv\end{array}$ \\
\hline & 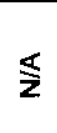 & 1 & $\lesssim$ & 1 & $\$$ & 1 & $\sqrt{1}$ & $\begin{array}{l}m \\
o \\
h \\
\gamma\end{array}$ & $\S$ & I & $\S$ & 1 & $\overleftarrow{\mathbf{z}}$ & 1 & $\wedge$ \\
\hline
\end{tabular}

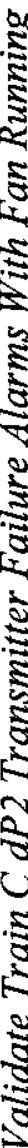

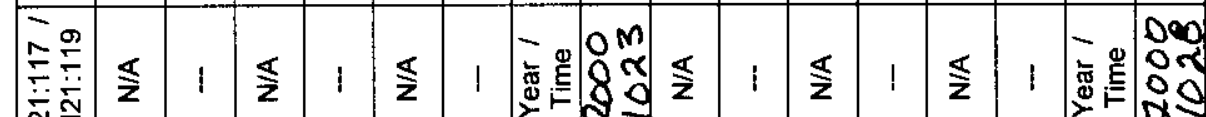

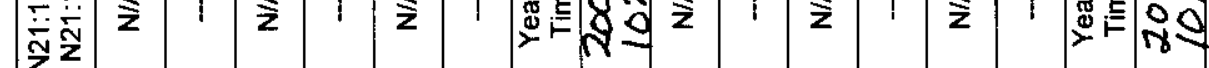

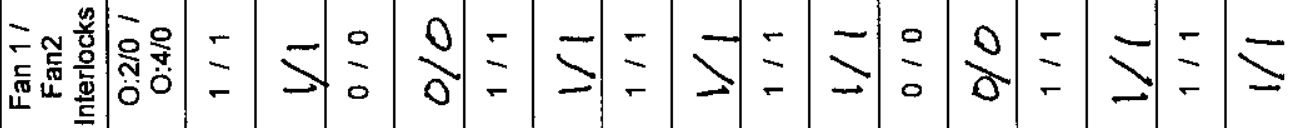

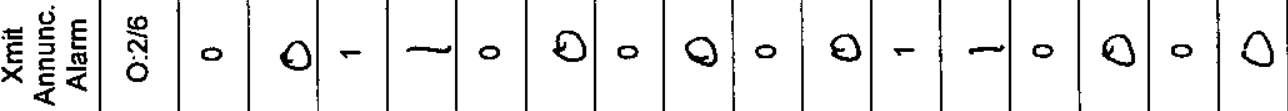

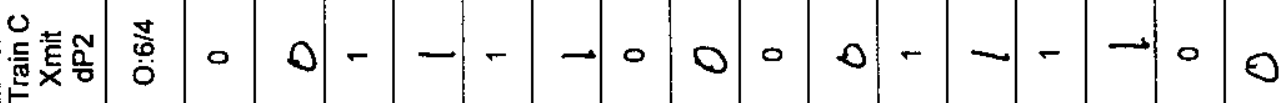

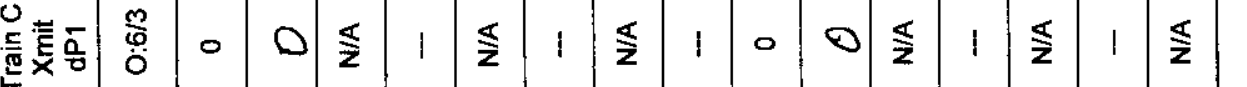
0 弯

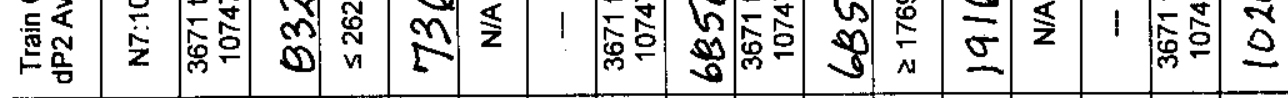

\begin{tabular}{|c|c|c|c|c|c|c|c|c|c|c|c|c|c|c|c|}
\hline $\begin{array}{l}0 \text { 罗 } \\
\text { 亮 }\end{array}$ & 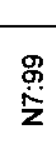 & 오웡 & $\frac{v}{5}$ & 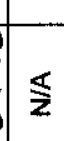 & 1 & 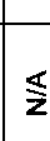 & 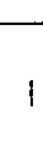 & $\$$ & 1 & 웅 & 武 & 1 & $\$$ & 1 & $\$$ \\
\hline
\end{tabular}

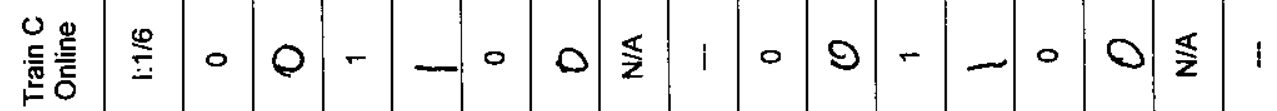

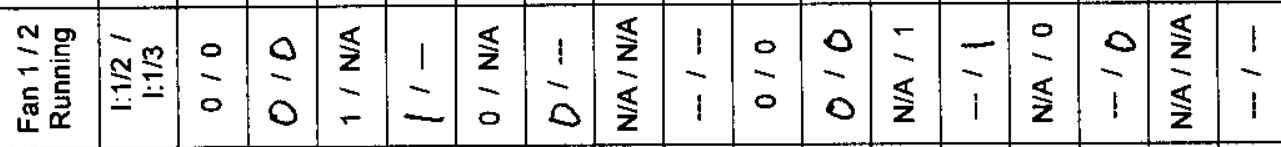
$\frac{\sqrt{2}}{\frac{\pi}{\pi}}$

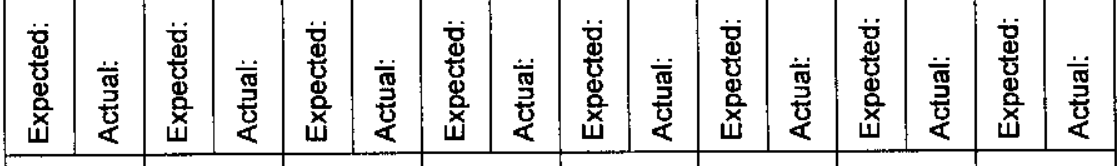

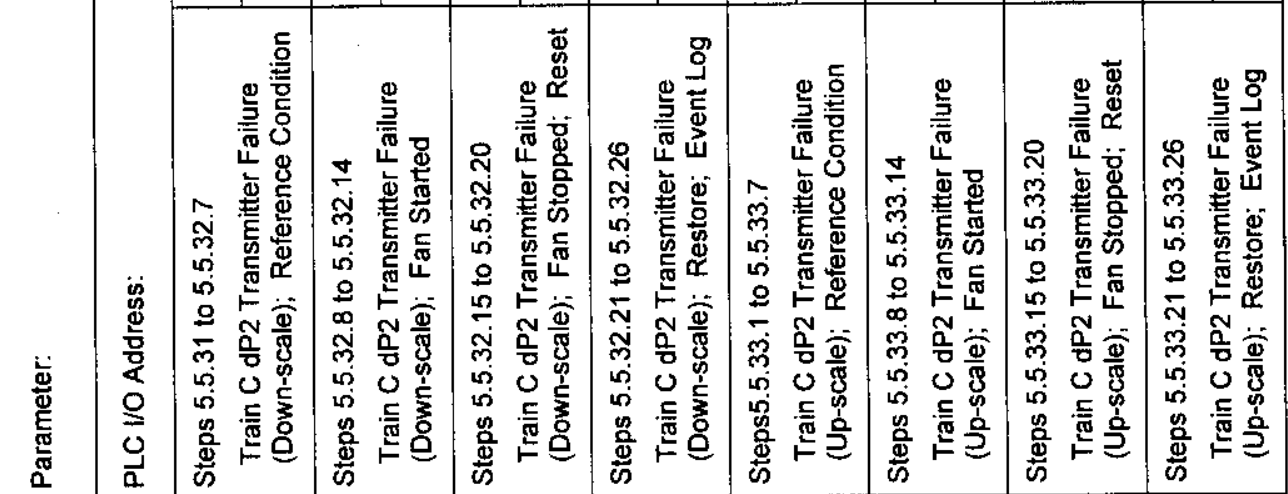




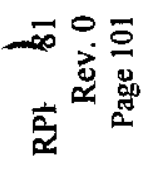

\begin{tabular}{|c|c|c|c|c|c|c|c|c|c|c|c|c|c|c|c|}
\hline & & & $\begin{array}{l}0 \\
8 \\
0 \\
1 \\
0\end{array}$ & & \begin{tabular}{l|l}
8 & \\
8 & \\
0 & 1 \\
0 & 3
\end{tabular} & & & & & $\begin{array}{l}38 \\
30 \\
1\end{array}$ & & & & \begin{tabular}{l|l}
0 & 3 \\
1 & 3 \\
5 & 3 \\
0 & 3 \\
\end{tabular} & $\begin{array}{l}0 \\
9 \\
9 \\
0\end{array}$ \\
\hline 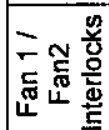 & & | & $\beth$ & $\equiv$ & $\Xi$ & $\equiv$ & 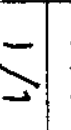 & $\equiv$ & & $\equiv$ & $y=$ & $\Xi$ & $\Xi \sum$ & $\Xi=$ & $\searrow$ \\
\hline 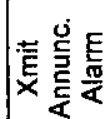 & I̊ & 0 & 0 & 0 & 0 & 。 & 0 & 。 & 0 & 。 & 0 & & $\circ 0$ & 0.0 & 0 \\
\hline 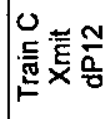 & \%ั & 0 & 0 & - & - & - & - & 。 & 0 & o & d. - & & -- & -10 & $\Delta$ \\
\hline 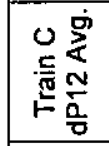 & $\begin{array}{l}\bar{\sigma} \\
\stackrel{\bar{z}}{z} \\
\end{array}$ & 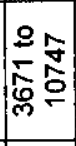 & $\underset{\substack{n \\
\alpha}}{a}$ & 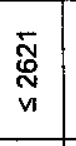 & $\tilde{\Xi}$ & $\underline{\mathbf{s}}$ & & 资 & & & 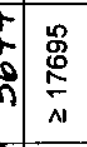 & $\begin{array}{l}\text { รี } \\
\text { a }\end{array}$ & $\frac{\pi}{2}$ & 1 & $\frac{m}{2}$ \\
\hline 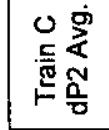 & $\frac{8}{\tilde{z}}$ & 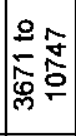 & & $\underline{\mathbf{s}}$ & 1 & $\frac{\hat{s}}{\mathbf{z}}$ & 1 & 些 & & & ât & 1 & \begin{tabular}{l|l}
$\mathbf{s}$ & 1
\end{tabular} & $1 \frac{\mathbf{s}}{\mathbf{z}}$ & 1 \\
\hline 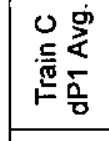 & $\begin{array}{l}\stackrel{9}{0} \\
\stackrel{2}{\hat{~}}\end{array}$ & $\mid$ & $\frac{\sqrt[J]{*}}{\infty}$ & $\frac{\pi}{2}$ & 1 & $\frac{\mathbf{s}}{\mathbf{z}}$ & 1 & $\frac{5}{2}$ & & $\begin{array}{c}0 \\
0 \\
0\end{array}$ & |ै। & 1 & \begin{tabular}{l|l}
$\frac{\mathbf{s}}{\mathbf{z}}$ & 1
\end{tabular} & | $\mid \frac{\mathbf{s}}{\mathbf{z}}$ & 1 \\
\hline 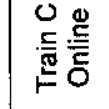 & $\stackrel{\mathscr{Q}}{\underline{.}}$ & 0 & 0 & - & - & $\circ$ & & $\frac{\mathbf{s}}{\mathbf{z}}$ & 1 & \begin{tabular}{l|l}
0 & 6
\end{tabular} & - & - & 。 & $0 \mid \frac{\Sigma}{z}$ & 1 \\
\hline 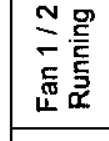 & 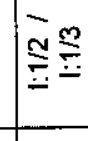 & $\frac{0}{0}$ & $\frac{0}{0}$ & 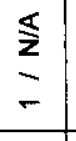 & $\stackrel{1}{=}$ & $\begin{array}{l}\frac{1}{2} \\
0 \\
0\end{array}$ & $\frac{1}{0}$ & 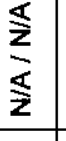 & $\frac{1}{1}$ & & 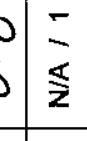 & $\vec{i}$ & \begin{tabular}{l|l}
0 & 5 \\
& 1 \\
\end{tabular} & \begin{tabular}{l|l}
0 & $\frac{5}{2}$ \\
1 & $\frac{\pi}{z}$ \\
\end{tabular} & $\frac{1}{1}$ \\
\hline & & & \begin{tabular}{|l|} 
\\
$\frac{3}{3}$ \\
\end{tabular} & 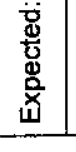 & 产 & 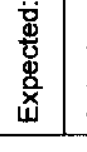 & 㨱 & & 縺 & 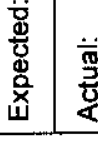 & 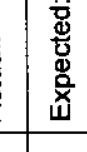 & \begin{tabular}{|l|} 
\\
妾 \\
\end{tabular} & 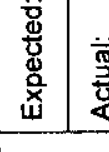 & 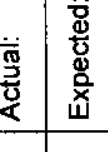 & 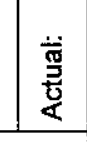 \\
\hline 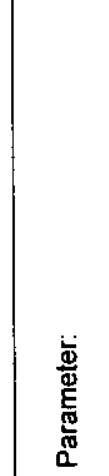 & 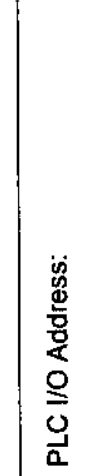 & $\mid \begin{array}{l}0 \\
0 \\
0 \\
0 \\
0 \\
0 \\
0 \\
0 \\
0 \\
0 \\
0 \\
0\end{array}$ & 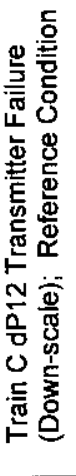 & 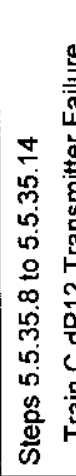 & 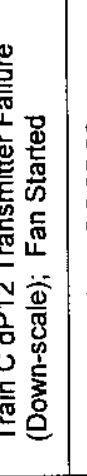 & 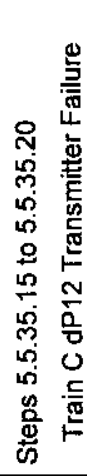 & & 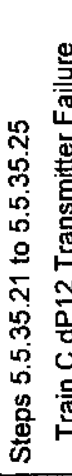 & & 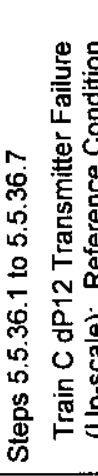 & & 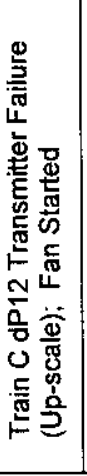 & 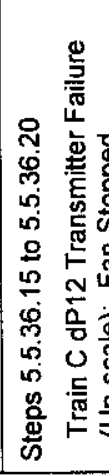 & 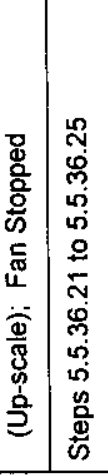 & 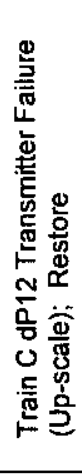 \\
\hline
\end{tabular}




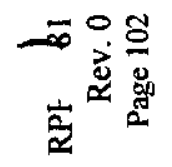

\begin{tabular}{|c|c|c|c|c|c|c|c|c|c|c|c|c|c|c|c|c|c|}
\hline \multicolumn{2}{|c|}{ 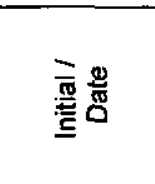 } & $\begin{array}{l}\frac{3}{3} \\
\text { ब }\end{array}$ & $\begin{array}{l}0 \\
0 \\
\vdots \\
\dot{\sigma} \\
\dot{s}\end{array}$ & $\begin{array}{c}3 \\
3 \\
a\end{array}$ & $\begin{array}{l}0 \\
9 \\
1 \\
1 \\
50\end{array}$ & $\begin{array}{c}3 \\
3 \\
0\end{array}$ & $\begin{array}{l}8 \\
\vdots \\
1 \\
0\end{array}$ & $\begin{array}{l}3 \\
3 \\
0\end{array}$ & $\begin{array}{l}0 \\
0 \\
1 \\
\infty\end{array}$ & $\begin{array}{l}3 \\
3 \\
0\end{array}$ & $\begin{array}{l}8 \\
0 \\
1 \\
1 \\
0\end{array}$ & $\begin{array}{l}3 \\
3 \\
E\end{array}$ & $\begin{array}{l}0 \\
0 \\
1 \\
0 \\
0\end{array}$ & $\begin{array}{l}3 \\
3 \\
3\end{array}$ & $\begin{array}{l}p \\
\frac{1}{1} \\
\infty\end{array}$ & $\begin{array}{l}3 \\
3 \\
1\end{array}$ & $\begin{array}{l}0 \\
0 \\
1 \\
0 \\
0\end{array}$ \\
\hline \multirow{2}{*}{ 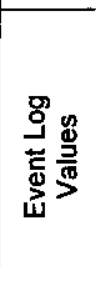 } & 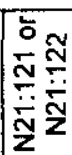 & $\frac{\mathbf{u}}{\mathbf{z}}$ & 1 & 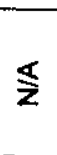 & 1 & $\frac{\mathfrak{c}}{\mathbf{z}}$ & I & 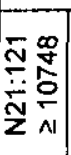 & $\stackrel{0}{\bar{m}}$ & 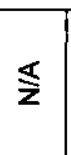 & 1 & $\stackrel{\coprod}{\mathbf{z}}$ & 1 & $\$$ & I & 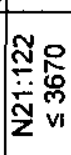 & $\begin{array}{l}0 \\
\infty \\
\gamma \\
n\end{array}$ \\
\hline & $\frac{1}{\frac{N}{2}} \frac{0}{\frac{\pi}{2}}$ & $\overline{\mathbf{z}}$ & I & $\widehat{\mathbf{z}}$ & 1 & 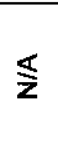 & 1 & 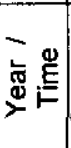 & 8 & 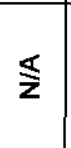 & 1 & 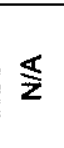 & 1 & $\frac{\pi}{z}$ & 1 & है & ชู \\
\hline 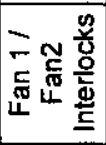 & & - & 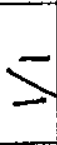 & $\frac{0}{0}$ & $\frac{0}{0}$ & $=$ & 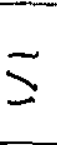 & $\frac{\hat{z}}{\underline{z}}$ & $\frac{1}{1}$ & $=$ & 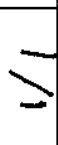 & $\frac{0}{0}$ & $\frac{0}{0}$ & $=$ & $\beth$ & $\frac{\mathbf{s}}{\mathbf{z}}$ & 1 \\
\hline $\begin{array}{l}\text { 눙 } \\
\text { 동 }\end{array}$ & & $c$ & $\frac{0}{0}$ & $\frac{5}{z}$ & $\frac{1}{2}$ & $\frac{\widehat{s}}{\mathbf{z}}$ & $\frac{1}{0}$ & 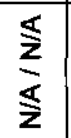 & $\frac{1}{1}$ & $\frac{0}{0}$ & $\frac{0}{0}$ & $\bar{z}$ & $\overline{1}$ & $\frac{0}{\frac{1}{2}}$ & $\frac{0}{1}$ & $\frac{\aleph}{\frac{\aleph}{z}}$ & 1 \\
\hline
\end{tabular}

\begin{tabular}{|c|c|c|c|c|c|c|c|c|c|c|c|c|c|c|c|c|c|}
\hline 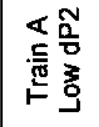 & ָั & 0 & 0 & 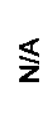 & i & 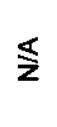 & 1 & $\overleftarrow{\mathbf{z}}$ & 1 & 0 & 0 & - & $\rightarrow$ & 0 & 0 & 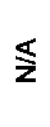 & 1 \\
\hline
\end{tabular}

\begin{tabular}{|c|c|c|c|c|c|c|c|c|c|c|c|c|c|c|c|c|c|}
\hline 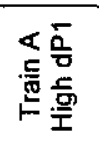 & స్ & 0 & 0 & - & 一 & 0 & 0 & $\widehat{\widehat{z}}$ & 1 & 0 & 0 & $\overleftarrow{\Sigma}$ & 1 & $\$$ & $!$ & $\frac{5}{\mathbf{z}}$ & 1 \\
\hline 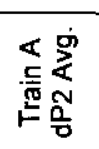 & 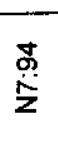 & 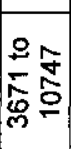 & $\frac{0}{\theta}$ & $\$$ & 1 & $\widehat{\Sigma}$ & 1 & $\$$ & 1 & \begin{tabular}{l}
2 \\
\hdashline \\
0 \\
\end{tabular} & $\begin{array}{l}N \\
0 \\
D\end{array}$ & $\begin{array}{l}\text { P } \\
\text { o } \\
\text { vi }\end{array}$ & $\begin{array}{l}0 \\
\infty \\
r \\
n\end{array}$ & 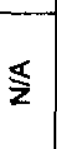 & 1 & 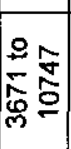 & $\begin{array}{l}\bar{m} \\
m\end{array}$ \\
\hline 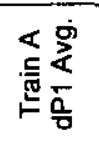 & $\begin{array}{l}\stackrel{\leftrightarrow}{\stackrel{\tilde{z}}{z}} \\
\text { }\end{array}$ & 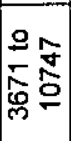 & $\begin{array}{l}v \\
v \\
g\end{array}$ & $\frac{\stackrel{\infty}{\vdots}}{\stackrel{0}{5}}$ & $\stackrel{0}{\underline{n}}$ & $\S$ & 1 & 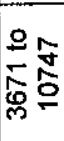 & v & 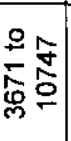 & $\begin{array}{c}n \\
6 \\
6\end{array}$ & 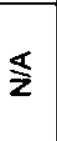 & 1 & 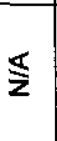 & 1 & $\overleftarrow{z}$ & 1 \\
\hline
\end{tabular}

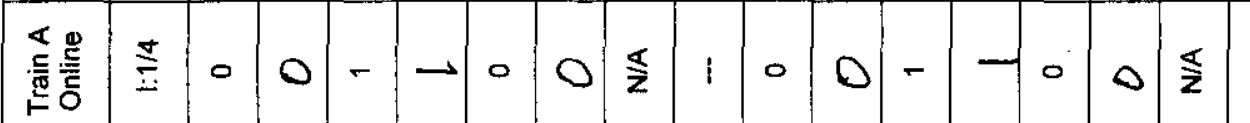

\begin{tabular}{|c|c|c|c|c|c|c|c|c|c|c|c|c|c|c|c|c|c|}
\hline 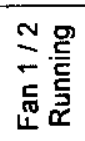 & $\stackrel{9}{=}$ & $\frac{0}{0}$ & $\frac{0}{0}$ & $\frac{\mathbf{z}}{\mathbf{z}}$ & $\frac{1}{2}$ & $\frac{\mathbf{s}}{\mathbf{z}}$ & $\frac{1}{0}$ & 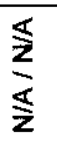 & $\frac{1}{1}$ & $\frac{0}{0}$ & $\frac{0}{0}$ & $\begin{array}{l}5 \\
\frac{5}{2}\end{array}$ & $\overrightarrow{1}$ & $\begin{array}{l}0 \\
\vdots \\
\mathbf{z}\end{array}$ & $\frac{0}{1}$ & $\frac{\mathbb{s}}{\frac{\pi}{z}}$ & $\frac{1}{1}$ \\
\hline & & 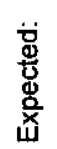 & $\begin{array}{l}\dot{\overline{\mathrm{m}}} \\
\dot{\mathrm{U}}\end{array}$ & 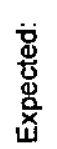 & 宮 & 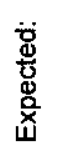 & 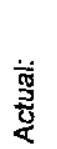 & 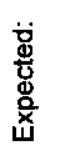 & 毘 & 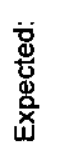 & 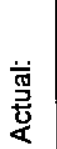 & 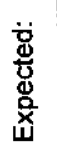 & 鯄 & 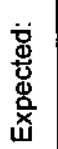 & 然 & $\begin{array}{l}\ddot{\mathbf{g}} \\
\dot{\mathbf{g}} \\
\dot{\Phi} \\
\dot{x}\end{array}$ & 弟 \\
\hline
\end{tabular}

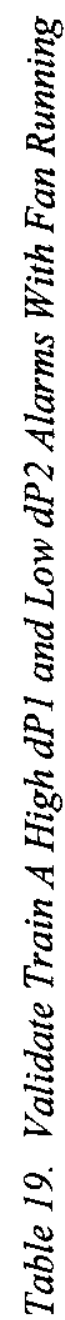

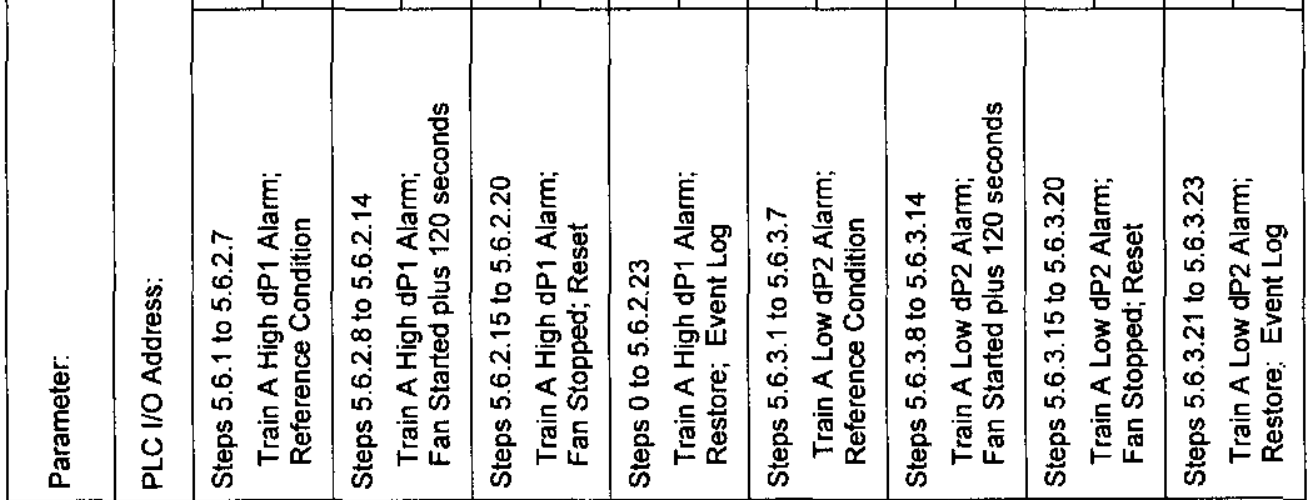




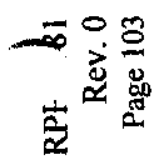

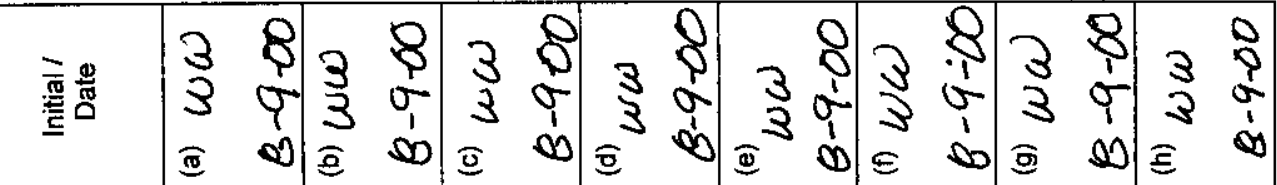

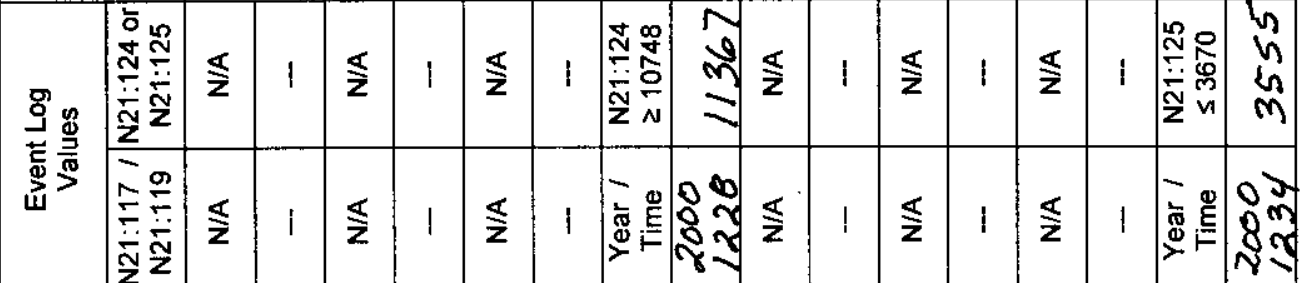

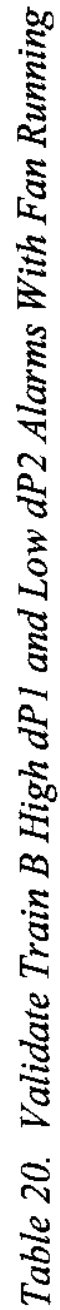

\begin{tabular}{|c|c|c|c|c|c|c|c|c|c|c|c|c|c|c|c|c|c|}
\hline 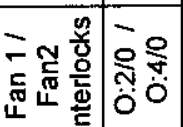 & $=$ & $\bar{J}$ & $\frac{0}{0}$ & $\frac{0}{0}$ & $=$ & $\beth$ & $\frac{5}{3}$ & $\frac{1}{1}$ & - & $=$ & 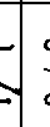 & 0 & (2) & & & - & $\frac{5}{2}$ \\
\hline
\end{tabular}

宅

牙舟

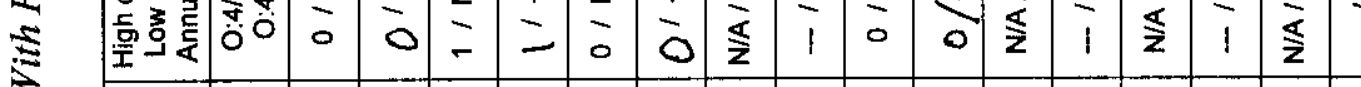

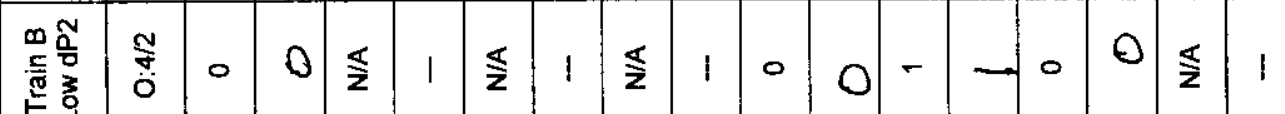

\begin{tabular}{|c|c|c|c|c|c|c|c|c|c|c|c|c|c|c|c|c|c|}
\hline 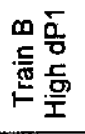 & 产 & 0 & 0 & - & - & 0 & 0 & 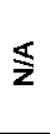 & 1 & 0 & 0 & $\underline{\mathbf{s}}$ & 1 & $\mathbf{z}$ & I & $\frac{\mathbb{z}}{\mathbf{z}}$ & 1 \\
\hline 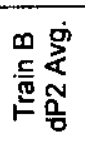 & $\begin{array}{l}\stackrel{\hat{\sigma}}{\hat{\mathbf{z}}} \\
\text { }\end{array}$ & 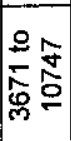 & $\begin{array}{l}n \\
N \\
0\end{array}$ & 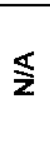 & 1 & $\$$ & 1 & $\$$ & 1 & 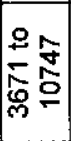 & $\begin{array}{l}0 \\
N \\
0\end{array}$ & $\begin{array}{l}\text { P } \\
\stackrel{0}{0} \\
\text { vil }\end{array}$ & $\begin{array}{l}n \\
n \\
m \\
m\end{array}$ & $\widehat{\mathbf{z}}$ & 1 & 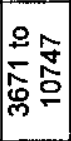 & $\frac{\gamma}{2}$ \\
\hline
\end{tabular}

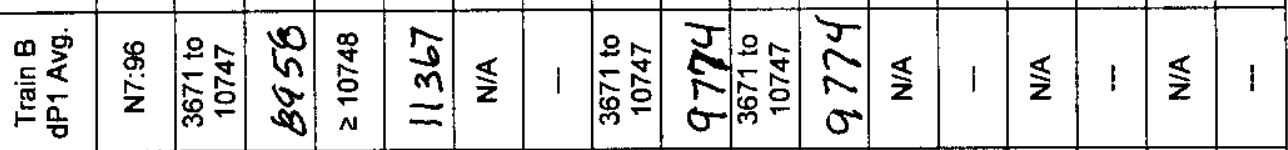

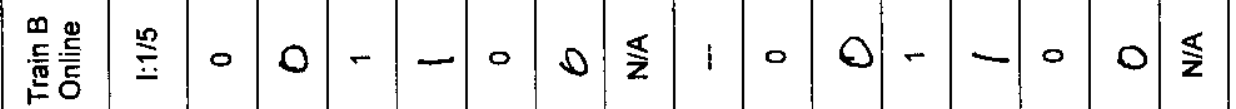

\begin{tabular}{|c|c|c|c|c|c|c|c|c|c|c|c|c|c|c|c|}
\hline 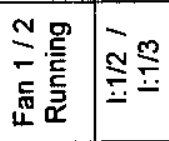 & $\frac{0}{0}$ & $\frac{0}{0}$ & $\underline{\Sigma}$ & $=$ & $\frac{5}{\mathbf{z}}$ & $\frac{1}{0}$ & $\frac{\mathfrak{z}}{\mathbf{z}}$ & $\frac{1}{1}$ & $\frac{0}{0}$ & $\frac{0}{0}$ & $\frac{5}{2}$ & - & $\frac{0}{2}$ & $\frac{0}{1}$ & 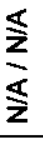 \\
\hline & 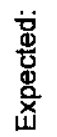 & $\begin{array}{l}\dot{\bar{g}} \\
\dot{\vec{z}}\end{array}$ & 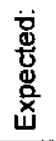 & 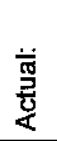 & 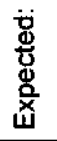 & 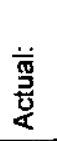 & 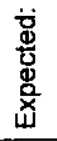 & $\begin{array}{l}\dot{\bar{\pi}} \\
\dot{\vec{z}} \\
\dot{\alpha}\end{array}$ & 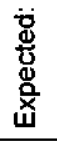 & 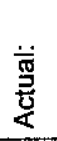 & 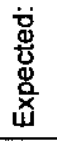 & 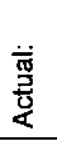 & 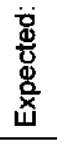 & 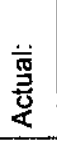 & 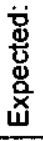 \\
\hline
\end{tabular}

:

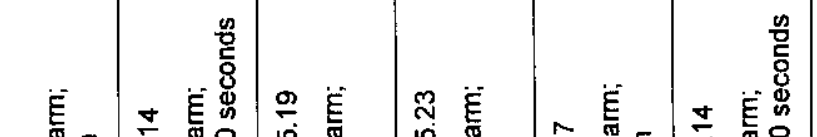

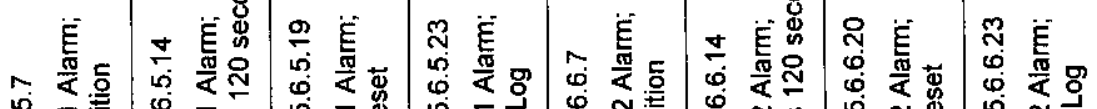

出

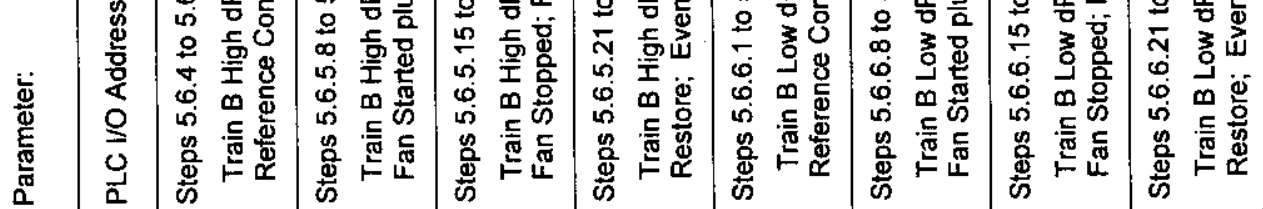




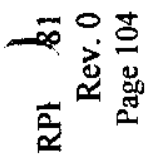

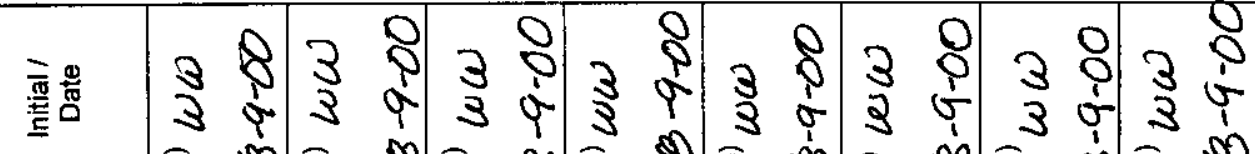

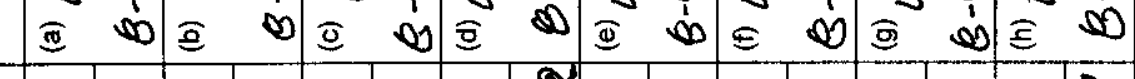

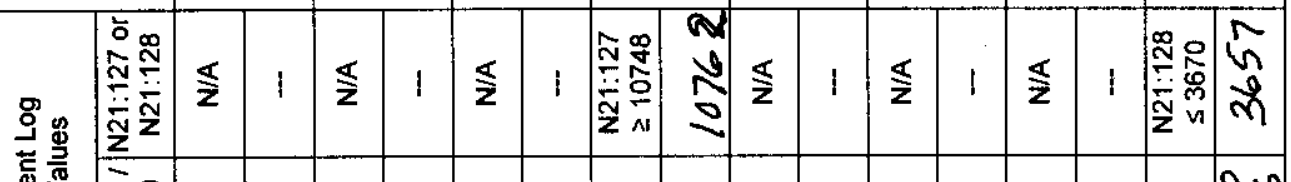
>

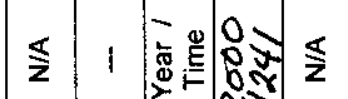

$\S$

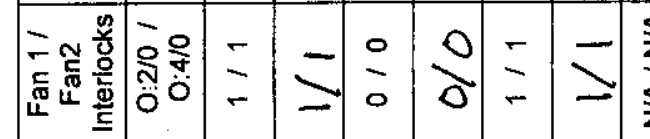

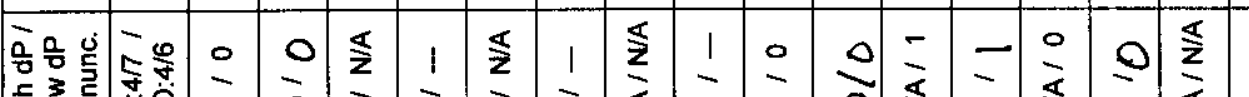

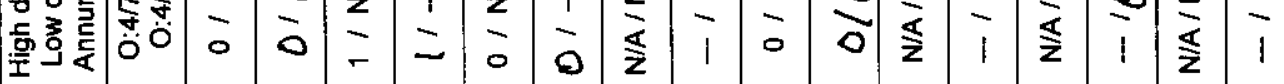

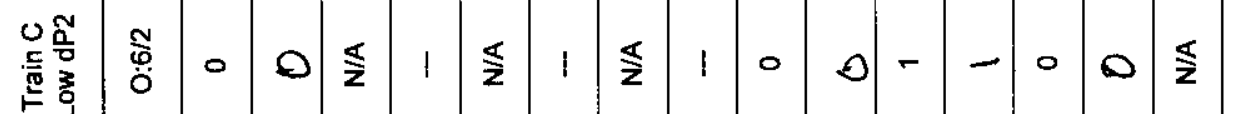

\begin{tabular}{|c|c|c|c|c|c|c|c|c|c|c|c|c|c|c|c|c|c|}
\hline 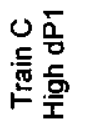 & & 0 & 0 & - & - & 0 & 0 & $\S$ & 1 & 0 & $\infty$ & 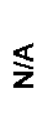 & 1 & $\stackrel{\varsigma}{z}$ & 1 & $\S$ & 1 \\
\hline 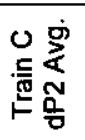 & $\frac{8}{\stackrel{8}{\dot{z}}}$ & 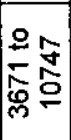 & $\begin{array}{l}\text { h } \\
\text { సิ } \\
\text { o }\end{array}$ & $\stackrel{\S}{\mathbf{z}}$ & 1 & $\frac{\pi}{z}$ & 1 & 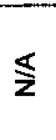 & 1 & 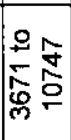 & $\begin{array}{l}n \\
\text { ते } \\
0\end{array}$ & $\begin{array}{l}\stackrel{0}{0} \\
\text { o } \\
\text { vi }\end{array}$ & $\begin{array}{l}N \\
B \\
m\end{array}$ & $\stackrel{\varsigma}{\mathbf{z}}$ & 1 & 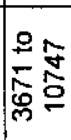 & 5 \\
\hline U & / & \% & $\theta$ & $\underset{\infty}{\infty}$ & 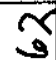 & & & 97 & & 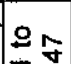 & $T$ & & & & & & \\
\hline
\end{tabular}

\begin{tabular}{|c|c|c|c|c|c|c|c|c|c|c|c|c|c|c|c|c|}
\hline 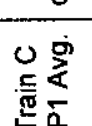 & $\begin{array}{l}\stackrel{\text { g }}{5} \\
\stackrel{5}{5}\end{array}$ & 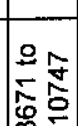 & $\frac{0}{2}$ & 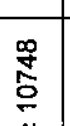 & $\begin{array}{l}3 \\
5 \\
5\end{array}$ & $\$$ & 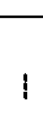 & 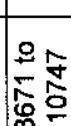 & 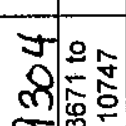 & $\begin{array}{l}J \\
0 \\
n\end{array}$ & $\$$ & 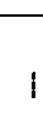 & & & 1 & $\$$ \\
\hline
\end{tabular}

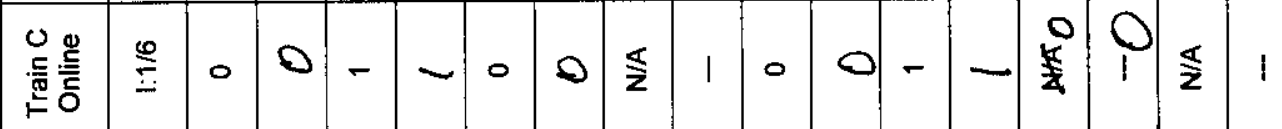

\begin{tabular}{|c|c|c|c|c|c|c|c|c|c|c|c|c|c|c|c|c|c|}
\hline 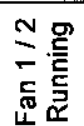 & $\stackrel{2}{=}$ & $\frac{0}{0}$ & $\frac{0}{0}$ & $\frac{\mathbb{s}}{\mathbf{z}}$ & $=$ & $\frac{\widehat{s}}{\mathbf{z}}$ & 0 & $\frac{\overleftarrow{z}}{\underline{z}}$ & $\frac{1}{1}$ & 0 & $\frac{0}{0}$ & $\mathbf{z}$ & $\overline{1}$ & 0 & 1 & $\frac{\mathbf{s}}{\mathbf{z}}$ & l \\
\hline
\end{tabular}

$\frac{\grave{2}}{\frac{\pi}{0}}$

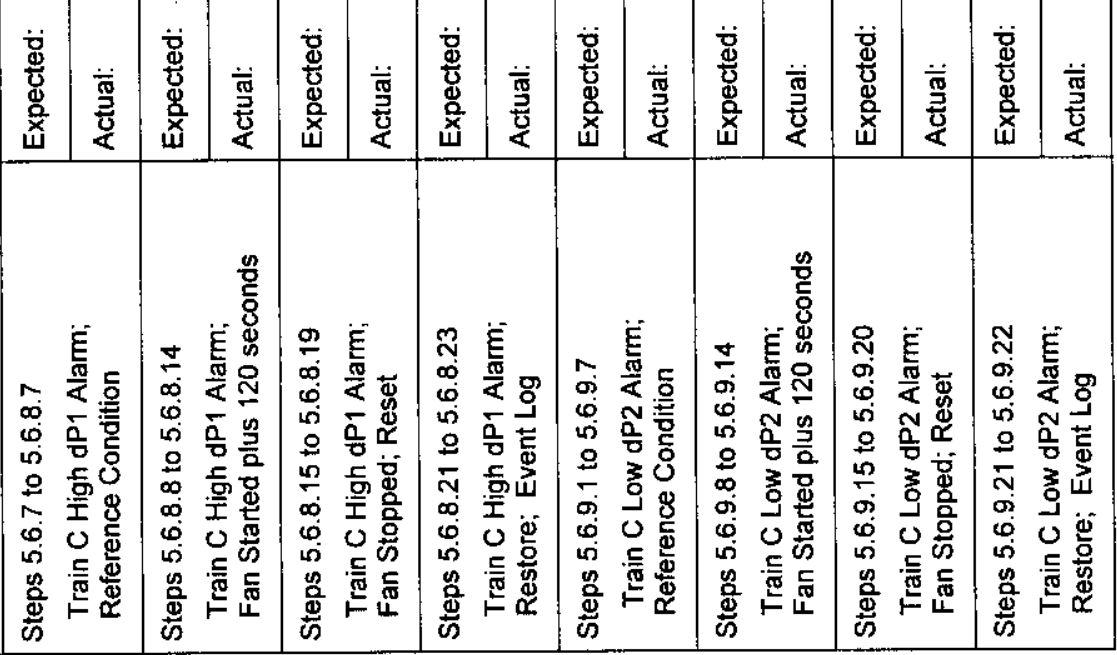


象竞总

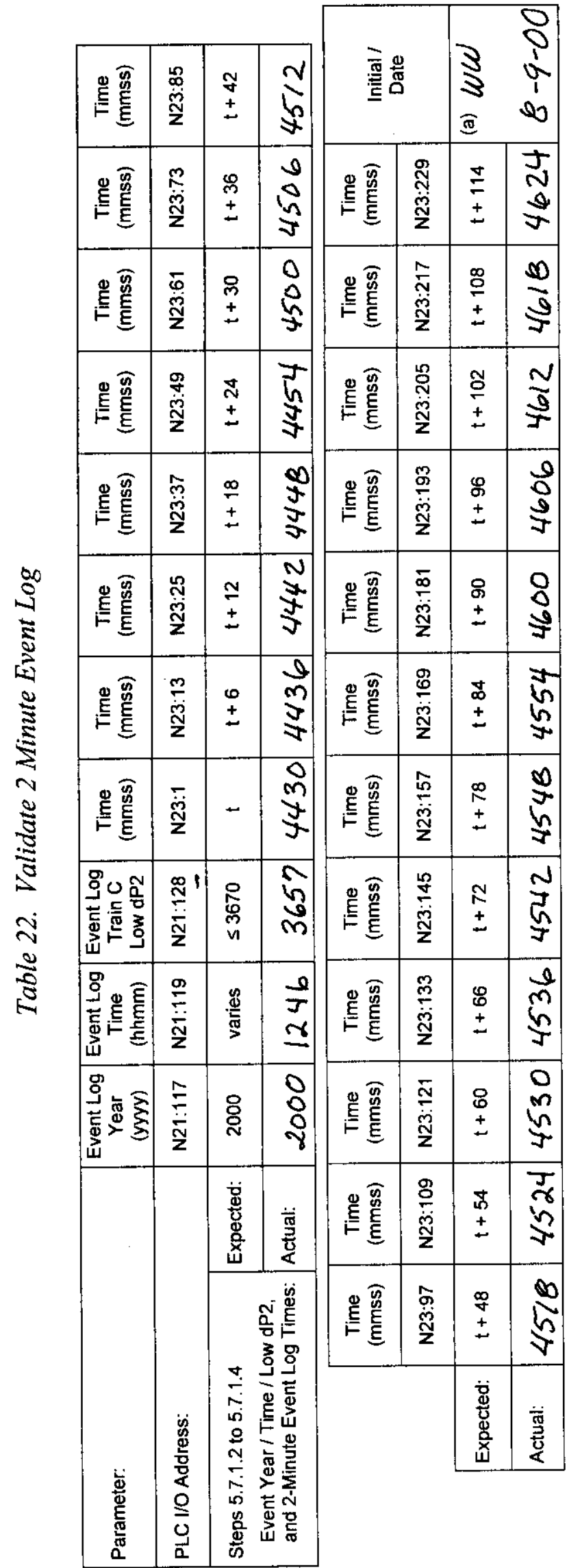

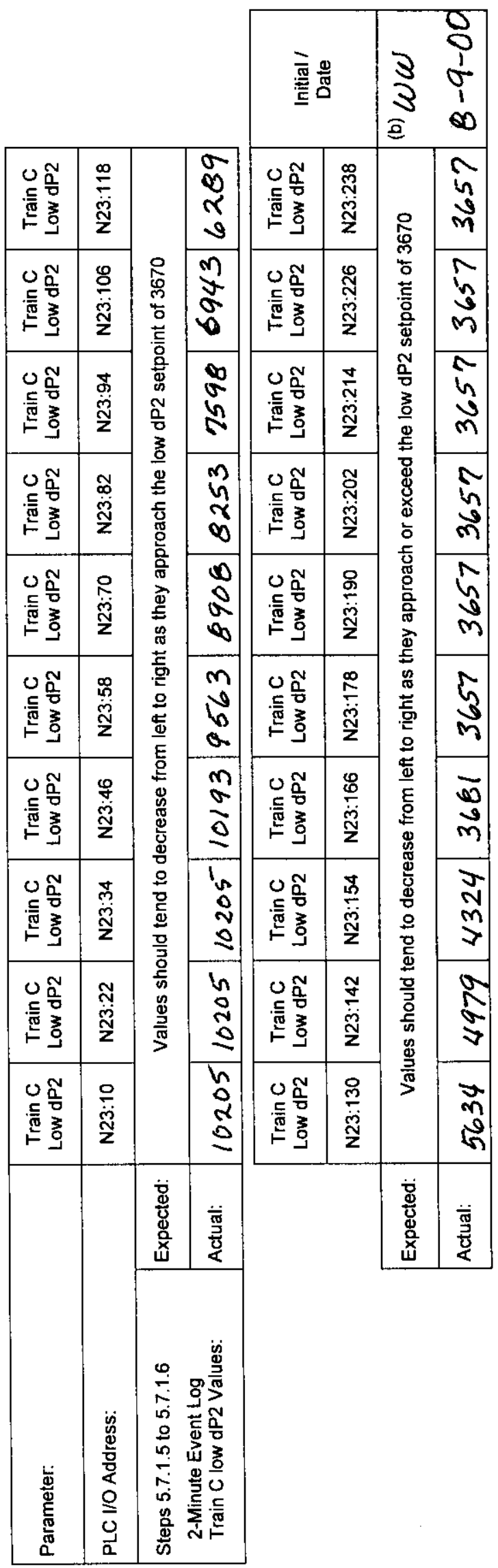




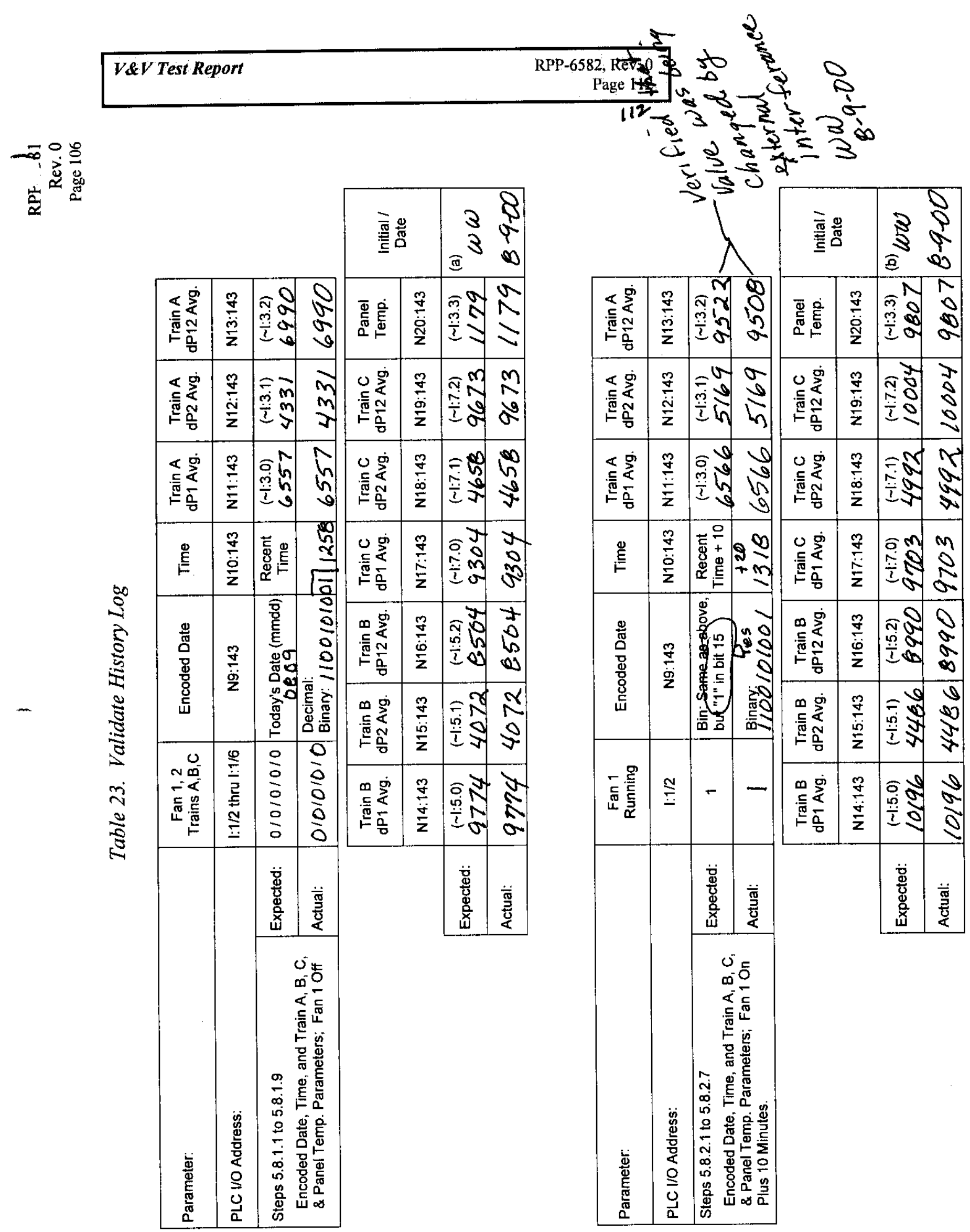


V\&V Test Report

RPP-6582, Rev. 0

RPP-658 1

Page 113

Rev. 0

Page 107

Attachment 1. Test Exceptions

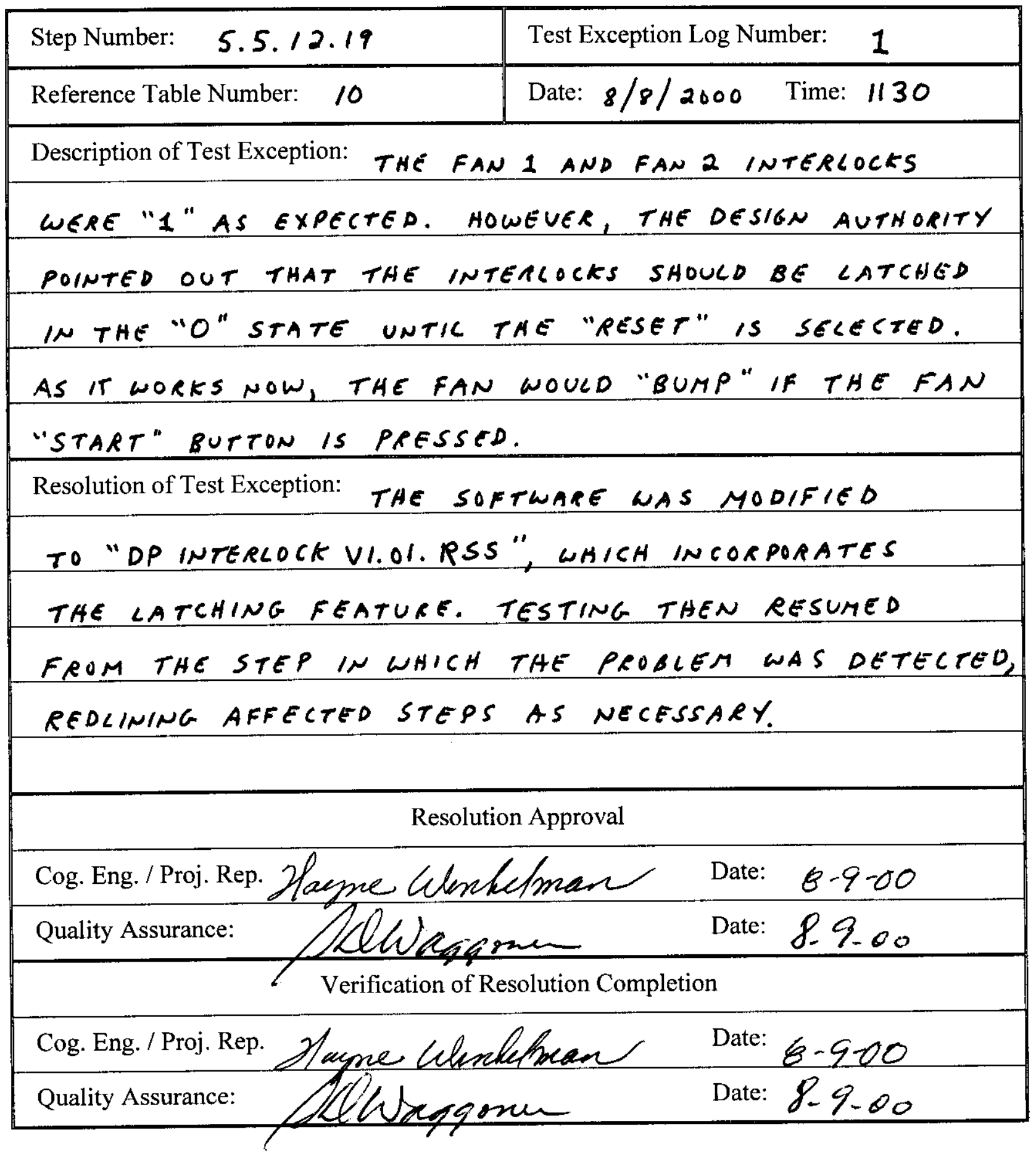


Attachment 2. Test Plan Changes

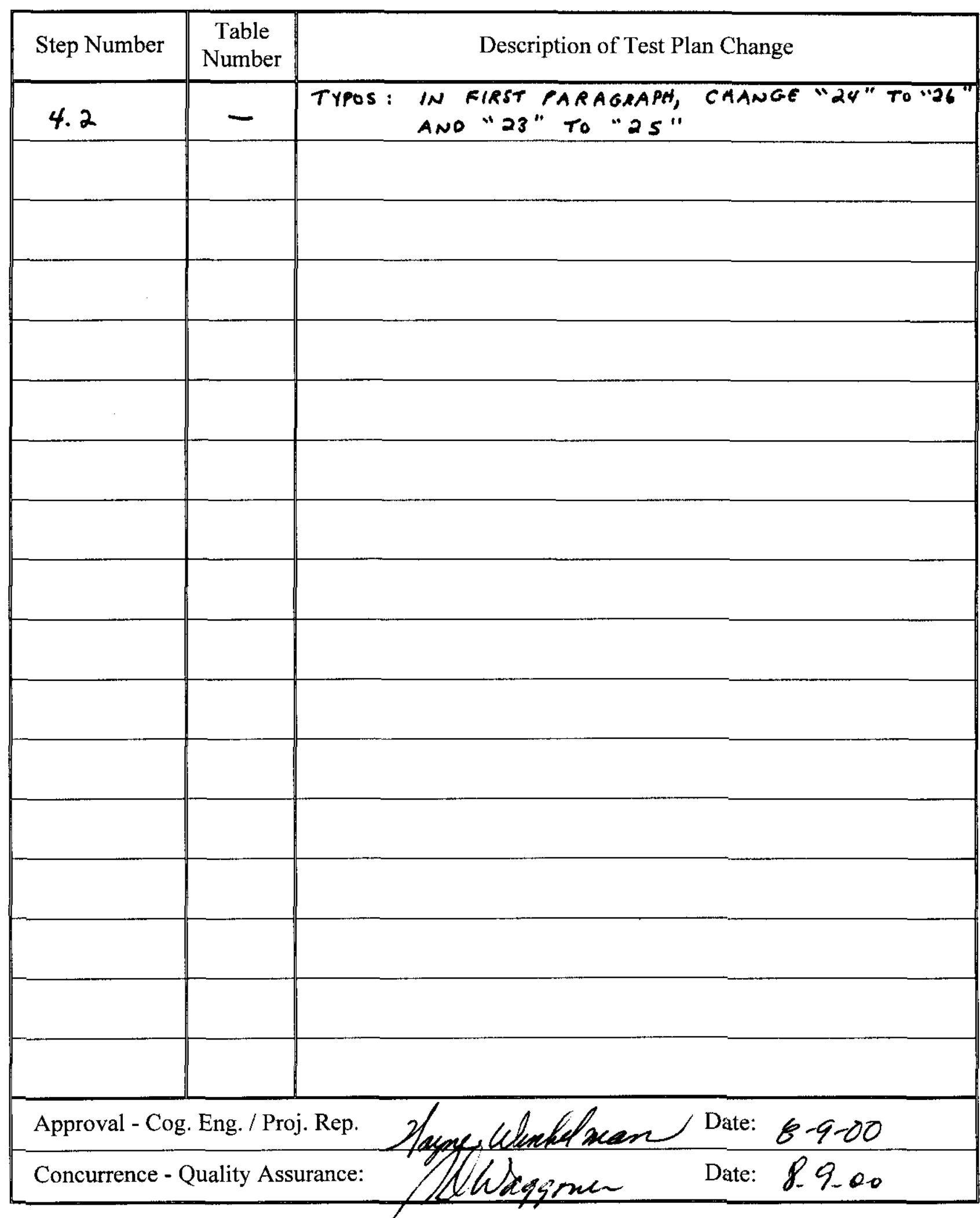

